This item was submitted to Loughborough's Research Repository by the author.

Items in Figshare are protected by copyright, with all rights reserved, unless otherwise indicated.

\title{
Reactive filtered arc evaporation
}

PLEASE CITE THE PUBLISHED VERSION

PUBLISHER

(C) N.M. Mustapha

\section{PUBLISHER STATEMENT}

This work is made available according to the conditions of the Creative Commons Attribution-NonCommercialNoDerivatives 4.0 International (CC BY-NC-ND 4.0) licence. Full details of this licence are available at: https://creativecommons.org/licenses/by-nc-nd/4.0/

\section{LICENCE}

CC BY-NC-ND 4.0

REPOSITORY RECORD

Mustapha, Nazir M.. 2019. “Reactive Filtered Arc Evaporation”. figshare. https://hdl.handle.net/2134/26797. 


\section{Loughborough University}

This item was submitted to Loughborough University as a PhD thesis by the author and is made available in the Institutional Repository

(https://dspace.lboro.ac.uk/) under the following Creative Commons Licence conditions.

\section{cc) creative}

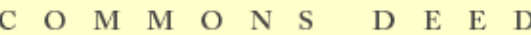

Attribution-NonCommercial-NoDerivs 2.5

You are free:

- to copy, distribute, display, and perform the work

Under the following conditions:

Attribution. You must attribute the work in the manner specified by the author or licensor.

Noncommercial. You may not use this work for commercial purposes.

No Derivative Works. You may not alter, transform, or build upon this work.

- For any reuse or distribution, you must make clear to others the license terms of this work.

- Any of these conditions can be waived if you get permission from the copyright holder.

Your fair use and other rights are in no way affected by the above.

This is a human-readable summary of the Leqal Code (the full license).

Disclaimer 민

For the full text of this licence, please go to: http://creativecommons.org/licenses/by-nc-nd/2.5/ 
BLDSC no:- DX 188330

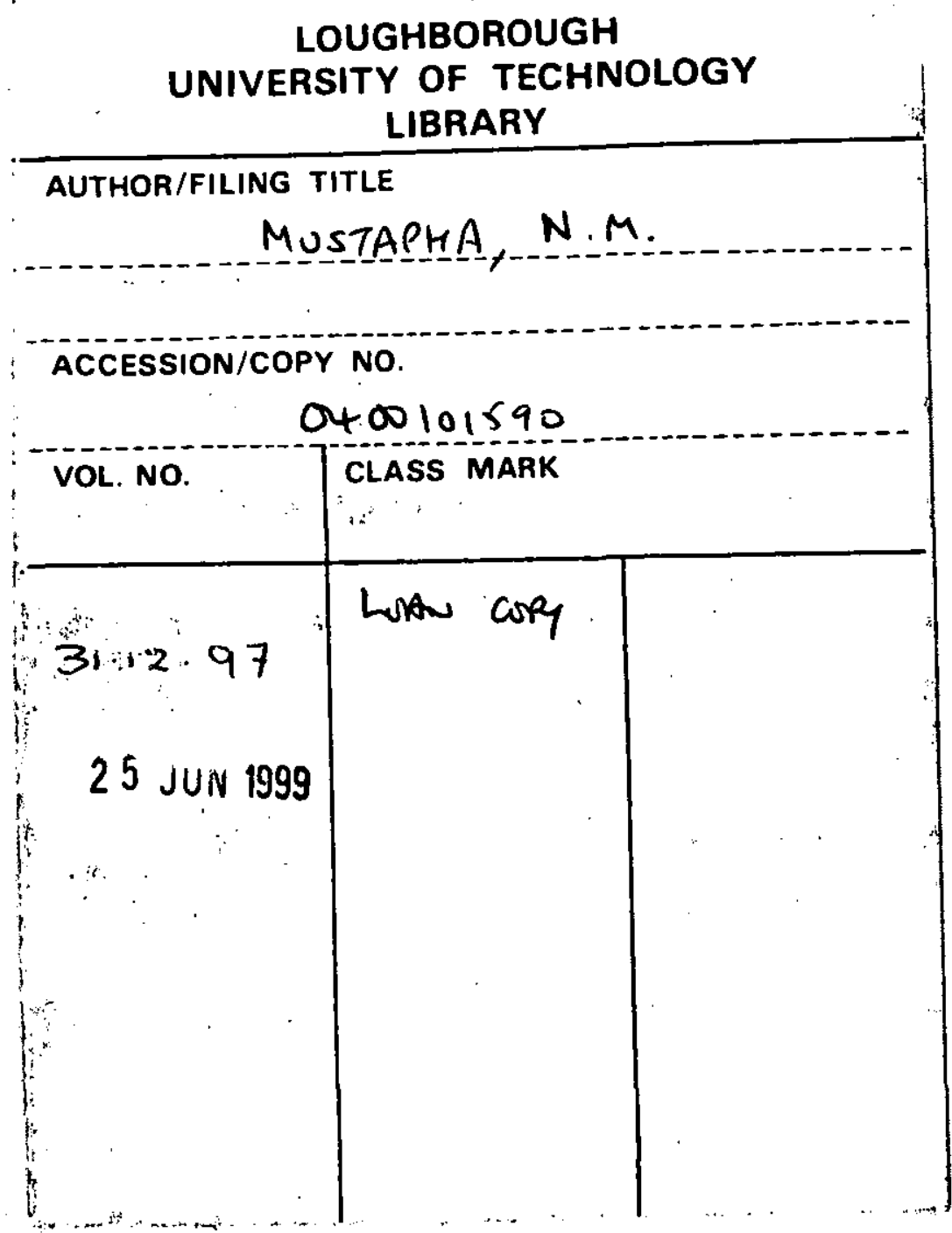





\title{
REACTIVE FILTERED ARC EVAPORATION
}

\author{
by \\ Nazir Mohamad Mustapha
}

A Doctoral thesis submitted in partial fulfilment of the requirements for the award of the

Degree of Doctor of Philosophy of

Loughborough University of Technology

August 1993

Supervisor : Prof. R. P. Howson

Department of Physics 


\begin{tabular}{|c|c|}
\hline \multicolumn{2}{|c|}{ 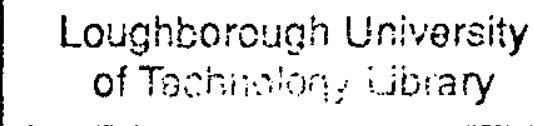 } \\
\hline Date & Febas \\
\hline \multicolumn{2}{|l|}{ Class } \\
\hline $\begin{array}{l}\text { Acc. } \\
\text { No. }\end{array}$ & $\sigma_{t 0101590}$ \\
\hline
\end{tabular}




\section{Dedication}

to my loved ones :

my wife Zakia, my mother and my family 


\section{ACKNOWLEDGEMENTS}

I would like to thank my supervisor Prof R. P. Howson for the opportunity to undertake this project. His enthusiasm, knowledge and tireless effort was a continual inspiration.

I am grateful to my director of research Prof. K. A. Zeibeck who welcomed me in the department and was always available to steer me in the right direction with all problems.

My sincere gratitude to $\operatorname{Dr}$ A. G. Spencer for his time, knowledge and friendship, Dr H. A. Ja'fer, Dr. G. Hall and Mr E. M. Stenlake for the technical assistance, help, guidance and the useful discussions we had.

The completion of this programme was greatly aided by Messrs F. Page and J. Bates on the SEM work.

Finally I would like to acknowledge the financial support of my sponsors and the moral support and encouragement of my parents, my wife Zakia and all my friends during my studies. 


\section{ABSTRACT}

Conventional physical vapour deposition (PVD) techniques usually result in films of lower quality than the corresponding bulk material. A major problem with PVD films is the presence of columns and voids throughout the thickness of the film. The films may have a low packing density, low micro-hardness and in many cases poor adhesion to the substrate. Many of these problems are a direct consequence of the low energy of the depositing atoms arriving at the substrate during film growth. The resulting film porosity gives rise to a reduction in mechanical strength, and in the case of dielectric optical films, a reduction in the refractive index.The properties of deposited films are greatly improved when the substrate or the growing film is bombarded with more energetic particles. An ideal deposition process requires a high flux of film atoms with an energy of approximately $5-50 \mathrm{eV}$ in order to achieve sufficient surface mobility at the substrate to overcome columnar growth.

Recently, the cathodic arc deposition process has received much attention because of its ability to generate a much higher degree of ionization than conventional ion-plating processes. It evaporates the material in a "flash" technique, preserving the composition of an alloy target in the deposited films and creates a highly ionised evaporant. The large number of ions in the depositing material allow ion plating and highly activated reactive techniques to be used. It does, however, result in some particulate content in the growing film. More recently, arc evaporation techniques have had great success in producing TiN onto tool steel and for decorative coatings.

In this research, an arc evaporation source $32 \mathrm{~mm}$ in diameter has been constructed which is operated in argon to provide ion plating of the growing films. The performance of the system is compared to the unbalanced magnetron, as is the quality of both elemental and reactively produced compound films such as $\mathrm{Al}, \mathrm{Ti}, \mathrm{Cu}, \mathrm{TiN}$, $\mathrm{Al}_{2} \mathrm{O}_{3}$, $\mathrm{AlN}$ and $\mathrm{TiO}_{2}$.

In reactive processing the ionised metal constituent provided by arc evaporation appears to make the kinetics of the substrate reaction process much more simple than the careful balance required with argon-ion-assisted sputter processes. It has been found in the case of TiN better quality films could be prepared onto room temperature substrates than by sputtering, while for $\mathrm{Al}_{2} \mathrm{O}_{3}$ the deposited films show good adhesion, good optical properties and were nearly stoichiometric with a refractive index of 1.66 . 
$\mathrm{TiO}_{2}$ films deposited at room temperature were absorbing and substrates have to be heated to obtain films with low absorption, while in reactive sputtering of $\mathrm{Al}_{2} \mathrm{O}_{3}$ and $\mathrm{TiO}_{2}$, as the partial pressure of oxygen is increased, reaction products form on the target ( it is poisoned ) which lead to an unstable situation.

In addition to metal, oxide and nitride coatings, hard,thick and adhesive diamond-like carbon (DLC) were produced onto a variety of substrates at room temperature. Furthermore, the effect of a magnetic field on the plasma produced by arc evaporation, and bombarding the substrate, has been observed. In particular, the floating potential and the ion current of the substrate were measured by using a probe at the substrate position.

To optimize the cathodic arc deposition process, films deposited over a range of reactive gas pressures and evaporation rates, were analyzed for film characterization using XRD, SEM, optical transmission and reflectance, refractive index and sheet resistance for conducting films such as TiN.

The manipulation of the product of arc evaporation has been shown to be possible with a simple low field solenoid following the principles seen with an unbalanced magnetron. Direction of the product to a substrate out of direct line of the source results in films free from droplet contamination, and on the evidence Aluminum and Titanium films with high quality, high reflectance and good adhesion were prepared with no signs of droplet contamination. 


\section{TABLE OF CONTENTS}

page No

Dedication ...................... i

Acknowledgements ................... ii

Abstract ....................... iii

Table of Contents ......................

CHAPTER 1: INTRODUCTION AND LITERATURE SURVEY . . . . . . . 1

1.1 History of the Vacuum Arc . . . . . . . . . . 1

1.2 Literature Review . . . . . . . . . . . . . 3

1.3 Recent Developments of Arc Coatings ........ . 6

1.4 Aims of the Investigation . . . . . . . . . . 10

References ................ 11

CHAPTER 2 : THE PHYSICAL VAPOUR DEPOSITION PROCESSES . . . . 17

2.1 Introduction . . . . . . . . . . . . . 17

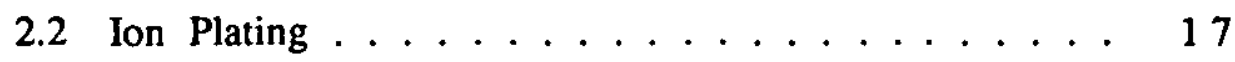

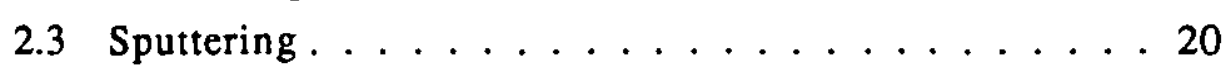

2.4 Evaporation ................ 20

2.4.1 General Considerations ............ 24

2.4.2 Evaporation Methods ............ 27

2.4.2.1 Resistive heating . . . . . . . . . . . 27

2.4.2.2 Sublimation ............. . 31

2.4.2.3 Multiple-component evaporation . . . . . . . 31

2.4.2.4 Electron beam evaporation ........ 33

A. Thermionic guns . . . . . . . . . 35

B. Plasma electron beam gun ... . . . . . 37

a) The cold cathode plasma electron beam . . . . . 38

b). The hot hollow cathode discharge beam . . . . . 38

2.4.2.5 RF Induction heating . . . . . . . . . 38

2.4.2.6 Flash evaporation .......... 40

2.4.2.7 Exploding wire technique . . . . . . . 40 


\section{page No}

2.4.2.8 Laser Evaporation

2.4.2.9 Arc Evaporation . . . . . . . . . . 43

2.5 Summary . . . . . . . . . . . . . . . . . .

References ................ 47

CHAPTER 3: THE CATHODIC ARC DEPOSITION PROCESS $\ldots \ldots \ldots 51$

3.1 Introduction . . . . . . . . . . 51

3.2 Electrical Properties . . . . . . . . . . . . . 51

3.2.1 Definition of Arc . . . . . . . . . 51

3.2.2 Arc Characteristics . . . . . . . . . . 53

3.2.3 The cathodic Arc Spot and Plasma . . . . . . . 53

3.2.4 Retrograde Motion of the Cathode Spot . . . . . . 55

3.2.5 The Cathodic Arc Sources . . . . . . . . . 58

3.2.6 Cathodic Arc Types . . . . . . . . . . . 63

3.2.6.1 Pulsed Mode. . . . . . . . . . 63

3.2.6.2 Continuous Mode . . . . . . . . . . 63

A. Random Arc . . . . . . . . . 63

B. Steered Arc . . . . . . . . 66

3.2.7 Arc Ignition . . . . . . . . . . . . 69

3.3 Emission Characteristics $\ldots \ldots \ldots \ldots 70$

3.3.1 Definition . . . . . . . . . 70

3.3.2 Emitted Material . . . . . . . . . . . . .73

3.3.3 Microdroplet Emission . . . . . . . . . . . 76

3.3.4 Reactive Deposition Process . . . . . . . . . . . . 79

3.4 Filtered Arc . . . . . . . . . . . . . . . 87

3.4 .1 Magnetic Filtering . . . . . . . . . . . . . 87

3.4.2 Magnetic Plasma Duct . . . . . . . . . 9 91

3.4.3 Motion of the Plasma in the Duct . . . . . . . . . 94

3.4.4 Induced Ion Bombardment . . . . . . . . . 99

3.4.5 Cathodic Arc deposited Films . . . . . . . . 102

3.5 Summary . . . . . . . . . . . . . . 102

References ................ 103 
CHAPTER 4 : FILM ANALYSIS TECHNIQUES . . . . . . . . . . . 112

4.1 Sheet Resistance Measurement . . . . . . . . . 112

4.2 Ellipsometry $\ldots \ldots \ldots \ldots \ldots$

4.3 Measuring Thin Film Deposits . . . . . . . . . 116

4.4 X-ray Diffraction (XRD) $\ldots \ldots \ldots . . \ldots 116$

4.5 Scanning Electron Microscopy (SEM) . . . . . . . 117

4.6 Spectrophotometry . . . . . . . . . . . 118

References . . . . . . . . . . 120

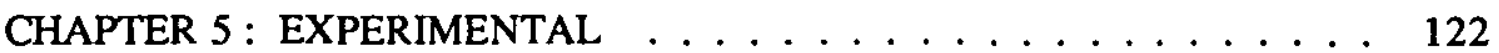

5.1. Vacuum System . . . . . . . . . . . 122

5.2. Pressure Gauges . . . . . . . . . . . 122

5.3. First Experimental Approach . . . . . . . . . . . 122

5.3 .1 Arc Control . . . . . . . . . . . 126

5.4. Second Experimental Approach . . . . . . . . 129

5.5. Third Experimental Approach . . . . . . . . . 130

5.6. The cathodic Arc Source . . . . . . . . . . . . 132

5.6.1. The Cathode Target . . . . . . . . . 133

5.6.2. The Anode . . . . . . . . . . . . . . . 134

5.6. 3. The Arc Source Shield . . . . . . . . . . 134

5.6.4. Arc Trigger/Ignitor . . . . . . . . . . 136

5.7. Arc Power Supply . . . . . . . . . . . . . . 137

5.8. Bias and Coil Supplies . . . . . . . . . . . . . 138

5.9. Filament Discharge Enhancement . . . . . . . . . 138

5.10. Magnetic Confinement . . . . . . . . . . . . 141

5.10.1. Cathode Spot Confinement . . . . . . . . 141

A. Coil Behind the Target . . . . . . 141

B. Magnet Ring . . . . . . . . . 143

5.10.2. Plasma Binding by a Permanent Target . . 146

5.10.3. Plasma Duct. . . . . . . . . . . . . 149

5.11. Probe Configuration . . . . . . . . . . . . . . 154

5.12 Substrate Holder . . . . . . . . . . . . . 155

5.12. Summary . . . . . . . . . . . . . . . 157

References . . . . . . . . . . . . 158 
page No

CHAPTER 6 : COMPARISON OF REACTIVE MAGNETRON SPUTTERING 159 AND REACTIVE FILTERED ARC EVAPORATION

6.1. Introduction .............. 159

6.2. Systems ................. 160

6.3. Metal Materials . . . . . . . . . . . . 166

6.4. Reactive Processes . . . . . . . . . . . 167

6.5. SEM . . . . . . . . . . . . . 169

6.6. Concluding Remarks . . . . . . . . . . . . . 172

References ............... . . . . . . . . . . .

CHAPTER 7 : RESULTS . . . . . . . . . . . . . . . 174

7.1 TiN Films . . . . . . . . . . . . 174

7.1.1. Introduction . . . . . . . . . . . . 174

7.1.2. Experimental Procedure . . . . . . . . . . 174

7.1.3. Results and discussion . . . . . . . . . . 175

7.1.3.1. Process Rate . . . . . . . . . . 175

7.1.3.2. Optical Properties . . . . . . . . . . 176

7.1.3.3. X-ray Diffraction (XRD) . . . . . . . 180

7.1.3.4. Scanning Electron Microscopy (SEM) . . . 181

7.1.3.5. Sheet Resistance . . . . . . . . . 182

7.1.4. Concluding Remarks . . . . . . . . . . . 182

References .............. 183

$7.2 \mathrm{Al} 2 \mathrm{O} 3$ Films . . . . . . . . . . . . . . . 184

7.2.1. Introduction .............. . 184

7.2.2. Experimental Details . . . . . . . . . . . . 184

7.2.3. Results . . . . . . . . . . . . . 185

7.2.3.1. Process Rate . . . . . . . . . . . . . 185

7.2.4. Optical Properties . . . . . . . . . . . 187

7.2 .5 X-ray Diffraction . . . . . . . . . . . . 188

7.2 .6 SEM . . . . . . . . . . . . 188

7.2.7 Concluding remarks . . . . . . . . . . 190

References .............. 191 
7.3. AlN Films . . . . . . . . . . . . . . . . . . . . . 192

7.3.1 Introduction . . . . . . . . . . . . . . 192

7.3.2 Experimental Details . . . . . . . . . . . . 192

7.3 .3 Results . . . . . . . . . . . . . . 193

7.3.3.1 Process Rate . . . . . . . . . . . . . 193

7.3.3.2 Optical Properties . . . . . . . . . . . 194

7.3.3.3 SEM . . . . . . . . . . . . 196

7.3.3.4 X-ray Diffraction . . . . . . . . . . . 197

7.3.4. Concluding Remarks . . . . . . . . . . 197

References . . . . . . . . . . . . . . . . . . . . . 198

7.4 TiO2 Films . . . . . . . . . . . . . . . . . 199

7.4.1. Introduction . . . . . . . . . . . . . . . . 199

7.4.2. Experimental Procedure . . . . . . . . . . . . 199

7.4.3. Results and Discussions . . . . . . . . . . . . 199

References . . . . . . . . . . . . . . . . . 202

7.5. Carbon Films . . . . . . . . . . . . . . . 203

7.5.1. Introduction . . . . . . . . . . 203

7.5.2. Experimental Details . . . . . . . . . . . 203

7.5.3. X-ray Diffraction . . . . . . . . . . . . 208

7.5.4. Conclusion and Discussions _. . . . . . . 208

References . . . . . . . . . . . . . . 210

7.6. The plasma Effects on the Substrate . . . . . . . 211

7.6.1. Concluding Remarks . . . . . . . . . . 211

7.7. Elemental Materials . . . . . . . . . . . . . 213

7.7.1. Concluding Remarks . . . . . . . . . . 219

CHAPTER 8: CONCLUSIONS AND SUGGESTIONS FOR FUTURE WORK. . 220

8.1 Conclusions . . . . . . . . . . . . . 220

8.2 Suggestions for Future Work . . . . . . . . . . 223

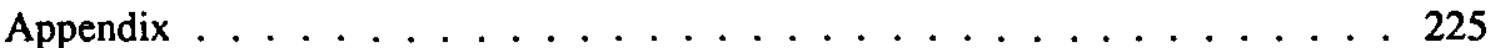




\section{CHAPTER 1 \\ INTRODUCTION AND LITERATURE}

SURVEY

\subsection{HISTORY OF THE VACUUM ARC}

Thomas Edison knew more than a century ago that coatings could be produced by using a vacuum arc [1-2]. Hiesinger describes in his patent [3], how metals can be evaporated "in an arrangement whereby an electric spark is generated between electrodes which consist of the material which is to be deposited in a high vacuum". He added that the method can be used with " advantage in the form where the ions produced by the electric spark are accelerated by an electric field, so that the energy of atomic impact on the substrate is increased beyond the normally available thermal energy" [4]. Later in 1955, Vodar et al described an apparatus in which the arc was operated using a relay coil to make repeated intermittent contact of the electrodes. These researchers found that the metal vapour was emitted from the cathode and the metal particles were mainly negatively charged [5]. In 1958, Wroe recognized when he examined the vacuum arc control during a welding operation, that they might be employed for the production of coatings [6]. He described a magnetically stabilized dc arc evaporation apparatus. His suggestion received little notice due to a lack of commercial application. Commencing in the 1960's, a group of researchers including Kikuchi, Nagakura, Naoe and Yamanaka at the Tokyo Institute of Technology, reported the first study of the properties of coatings produced by a vacuum arc. An intermittent a.c. arc apparatus was used in their initial investigations where a deposition rate of the order of $0.1 \mu \mathrm{m} / \mathrm{s}$ was achieved. The film structure was studied as well as the effect of substrate material and temperature. It was found that amorphous films were obtained at low temperature, while crystalline films required higher temperatures [7,8]. Other researchers have used an 11-16 Amperes d.c. arc between the face of a cylindrical source cathode surrounded by a ceramic insulator, and an Mo rod anode. An axial magnetic field was used to enhance the deposition rate. Various ferrites were deposited, $\mathrm{Si}$ and $\mathrm{SiO}$ were also deposited using a $\mathrm{Si}$ cathode in a background pressure of $1 \times 10^{-3}$ torr [9-11]. Early in the 1970's, Snaper described in his patents $[12,13]$ the use of cathode arcs to produce coatings. This was followed by Sablev's patents $[14,15]$ who again described an apparatus for vacuum evaporation of metals under the action of 
an electric arc. He noticed the advantage of the cathodic arc over other evaporation and melting techniques so that a refractory crucible material is avoided. His system included a conical anode and planar water-cooled cathode in a gun arrangement. Magnetic fields were used to increase the evaporation rate and to direct the ions to the substrate. Sablev mentioned a modification to his invention, in which the beam gun for use in an arc deposition process, is particularly useful for operation by three-phase AC power, between a common cathode and separate anodes.

This method is suggested for coating large objects using several gun sources along the walls of a large chamber $[8,14,15]$.

Since the late 1970 's, serious efforts have been made in Russia to apply the cathodic arc technology process for the production of coatings on a commercial basis by a group of researchers including Sablev, Akșenov, Strel'nitskii et al. Considerable attention was focussed on two technical problems:

1. Control of the cathode spot location on the target surface.

2. Reduction of microdroplets emission which contaminates the coatings [16-20].

In the United States, during the same time period, little research was carried out on cathodic arcs for coating production with a notable exception of the paper published by Gilmour in 1972 [21]. His primary objective was to produce a source of ions for physics experiments, he recognized the potential for using such ion beams for the production of coatings. In spite of the fact that vacuum arcs have been used since the early 1960's in the United States for current interruption in commercial power systems, extensive research into the arc behaviour has been carried out in support of that application since that time [20-24]. It has been only in the last decade that arc technology has been commercially employed for producing machining cutting tools with metal nitrides in order to prolong their life-times [25].

The technology was based either on the Snaper patents [12-13] coupled with a more recent patent by Mularie [26,27] or on Russian technology originating with Sablev $[14,15]$.

According to Soviet sources, more than 200 arc deposition systems are employed in industrial plants throughout the Soviet Union. The technology was introduced in the United States in 1980 by Multi-Arc Vacuum Systems Inc. At this time, several companies in the U.S. and Europe are developing capabilities for arc source 
deposition of TiN and other wear resistant hard coatings. The number of industrial applications in which arc-deposited TiN has successfully combated wear and increased producibility is growing rapidly [28]. The method has been highly successful in TiN owing both to the high degree of ionization and the energy of the evaporated species [29].

\subsection{LITERATURE REVIEW}

Conventional arc evaporation sources which are used in the deposition of coatings on cutting tools and wear parts contained microdroplets where the presence of microdroplets of dimension 1-5 $\mu$ is not disadvantageous [30].

For example, TiN coatings deposited by the arc process on cutting and forming tools have typically resulted in performance improvements from $\times 2$ to $\times 12$. Despite this fact, these TiN coatings contained: a considerable number 1 of droplets ejected from the target by the arc [31-32].

However, hard coatings with particularly good adhesion and high density are deposited by the arc technique on many parts at relatively low temperatures.

In order to develop arc evaporation for much wider ranging applications in high quality coating, e.g. in electronics, optics, decorative, architectural and solar coatings, the only problem with the arc technique concerns the droplets which are hurled off the arc cathode as molten particles and integrated into the coatings, adversely affecting the surface roughness of the arc coatings. Therefore, it is necessary to eliminate the macroparticles, because these particles have restricted the application of arc technology to routine metallization and the deposition of wear-resistant coatings on tools [12, 29-30].

On the other hand, the properties of thin films deposited by physical vapour deposition (PVD) are frequently inferior of those of the bulk material. A major problem with PVD films is the presence of columns and voids throughout the film thickness which limit the mechanical strength of the deposited film and also affect other properties such as optical stability, causing poor tensile strengths, and also affect optical properties and barrier properties. The properties of the deposited films are greatly improved when the substrate and / or film is bombarded with energetic particles. An ideal deposition process requires a high flux of film atoms with an energy of approximately 5 to 50 $\mathrm{eV}$ in order to achieve sufficient surface mobility at the substrate to overcome columnar growth [34]. In fact these conditions are achieved in arc evaporation technique, but the 
principle disadvantage of the method is the presence of microdroplets of cathode material in the vapour stream.

Several means have been used to eliminate the macroparticles. They have relied on screening the substrate from direct line of sight of the cathode, either by interposing a baffle between the cathode and substrate or by careful placement of the substrate in the deposition chamber [34].

One approach for dealing with microdroplets is to minimize their formation during the arc deposition process. This can be done to some extent by constraining the arc motion on the cathode surface using a magnetic field that limits the arc to a well-defined path. This was described by Ramalingam in his patent and so-called "steered arc" mode [36]. Boelens and Veltrop were able to reduce the amount of microdroplets of TiN, (TiHf)N and (TiNb)N coatings to very low level using this approach [37]. However this method is quite promising for ceramic coatings produced in a reactive deposition process, although it is apparently not yet possible to form low microdroplets coatings from pure metals such as aluminum, titanium and copper.

Ramalingam has suggested that "steered arcs" are a type of diffusion arc which avoid producing microdroplets by reducing the local current density.

Erturk et al [38], suggested that the microdroplets are reduced because magnetic fields accelerate the arc and cause overlap of surface meltings areas, thereby reducing local splashing.

Another method for avoiding microdroplets was proposed by D. M.Sanders, in which the vacuum arc used as a source of ions to carry out a self-sputtering process [39]. Sanders describes an ion-beam self sputtering process using a cathodic arc ion source. A low-voltage / high-current vacuum arc offers a means of producing high-current ion beams. These beams can be employed in conjunction with suitable anode and sputter target configurations to permit coating production by self-sputtering without the necessity for adding process gas. Self-sputtering of $\mathrm{Cu}, \mathrm{Al}, \mathrm{Nb}$ and $\mathrm{Ti}$ was carried out without the addition of process gas [39-40].

In addition to metal, oxide and nitride coatings, hard diamond-like carbon (DLC) were recently produced using three variations of the vacuum arc technique. The first technique uses a curved magnetic field to filter macroscopic particles from the arc plasma stream $[41,44]$, the second uses a pulsed arc [45-46], while the third uses a r.f. 
biasing of the substrate [47-48]. Aksenov et al have demonstrated that the use of the plasma-optical separator makes it possible to produce high quality diamond-like coatings, the density of the coatings was $3.4 \mathrm{~g} \mathrm{~cm}^{-3}$ and electrical resistivity of $10^{8}$ ohm.m which are very similar to those of diamond. The properties and structure of the coatings can be varied in a wide range from diamond to graphite as a function of deposition conditions [41]. Diamond-like coatings (DLC's) produced by the deposition of fast atoms or carbon ion fluxes on to cooled substrates possess mechanical properties resembling those of diamond, and can evidently be used as a wear-resistant material to strengthen different sliding units and machine parts [42].

The pulsed arc-discharge method can be used to produce DLC films with excellent tribological properties. These properties are comparable to those of films deposited using mass-separated ions. The coefficient of friction is about the same as that of natural diamond. The curved solenoid reduces the number of particles hitting the deposited sample. By applying an appropriate vacuum system it should be possible to reduce the hydrogen impurities $[45,46]$. As a result of using the three mentioned vacuum arc techniques for deposition of carbon films, hard, thick and highly adhesive coatings are obtained on to a variety of substrates at room temperatures [41-48].

By the end of 1980's Ehrich et al. reported a new type of arc discharge ignited in vacuum and sustained by metal vapour produced at a consumable anode [49-50]. The anode may be constructed in the form of a twisted $\mathrm{W}$ wire, which will support a molten drop of some other metal, or a refractory crucible containing a larger quantity of the evaporant. The sides of the cathode are shielded, and substrates are mounted below the plane of the cathode, so that no line of site exists from the exposed region of the cathode to the substrates, preventing macroparticle deposition but allowing deposition from the evaporating anode.

This new discharge generates a gas and droplet free metal vapour plasma expanding into the ambient vacuum and producing thin metallic films at the surface of substrates. An analysis of the metal-plasma at the position of a possible substrate for different materials ( $\mathrm{Al}, \mathrm{Cu}, \mathrm{Ti}, \mathrm{V}, \mathrm{Cr}$ and $\mathrm{Ag}$ etc.) at arc currents exceeding $20 \mathrm{~A}$, yielded the following results: electron densities of $10^{15}-10^{17} \mathrm{~m}^{3}$, electron temperature of $0.2-1$ $\mathrm{eV}$, degree of ionization of $1 \%-25 \%$ and ion energies of $5 \mathrm{eV}$. Coatings are generated with deposition rates up to $100 \mathrm{~nm} / \mathrm{s}$ and show a purity $99.9 \%$, a polycrystalline structure with grain sizes between a few and some $100 \mathrm{~nm}$ within $2 \%$ density of the bulk material [51]. With respect to coating, the vacuum arc source with consumable anode combines the advantages of thermal evaporation, namely high evaporation rates, low thermal load to a substrate, low voltage operation, and 
inexpensive equipment. To date, this new coating process has been developed to a laboratory stage. A prerequisite for industrial applications is the transfer of the laboratory-scale process to industrial use. At the moment, this scaling up of the laboratory process is under development with regard to selected technical applications such as optical coatings, coatings for corrosion protection, the metallization of packaging films and electromagnetic interference shielding of plastic housings [42-51]. In summary, most research has concentrated on cathode spot arc coatings, for which industrial scale equipment has been developed owing to special process development features and particular requirement to be met by the coatings such as good adhesion, wear resistance, corrosion resistance, and decorative properties. Continued development of the arc evaporation process has concentrated on optimizing the process parameters such as arc current, gas pressure, substrate cleaning procedure, bias, and temperature, thickness uniformity, deposition rate and optical properties, in order to control the adhesion, the structure, crystallographic orientation and application performance.

\subsection{RECENT DEVELOPMENTS OF ARC COATINGS}

Considerable attentionhas been focusedon the control of the motion and location of the cathode spots, reduction or elimination of macroparticle contamination, developing techniques for depositing new coatings materials, including temary and higher-order alloys, by using several independent cathodes of different materials, or composite cathodes in a mixture of gases [37,52]. Amongst the materials deposited in this way are $\mathrm{TiC}(\mathrm{x}) \mathrm{N}(1-\mathrm{x}),(\mathrm{Ti}, \mathrm{Al}) \mathrm{N},(\mathrm{Ti}, \mathrm{Zr}) \mathrm{N},(\mathrm{Ti}, \mathrm{Al}, \mathrm{V}) \mathrm{N},(\mathrm{Ti}, \mathrm{Hf}) \mathrm{N},(\mathrm{Ti}, \mathrm{Nb}) \mathrm{N}$, brass $(\mathrm{Cu}-\mathrm{Zn})$, nickel-silver ( $\mathrm{Cu}-\mathrm{Zn}-\mathrm{Ni})$ and stainless steel (Fe-18Cr-8Ni) etc.[54,55].

\footnotetext{
i has been

A filtered arc deposition process : used to produce ceramic coatings by running the arc in a low background pressure of an alloying gas, using the respective cathode metals as nitrides, oxides, carbides, borides and mixtures thereof. Some of the coatings most frequently used are $\mathrm{TiN}, \mathrm{TiC}, \mathrm{TiO}_{2}, \mathrm{Ti}(\mathrm{CN}), \mathrm{ZrN}, \mathrm{CrN}, \mathrm{Al}_{2} \mathrm{O}_{3}, \mathrm{ZrO}_{2}, \mathrm{AlN}$, $\mathrm{VO}_{2}, \mathrm{VN}$ etc. $[29,56-59]$.
}

Aluminum oxide films have been deposited using a modified cathodic arc plasma deposition process. The films were found to have the correct stoichiometry, high density, mechanical and optical properties. The cathodic arc process yielded aluminum oxide films with deposition rates almost three times that of $r$.f. sputtered films. The films deposited at low temperatures $\left(250^{\circ} \mathrm{C}\right.$ or less ) were amorphous. However the 
films deposited at temperatures of $300^{\circ} \mathrm{C}$ or higher had a polycrystalline hexagonal phase [56-57]. The nitrides are deposited in a reactive mode using nitrogen gas whereas carbides were deposited using methane or acetylene as the reactive gas. Most nitride, carbide and carbonitride films exhibit very interesting colours for decorative applications. The group IVb nitrides in particular TiN, with their gold-like colours, have generated a great deal of interest as economical, hard, scratch-resistant decorative coatings [60-64].

The transition metals of carbides and nitrides have received enormous attention for the last two decades, and in particular TiN due to the combination of mechanical, electrical and optical properties that it possesses The metal titanium belongs to the IVa group of the transition metals in the periodic table. In vacuum deposition when titanium vapour is reacted with nitrogen the resulting optimum TiN compound exhibits golden appearance.

TiN crystallises in $\mathrm{NaCl}$ structure (f.c.c) which exists over a wide range of composition ratio ( nitrogen to titanium ratio $=0.62-1.16$ ) [65]. Due to its high hardness and resistance against erosion and abrasion it was applied in the form of thick coating in industrial applications as a hard and decorative coatings $[66,73]$.

The extreme hardness and high melting temperature of $\operatorname{TiN}\left(2970^{\circ} \mathrm{C}\right.$ ) due to strong metallic bonding are responsible for the metallic behaviour which is characterised by high conductive properties. The electrical properties of TiN characterised by high conductivity (low contact resistance) attracted large number of investigations to be done for its applications in IC technology [74,77].

In recent times, techniques of providing relatively low voltage ion-bombardment of a growing film have appeared, which have been shown to result in improved properties of the films that are made. They involve placing the insulating or isolated substrate in a dense DC plasma; the self-bias that appears on the surface due to the need for electron and ion currents to equalize causes the ions to be accelerated through voltages of up to 100 volts [78]. This bombardment is of particular consequence in reactive processing and has been used with plasmas produced by low voltage electron beam guns in evaporation systems [79], the highly ionised product of arc evaporation [80] and by redirecting the plasma created in a planar magnetron onto the isolated substrate by unbalancing the magnetic field which confines it [81]. 
The success of arc evaporation methods has been attributed to the considerable proportion of the evaporated material which is ionised, the reason for this being the low voltages present in an arc, for which there is a considerably greater cross section for ionization of atoms by electrons than at the higher voltages encountered in electron beam and magnetron systems [80]. The technique has demonstrated considerable success in producing highly adherent thick films of titanium nitride onto biased metal substrates to provide wear resistant surfaces [80]. The coatings have been found to contain considerable amounts of droplets ejected from the target by the arc. These can be removed by separating ionized atoms from larger particles in a mass spectrometer type selector [30].

Cathodic arc plasma deposition CAPD is markedly different from other physical vapour deposition (PVD) processes. Some of its characteristic features are summarized as follows:

1. The material plasma is generated by one or more arc spots.

2. A high percentage of the evaporated material is ionized, typically $30 \%-100 \%$. The ionised fraction of the condensing titanium vapour during TiN deposition is approximately $84 \%$ [82-85].

3. The ions exist in multiple charge states [86], e.g. for titanium, $\mathrm{Ti}^{+}, \mathrm{T}^{2+}, \mathrm{Ti}^{3+}$. etc.

4. The ions possess very high kinetic energies, i.e. $10-100 \mathrm{eV}$ [87].

These characteristics of CAPD result in deposits that are of superior quality in comparison with those from other PVD processes. Some of these advantages are as follows :

a. good quality films over a wide range of deposition conditions, e.g. stoichiometric reacted films with enhanced adhesion and film density can be obtained over a wide range of reactive gas pressures and evaporation rates;

b. high deposition rates for metals, alloys and compounds with excellent coating uniformity;

c. low substrate temperature [88];

d. retention of alloy composition from source to deposit [89];

e. ease of reaction of compound films [90]. 
In terms of thin film deposition, the most interesting properties of the arc process are (i) average charge state per ion, (ii) ion fraction and (iii) ion energy.

The high energy of the arriving ions may also be important for the formation of dense, pore-free coatings. The energy ions have greater surface mobility, and thus are able to reach empty locations in the growing film. In a molecular dynamics simulation of the coating process with a mixture of $0.1 \mathrm{eV}$ atoms and $50 \mathrm{eV}$ ions, Martin et al [91] showed that voids and less perfect film density are obtained if there are no ions in the mixture. The density increases with increasing ion : atom ratio, reaching the theoretical limit for ion : atom ratios exceeding 0.2 .

Martin et al [91] and Bergman [85] have made detailed optical and electrical measurements of the plasma present during the reactive arc deposition of TiN. They all agree that a charge-exchange reaction between the multiple ionized titanium and nitrogen molecules leads to the formation of some ionized nitrogen :

$$
\mathrm{Ti}^{\mathrm{n}+}+\mathrm{N}_{2} \cdots-\cdots \mathrm{Ti}(\mathrm{n}-1)++\mathrm{N}_{2}+
$$

Bergman argues that the amount of ionized nitrogen that exists as a result of this reaction is quite small in comparison to the ionized titanium. He measured the extent of ionization of the titanium to be $84 \%$ and the average charge to be $1.6 \mathrm{e}$.

Sathrum [92] has shown that the addition of a solenoid magnetic field around the source can increase this value to $2.08 \mathrm{e}$. The charge state is strongly material dependent [93], ranging from $\mathrm{Ti}^{3+}$ to $\mathrm{U}^{7+}$ [94]. The ion fraction is also found to be material dependent [85]. Estimates of ion fractions for other materials range from $12 \%-15 \%$ for $\mathrm{Cd}$ to $80 \%-100 \%$ for $\mathrm{Mg}$ [93]. The average ion energy for $\mathrm{Ti}$ has been estimated to be $1.6\left(10+V_{s}\right) e V[85]$, where $V_{s}$ is the negative substrate bias. Measurements of the ion energy distribution from a $\mathrm{Ti}$ arc showed the peak energy of the total distribution to be $44 \pm 2 \mathrm{eV}$ with a full width half maximum of $36 \mathrm{eV}$ [95].

The minimum energy of the ions from the arc source depends upon the nature of the cathode and is in the range of $28-50 \mathrm{eV}$ peak energy. The energy of the ions at the substrate may be increased simply by applying a high negative bias to accelerate the ions [96]. The deposition flux from cathodic arc sources consists almost entirely of ions and microdroplets [97], the concentration of neutral metal vapour is less than $1 \%$ of the mass transfer [98]. 
Reactive deposition of titanium nitride ( TiN ) is presently the most common application of cathodic arc deposition technology. Factors which favourably influence the efficiency of reactions in cathodic arc deposition include the high degree of ionization in the plasma, the existence of substantial numbers of ions in multiple charge states, ion and / or molecule collisions and the energy of the ions at the substrate [92, 99-102].

\subsection{AIMS OF THE INVESTIGATION}

The cathodic arc technique, having proved to be extremely successful in cutting tool applications, is now finding much wider ranging applications in the deposition of erosion resistance, corrosion resistance, decorative coatings, and architectural and solar coatings. The aim of this project was to design an arc source which can be operated in argon to investigate the deposition parameters and their effect on the films obtained. Magnetic stabilization of the arc on the cathode surface is provided to maintain the cathode spot on the the target surface. The coating of elemental and reactively'deposited compounds films has been found to contain considerable amounts of droplets ejected from the target by the arc. Therefore, a curved solenoid was provided to divert and direct the plasma created around the surface of the target onto the substrate and growing film surface. The magnetic field produced by the solenoid directs the electrons in the plasma, the ions are moved by the electrostatic attraction of them to the electrons. Larger particles were removed and droplets-free- films were obtained at the exit of the filter solenoid. The deposits of arc evaporator were compared to other physical vapour deposition techniques such as sputtering and evaporation for optical applications in order to investigate the advantages, if any, of the cathodic arc process. 


\section{REFERENCES}

[1]. David M. Sanders, David B. Boercker and Steven Falabella.

Coating Technology Based on the vacuum arc . A review. IEEE Trans. on Plasma Science, vol.18, No.6, December (1990).

[2]. T.A. Edison, U.S.Patent 484,582, ( 1892).

[3]. L. Hiesinger, German patent No. 915 765, July 29, (1954).

[4]. Holland L., Evaporation from an electric arc in vacuum. Nature Vol. 178, 328, August 11, (1956).

[5]. B.Vodar, S.Minn, and S.Offret, J. Phys. Rad., 16, 811, (1955).

[6]. H. Wroe, Br. J. Appl. Phys. 9, 488 (1958).

[7]. M. Kikuchi, S. Nagakura, H. Ohmura, and S. Oketani, Japan. J. Appl.Phys. 4, 940, (1965).

[8]. R. L. Boxman and S. Goldsmith; " Principles and applications of vacuum arc coatings".VIIIth International Symposium on Discharges and Electrical Insulation in Vacuum, Paris, 281-286, (1988).

[9]. M. Naoe, and S. Yamanaka, Japan. J. Appl. Phys. 8, 287, (1969).

[10]. M. Naoe, and S. Yamanaka, Japan. J. Appl. Phys.9, 293, (1970).

[11]. M. Naoe, and S. Yamanaka. Vacuum arc evaporations of ferrites and compositions of their deposits. Japan. J. Appl. Phys.10, 747, (1971).

[12]. A. A. Snaper, Arc Deposition and apparatus, U.S. Patent No. 3, 625, 848 (7 December 1971).

[13]. A. A. Snaper, Arc Deposition and apparatus, U. S. Patent No. 3, 836, 451 (17 September 1974).

[14]. L. P. Sablev, Apparatus for vacuum evaporation of metals under the action of an electric arc, U. S. Patent No. 3, 783, 231 (1 January 1974).

[15]. L. P. Sablev, Apparatus for metal evaporation coating, U. S. Patent No. 3,793, 179 ( 14 December 1983).

[16]. I. I.Aksenov, V. A.Belous, V. G. Padalka, and V. M. Khoroshikh. Transport of plasma streams in a curvilinear plasma-optics system. Sov.J.Plasma Physics, 4(4), 425-428 July-August (1978).

[17] I. I. Aksenov, I. I. Konovalov, E.E.Kudryastseva, V. V. Kunchenko, V. G. Padalka, and V. M. Khoroshikh. Droplet phase of cathode erosion in a steady vacuum arc. Sov. Phys. Tech. Phys. 29(8), 893-894 August (1984).

[18] I. I. Aksenov, V. A. Belous, V. G. Padalka, and V. M. Khoroshikh. Apparatus to rid the plasma of a vacuum arc of macroparticles. Translated from Pribory i. Tekhnika Eksperimenta, No.5, 236-237, Sep/Oct (1978).

[19]. V. E. Strel'nitskii, V. G. Padalka, and S. I. Vakula. Sov Phys. Tech. Phys. 23,222 , (1978). 
[20] A. S. Bakai and V. E. Strel'nitskii, Sov. Phys. Tech. Phys. 26, 1425, ( 1981).

[21]. A. S. Gilmour Jr. And D. L. Lockwood. Proc. IEEE 60 (8), 977 (1972).

[22]. David $\mathrm{m}$. Sanders. A review of ion-based coating processes derived from the cathodic arc. J. Vac. Sci. Technol. A7(3), pp 2339-2345 May Jun (1989).

[23]. Peter Malkin. The vacuum arc and vacuum interruption. J. Phys. D: Appl Phys. 22, pp.1005-1019 (1989).

[24]. A. N. Greenwood, "Vacuum arc applications", in Vacuum Arcs: Theory and application. J. M. Lafferty, (ed.) New York: Wiley: pp 1-18 (1980).

[25]. H. Randhawa . TiN coated high speed steel cutting tools. J. Vac. Sci. Technol. A4(6), pp. 2755-2758 Nov /Dec. (1986).

[26]. W. M. Mularie, Evaporation Arc Stabilization, U. S. Patent No. 4, 430, 184 (7 Feb 1984).

[27]. W. M. Mularie, Apparatus for Evaporation Arc Stabilization during the initial clean-up of an arc target. U. S. Patent No. 4, 559, 125 (17 December 1985).

[28]. Clark Bergman. TiN Deposition using a vacuum arc source. Multi-arc vacuum systems, Inc. St. Paul Minesota, USA. pp. 115-122 (1987).

[29]. P. J. Martin, R. P. Netterfield and T. J. Kinder. Deposition of TiN , TiC and $\mathrm{TiO}_{2}$ films by filtered arc evaporation. Surface and coatings technology, 49 pp.239-243 (1991).

[30]. P. J. Martin, R. P. Netterfield and T. J. Kinder.Ion-beam-deposited films produced by filtered arc evaporation. Thin solid films, 193/194 (1990) 77-83

[31]. H. Randhawa and P. C. Johnson. Cathodic arc deposition advances coating technology. Research and development. p.173 Feb. (1987).

[32]. P. W. Hatto and D. G. Teer. Ion plating with an arc source. Vacuum/ volume 36/ No. 1-3, 67-69, (1986).

[33]. Paul A. Lindfors and William M. Mularie.Cathodic arc deposition technology. Surface and coatings Technology, 29, 275-290, (1986)

[34]. P. J. Martin, D. R. Mckenzie, R. P. Netterfield, P. Swift and S. W. Filipczuk.Thin Solid Films, 150, p.91 (1987).

[35]. H. E. Brandoff, U. S. Patent 4, 511, 593, (1985).

[36]. S. Ramalingam. Controlled vacuum arc material deposition, method and apparatus. World patent $8,503,954,(1985)$

[37]. S. Boelens and H. Veltrop. Hard coatings of TiN, ( TiHf)N, (TiNb)N deposited by random and steered arc evaporation. Surface and Coatings Technology, vol.33, pp.63-71 (1987). 
[38]. E. Erturk, H. J. Heuvel and H. G. Dederichs. Comparison of the steered arc and random arc techniques. Surface and Coatings Technology, 39/40, p.455-464 (1989) .

[39]. D. M. Sanders. Ion beam self- sputtering using a cathodic arc ion sources.

J. Vac. Sci. Technol., vol. A6(3), pp.1929-1933 (1987).

[40]. D. M. Sanders. Review of ion-based coating processes derived from the cathodic arc. J. Vac. Sci. Technol. A7(3), May/Jun. (1989).

[41]. I.I. Aksenov and V. E. Strel'nitskij. Properties of diamond- like coatings prepared by vacuum arc deposition. Surface and Coatings Technology, 47 98-105 (1991).

[42]. I.I. Aksenov and V. E. Strel'nitskij. wear resistance of diamond-like carbon coatings. Surface and coatings technology, 47, pp. 252-256 (1991).

[43]. P. J. Martin, S. W. Filipczuk, R.P. Netterfield, J. S. Field, D. F. Whitnall and D. R. Mckenzie. Structure and hardness of diamond- like carbon films prepared by arc evaporation. Journal of Materials Science Letters 7, pp.410-412 (1988).

[44]. D.R.Mckenzie, D. Muller, B. A. Pailthorpe, Z. H. Wang, E. Kravtchinskaia, D. Segal, P. B.Lukins, P. D. Swift, and P. J. Martin (Australia )

G. Amaratunga, P. H. Gaskell and A. Saeed (UK). Properties of tetrahedral amorphous carbon prepared by vacuum arc deposition. Diamond and related materials, 1, pp. 51-59 (1991).

[45]. E. I. Tochitsky, A. V. Stanishevskii, I. A. Kapustin, V. V. Akulich and O.

V. Selifanov. Structure and properties of carbon films prepared by pulsed vacuum arc deposition .Surface and Coatings Technology, 47 ,pp. 292-298 (1991).

[46]. J. Koskinen and A. Anttila (Finland).

J.-P. Hirvonen (USA). Diamond- like carbon coatings by arc-discharge methods.Surface and coatings technology, 47, pp. 180-187 (1991).

[47]. S. Mitura and Z. Has (Poland).

V. Gorokhovsky (U.S.S.R.), The system for depositing hard diamond-like films onto complex-shaped machine elements in an r.f. arc plasma.

Surface and Coatings Technology, 47, pp. 106-112 (1991).

[48]. V. E. Strel'nitskii, V. G. Padalka and S. I. Vakula. Sov. Phys. Tech. Phys. 23, p.222 (1978).

[49]. H. Ehrich. The anodic vacuum arc. I. Basic construction and phenomenology. J. Vac. Sci. Technol. A6 (1), pp.134-138 Jan/Feb.(1988). 
[50]. H. Ehrich, B. Hasse, K. G. Muller, and R. Schmidt. The anodic vacuum arc. II. Experimental study of arc plasma. J. Vac. Sci. Technol. A6 (4), pp.2499-2503, Jul./Aug. (1988).

[51]. H. Ehrich, B. Hasse, K. G. Muller, and M. Mausbach. The anodic vacuum arc and its application to coating. J. Vac. Sci. Technol. A8 (3), pp.2160-2164 May/Jun (1990).

[52]. H. Randhawa. Cathodic arc plasma deposition of $\mathrm{TiC}$ and $\mathrm{TiC}_{\mathrm{x}} \mathrm{N1-x}$. Thin Solid Films, 153, pp. 209-218 (1987).

[53]. H. Randhawa, P. C. Johnson and R. Cunningham.

Deposition and characterization of tenary nitrides. Presented at American society , Anaheim, (1987).J. Vac. Sci. Technol., A6 (3) , p. 2136 (1988).

[54]. S. Ramalingam, K. Kim, R. F. Chang, Deposition, structure and properties of tenary nitrides of $\mathrm{Ti}, \mathrm{Zr}$, and $\mathrm{Hf}$ with nitrogen and molybdenum nitrides produced with steered arc coating. Int. Cong. Metal coat., San Diego, p.91(1987).

[55]. M. Otsu and E. Ko, T. Yoshikawa and K. Tsuji. Preparation of alloy thin films by the CAPD process. Thin Solid Films, 181 pp. 351-356 (1989).

[56]. H. Randhawa. High-rate deposition of $\mathrm{Al}_{2} \mathrm{O}_{3}$ films using modified cathodic arc plasma deposition processes. J. Vac. Sci. Technol, A7(3), pp. 2346-2349 May/Jun (1989).

[57]. T. D. Schemmel, R. L. Cunningham and H. Randhawa. Process for high rate deposition of $\mathrm{Al}_{2} \mathrm{O}_{3}$. Thin Solid Films, 181 pp. 597-601 (1989).

[58] H. Randhawa, and P. C. Johnson.

Zirconium nitride films prepared by cathodic arc plasma deposition process. Surf. Coat. Technol. , 33, pp.53-62 (1987).

[59]. C. N. Tai and E. S. Koh and K. Akari. Macroparticles on TiN films prepared by the arc ion plating process. Surface and coatings technology, $43 / 44, \mathrm{pp}$. 324-335 (1990).

[60]. A. Mumtaz and W. H. Class, J. Vac. Sci. Technol., 20, p.345 (1982).

[61]. S. Schiller, G. Beister and W. Sieber, Thin Solid Films, 111, p.259 (1984).

[62]. A. J. Perry, J. Vac. Sci. Technol. A, 4(6),p.2670 (1986).

[63]. H. Randhawa, 7th Int. Conf. on Thin films, New Delhi, India, Dec. 7-11, (1987), in Thin Solid Films, 167 (1988).

[64]. I. Aoki, R. Fukutome and Y. Enomoto, Thin Solid Films, 130, p.253 (1985).

[65]. L. E. Toth, Transition metals carbides and nitrides, Academic press, New York (1971). 
[66]. S. Schiller, G. Beister, J. Reshke and Hoetzsch, J. Vac. Sci. Technol., A5, 4, p.2180 (1987).

[67]. H. Randhawa, paper represented at the 15 th International conference on Metallurgical Coatings, San Diago, Ca, USA, April, 11-15, (1988), Surf. Coat. Technol., 36, pp. 829-836 (1988).

[68]. S. Kadlec, J. Musil and W. D. Munz, J. Vac. Sci. Technol, A8, 3, p.1318 (1990).

[69]. R. Buhl, H. K. Pulker and E. Moll, Thin Solid Films, 80, p.265 (1981).

[70]. B. Zega, M. Kornmann and J. Amiguet, Thin Solid Films, 45, p. 577 (1977).

[71]. H. E. Hintermann, Thin Solid Films, 84, p. 215 (1981).

[72]. R. F. Bunshah and C. V. Deshpandy, Vacuum, 39, 10, p. 955 (1989) .

[73]. E. Tsunasawa, K. Inagaki, and K. Yamenaka, J. Vac. Sci. Technol., 14 p. 651 (1977).

[74]. W. J. Garceau, P. R. Fournier and G. K. Herb, Thin Solid Films, 60, p.237 (1979).

[75]. M. Wittmer, Appl. Phys. Lett., 36, p.456 (1980).

[76]. M. Wittmer, Appl. Phys. Lett., 37, p.540 (1980).

[77]. N. W. Cheung, H. Von Seefeld, M-A. Nicolet, F.Ho, and P. Hes, J. Appl. Phys., 52, p.4297 (1981).

[78]. R.P. Howson, H. A. J'afer and A. G. Spencer. Substrate effects from an unbalanced magnetron. Thin Solid Films, 193/194, 127-137 (1990).

[79]. J. Ebert. Ion assisted reactive deposition processes for optical coatings. Surface and Coatings Technology, 43/44, 950-962 (1990).

[80]. J. Vyskocil and J. Musil, Arc evaporation of hard coatings process and film properties. Surface and Coatings Technology, 43/44, 299-311, (1990)

[81]. B. Window and N. Savvides. Unbalanced magnetrons as sources of high ion fluxes. J. Vac. Sci. Technol., A4(3), 453-456, (1990).

[82]. L. P. Harris, in J. M. Lafferty (ed), Arc cathode phenomena, Wiley Interscience, New York, pp 127-128 (1980).

[83]. C. W. Kimblin, J. Appl. Phys., 45,p. 5235 ( 1974).

[84]. J. T. Tuma, C. L. Chen and D. K. Davies, Erosion products from the cathode spot region of a copper vacuum arc. J. Appl. Phys., 49, p.3821 (1978) .

[85]. Clark Bergman. Ion flux characteristics in arc vapour deposition of TiN. Surface and Coatings Technology, 36, 243-255, (1988).

[86]. V. M. Lumeer, V. G. Padalka and V. M. Khoroshikh, Sov. phys. Tech. Phys., 22, p.858 ( 1978 ).

[87]. J. E. Daalder, Cathode erosion of metal vapor arcs in vacuum, phD. thesis, Technische Hygelschol, Eindhoven, The Netherlands (1978). 
[88]. H. C. Miller, J. Phys. D., 12, p. 1293 ( 1979).

[89]. Dorodnov, A. M. and B. A. Petrosov, Physical principles and types of technical vacuum plasma devices, Sov. Phys. Tech. Phys., 26 ( 3 ) pp.304 -315, March (1981).

[90]. Aksenov, I.I., Yu P. Antufev, V. G. Bren, V. G. Padalka, A. I. Popov and V.M. Khoroshikh, Sov. Phys. Tech. Phys., 26, 187, ( 1981)

[91]. P. J. Martin et al. Characteristics of titanium arc evaporation processes, Thin Solid Films, 153, pp. 91 - 102 ( 1987 ).

[92]. P. Sathrum and B. F. Coll, Surf. Coat. Technol., 50, p.103 ( 1992 ).

[93]. P. J. Johnson, Phys. Thin Films, 14,p. 128 ( 1989 ).

[94]. I. Brown, J. E. Galvin and R. A. MacGill, Appl. Phys. Lett., 4, p.358 (1985).

[95] P. J. Martin, R. P. Netterfield and T. J. Kinder, Thin Solid Films, 153, p.77 ( 1990 ).

[96]. P. J. Martin et al. Thin film deposition by filtered arc evaporation. Surf. Coat. Technol., 54 / 55, pp. 136 - 142 ( 1992 ).

[97]. J. E. Daalder, Physica, 104C, 91 - 106 ( 1981 ).

[98]. H. C. Miller, J. Appl. Phys., 52, 4523 - 4530 ( 1981).

[99]. A. M. Dorodnov, Technical applications of plasma accelerators, Sov. Phys. Tech. Phys., 23, pp.1058 - 1063 ( 1978 ).

[100]. I. I. Aksenov, V. G. Bren', V. G. Padalka and V. M. Khoroshikh, Chemical reactions in the condensation of metal - plasma streams, Sov. Phys. Tech. Phys., 23, pp. 651 - 653 ( 1978 ).

[101]. I. I. Demindenko, N. S. Lomino, V. D. Ovcharenko, V. G. Padalka and G. N. Polyakova, Ionization mechanism for nitrogen in a vacuum arc discharge, Sov. Phys. Tech. Phys., 29, pp. 895 - 897 ( 1984 ).

[102]. I. I. Aksenov, V. G. Bren', V. G. Padalka and V. M. Khoroshikh, Special features in synthesis of nitrides on condensation of metal plasma, Sov. Phys.Tech. Phys., 17, pp.200- 202 ( 1983 ). 


\section{CHAPTER 2 \\ THE PHYSICAL \\ VAPOUR DEPOSITION PROCESSES}

\subsection{INTRODUCTION}

Physical vapour deposition technology has evolved over the years from the use of simple resistively heated sources to complex procedures making use of lasers and ion beams. Generally, the greater the energy of the deposition process, the greater the flexibility to produce dense, smooth, and adherent coatings.

Physical vapour deposition in the guise of vacuum evaporation, sputtering and ion plating is a process extensively used for depositing various coatings onto a wide range of substrate materials. In recent years, it has found many applications for the deposition of hard coatings, for example titanium nitride, for such demanding applications as wear reduction of machine tools. The application of these techniques ranges also over a wide variety of applications from decorative to utilitarian over significant segments of the engineering, chemical, nuclear, microelectronics and related industries.

This chapter describes, in general, the physical vapour deposition ( PVD ) processes including evaporation, ion plating and sputtering and the related technology for preparing thin solid films for research, development, and production. It is intended to present in depth the thermal evaporation processes, theory and mechanisms. A comparison of the PVD methods is presented through the context with the advantages and limitations of each method.

\subsection{ION PLATING}

The term " ion plating " was introduced by Mattox [1] for processes which include ion bombardment of the substrate and of the growing film [2]. A basic ion plating process is illustrated in figure 2. 1, [3].

Patents relating to the process can be traced to Berghaus ( 1938 ) [4].The technique refers to a process in which the substrate and/ or growing film is exposed to energetic particles with the purpose of improving adhesion and / or other film properties [3]. Ions are produced by thermally evaporating material in the region of a $1-5 \mathrm{KV}$ inert gas discharge operating at a pressure of around $10^{-2}$ Torr. The ionized atoms are then 
accelerated by an electric field to the substrate. Multiple collisions with the inert gas result in energy loss and charge transfer. The reported deposition rate was 0.4 to 0.6 $\mathrm{nm} / \mathrm{s}$ [3].

In ion plating, the substrate is cleaned prior to plating and is maintained clean during deposition by ion bombardment, and therefore the first condition for good adhesion is satisfied [5]. All practical coating systems are based on ion plating [6,7] and consist of a source of metal vapour and some means of creating an intense plasma, so that the electrically biased samples are bombarded with energetic ions during deposition.

The main factor affecting the adhesion and structure of the coatings is the level of ion bombardment [8]. Teer [5] has estimated the average energy of the ions arriving at the cathode to be $3000 \mathrm{eV}$, and the average energy of the neutral particles to be $135 \mathrm{eV}$. The process has a high throwing power in that gas scattering enables sides of the substrate to be coated, although often some degree of rotation is required [3]. Many investigators have reported excellent results for optical films of $\mathrm{TiN}, \mathrm{TiO}_{2}, \mathrm{Al}_{2} \mathrm{O}_{3}$, $\mathrm{SiO}_{2}, \mathrm{ZrO}_{2}$ and other films deposited onto unheated substrates [9]. 


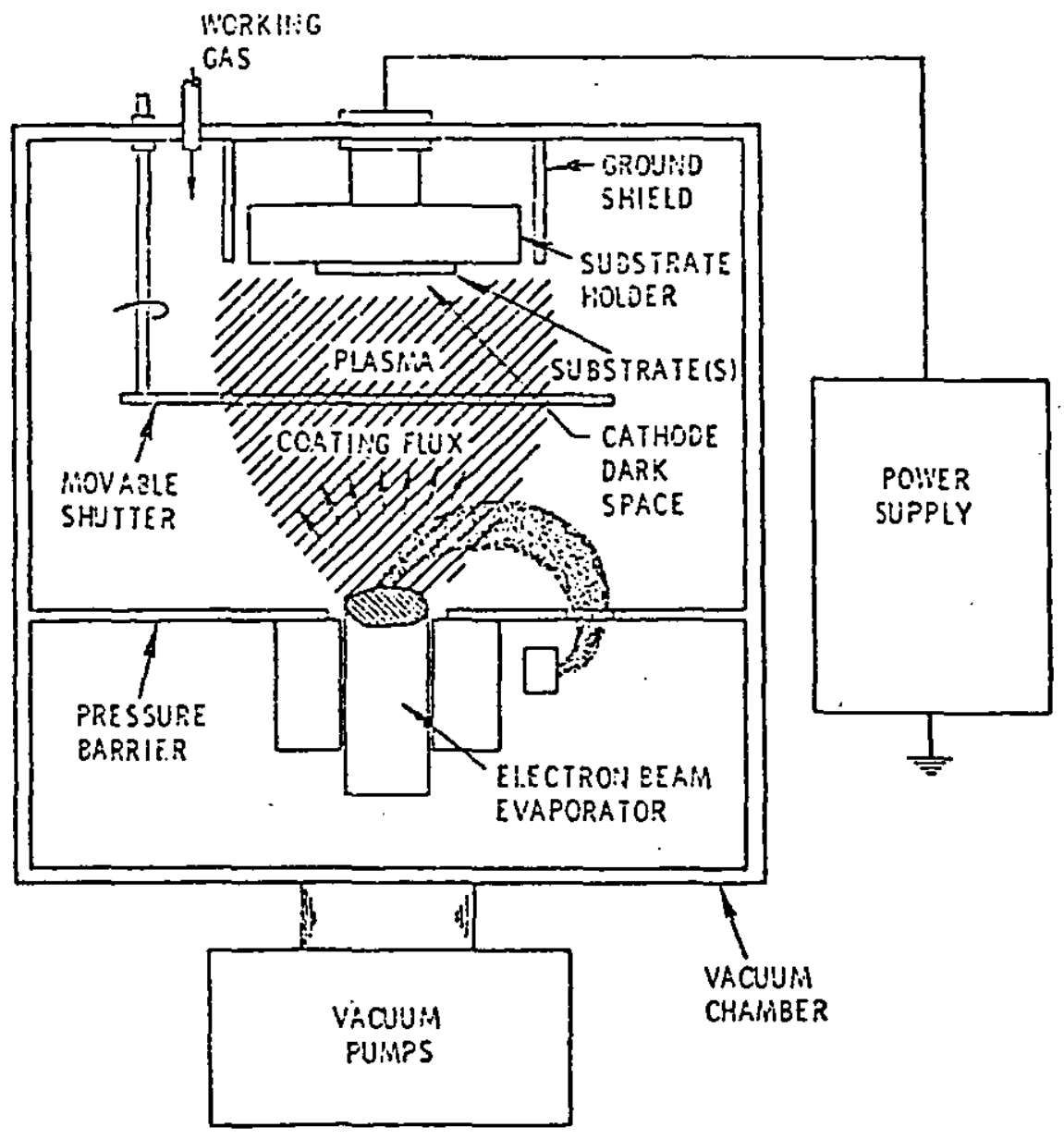

Figure 2.1 : Ion-plating process. 


\subsection{SPUTTERING}

A basic sputtering process is illustrated schematically in figure 2.2. In this process, positive gas ions usually argon ions produced in a glow discharge bombard the target material (cathode) dislodging groups of atoms which then pass into the vapour phase and are deposited onto the substrate [10]. Secondary electrons, created at the target surface by ion bombardment, accelerate and ionize the gas atoms to sustain a discharge [3]. Higher efficiency is achieved by confining the primary electrons to paths close to the cathode surface with applied magnetic fields [3].

A recent development is unbalanced magnetron sputtering (UMS), a variant in which the magnetic field is "unbalanced" [11,12]. This maintains the plasma enhancement of the magnetron, but allows a much higher ion flux to reach the substrates. The use of the ion bombardment, arising from the use of an unbalanced magnetron, was demonstrated to give optical thin films of improved properties [13].

\subsection{EVAPORATION}

In the evaporation process, vapours are produced from a material located in a source which is heated by direct resistance, radiation, eddy currents, electron beam, laser beam or an arc discharge. The process is usually carried out in vacuum (typically $10^{-5}$ to $10^{-6}$ Torr ) [10]. The following sequential basic steps take place:

1. a vapour is generated by boiling or subliming a source material;

2. the vapour is transported from the source to the substrate; and

3. the vapour is condensed to a solid film on the substrate surface [14].

To ensure uniformity of films deposited, a precise substrate motion is required, and additional complications include the need for process monitoring and control. The higher deposition rates having come about in the last 20 years with the advent of electron beam heated sources [10]. Use of the cathodic arc evaporation technique has recently become wide spread. It offers the potential from high specific evaporation rates, low temperature deposition $[15,16]$. Deposition rates of the PVD processes are shown in Table 2.1 .

Figures 2.3 and 2.4 show the vacuum evaporation process, and film formation throughout the process, respectively. 


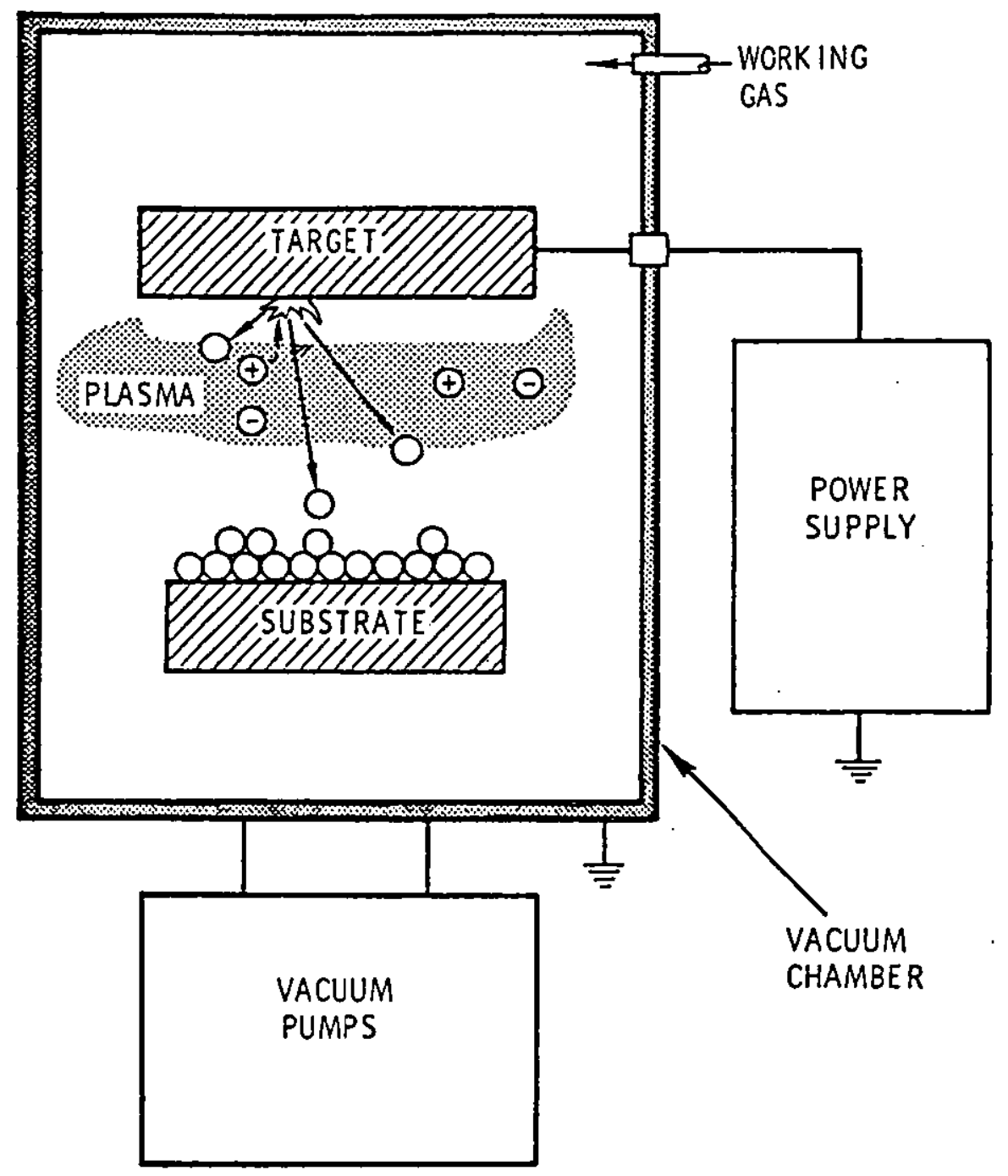

Figure 2.2. A basic sputtering process 


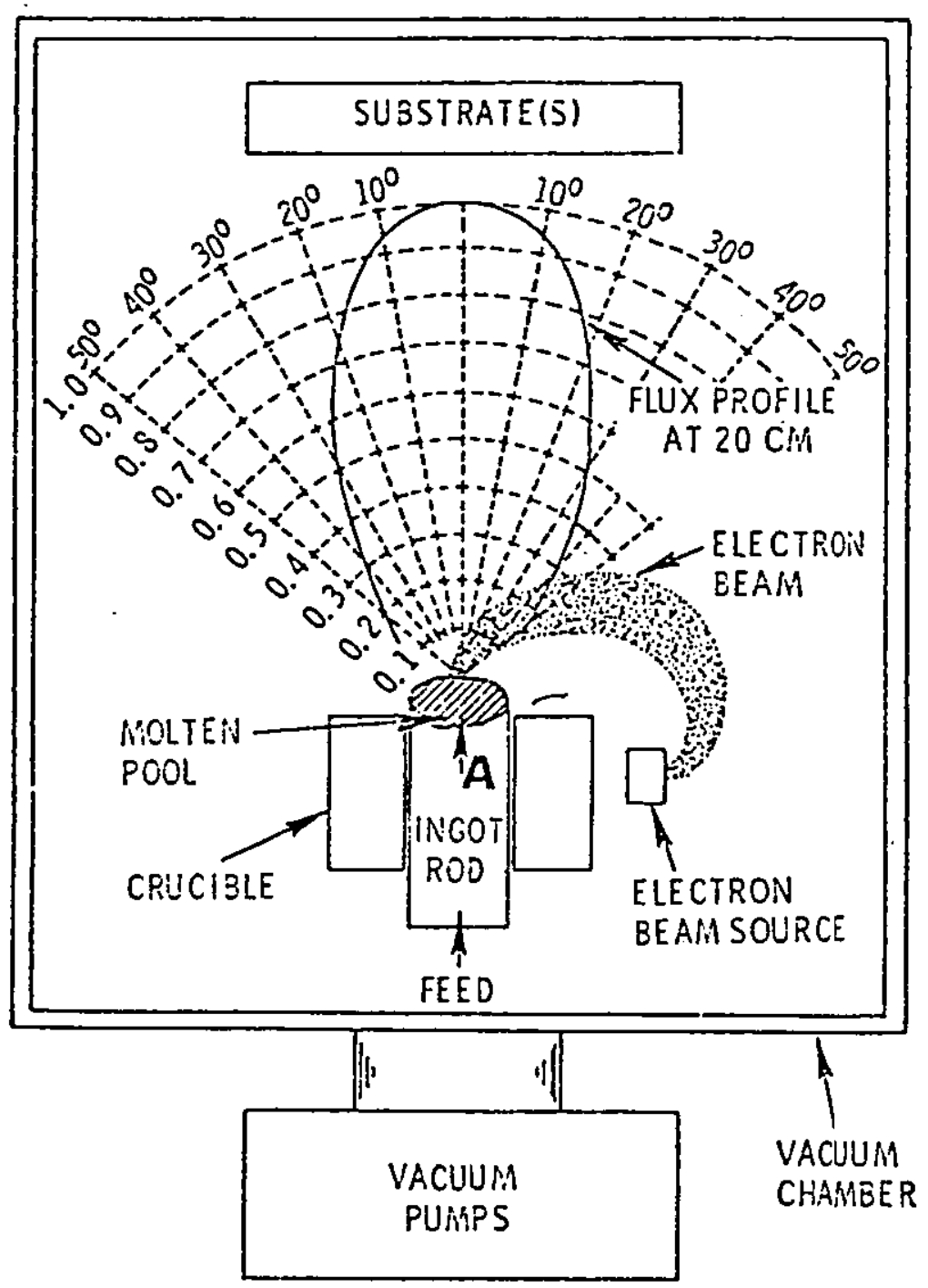

Figure 2.3. Vacuum evaporation process using electron beam heating 


\begin{tabular}{|l|c|}
\hline Process & $\begin{array}{c}\text { Deposition rates } \\
\mathbf{A}^{\mathbf{0}} / \mathrm{min}\end{array}$ \\
\hline Evaporation & $100-250,000$ \\
Ion plating & $100-250,000$ \\
Sputtering & $25-10,000$ \\
\hline
\end{tabular}

Table 2.1 Deposition rates for various PVD processes [10].

Step 3 : Film growth on substrate

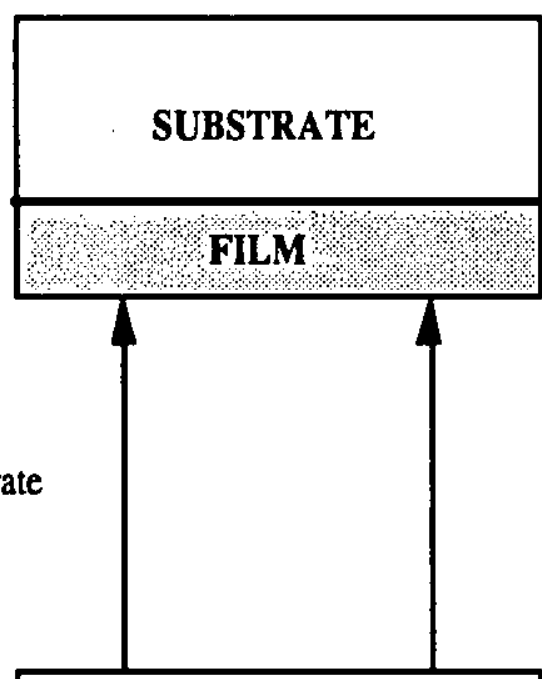

Step 2 : Transport from source to substrate

Step 1 : Creation of deposition species

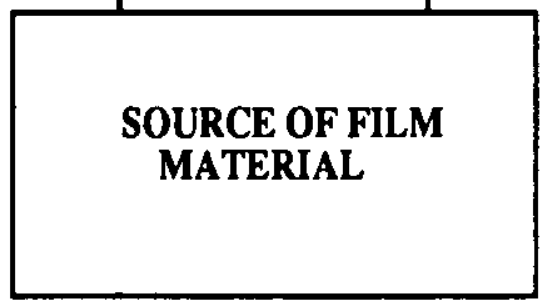

Evaporation Ion plating Sputtering, etc.

Figure 2.4. The three steps in film deposition 


\subsubsection{GENERAL CONSIDERATIONS}

Solid materials vaporize when heated to sufficiently high temperatures. The condensation of the vapour onto a cooler substrate yields thin solid films [17]. The deposition by thermal evaporation method is simple and very convenient and is at present the most widely used [18-19]. Because of collisions with ambient gas atoms, a fraction of the vapour atoms proportional to $\exp (-d / 1)$ will be scattered and hence randomized in direction in a distance $d$ during their transfer through the gas. Here $l$ is the mean free path ( $\mathrm{mfp}$ ) of gas atoms which for air molecules at $25^{\circ} \mathrm{C}$ and pressures of $10^{-4}$ and $10^{-6}$ Torr, respectively, is about 45 and $4,500 \mathrm{~cm}$; thus, pressures lower than $10^{-5}$ Torr are necessary to ensure a straight-line path for most of the emitted vapour atoms, for substrate-to-source distances of $\sim 10$ to $50 \mathrm{~cm}$ in a vacuum evaporator. The rate of free evaporation of vapour atoms from a clean surface of unit area in vacuum is given by the Langmuir expression :

$$
m_{e}=5.83 \times 10^{2} \mathrm{Pe} \sqrt{\frac{M}{T}} \quad \mathrm{~g} /\left(\mathrm{cm}^{2}\right)(\mathrm{sec})
$$

where :

$$
\begin{aligned}
& \mathrm{Pe}\left(<10^{-2}\right) \text { is the equilibrium vapour pressure ( in Torr ) of the evaporant } \\
& \text { under saturated-vapour conditions at a temperature } \mathrm{T} \text {, and } \\
& \mathrm{M} \\
& \text { is the molecular weight of the vapour species. }
\end{aligned}
$$

Alternatively, we may write the evaporation rate, $\mathrm{N}_{\mathrm{e}}$, as:

$$
\mathrm{N}_{\mathrm{e}}=3.513 \times 10^{22} \mathrm{Pe} \sqrt{\frac{1}{\mathrm{MT}}} \quad \text { molecules } /\left(\mathrm{cm}^{2}\right)(\mathrm{sec})
$$

Note, however, that the rate of deposition of the vapour on a substrate depends on the source geometry, its position relative to the substrate, and the condensation coefficient. Holland [18] has discussed thoroughly the theoretical distribution of vapour from a point, a wire, a small surface, an extended strip, and from cylindrical and ring types of sources. For the ideal case of deposition from a clean, uniformly emitting point source onto a plane receiver, the rate of deposition varies as $\cos \theta / r^{2}$ (Knudsen cosine law ), where $r$ is the radial distance of the receiver from the source and $\theta$ is the angle between the radial vector and the normal to the receiver direction. If $t_{0}$ and $t$ are the thicknesses 
of deposits at the receiver vertically below the source at a distance $h$, and at a horizontal distance $x$ from the vertical line, respectively, then the deposit distribution ( assuming the same condensation coefficient ) is given by :

$$
\frac{t}{b}=\frac{1}{\left[1+\left(\frac{x}{h}\right)^{2}\right]^{\frac{3}{2}}}
$$

For evaporation from a small area onto a parallel plane receiver, the deposition rate is proportional to $\cos ^{2} \theta / \mathrm{r}^{2}$, and the thickness distribution is given by :

$$
\frac{t}{t_{0}}=\frac{i}{\left[1+\left(\frac{x}{h}\right)^{2}\right]^{2}}
$$

In both cases, the thickness decreases by about 10 percent for $x=h / 4$. More complicated expressions for the distribution of the deposit result for other types of sources.

A parameter of interest in understanding the influence of ambient gases on the properties of films is the impingement rate of gas atoms or molecules. This is given by the kinetic theory of gases under equilibrium conditions as

$$
\mathrm{N}_{\mathrm{g}}=3.513 \times 10^{2} \frac{\mathrm{P}_{\mathrm{g}}}{\sqrt{\mathrm{M}_{\mathrm{g} g}}} \quad \text { molecules } /\left(\mathrm{cm}^{2}\right)(\mathrm{sec})
$$

which is the same expression as eq. (2.2), with the subscript $\mathrm{g}$ for gas.

Table 2.2 lists the $\mathrm{mfp}$ and impingement rate of air molecules at different pressures.Note that at constant gas and evaporation temperatures, the ratio $\mathrm{N}_{g} / \mathrm{N}_{\mathrm{e}}$ is proportional to $\mathrm{P}_{\mathrm{g} / \mathrm{P}}$. Values of $\mathrm{N}_{\mathrm{g}}$ given in Table 2.1 show that under the commonly employed experimental conditions of vacuum $\left(\sim 10^{-5}\right.$ Torr $)$ and deposition rates ( $\sim 1 \AA$ / sec), the impingement rate of gas atoms is relatively quite large, so that if the 
sticking coefficient of gas atoms is not negligibly small, a considerable amount of gas sorption could occur.

The above discussion points out one of the problems with evaporation technology, i.e.the variation in thickness of the deposit on a flat substrate. Numerous solutions are possible which involve either moving the substrate in a manner so as to randomly sample the vapour flux, or the use of multiple sources in order to achieve thickness uniformity $[17,18,20,21]$.

\begin{tabular}{|c|c|c|c|l|}
\hline $\begin{array}{l}\text { Presure } \\
\text { (Torr) }\end{array}$ & $\begin{array}{c}\text { Mean free path, cm } \\
\text { (between collisions) }\end{array}$ & $\begin{array}{l}\text { Collisions / sec } \\
\text { (between molecules) }\end{array}$ & $\begin{array}{c}\text { Molecules/ } \mathrm{cm}^{2} \text { ) }(\mathrm{sec}) \\
\text { scriking surface }\end{array}$ & Monolayers / sec * \\
\hline $10^{-2}$ & 0.5 & $9 \times 10^{18}$ & $3.8 \times 10^{18}$ & 4,400 \\
\hline $10^{-4}$ & 51 & 900 & $3.8 \times 10^{16}$ & 44 \\
\hline $\begin{array}{c}-5 \\
10^{-5}\end{array}$ & 510 & 90 & $3.8 \times 10^{15}$ & 4.4 \\
\hline $10^{-7}$ & $5.1 \times 10^{4}$ & 0.9 & $3.8 \times 10^{13}$ & $4.4 \times 10^{-2}$ \\
\hline $10^{-9}$ & $5.1 \times 10^{6}$ & $9 \times 10^{-3}$ & $3.8 \times 10^{11}$ & $4.4 \times 10^{-4}$ \\
\hline
\end{tabular}

- Assuming the condensation coefficient is unity

Table 2.2. Some facts about the residual air at $25^{\circ} \mathrm{C}$ in a typical vacuum used for film deposition. 


\subsubsection{EVAPORATION METHODS}

Thermal evaporation may be achieved directly or indirectly ( via a support ) by a variety of physical methods.

\subsubsection{RESISTIVE HEATING}

This method consists of heating the material with a resistively heated filament or boat, generally made of refractory metals such as tungsten W, molybdenum Mo, tantalum $\mathrm{Ta}$, and Niobium Nb, with or without ceramic coatings. Crucibles of quartz, graphite, alumina, beryllia, and zirconia are used with indirect heating. The choice of the support material is primarily determined by the evaporation temperature and resistance to alloying and / or chemical reaction with the evaporant. With the exception of highly reactive materials such as $\mathrm{Si}, \mathrm{Al}, \mathrm{Co}, \mathrm{Fe}$, and $\mathrm{Ni}$, most materials present no problem with evaporation from suitable supports. New materials are constantly being developed to overcome difficulties with reactive evaporants [17]. A comprehensive list of materials, their physical properties of interest for thermal deposition, possible support materials, and applicable deposition techniques other than by evaporation have been reviewed by Holland [18] and Glang [ 22].

Vapour sources of various types, geometries and sizes can be easily constructed or obtained commercially at sufficiently low prices. The simplest vapour sources are resistance-heated wires and metal foils of various types as shown in figure (2.5).

They are usually made from the refractory metals, tungsten, molybdenum and tantalum which have high melting points and low vapour pressure so as not to contaminate the deposit. Their properties are given in table 2.3. 


\begin{tabular}{|c|c|c|c|}
\hline Property & Tungsten & Molybdenum & Tantalum \\
\hline Melting point, ${ }^{\circ} \mathrm{C}$ & 3380 & 2610 & 3000 \\
\hline${ }^{\circ}{ }^{\circ} \mathrm{C}$, for $\mathrm{p}=10^{-6}$ Torr & 2410 & 1820 & 2240 \\
\hline Electrical resistivity, 10 ohm-cm & & & \\
At $20{ }^{\circ} \mathrm{C}$ & 5.5 & 5.7 & 13.5 \\
At $1000{ }^{\circ} \mathrm{C}$ & 33 & 32 & 54 \\
At $2000{ }^{\circ} \mathrm{C}$ & 66 & 62 & 87 \\
\hline Thermal expansion, \%: & & & \\
From 0 - $1000{ }^{\circ} \mathrm{C}$ & 0.5 & 0.5 & 0.7 \\
From 0 - $2000{ }^{\circ} \mathrm{C}$ & 1.1 & 1.2 & 1.5 \\
\hline
\end{tabular}

Table 2.3 Properties of refractory metals [23] 
Platinum, iron or nickel are sometimes used for materials which evaporate below 1000 ${ }^{\circ} \mathrm{C}$. The capacity ( total amount of evaporant ) of such sources is small. The hairpin (A) and wire helix (B) sources are used by attaching the evaporant to the source in the form of small segments. They are commonly made from 0.02 to 0.06 -in-diameter tungsten wire. Upon melting, the evaporant must wet the filament and be held by its surface tension. Spreading of the molten evaporant across the wire is desirable to increase the evaporation surface and thermal contact. Multistrand filament wire is preferred because it increases the surface area. Because of their simplicity and low cost, wire sources are also used to evaporate metals such as $\mathrm{Al}, \mathrm{Ni}, \mathrm{Fe}$, or $\mathrm{Pt}$ which are known to alloy with tungsten. Even if the evaporant does not alloy with the filament, the capacity of wire sources is small and the maximum amount held is about 1 gram. Wire baskets as shown in fig 2.5(C) are used to evaporate pellets or chips of dielectrics or metals which either sublimate or do not wet the wire material upon melting. In such cases, if wetting occurs, the turns of the baskets are shorted and the temperature of the source drops. Metal foils as shown in fig 2.5 (D), (E) and (F) may hold up to a few grams and are the most universal types of sources for small evaporant quantities. They are fabricated from 0.005 - to 0.015 - in- thick sheets of tungsten, molybdenum, or tantalum. The dimpled sources have reduced widths in the center to concentrate the heating in the area of the evaporant.

Canoe or boat sources may be made in the laboratory by bending metal sheets into the desired shape. This is easily done with tantalum and not very difficult with molybdenum. However, tungsten is very brittle and breaks if it is bent at room temperature.

Deformation is possible at elevated temperatures in a non oxidizing atmosphere [18]. All three metals embrittle after having been heated in vacuum, especially if alloying with the evaporant has occured. Kohl has reviewed their mechanical properties in detail in reference [24]. Wetting of the metal-foil surface by the molten evaporant is desirable in the interest of good thermal contact. However, molten metals also lower the electrical resistance of the foil in the contact area, thereby causing the temperature to drop. This problem is avoided with oxide-coated foils as shown in fig 2.5 (E). Olsen et al [25], were the first to describe oxide-coated metal sources. The oxide layer such as $\mathrm{Al}_{2} \mathrm{O}_{3}$ or BeO was applied to tungsten-wire baskets and is claimed to be non-porous and withstands temperature cycling without chipping. Maximum operating temperatures of 1850 to $1900^{\circ} \mathrm{C}$ are possible, but the vapour pressure of molybdenum exceeds $10^{-6}$ Torr in this range and that of alumina is even higher. The power requirements of such sources are $30 \%$ to $50 \%$ above those of comparable uncoated foils since the thermal 
contact between the resistance-heated metal and the evaporant is reduced by the oxide coating. Since the electrical resistance of the source is small, low voltage power supplied, 1 to $3 \mathrm{~kW}$ are recommended. The current in the source may range from $20 \mathrm{~A}$ for some of the wire sources, to $500 \mathrm{~A}$ for some foil sources. If the source current exceeds $100 \mathrm{~A}$, it is advisable to use water-cooled feedthroughs. The rate of evaporation from such sources may vary considerably due to localized conditions of temperature variation, wetting, hot spots etc. Therefore, for a given thickness of film, the procedure is to load the source with a fixed weight of evaporant and evaporate to completion or use a rate monitor and / or thickness monitor to obtain the desired rate and thickness [10]. Finally, there are wire or foil sources to evaporate small charges of nearly all elements except the refractory metals themselves. Films of W, Mo and To have been prepared by spring-loading two wires ( 0.02 in diameter) of the respective metals such that their ends touch and from a high-resistance junction. Melting of the junction and evaporation are induced by passing an electric current through the arrangement [26]. An alternative technique is vacuum-arc evaporation. Lucas et al [27] established short arcs between zone-purified rods of $\mathrm{Ta}, \mathrm{Nb}$, and $\mathrm{V}$ by means of a dc welding generator. A similar arrangement has been described by Massey [28], who sustained an arc between two carbon rods and produced carbon films up to $1 \mu$ thick.in general, however, heating by electron bombardment is the preferred technique to evaporate refractory metals.

$$
\text { A. }
$$

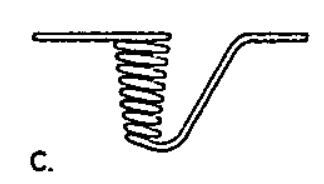

$$
\text { c. }
$$
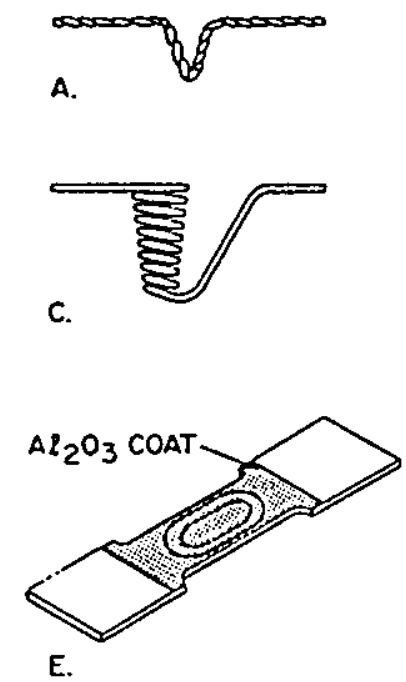

B.
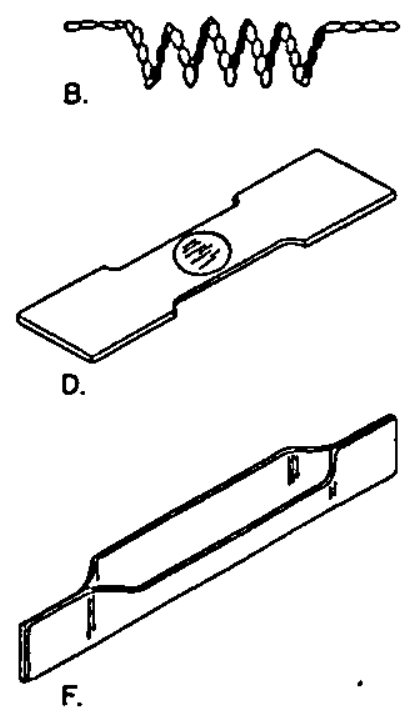

Figure 2.5. Wire and metal-foil sources. (A) Hairpin source. (B) Wire helix. (C) Wire basket. (D) Dimpled foil. (E) Dimpled foil with alumina coating. (F) Canoe type [23]. 


\subsubsection{SUBLIMATION}

If a material has a sufficiently high vapour pressure before melting occurs, it will sublime, and the condensed vapours form a film. Such materials therefore can be readily evaporated from resistance-heated sources with much less concern for source / evaporant reaction and contamination. Since the rates of sublimation for most materials are small, and controlling the technique is difficult, this method does not find widespread application for depositing metal films. However, a useful application has been obtained in sublimation of resistively heated nichrome wires.

Huijer et al $[29,30]$, showed that as a result of diffusion of $\mathrm{Cr}$ at elevated temperatures, an equilibrium state is reached under which the nichrome components sublimate at relative rates equal to their relative concentration in the alloy, thereby making it possible to obtain films of the same composition as the evaporant. Calculations and experiments show that equilibrium is reached when nichrome wire is held at $1330^{\circ} \mathrm{C}$ for 3 hours [17]. The elements such as $\mathrm{Cr}, \mathrm{Mo}, \mathrm{Pd}, \mathrm{V}, \mathrm{Fe}$, and $\mathrm{Si}$ reach vapour pressures of $10^{-2}$ Torr (i.e., have ireasonable: evaporation rates ) well before they melt and hence can sublimate to form films. High purity nickel and iron films have been produced by Behmdt [31] using this technique.

\subsubsection{MULTIPLE-COMPONENT EVAPORATION}

When multiplecomponent alloys or compounds are thermally evaporated, the components may evaporate at different rates because of their different vapour pressures, their different tendencies to react with the support material, and possible thermal decomposition of the parent material. These factors will obviously produce nonstoichiometric films. Due to vapour-pressure difference alone, the ratio of the evaporation rates of components A and B of an alloy may be obtained from Langmuir's expression equation (1) by assuming that the vapour pressure of each component in the alloy is depressed compared with that in the pure state by an amount proportional to the relative concentrations (called Raoult's law ) [17]. It is given by :

$$
\frac{N_{A}}{N_{B}}=\frac{C_{A} P_{A}}{C_{B} P_{B}} \sqrt{\frac{M_{B}}{M_{A}}}
$$

Where :

C's are the atomic fractions of the components. 
Generally this relation is not obeyed because of strong interaction between the components of the alloy, and one must introduce an activity coefficient [32] as a function of $\mathrm{C}$ to correct for the departure. A point of technical interest [33] is that the higher the evaporation temperature of an alloy of widely different vapour-pressure components is, the closer is the composition of the film to the bulk alloy. By using inert support materials and a suitable evaporation temperature, a large number of alloys and compounds can actually be deposited with only slight deviations from the original composition. Large deviations occur, however, for compounds which dissociate readily on heating [17]. A satisfactory method of preparing alloys and compounds with precisely controlled compositions is to evaporate each component from a separate source with reaction and homogeneity brought about at the substrate at an elevated temperature. Such a method is referred to as the "two-source" [34-37] or "three-temperature" or Gunther [38] in the case of semiconducting compounds technique.
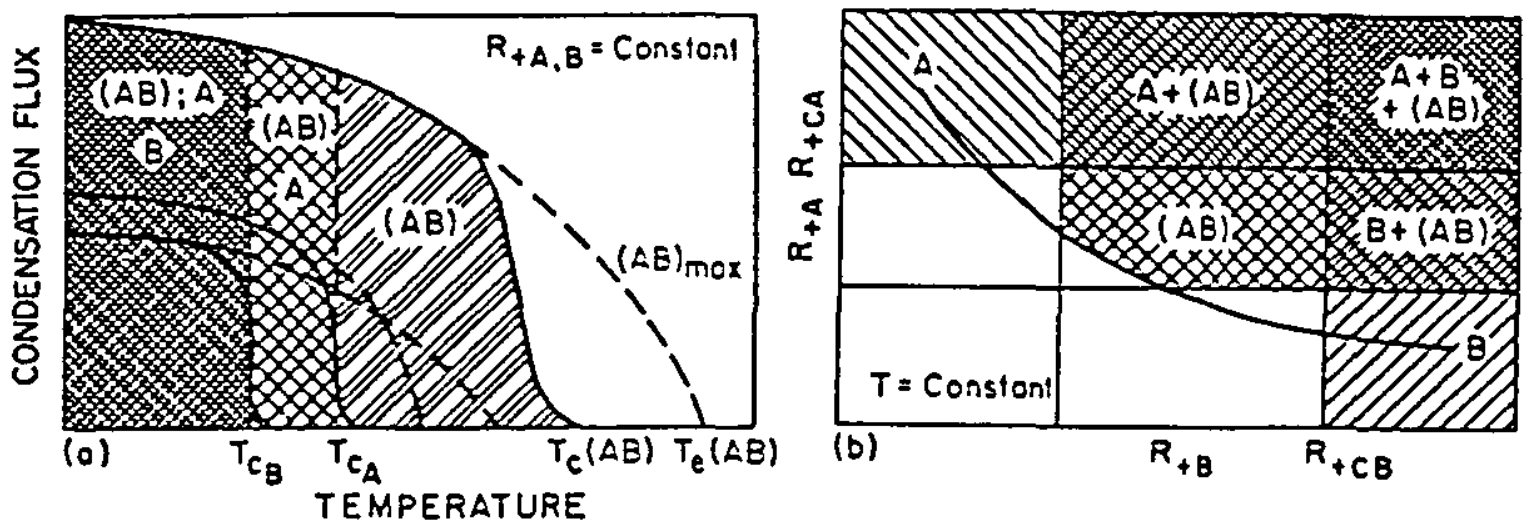

Figure 2.6.(a) Schematic representation of the variation of the condensation flux as a function of the substrate temperature for a constant flux of incident vapour of type $A$, $B$, and $A B$ molecules. The subscript with plus sign indicates the incident flux; the subscripts $c$ and e refer to the critical (for condensation ) and the equilibrium values, respectively. The dotted curves are the equilibrium curves which take into account the adatom densities of the other components. (b) Condensation diagrams for A and B incident vapour at a constant substrate temperature. Regions of different compositions obtained are shown. The region where only pure AB compound is formed is obtained by the straight lines representing critical flux conditions and the solid curve given by $R_{+A} \times R_{+B}=$ constant. (Gunther [38] ). 
Gunther [38], analyzed the condensation of multicomponent vapours on the basis of the nucleation theory [17], according to which a critical flux exists for energy substrate temperature ( and vice versa) at which spontaneous nucleation occurs. After nucleation, the condensation flux quickly approaches a maximum value. The schematic representation of the dependence of the condensation flux on the incident fluxes and the substrate temperature is shown in fig 2.6 (a) and (b) respectively. The vapour density is generally low enough to neglect collisions between particles of the A and $\mathbf{B}$ components in the vapour phase. However, attractive interaction takes place between these particles in the adsorbed stage on the substrate surface, which may lead to the formation of a general molecule of a stable compound :

$$
A+B \rightarrow A_{n} B_{m}
$$

As seen in fig (2.6), a broad stoichiometric interval exists for both temperature and incident fluxes of $A$ and $B$ vapours within which an exactly stoichiometric compound is condensed. Thus, in principle, the three-temperature method allows deposition of stoichiometric films of any material when one component has a significantly higher vapour pressure than the other [38].

\subsubsection{ELECTRON BEAM EVAPORATION}

A typical electron beam system consists of a cathode and an anode [39]. The cathode is a heated $W$ filament to supply electrons which are accelerated by the positive potential difference maintained between the cathode and the anode. For evaporative purposes, this potential ranges from a few kilovolts to about 20-30 KV. The electrons lose their energy in the material very rapidly, their range being determined by their energy and the atomic number of the material.

Thus the surface of the material becomes a molten drop and evaporates [17]. The electron beams guns are classified as work-accelerated or self-accelerated guns, depending on whether the work piese is placed directly over the anode or is located separately. A simple sketch of both of these types is given in figure 2.7. 


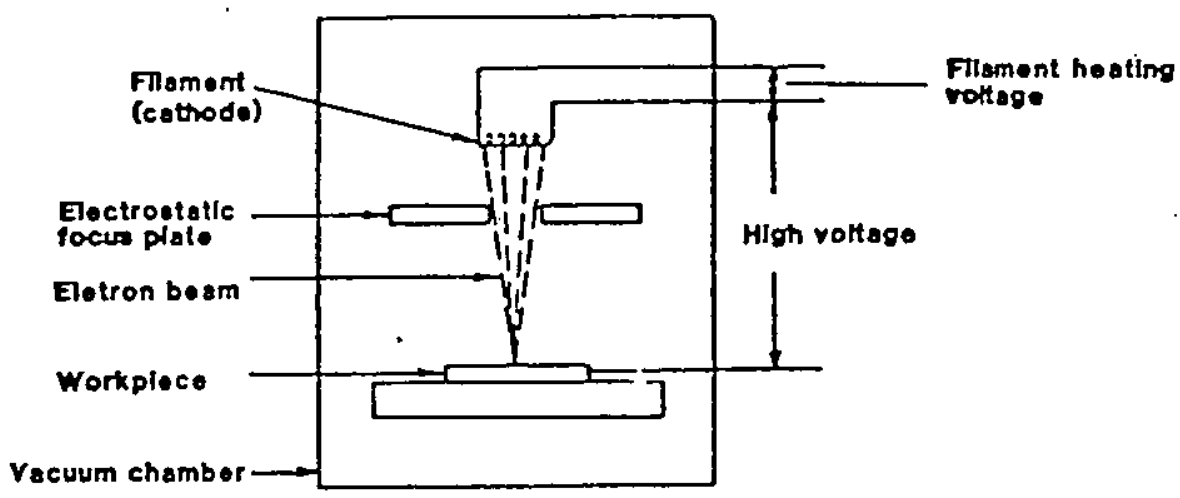

(a)

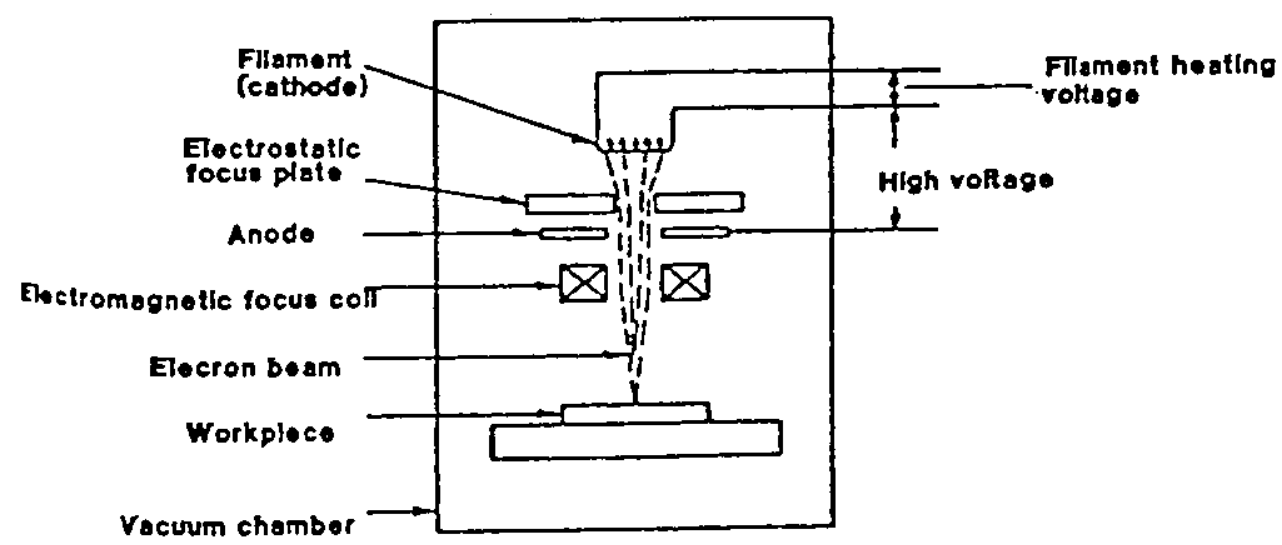

(b)

Figure 2.7. Simple electron-beam guns. (a) Work-accelerated gun, (b) self-accelerated gun. 
Electron beam evaporation sources offer these major advantages:

1. They have a higher power density, and hence a wide range of control over evaporation rate, from very low to very high.

2. Because the evaporant is contained in the water-cooled crucible, only its surface gets to a high temperature. Metallurgical reactions between crucible and evaporant leading to film contamination are therefore eliminated.

Depending on the mode of generation of electrons, electron beam guns are further divided into two categories: (a) thermionic guns and ( $b$ ) plasma guns.

\section{A. Thermionic guns}

In thermionic guns, the electrons are produced by resistive heating of wire or disks usually made up of high-temperature metal such as tungsten, and tantalum or alloy.

A major limitation of thermionic guns is their inability to operate at pressures above $10^{-3}$ Torr. Higher pressures cause scattering of the electron beam and shorten the cathode life because of erosion by ion bombardment. For reactive evaporation, filament life becomes a major concern, especially when a reactive gas such as oxygen is used. Although two-compartment chambers, with the gun filament assembly located in a separate chamber maintained at a low pressure help in alleviating these problems to a certain extent, they cannot be fully circumvented [39].

Some examples of thermionic electron-beam-heated work-accelerated sources are shown in fig 2.8. For further details on the design and operation of electron beam guns, with particular reference to their influence on evaporation characteristics of various materials, one can refer to an excellent book by Schiller et al [40]. 
A.

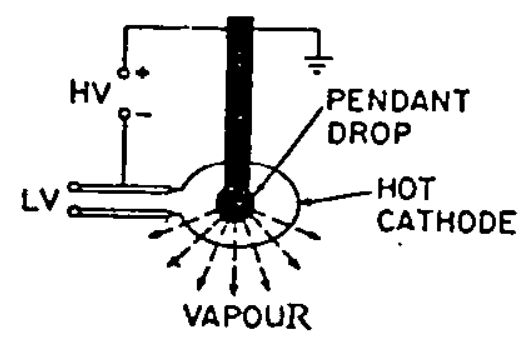

8.

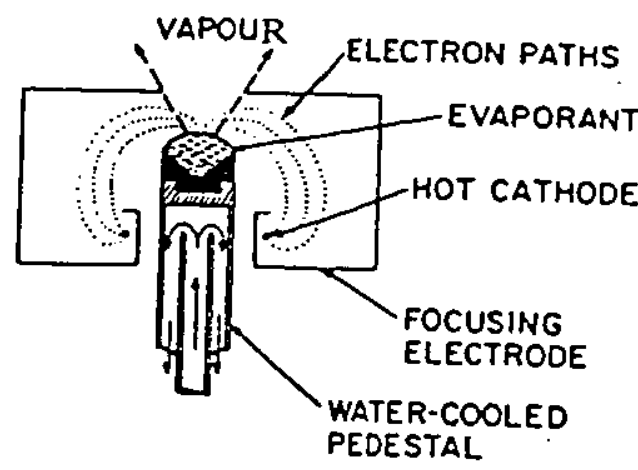

c.

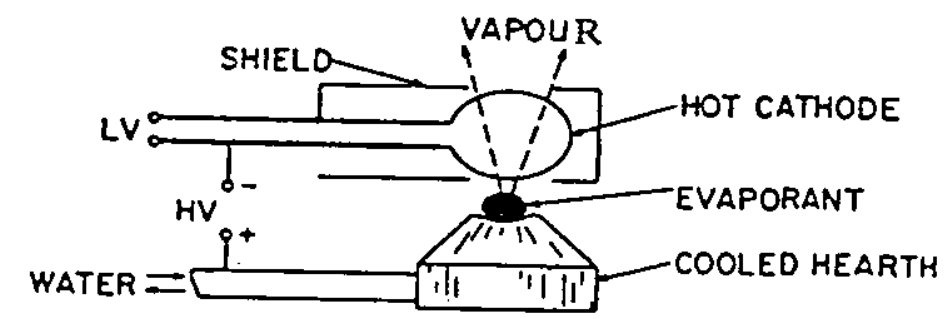

D.

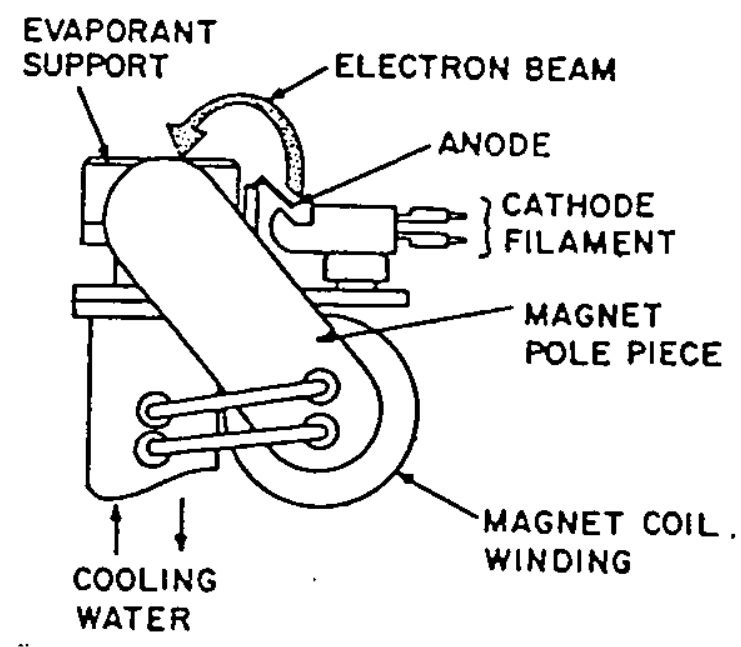

Figure 2.8. Work-accelerated electron bombardment sources.

(a) Pendant-drop method, (b) Shielded filament, Unvala [39],

(c) Shielded filament, Chopra and Randlett [17], (d) Bent-beam electron gun with water-cooled evaporant support. 


\section{B. Plasma Electron Beam gun}

A plasma is defined as a region of high-temperature gas containing a large number of free electrons and ions. By proper application of electrical potential, electrons can be extracted from the plasma to provide a useful energy beam similar to that obtained from thermionic guns [39]. There are two types of plasma electron beam guns, these are shown in figure 2.9 .

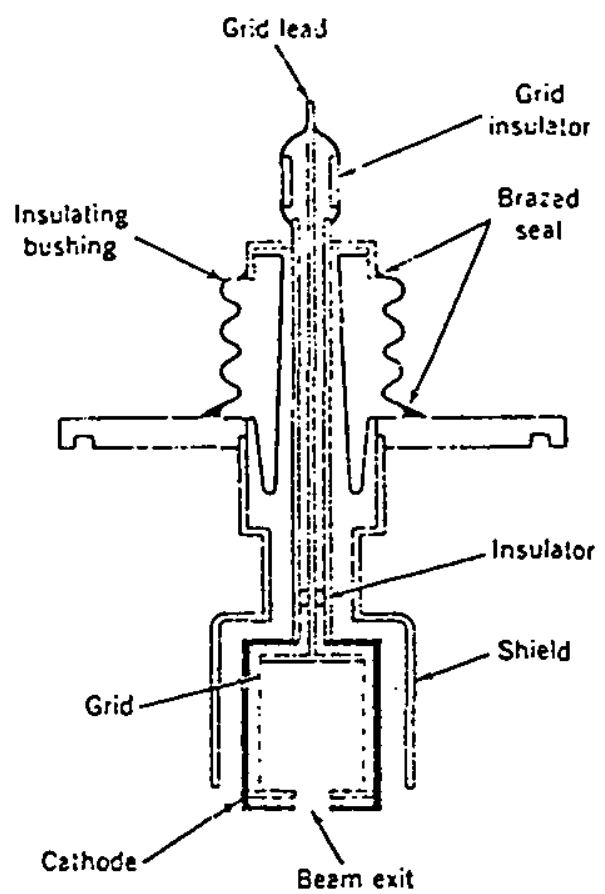

(a)

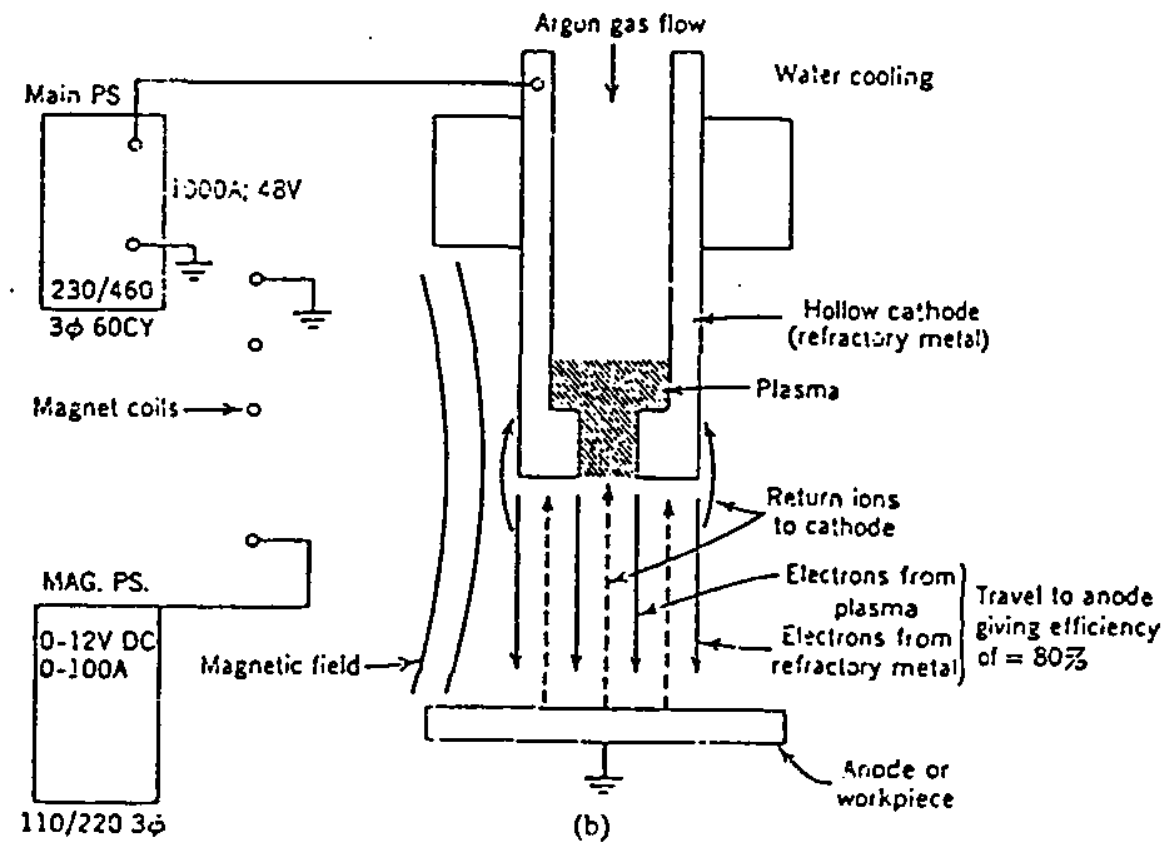

Figure 2.9. (a) Cold cathode plasma electron-beam gun.(b) Schematic of the hot hollow cathode electron beam. 


\section{a) The cold cathode plasma electron beam}

Fig 2.9. (a) shows the cold cathode plasma electron-beam gun. This plasma electron beam gun has a cylindrical cathode cavity made from a metal mesh or sheet containing the ionized plasma, from which electrons are extracted through a small aperature in one end. The cathode is maintained at a negative potential, e.g., -5 to $-20 \mathrm{kV}$, relative to the workpiece and the rest of the system, which are at ground potential [41].

\section{b) The Hot Hollow cathode discharge beam}

Fig2.9. (b) shows a schematic of the hot hollow cathode electron beam. Morley [42] reported that the hollow cathode discharge beam applied to vacuum processing differs in a number of respects from the plasma beam. The cathode must be constructed of a refractory metal, since it operates at an elevated temperature. An ionizable gas, usually argon, is introduced into the system through the tubular cathode. A pressure drop across the orifice in the cathode provides a sufficient amount of gas inside the cathode to sustain the plasma, which provides the electrons constituting the beam. This type of gun utilizes a low-voltage, high-amperage d.c. power supply. When ff power from a commercial welding starter is coupled to the gas, it becomes ionized and the plasma is formed. Continued ion bombardment of the cathode results in heating of the cathode and increased electron emission. Ultimately, a high-current "glow discharge" will occur, analogous to that experienced in vacuum arc melting at high pressures. At this point, the discharge appears as a low-power-density beam " flowing" from the cathode aperature and fanning out in a conical shape into the chamber, However a parallel axial. magnetic field is imposed on the beam, which then forms a high-power-density, well-collimated beam. The hollow cathode discharge beam is operationally stable and efficient over the pressure range from $10^{-4}$ to $10^{-1}$ Torr.

\subsubsection{RF / INDUCTION HEATING}

The RF or induction heating may be supplied to the evaporant directly or indirectly from the crucible material [43-45]. Refractory carbide, nitride, boride, or oxide crucibles are used for induction heating. By suitable arrangement of the rf coils, the induction-heated material can be levitated, thereby eliminating the possibility of contamination of the film by the support material. Induction heating has proved exceptionally useful for evaporating metals showing excessive wettability. 
Ames et al [46] made good use of RF heating to prevent migration of $\mathrm{Al}$ out of the crucible by evaporating it from the surface of a $\left(\mathrm{BN}+\mathrm{TiB}_{2}\right)$ crucible. It is shown in fig 2.10 .

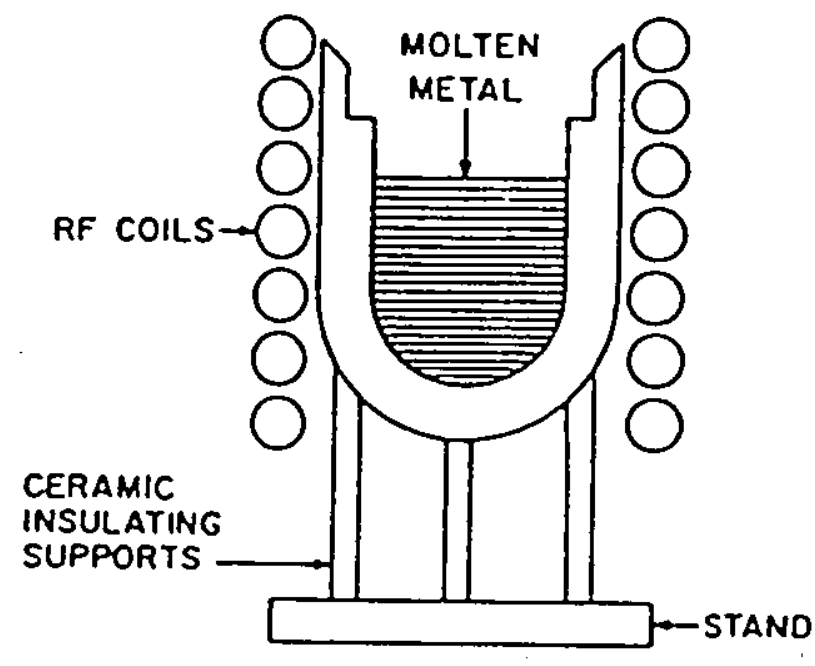

Figure 2.10. RF heated aluminum source with boron nitride, titanium dibonide crucible.

For details of coil design, as well as frequency requirements and tuning for different applications, one can refer to the book by Pirani and Yarwood [47]. They used a crucible thin enough near the surface to offer no shielding of the if field and thus allow heating of the $\mathrm{Al}$ melt by the $200 \mathrm{kc} / \mathrm{sec}$ field. However, the crucible was thick enough elsewhere to screen the melt from excessive coupling with the if field, thus minimizing turbulence [17].

Such types of sources are also useful for evaporating reactive metals such as $\mathrm{Ti}$ or $\mathrm{Be}$. $\mathrm{RF}$ / induction heating has the following advantages over radiation heating:

1. As part of the energy is coupled directly to the evaporant, it is not necessary to produce temperatures greatly in excess of the vaporization temperature to maintain the required heat flow, as in the case of radiation heating using resistance heaters. This minimizes the evaporant / container wall interactions. 
2. Energy is utilized more efficiently because of smaller heat losses by convection radiation.

3. The need for radiation shields is obviated by the water-cooled coupling coils around the crucible.

The major disadvantages of the induction heating are the higher cost and space requirements, and the necessity to design and optimize coupling coil geometry, as well as to tune the supply for the specific material or crucible to be used [39].

\subsubsection{FLASH EVAPORATION}

A rapid evaporation of a multi component alloy or compound, which tends to distill fractionally, may be obtained by continuously dropping fine particles of the material onto a very hot surface strip so that numerous discrete evaporations occur [48], thus maintaining the composition of the alloy in the deposit. It works very well for elements with high vapour pressures. Various possible arrangements have been used, figure 2.11(a) shows one of the arrangement used for flash evaporation [17]. Details on the experimental setup, as well as data on flash-evaporated films, are given in [10].This system has been used for preparing films of III-V compounds [38, 49-50]. The Ta boat is held at 1300 to $1400^{\circ} \mathrm{C}$ for II-V compounds, and the substrate is heated to $\sim 200$ to $550{ }^{\circ} \mathrm{C}$ for obtaining single phase compounds [17]. There is evidence that flash-evaporated films in some cases can show considerable deviation from the original composition [49]. Further, since the large amount of rapidly released gas produces spattering of particles from the evaporant, this method is not easily controllable.

\subsubsection{EXPLODING WIRE TECHNIQUE}

This technique consists of exploding a wire by a sudden resistive heating of the wire with a transient high current density approaching $10^{6} \mathrm{~A} / \mathrm{cm}^{2}$ [50]. This is achieved by discharge a bank of condensers $(\sim 10$ to $100 \mu \mathrm{F})$, charged to a voltage $\sim 1$ to $10 \mathrm{kV}$, through a metallic wire, fig. 2.11(b). Thus, a catastrophic destruction and vaporization of the wire at some region takes place. Kul'gavchuk and Novoskol'tseva [51] studied the kinetics of the explosion stages by X-ray techniques. But the evaporation kinetics remain obscure. The equivalent source temperature as deduced from the measured velocity of the vapour atoms is estimated to be as high as $10^{6} \mathrm{oK}$. Mattox et al [ 51] obtained equivalent film-deposition rates $\sim 10^{6} \mathrm{~A}^{0} / \mathrm{sec}$ by exploding $10-$ to 20 mil-diameter $\mathrm{Cu}$ and $\mathrm{Au}$ wires in less than $100 \mu \mathrm{sec}$, using 1,000 J of energy. Thin 
films formed showed regions of defects due to the condensation of microparticles spattered duing the explosion [17].

\subsubsection{LASER EVAPORATION}

The enormous intensity of a laser may be used to heat and vaporize materials by keeping the laser source outside the vacuum system and focusing the beam onto the surface of the material to be evaporated fig $2.11(c),[39,53,54]$.

Absorption characteristics of the material to be evaporated determine the laser wavelength to be used. Since the laser penetration depth is small ( $\sim 100 \AA)$, evaporation takes place at the surface only. Degassing and explosion of the specimen can be minimized by using material in a fine powder form $\left(\sim 10 \mu_{0}\right)$ [17], despite the fact that this method has not yet been fully exploited [ 53 - 54 ].

To obtain the high power density required in many cases, pulsed laser beams are generally employed, pulse width, repetition rate, and pulse intensity are selected for the specific application. Pulsed laser evaporation, also called laser ablation, has attracted great interest in recent years for the synthesis of high- $\mathrm{T}_{\mathrm{c}}$ superconductor.

For the evaporation of 1-2-3 films, Nd-YAG lasers with wavelengths between 532 / $242 \mathrm{~nm}$, and pulse energies in the range of 0.2-1 J and repetition rate of 10-30ns, have been extensively used. Schwarz and Tourtellotte [54] used a non-Q-spoiled glass neodymium laser to deliver 80 to $150 \mathrm{~J}$ of energy per burst with a duration of 2 to 4 msec to evaporate $\mathrm{Ba} \mathrm{TiO}_{3}, \mathrm{SrTiO}_{3}, \mathrm{ZnS}$, and $\mathrm{Sb}_{2} \mathrm{~S}_{3}$. Deposition of several thousand angstroms per burst was obtained corresponding to a rate $\sim 10^{6} \AA$ / sec. The actual rate may be higher, since most of the evaporation probably takes place in the initial 10 to $100 \mu \mathrm{sec}$. The temperature of the vapour source is estimated to be $\sim 20,000{ }^{\circ} \mathrm{K}$ corresponding to an energy of 1 to $1.5 \mathrm{eV}$. The emitted vapours were observed to be positively charged carrying a current up to $1 \mathrm{~mA}$. Although laser evaporation is an attractive approach for synthesis of high-purity metal alloys and compound films, it also suffers from the following limitations:

1. Complex transmitting and focusing systems need to be employed to direct the beam from the laser located outside the vacuum system onto the evaporant placed inside the system. This involves special designs and increases the cost of the setup. Also, a window material that efficiently transmits the wavelength 
band of the laser must be found and mounted in such way that it is not rapidly covered up by the evaporant flux.

2. It is not always possible to find a laser with a wavelength compatible with the absorption characteristics of the material to be evaporated.

3. The energy conversion efficiency is very low.
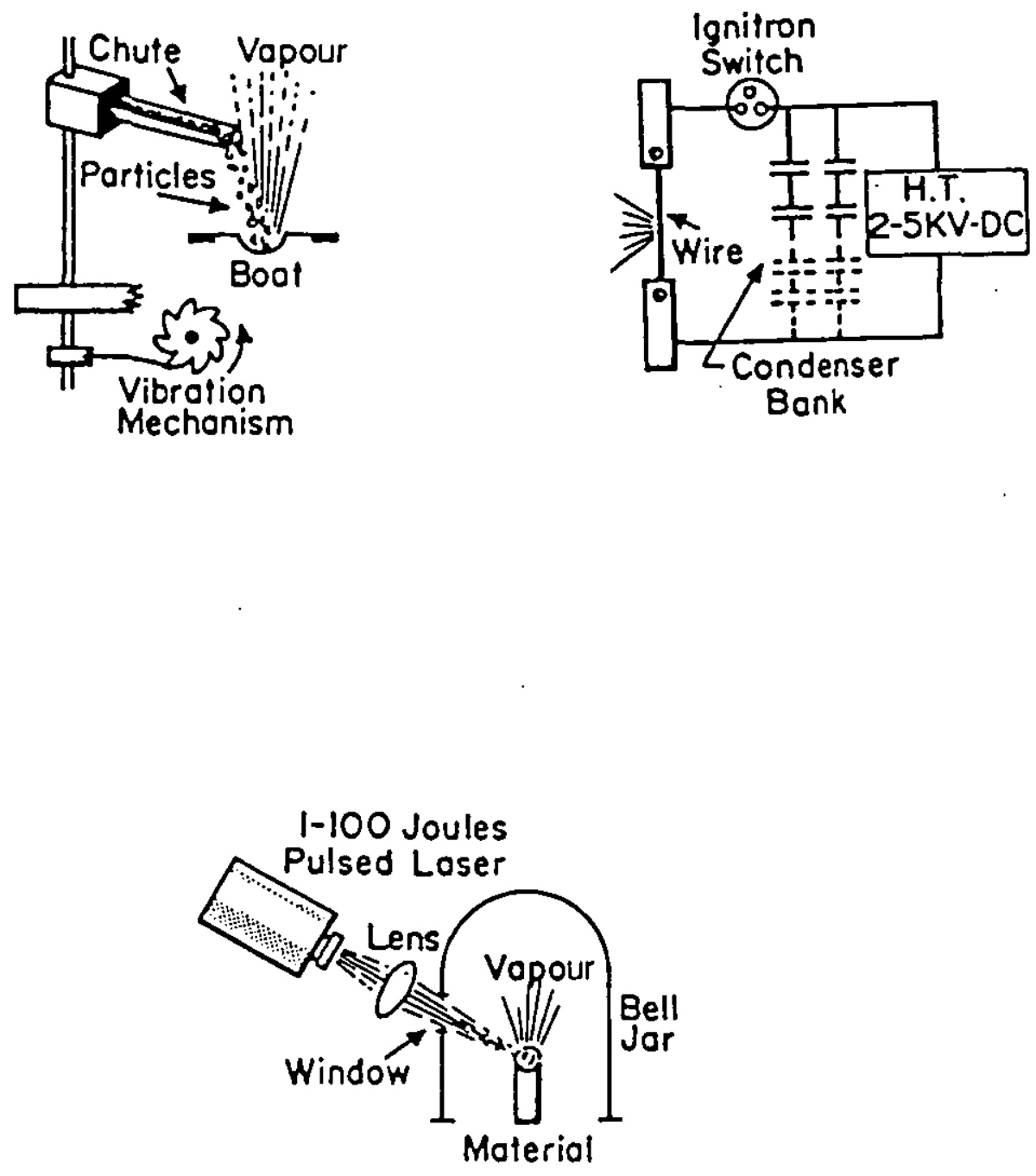

Fig. 2.11 Diagrams of some special, High-thermal-evaporation-rate sources.

(a) Flash evaporation, (b) exploding-wire (with current density), and (b) laser evaporation. 


\subsubsection{ARC EVAPORATION}

The arc evaporation process is discussed in detail in chapter III. Therefore, a brief comment will be made, for the sake of completeness. Arcs are high-current electrical discharges that are quite appropriate as heat sources for evaporation. There are two types of arc evaporation sources. One of them is the thermionic arc [55], and the other is the cathode arc [56] or the anode arc [57].

In the thermionic arc, a plasma is formed in an enclosure by electron impact ionization, and an electron beam is extracted through an aperture and impinges on the evaporation target, which is the anode. It is very similar in concept to the hot hollow cathode device.

Thermionic arc ion plating was invented at Balzers [58] and, right from the beginning, mainly applied to the production of titanium nitride films on HSS substrates $[55,58$, 59]. All important details are shown in fig 2.12. The evaporation metal is the anode of a non-self-sustaining arc discharge. The cathode is a resistance heated filament situated in a separate chamber under a relatively high noble gas pressure.

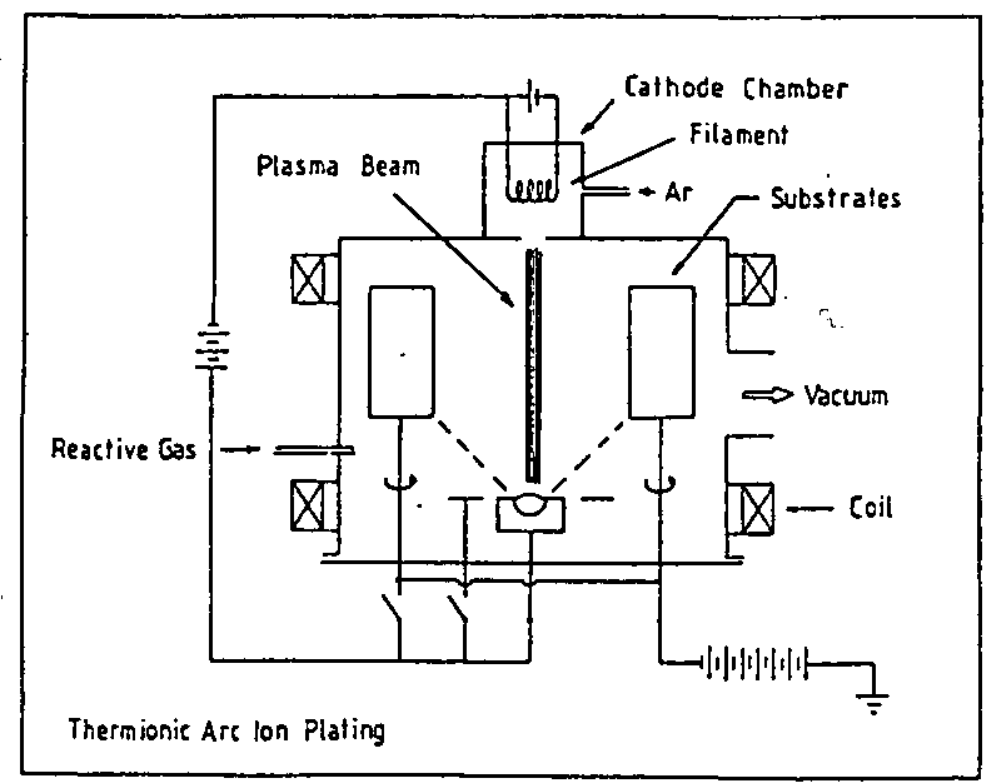

Figure 2. 12. Thermionic arc ion plating [58]. 
The arc plasma is confined by a small aperture mounted between the cathode chamber and the evaporation chamber, and by a magnetic field produced by two large coils. To prevent the electrons from losing their energy through collisions with gas atoms on the way to the anodic crucible, a lower pressure, e.g. $2 \times 10^{-3}$ mbar ; is maintained in the evaporation chamber. The direction of the magnetic field is chosen to guide the electrons in the confined plasma beam in a straight line to the anodic crucible. When the power density is high enough, for example using an aperture : with a diameter less than $10 \mathrm{~mm}$ and arc current of more than $100 \mathrm{~A}$ at an arc voltage of about $50 \mathrm{~V}$, certain materials such as titanium will be evaporated and then partially ionized. Due to the anodic source, a highly ionized, local vapour cloud is formed which, together with the noble gas in the cathode chamber, becomes the medium for the arc discharge. This is evidenced in the decrease of the arc voltage when evaporation begins, which results in additional concentration of the beam by anodic spot.

Normally a negative d.c. bias is applied to the substrates to achieve ion bombardment. The substrate current attains its saturation value of about $20 \mathrm{~A}$, (presuming arc current of about $100 \mathrm{~A}$ ) at a bias voltages as low as $50 \mathrm{~V}$. At higher voltages it only increases slowly. This is the favorable characteristic of a Langmuir probe which allows independent adjustment of the substrate voltage. The deposition rate is approximately proportional to the substrate current because of the high proportion of vapour ions [60]. For reactive processes, a reactive gas such as nitrogen is fed into the evaporation chamber. The nitrogen pressure there is maintained at constant level, e.g. 10-3 mbar . Thus when the evaporation rate is changed by changing the arc current, the nitrogen flow is automatically adjusted according to (i) the amount of nitrogen "pumped off " by the film formation, and (ii) the nitrogen not included in the film which is pumped off by the high-vacuum pump at a constant pumping speed [60].

The thermionic arc can be used in a triode arrangement in which argon ions are drawn from the arc discharge to the substrates. The great advantage of this method is that the substrates can be immersed in a very dense plasma, and at the same time, the low noble gas pressure ensures that the mean - free - path lengths are long in comparison with the structural detail of the substrates, thus providing excellent penetration. Control is easy and there are only minor problems with mixed loads. No high-voltage power supply is required [ 60 ].

An even more flexible system is obtained by combining an electron beam source with a thermionic arc source fig. 2.13 [60]. This can be done by insulating the crucible of the electron beam gun and then using it as the anode of the arc discharge. Such systems are 
used in box coaters for depositing TiN coatings on parts with delicate relief structures. When two electron-beam evaporators are mounted, this thermionic arc system can produce, at low substrate temperatures, extremely dense oxide coatings with alternating refractive indices for optical applications $[8,61,62]$.

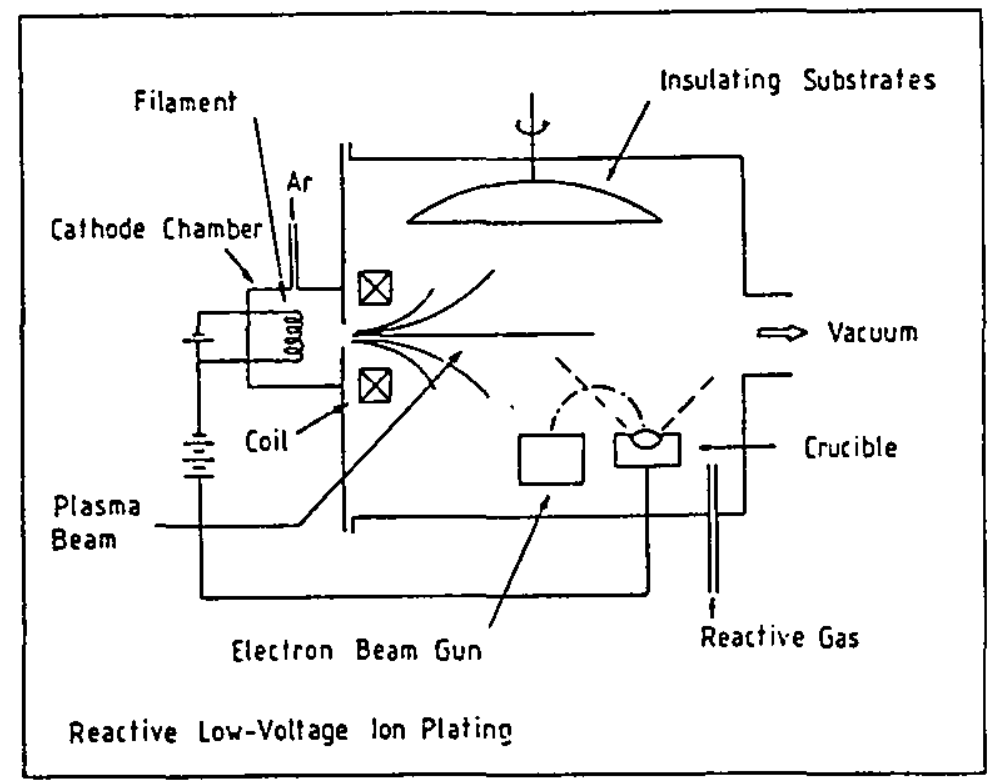

Figure 2.13. Reactive low voltage ion plating [58]. 
Cathodic arc evaporation as a means of depositing thin films has received increasing attention in the past few years [63-66]. The advantage of arc evaporation for film deposition lies principally in the high percentage of ions in the emitted flux ( $10 \%$ $-100 \%$ ) and the high kinetic energy of these ions ( $40-100 \mathrm{eV}$ ) [67]. The presence of energetic ions in film growth processes is particularly desirable since many of the benefits of ion-assisted deposition may be realized.

These benefits include enhanced adhesion, increased film packing density and high reactivity for compound film formation [68]. The arc process also has excellent throwing power for non-line-of sight coating of complex shapes. In the case of conducting substrates, a suitable bias voltage may be applied to heat the substrate, to sputter-clean the surface, or to deposit a film $[39,64]$. By its basic mechanism, a cathodic arc source can be compared to thermal evaporation; its behavior has many similarities with "flash" evaporation and also with the low energy electron beam evaporation. Very restricted areas of the target are instantaneously heated and the material is transformed from its solid state to vapor at a temperature level where the high vapour pressure makes it literally explode. As this flash of vapour is produced by a low energy, high intensity electron beam, concentrated in the cathodic spot, a high degree of ionization and excitation is present [69].

\subsection{SUMMARY :}

A general description of various thin films deposition processes with references is represented in this chapter.

- Disadvantages and advantages were presented to help to evaluate these techniques. 


\section{REFERENCES}

[1]. D. M.Mattox, Film deposition using accelerated ions. Electrochem. Technol.2, 295-298 ( 1964 ).

[2]. E. Moll, R. Buhl, H. K. Pulker and E. Bergmann. Activated reactive ion plating (ARIP). Surface and Coatings Technology, 39/40, pp. 475-486 (1989).

[3]. Phil. J. Martin and Roger P. Netterfield. Ion-assisted Dielectric and optical coatings, chapter 19, in Handbook of Ion-beam processing.Technology, principles, deposition, film modification and synthesis. J. J. Cuomo, S. M. Rossnagel and H. R. Kaufman (eds.), Noyes publications, New Jersey, (1990).

[4]. B.Berghaus, UK Patent 510,993 (1938).

[5]. D.G.Teer, The energies of ions and neutrals in ion plating. J. Phys. D9. L187-189 (1976).

[6]. Mattox, D. M., J. Appl. Phys., 34, p.2493 (1963).

[7]. D.G.Teer, Wear resistant Coatings, IPAT workshop, Amsterdam, 21, (1988).

[8]. Teer, D. G., Deposition of hard coatings using magnetron sputtering. D. G. Teer Coating Services Ltd. 285/286 Hartlebury Trading Est. Hartlebury, Nr. Kidderminster, Worcs. DY10 4JB (1985).

[9]. Pulker, H. K., Haag, W., Buhler, M. and Moll E., Optical and mechanical properties of ion-plated, oxide films. Proc. 5th Int. Conf. Ion and Plasma assisted Techniques. (H. Oechsner, ed. ) pp. 299-306, CEP, Edinburgh (1985).

[10]. R. F. Bunshah \& al. Deposition Technologies for Films and Coatings. Noyes publications, New Jersey, U.S.A., (1982).

[11]. R. Robinson and A. Matthews. Characteristics of a dual purpose cathodic Arc / Magnetron sputtering system. Surface and Coatings Technology, 43/44, pp. 288-298 (1990).

[12]. Window, B. and Savvides, N., Unbalanced magnetron ion-assisted deposition and property modification of thin films. J. Vac. Sci. Technol. A4(3), May/Jun. (1986).

[13]. R. P. Howson et al. Reactive sputtering with an unbalanced magnetron. Proc. 1st. Int. Symp. on ISSP 91, pp.43-52 Tokyo (1991).

[14]. Klaus K. Schuegraf (Ed.).Thin film deposition processes and techniques, chapter I, in Handbook of Thin film deposition processes and techniques. Noyes publications, U.S.A.(1988).

[15]. A. A. Snaper, U. S. Patent 3, 625, 848, (1971).

[16]. L. P. Sablev et al, U. S. Patent 3,793, 179, (1974). 
[17]. K. L. Chopra, Thin Film Phenomena. Robert e. Krieger Publishing Company, Huntington, New York (1979).

[18]. L. Holland, " Vacuum Deposition of Thin Films ". John Wiley \& Sons, Inc., New York, (1956).

[19]. L. Holland, in " Thin Film Microelectronics " (L. Holland, ed. ), Chap. IV, John Wiley \& Sons, Inc., New York, (1956).

[20]. H. Randhawa and P. C. Johnson. Cathodic arc deposition advances coating technology. Research and development,p.173, Feb. (1987).

[21]. R. F. Bunshah and R. S. Juntz, Trans. Vac. Met. Conf., American Vac. Soc., p. 799 (1968).

[22]. R. Glang, in Handbook of Thin film technology, ed. L. I. Maissel and R. Glang, McGraw-Hill, P.17, (1970).

[23]. Handbook of Thin Film Technology, ed. L. I. Maissel and R. Glang, McGraw-Hill , New York (1970).

[24]. Kohl, W. H., Handbook of materials and techniques for vacuum devices, Reinhold publishing corporation, New York, (1967).

[25]. Olsen, L.O., Smith C. S., and Crittenden, J. Appl. Phys., 16, 425 (1945).

[26]. Nicholson, J. L., Rev. Sci. Instr., 34, 118 ( 1963 ).

[27]. Lucas, M.S.P., C.R. Vail, W. C. Stewart, and H. A. Owen, Trans. 8th AVS Symp., p. 988, The Macmillan company, New York (1961).

[28]. Massey, B. J., Trans. 8th Avs Symp., p. 992, The Macmillan Company, New York (1961).

[29]. P. Huijer, W. T. Langendam, and J. A. Lely, Philips Tech. Rev., 34, 144 (1963).

[30]. T. K. Lakshmanan, Trans 8th Natl. Vacuum Symp., p. 868, Pergamon Press, New York, (1961).

[31]. K. H. Behrndt, J. Appl. Phys. 33, 193 ( 1962 ).

[32]. G. Zinsmeister, Vakuum-Tech., 8:223 (1964).

[33]. L. S. Palatnik, G. V. Fedorov, and P. N. Bogatov, Phys. Metals Metallog., $21: 89$ (1966).

[34]. J. Deklerk and E. F. Lelly, Rev. Sci. Instr., 36:506 (1965).

[35]. F. A. Pizzarello, J. Appl. Phys., 35:2730 (1964).

[36]. K.H. Behrndt and R. W. Love, Vacuum, 12: 1 (1962).

[37]. J. E. Davey and T. Pankey, J. Appl. Phys., 35: 2203 (1964).

[38]. "The use of thin films in physical investigations " ( J. C. Anderson, ed. ), Academic press Inc., New York, (1966). 
[39]. C. V. Deshpandey and R. F. Bunshah, Evaporation processes, in "Thin Films Processes" II. Academic Press Inc. (1991).

[40]. S. Schiller, U. Heisig, and S. Panzer. " Electron Beam Technology ". John Wiley \& Sons, New York, (1982).

[41]. M. A. Cocca and L. H. Stanffer, Trans. Met. Conf., Am. Vac. Soc., p.203 (1963).

[42]. J. R. Morley, Trans. Vac. Met. Conf., Am. Vac. Soc., p. 186 (1963).

[43]. J. A. Turner, J. K. Birtwistle, and G. R. Hoffman, J. Sci. Instr., 40: 557 (1963).

[44]. E. A. Roth, E. A. Margerum, and J. A.Amick, Rev. Sci. Instr., 33: 686 (1962).

[45]. J. Van Audenhove, Rev. Sci. Instr., 36: 383 (1965).

[46]. I. Ames, L. H. Kaplan, and P. A. Roland, Rev. Sci. Instr., 37: 1737 (1966).

[47]. M. Pirani and J. Yawood, "Principles of vacuum engineering ", Reinhold publishing Co., New York, (1961).

[48]. L. Harris and B. M. Siegel, J. Appl. Phys., 19 : 739 ( 1948).

[49]. S. G. Ellis, J. Appl. Phys., 38: 2906 (1967).

[50]. A. Inam, X. D. Wu, L. Nazar, M. S. Hedge, C. T. Rogers, T. Venkatesan, R. W. Simon, K. Daly, H. Padamsee, J. Kirchgessner, D. Moffat, D. Rubin, Q. S. Shu, D. Kalokitis, A. Fathy, V. Pendrick, R. Brown, B. Brycki, E. Belohoubek, L. Drabeck, G. Gruner, R. Hammond, F. Gamble, B. M. Lairson, and J. C. Bravman, Appl. Phys. Letts. 56 (12), 1178 (1990).

[51]. D. M. Mattox, A. W. Mullendore, and F. N. Rebarchik, J. Vac. Sci. Technol., $4: 123$ ( 1967 ).

[52]. V. M. Kul'gavchuk and G. A. Novoskol'tseva, Soviet Phys. Tech. Phys., 11: 406 ( 1966 ).

[53]. H. M. Smith and A. F. Turner, Appl. Opt., 4: 147 ( 1965 ).

[54]. H. schwarz and H. A. Tourtellotte, 13th Natl. Vacuum SYmp., p. 87, The Macmillan company, New York, (1966).

[55]. E. Moll and H. Daxinger, U.S. Patent 4, 254, 159, Dec. 23, (1977).

[56]. J. E. Daalder, Physica C., 104, 91 (1981).

[57]. J. H. Ehrich, B. Hasse, K. G. Muller, and R. Schmidt, J. Vac. Sci. Technol., A6 (1), 2499 (1988).

[58]. E. Moll and H. Daxinger, Method and apparatus for evaporating materials in a vacuum coating plant, U.S. Patent 4, 197175 ( 1977 ) assigned to Balzers AG.

[59]. R. Buhl, H. K. Pulker and E. Moll, TiN coatings on steel, Thin Solid Films, $80,265-270$, ( 1981 ). 
[60]. E. Moll, and E. Bergman. Hard coatings by plasma - assisted PVD technologies: industrial practice. Surface and coatings technology, 37, 483 - 509, ( 1989 ).

[61]. E. Moll, H. K. Pulker and W. Haag, Method and apparatus for the reactive vapour deposition of layers of oxides, nitrides, oxynitrides and carbides on a substrate, U. S. Patent 4, 619748 ( 1985 ), assigned to Balzers AG.

[62]. H. K. Pulker, W. Haag,M. Buhler and E. Moll , properties of ion plated oxide films, J. Vac. Sci. Technol., A, 3 (6) , pp.2700 -2701 ( 1985).

[63]. R. L. Boxman, S. Goldsmith, S. Shaley, H. Yaloz, and N. Brosh, Thin Solid Films, 139, 41 (1986).

[64]. P. J. Martin, D. R. Mckenzie, R.P. Netterfield, P. Swift, S. W. Filipczuk, K. H. Muller, C. G. Pacey, and B. James, Characteristics of titanium arc evaporation. Thin Solid Films 153, 93 ( 1987).

[65]. H. Randhawa and P. C. Johnson. Technical note: A review of cathodic arc plasma deposition processes and their applications. Surface and Coatings Technology, 31, 303-318, (1987)

[66]. P. A. Lindfors, W. M. Mularie and G. K. Wehner.Surface and Coatings Technology (1991).

[67]. V.M. Lunev, V. G. Padalka and V.M. Khoroshikh. Sov. Phys. Tech. Phys., 22, p.858 ( 1977 ).

[68]. P. J. Martin, Vacuum, 36, 585, ( 1986 ).

[69]. B. Zega. Hard decorative coatings by reactive physical vapor deposition: 12 years of development. Surface and Coatings Technology, 39/40, 507-520, (1989). 


\section{CHAPTER 3 \\ THE CATHODIC ARC DEPOSITION \\ PROCESS}

\subsection{INTRODUCTION}

The cathodic arc deposition process $[1,2]$ of thin films belongs to a family of ion plating processes, a family which includes evaporative ion plating $[3,4]$ and sputter ion plating $[5,6]$.

The term "ion plating" was introduced by Mattox for processes which include ion bombardment of the substrate and of the growing film $[7,8]$.

This chapter focuses on the cathodic arc. as a means for the production of coatings, the arc evaporation as an ion-assisted deposition technique, its emission characteristics, the methods used to reduce macroparticles; and the technique of filtering using magnetic plasma duct is discussed in detail with emphasis on the properties of films deposited by the filtered arc.

\subsection{EleCtRICAL PROPERTIES}

\subsubsection{DEFINITION OF ARC}

Prof. Karl T. Compton, of Princeton University, has defined the arc as a discharge of electricity, between electrodes in a gas or vapour, that has a voltage drop at the cathode of the order of the minimum ionizing or minimum exciting potential of the gas or vapour [9]. In his monograph, J. M. Lafferty added that the arc is a self-sustained discharge and capable of supporting large currents by providing its own mechanism of electron emission from the negative electrode [10].

The arc is a high current, low voltage type of discharge which can be sustained over a wide range of ambient gas pressures from high vacuum to atmospheric [11]. Arc discharges are characterized by low discharge voltages close to the ionization potential of the cathode and working gas atoms, high current densities on the cathode surface $\left(10^{5}-10^{11} \mathrm{~A} \mathrm{~m}^{-2}\right)$ and high particle densities in the cathode region (the electron density $\mathrm{N}_{\mathrm{e}} \sim 10^{20} \mathrm{~m}^{-3}$ ). An arc discharge consists of three distinct regions : (i) cathode region, (ii) positive plasma column and (iii) anode region. 
In the cathode region, there is a cathode fall with a low fall voltage $U_{c} \sim 20 \mathrm{~V}$ (considerably lower than in glow discharges) but a high electric field intensity $\mathrm{E}=10^{10}$ $\mathrm{Vm}^{-1}$. The $\mathrm{E}$ value in the plasma column is only about $10 \mathrm{Vm}^{-1}$ [12].

Electrically, the vacuum arc forms an extension to the gaseous glow discharge characteristics as shown in figure 3.1. Because of this, arcs can occur in sputtering and ion - plating equipment, hence much work has gone into designing arc suppression circuitry for power supplies used in such systems [13]. As can be seen from fig.3.1, the arc is a low voltage, high current discharge in which the current enters the cathode at one or more small "cathode spots" (10-8 to $10^{-4} \mathrm{~m}$ in diameter). This makes it particularly attractive from an electrical isolation / safety point of view. Typical voltages and currents drawn from the arc supply would be $15-50 \mathrm{~V}$ and $30-400 \mathrm{~A}$ respectively. The voltage is determined primarily by the composition of the cathode material, but it is influenced by the anode configuration, the gas pressure, the gas species and the magnetic fields [14-16].

The extremely high current densities at the cathode spot cause violent emission of the solid cathode material, most of which is then ionised in the intense plasma associated with the cathode spot.

Sufficient plasma is emitted to make the discharge self-sustaining in a vacuum, and the cathodic arc is therefore often referred to as a vacuum arc.

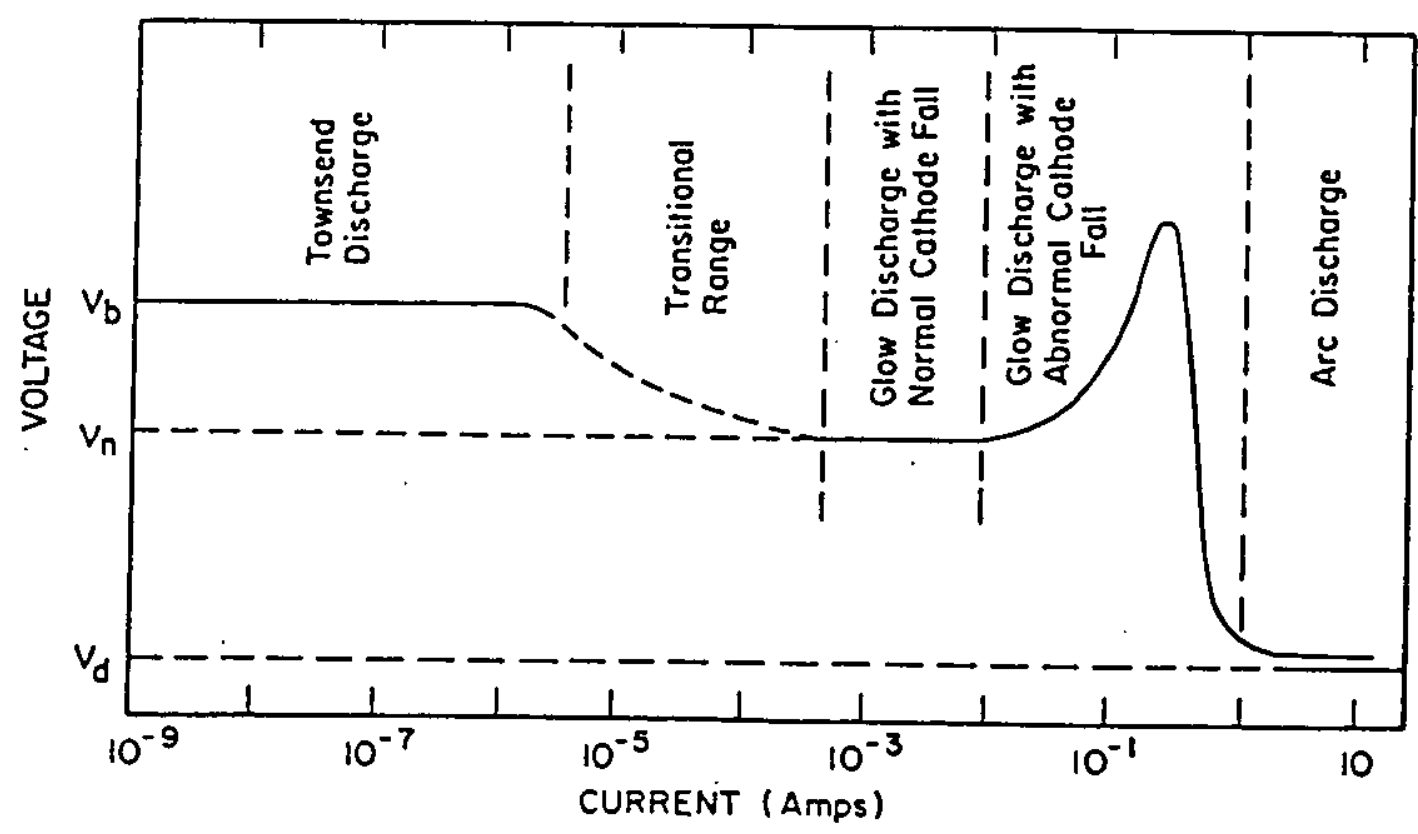

Figure 3.1 The gaseous glow discharge characteristics. 


\subsubsection{ARC CHARACTERISTICS}

Cathodic arcs have the following important physical characteristics :

1. Plasma is generated by a small and intense arc spot that moves rapidly and randomly over the surface of the cathode [14,15,17-21].

2. Plasma is formed from cathode material $[14,17,22,23]$.

3. A high percentage $(10 \%-100 \%)$ of material eroded from the cathode consists of ions [18,24-30].

4. The flux of evaporated material contains multiple-charged ions $(+2,+3$ etc.) e.g. for titanium, $\mathrm{Ti}^{+}$, $\mathrm{Ti}^{2+}, \mathrm{Ti}^{3+}$, etc $[14,17,25,29,31-35]$.

5. The energy of the emitted ions is in the range $(10-100 \mathrm{eV})$ $[14,17,24,29,33-37]$.

These physical characteristics of cathodic arc deposition process result in deposits that are of superior quality in comparison with those from other PVD processes. Some of these advantages regarding deposition of films and coatings are as follows :

i. exceptional control over film morphology $[23,27,38-40]$,

ii. low substrate temperatures $[38,41]$,

iii. high film density [42],

iv. high film adhesion $[37,38]$,

v. high quality, stoichiometric coatings over a wide range of processing conditions $[38,43,44]$,

vi. high deposition rates with excellent coating uniformity including coating of non-line-of-sight surfaces $[38,45]$, and

vii. retention of alloy composition from source to substrate $[22,46]$.

\subsubsection{THE CATHODIC ARC SPOT AND PLASMA}

At the core of the cathodic arc process is the arc spot which erodes the consumable cathode, while the cathode surface remains solid $[22,47,48]$. Understanding of the physics of the arc spot is difficult and not complete at this time, and there is controversy in the literature regarding the events occuring at the spot and the magnitude of the various physical values. 
The arc is sustained by material generated from the cathode $[17,20,25]$. No external working gas is required. There is general agreement, however, that the arc spot is a small luminous region ( $10^{-8}$ to $10^{-4} \mathrm{~m}$ in diameter) which is the source of electron, positive-ion, neutral-vapour and microparticle emission in the vacuum $[17,18,20,49]$. Once initiated, the cathode spot moves randomly over the cathode surface at a velocity up to $10^{2} \mathrm{~ms}^{-1}[15,17,21]$, and its current density is high $\left(10^{6}\right.$ to $\left.10^{12} \mathrm{~A} \mathrm{~m}^{-2}\right)$. $[14,18,20,37,49-51]$.

The velocity of the arc spot is influenced by a number of factors: the composition of the surface of the cathode, the gas pressure and the species and can be controlled by the application of magnetic fields [14,51-53].

The determination of the spot size is linked to the method of measurement used. Two major methods have been employed to determine spot size $[49,54,55]$. One of them is referred to as the autograph method, and employs the size of the erosion trail, or erosion craters to estimate cathode spot size or diameter. Clearly, this method is indirect and has a number of limitations including the resolution between craters and indeed the uncertainty over the relationship between crater radius and the real emitting area $[54,55]$. The second technique, known as the fast registering/ registry method, refers to the size of the highly intense luminescent area to estimate the size of the spot. This technique has also been criticised by Harris [30] in that it is possible that the luminous area expands due to scattering from excited ions and atoms from the cathode spot plasma.

As can be expected, the two methods yield differing estimates of the spot size; spot areas are typically reported to be $8 \times 10^{-4} \mathrm{~cm}^{2}$ as measured by the autograph method, and $7.8 \times 10^{-3} \mathrm{~cm}^{2}$ for the fast registry method [43]. 


\subsubsection{RETROGRADE MOTION OF THE CATHODE SPOT}

The cathode spot moves randomly around the surface of the cathode in the absence of a magnetic field. In the presence of a magnetic field, vacuum arc motion is normally retrograde, i.e. opposite to the direction of $\mathrm{J} \times \mathrm{B}$ ( where $\mathrm{J}$ is conventional current density and $B$ is the magnetic field), for which a large number of mechanisms have been proposed, none of which appears to account for all aspect of spot motion [56-61]. The retrograde motion of the cathode spot relates to the fact that, under certain conditions, the spot moves contrary to Ampere's rule [43].

The speed of this retrograde motion appears to be sensitive to the arc current, the cathode material and its surface condition as well as the magnitude of the applied magnetic field [55,57] and the background gas in the vacuum chamber $[57,59]$.

It was noted that the motion is retrograde so long as the pressure remains low; as pressure increases, however, it reaches a critical value at which the motion changes to the ampere direction. The critical pressure value is greater for lower arc currents and stronger applied magnetic fields [61].

A magnetic field forces the cathode spot into a circular track on the surface of the cathode. The spot is stable only in the region where the normal component of the field is zero $[57,60]$. The stability of this trajectory of the cathode spot can be understood by consideration of the force on a positively charged body, $+q$, through which passes a current, $\mathrm{J}$, into the cathode as shown in fig 3.2 [60].

The existence of a positive charge on the cathode spot is consistent with the model proposed by Plyutto, Ryzhkov, and Kapin [14] and Davis and Miller [17], in which a positive space charge produces a potential maximum in the vicinity of the spot. Since the velocity of the spot is retrograde, we have:

$$
\mathrm{v} \sim-\mathrm{JxB}
$$

so that for the force on q, F, due to the magnetic field, B, we have:

$$
\mathrm{F} \sim \mathrm{q}\left\{[\mathrm{B}]^{2} \mathrm{~J}-(\mathrm{B} . \mathrm{J}) \mathrm{B}\right\}
$$


As can be seen from equation (3.2) and Fig 3.2, the sign of B.J determines that the force will act to restore the cathode spot to the position where [60]

$$
\text { B.J }=0 \text {. }
$$




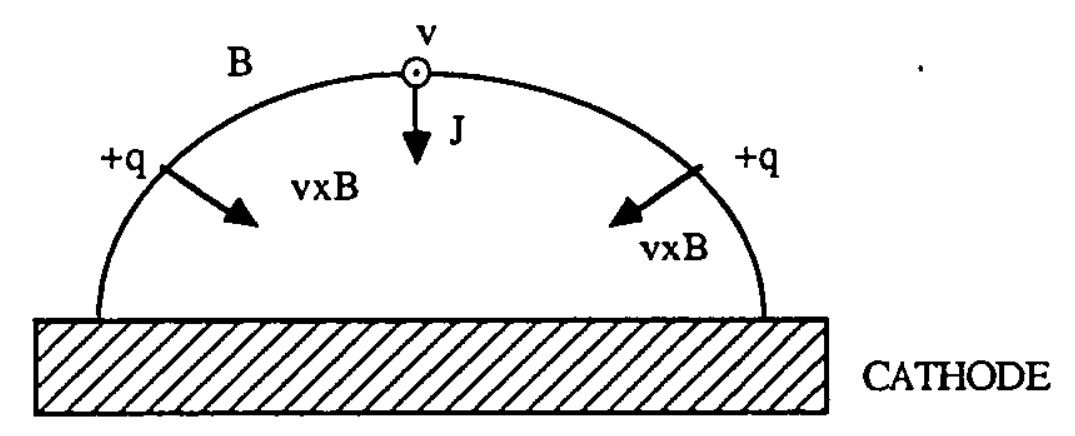

Figure 3.2 Force on a positive charge, $+q$, moving in a retrograde sense with velocity $v$ in a magnetic field $B$. 


\subsubsection{THE CATHODIC ARC SOURCES}

The cathodic arc source consists of a source material (consumable cathode), an anode arrangement, an igniter, and a means of confining the arc spot to the surface of the cathode [42].

The arc is confined by either a passive border or by magnetic fields. Erosion of the cathode is more uniform when the arc spot is confined by passive borders than when magnetic fields are used.

Because the cathode melting induced by the arc spot is limited to microscopic areas of a few micrometers in diameter, the surface of the cathode remains solid and it is, therefore, possible to mount a source in any orientation in a vacuum system $[1,13]$.

There are two main types of cathodic arc which are differentiated by the manner in which the arc spots are controlled and confined [43]. They are based upon the patents of Sablev et. al. and Snaper. Figure 3.3 shows cathodic arc sources of (a) Snaper and (b) Sablev types.

The Sablev design uses a simple water cooled cathode mounted on and isolated from the vacuum chamber wall which acts as an anode. The arc is ignited by a mechanically operated tungsten trigger wire. Arc sources based on the Sablev Patents $[62,63]$ employ boundary shields and extinguish the arc when it leaves the surface of the target. The Snaper source differs in that the anode is mounted on the source itself and a magnetic field is used to focus the plasma [64].

The basic source design is sometimes modified by adding special materials around the cathode to confine the arc and stabilize operation [65]. Arc sources based on the Mularie patent [65] employ a passive confinement border to keep the arc on the surface of the target, boron nitride (BN) being the preferred material.

Cathodes of the Sablev type that use magnetic field confinement or boundary-shield confinement generally are limited to sizes of few inches in diameter. As a result, only limited coating uniformity can be achieved. Generally, several of these sources are placed in a vacuum chamber at one time to obtain good coating uniformity over an extended substrate mounting area [42].

Since the arc is extinguished when it leaves the target surface, further difficulty with such sources arises with the necessity to re-ignite the arc. The repeated re-ignition has a detrimental effect on film quality because, at each ignition event, an intense pulse of microdroplets is emitted from the source [43]. This results in deposited films which contain a relatively high concentration of macroparticles. 


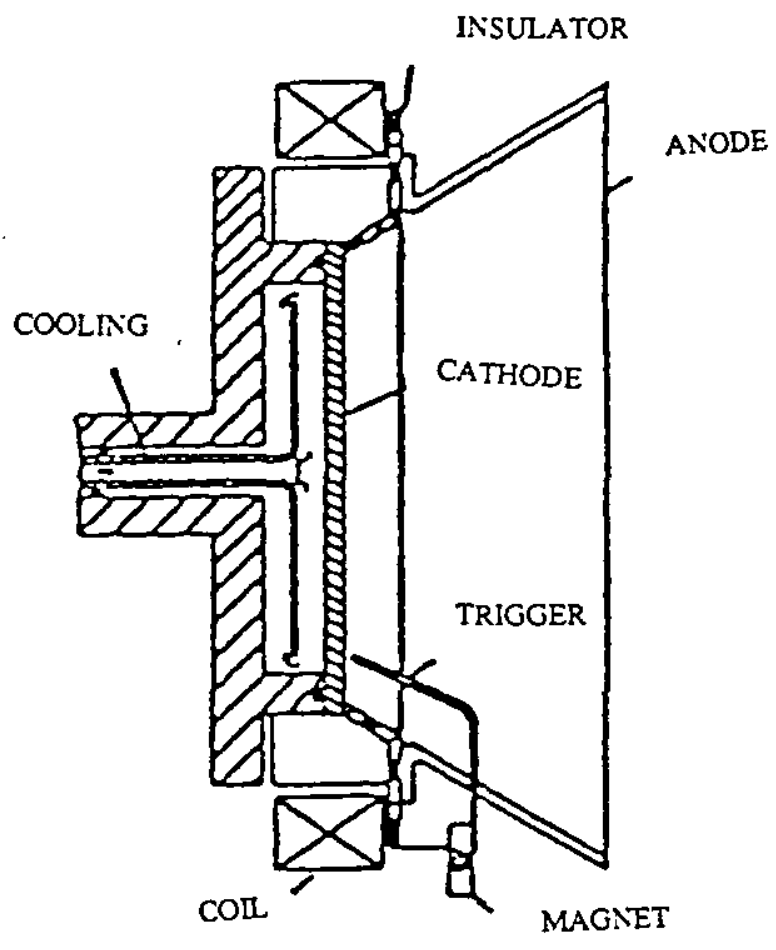

a. SNAPER TYPE

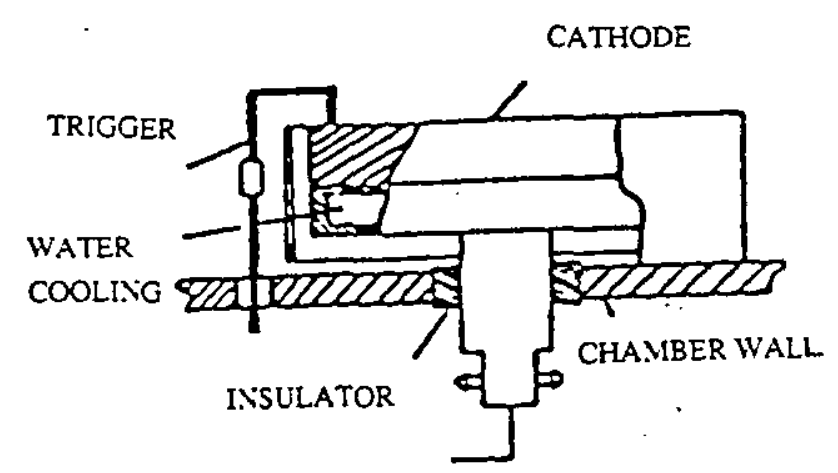

b. SABLEV TYPE

Figure 3.3. Cathodic arc sources. (a) Snaper type, (b) Sablev type. 

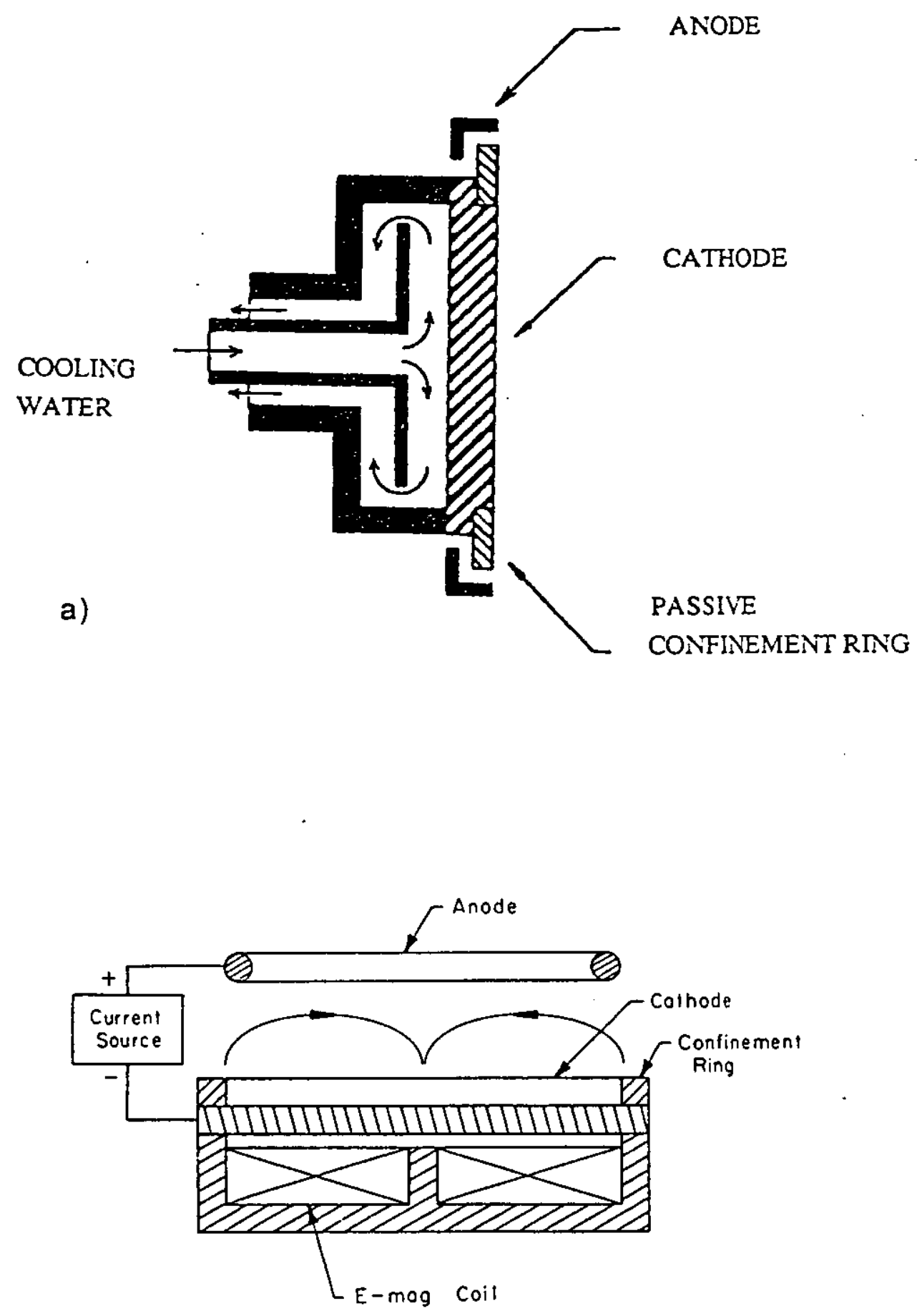

b)

Fig. 3.4. a) Schematic cross-section of a typical passive confinement arc source (spot moves randomly on the surface except at the edge) [1].

b) Magnetically guided arc source [66]. 
Arc source designs that use passive confinement borders with predetermined electronic characteristics [65] make it possible to fabricate cathodes over a wider range of sizes. These cathodes provide good coating thickness uniformity over large area substrates, such as broaches, or over large loads of small parts. A cross-section of a typical passive confinement arc source is shown in figure 3.4 (a) [1]. A further benefit of the passive confinement border approach is the stable operation of such sources. The passive border does not extinguish the arc but constrains it on the cathode surface, and neither does the arc spontaneously extinguish; hence, the source operates in a stable manner over extended periods, and re-ignition during a coating cycle is an extremely rare requirement.

The anode in the arc discharge circuit can be either an isolated electrode or the vacuum chamber itself.

In the case of the discrete anode, the electrode is isolated from the vacuum chamber and connected directly to the positive side of the arc power supply $[43,60]$.

Use of an isolated anode has several benefits :

(i) The anode has the effect of deflecting the path of the ions emitted from the cathode. By careful selection of anode size and position relative to the cathode, it is possible to deflect some part of the coating flux, which would otherwise be lost to the chamber walls.

The anodes can be used, then, to increase the effective deposition rate, to improve target utilization, and also to modify the deposition uniformity at the substrate.

(ii) The anode also acts as a collector of material that would otherwise be deposited on the wall of the chamber, reducing both accumulation of coating on chamber walls and the need for frequent maintenance.

(iii) The minimum current and discharge voltages required for stable arc source operation are strongly dependent on the anode configuration. The larger the area of the anode exposed to the anc source, the lower the discharge voltage.

In the case where the vacuum chamber itself is the anode, it is normal practice to ground both the positive side of the arc power supply and the vacuum chamber and its internal components [43]. 
Morrison [66] described a method in which, a simple stationary magnetic field coil positioned behind the target, is used both to guide the arc and to increase the velocity of the arc spot over the target surface fig 3.4 (b). The resultant motion of the spot produces a significant improvement in deposition uniformity, since the arc spot can be steered over the full length of a large-area rectangular source. A development of this approach incorporates several magnetic coils arranged one within another. By switching the power between the coils and thus capturing the arc in another field loop, it is possible to broaden the erosion groove and hence considerably increase the utilization of the target.

Martin et al [67] studied the affects of both internal and external magnetic fields on the deposited films. While the external magnetic field reduced the numbers of macroparticles, no reduction was observed in the case of the internal magnetic field.

The benefits associated with the steered arc in reducing the macroparticle density and size have been well illustrated in the work of Randhawa [68,69] and Boelens and Veltrop [70] in both wear and decorative aplications. 


\subsubsection{CATHODIC ARC TYPES}

From earliest times, cathodic arc devices for producing coatings could be divided into pulsed and continuous types [71].

\subsubsection{PULSED MODE}

Recently, a new coating process was developed making use of pulsed high-current vacuum arcs. The process is based on setting up a high-current electrical discharge between two metallic electrodes located in a vacuum chamber. The electrical current is conducted by a plasma consisting of the ionized vapour of the electrode materials. The production of plasma and emission of electrons are concentrated at one or more minute cathode spots. Each cathode spot produces an energetic plasma jet that flows from cathode to anode Figure 3.5.(a), and deposits on the anode as a coated film [72].

The coating rate in this process is a function of discharge current [72], and for discharge currents in the range of $1-3 \mathrm{kA}$ the coating rate can approach $400 \mu \mathrm{m} / \mathrm{s}$. In the pulsed mode, the arc is repeatedly ignited and extinguished using a capacitor bank to supply the arc power [72].Pulsed arcs have the advantage of allowing the target material to cool between arc events. This makes it possible to arc an extremely wide variety of materials with less concern for the overheating of the target. Pulsed arcs, however, have a dead time in between arc events which limits the steady-state coating rate and can lead to increased coating contamination [71].

\subsubsection{CONTINUOUS ARC MODE}

The continuous cathodic arc can either be random in nature or controlled. Figure 3.4 (a) shows an example of a random arc source where the arc is constrained at the edge of the target, but allowed random motion within that constraint $[65,73]$.

\section{A. RANDOM ARC}

Random arc sources have the advantage of simplicity and excellent target utilization because the entire target (except near the very edge ) is used in the arc process. These sources can be scaled in a straight forward manner to provide for uniform coating of very large parts.

The main disadvantage of the random arcing is the formation of macroparticles which may cause the resulting coating to be unsuitable in some applications. 


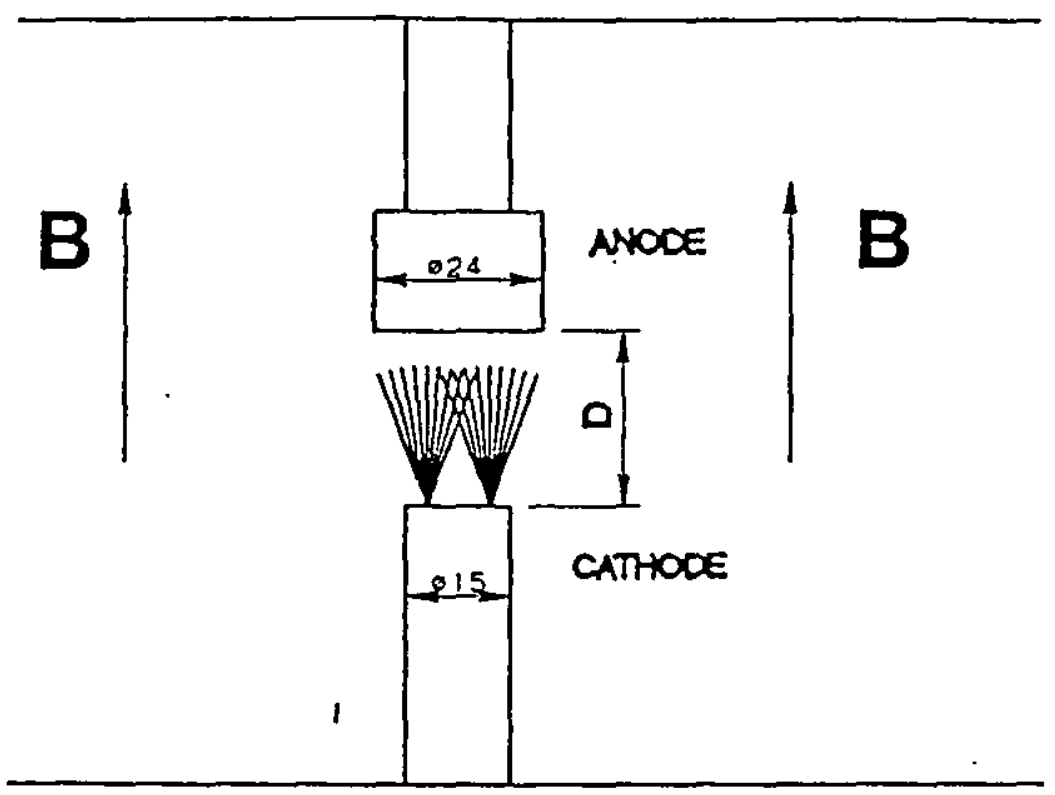

a)

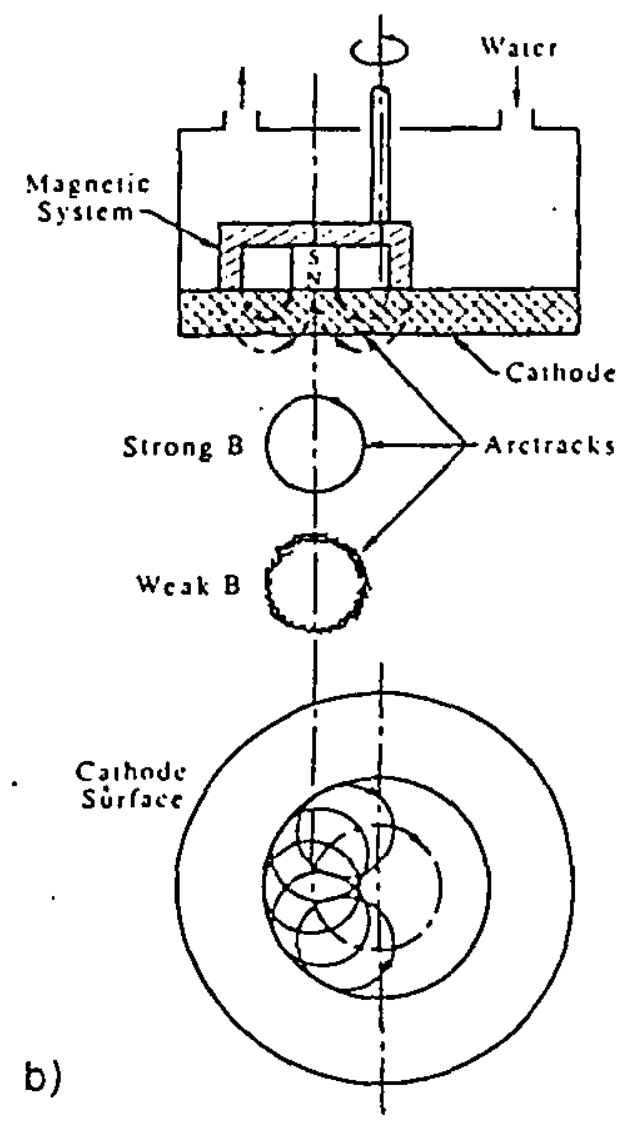


chapter three

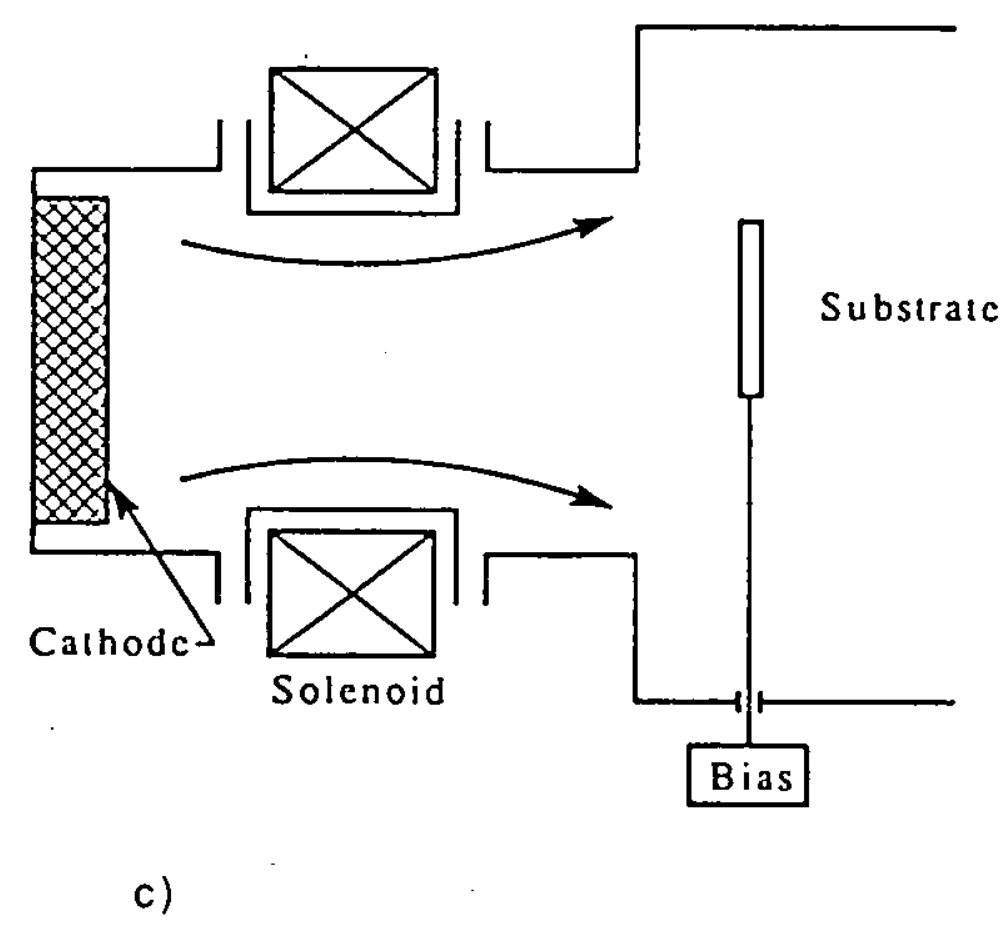

Figure 3.5 a) Pulsed arc coatings system [72]. b) Magnetic steering of the cathode spot by means of an "internal" rotating magnetic field [74], c) shows a modified arc evaporation source employing an "external" solenoidal magnetic field $[80,81]$. 


\section{B. STEERED ARC}

The cathode spot may be steered around the surface of the cathode by applying a magnetic field to the source. This is usually achieved by placing either a permanent or electromagnetic system at the back of the cathode. The cathode spot is forced into a trajectory which is determined by the shape and magnitude of the magnetic field.

In more recent developments, Ramalingham et al [74] used an "internal" magnetic field i.e. a field applied directly behind the cathode itself, to guide or steer the arc on the target surface. Benefits of such steering of the arc include more uniform deposition from large-area sources, and reduction in microdroplet emission, resulting from the increased velocity of the arc spot over the cathode surface.

Erturk et al. [75] have concluded that droplet formation can be reduced in the arc coatings by considering the following points :

(i) The volume of molten material produced during the life of a spot must be kept low, i.e. small craters (low arc current) and short spot life which can be caused as a result of external movable magnetic fields.

(ii) The arc path should be as elongated as possible to prevent widespread melting of the cathode surface (magnetic guidance). At the same time, efficient cooling of the cathode is essential. Boxman and Goldsmith [76] have estimated the front surface of a titanium cathode $100 \mathrm{~mm}$ diameter, $10 \mathrm{~mm}$ thick and supporting a current of $100 \mathrm{~A}$ to be $41^{\circ} \mathrm{C}$.

(iii) A high melting point of the cathode material reduces the mean radius of craters and a low thermal conductivity limits the extension of molten areas. 
Erturk et al [75] have used a permanent magnet which is positioned directly behind the anc cathode so its magnetic field lines penetrate the arc cathode and exert a hall force on the arc as current-carrying conductor. The effect is to move the arc around the surface of the cathode in a predeterminedif track. This Hall force is also exerted on the ions which form directly in front of the cathode spot ( a distance of approximately one mean free path) as a result of the impact of electrons on evaporated cathode material. Some of these ions form the positive cloud in front of the cathode and are attracted by the cathode again. They are therefore overcome by the Hall force and arrive with circular deflection in the vicinity of the arc spot. This new impact point is heated locally. It emits electrons and prepares the location of the new arc spot. The process is presented schematically in Fig 3.5.(b) [75].

The method may be used to achieve a more uniform erosion of the cathode surface or to steer the arc to specific areas on a multi-element segmented cathode in order to produce alloys or modulated layers. Erturk et al $[75,78]$ demonstrated that steered arc resulted in smaller crater size when compared to that of the random arc.

The droplets are reduced in size by adding nitrogen in TiN deposition but this does not eliminate all macroparticles. During TiN films deposition, nitrogen in the chamber causes poisoning of the cathode, i.e. the formation of a component (TiN) which melts at higher temperatures than titanium resulting in smaller craters on the cathode. The deposition rate was also reduced from $13 \mu \mathrm{m} \mathrm{h}^{-1}$ to $5 \mu \mathrm{m} \mathrm{h}^{-1}$ ( $80 \mathrm{~A}$ arc, $125 \mathrm{~m}$ diameter steered arc, $63 \mathrm{~mm}$ diameter random arc).

Similar result for TiN deposition was reported by Steffens et al [79] but they found that magnetic fields up to $10 \mathrm{mT}$ did not reduce droplet emission in non-reactive evaporation.

The influence of "external" magnetic fields on arc evaporation was studied by several investigators $[103,104]$. Generally these fields are applied by means of a magnetic solenoid mounted directly in front of the cathode, figure 3- (c) shows a modified arc evaporation source employing an "external" solenoid magnetic field [80,81]. 
In the case of $\mathrm{Ti}$ the solenoid field has the effect of increasing the ionized fraction of the emission to $100 \%$ and the average charge per ion to 2.08 [80]. Martin et al [82] reported that the enhancement in ionization results in an increase in the photon emission from $\mathrm{Ti}^{+}$and $\mathrm{Ti}^{2+}$ species as the magnetic field is increased from 0 to $10 \mathrm{mT}$. The ion energy is also increased through Hall acceleration. It has been suggested that the macroparticles are evaporated by collision with electrons in this arrangement since the electron density is increased greatly by the application of the magnetic field.

Akari et al [81] reported that the number of macroparticles could be reduced to $10 \%$ when a magnetic field is used compared to the conventional process .

The use of an external solenoid for magnetic enhancement of cathodic arc deposition process resulted in reductions in macroparticle content and increases in coating adhesion [83]. This external solenoid source has also been adjusted to produce a high intensity ion source [84]. The source was used in conjunction with suitable anode to sputter a wide variety of materials from a water-coled target onto a substrate facing the target. Films of titanium, aluminium, niobium and copper were produced. In the case of $\mathrm{Ti}$ and $\mathrm{Nb}$, the arc sputtering process produces fine grained coatings and free of macroparticles. The deposition rate ranged from 2 to $6 \mu \mathrm{m} \mathrm{h}^{-1}$ depending on the target material and substrate bias. 


\subsubsection{ARC IGNITION}

The vacuum arc as a source of material for film deposition and as a high-current source of metal ions may be operated in either a continuous or a pulsed mode.

Initiating an arc requires a triggering mechanism. Arc sources used for coating commonly employ mechanical triggers, arcing is initiated when a conductor carrying tens of amps is separated from the cathode.

In the continuous mode, the arc may be created or "triggered" in several ways. The most commonly used method to initiate the arc is to make a momentary contact to the cathode surface with a contactor [65], and then withdraw it, the open circuit voltage of the arc power supply being the potential difference between the cathode target and the contactor (igniter). The open circuit voltage of the power supply must exceed approximately $30 \mathrm{~V}$ for reliable ignition. This method is very reliable, provided a tungsten / molybdenum contactor is used $[43,60]$. As the surface temperature of the target increases, the possibility of the igniter becoming welded to the target also increases; this possibility is avoided by the use of material which has a high melting point such as molybdenum (2620 $\left.{ }^{\circ} \mathrm{C}\right)$ or tungsten $\left(3410^{\circ} \mathrm{C}\right)$.

The main drawback of the momentary contact of the igniter with the cathode surface, is the necessity to move the igniting device over the working surface of the cathode, where it is subject to the destructive effects of the arc.

One alternative of the contact igniter is the so-called gas igniter, which admits a burst of gas to the chamber to elevate the pressure while simultaneously applying a high-voltage, low-current pulse between the cathode and an adjacent trigger electrode [85]. The advantages in the contactless igniters are that they have no moving parts inside the vacuum, and also do not produce a burst of microdroplets or macroparticles as is the case with the contacting igniters.

Aksenov et. al. [86,87] described a method for igniting a constant-current arc in a vacuum which is based on exciting the cathode spot on the non-working surface of the cathode by means of a plasma stream generated by a low-power pulsed source and then directing the spot onto the working surface, using an external magnetic field.

RF ignition may also be used $[43,64,88]$; when either or both of the two electrodes are made of an insulating material, then the application of a d.c. potential cannot initiate a discharge. However the main concern is restricted to cathodes that either conductors or 
semiconductors. It is possible to use insulating materials as cathodes by operating a cathodic arc deposition system in a RF mode [64]. However, there has been little pursuit of the possibilities using an RF mode of operation. To conclude the description of RF discharges the main features may be summarized:

(i) insulating materials can be deposited,

(ii) the substrate bias can be varied via the electrode geometries and

(iii) the RF frequency is determined by the capacitance of the electrodes and the applied voltage .

The main disadvantage with RF ignition is the increased cost of the power supply [89].

\subsection{EMISSION CHARACTERISTICS}

\subsubsection{DEFINITION}

The term "vacuum arc" refers to a class of gas discharges where electron-molecule interactions and ionizing processes occur in metal vapour released from the cathode by the arc. Without the metal vapour there is no arc and the metal vapour is produced by the arc. The discharge processes occur primarily in what are called cathode spots. These spots, which are visible as intense luminous glows, are confined to volumes on the order of $100 \mu \mathrm{m}$ in diameter on the cathode surface [46].

Observations of cathode arc tracks indicated that arcing produces craters having diameters on the order of ten times smaller than the luminous cathode spots [46]. Figure 3.6 is a schematic of arc emission processes [46].

Starting with an active crater, electrons and metal vapour spew from the crater into the vacuum. Daalder [46] has shown that Joule heating by electrons converging at emission sites from within the cathode may be the primary heating mechanism for active craters. The emission site of a discrete cathodic spot on the surface of the cathode is active for a short period, extinguishes and is re-established close to the original site. The emission site is a source of electrons and atoms of cathode material that are subsequently ionized immediately above the arc site. 
The ions flow toward the cathode and are also accelerated away from the "ion cloud" towards the anode along with the electrons.

The precise mechanism involved in the ion acceleration is the subject of some debate but the simple model assumes that a "potential hump" arises from the location of the ion cloud above the site which repels the ions away from the cathode. A mechanism of this nature is required in order to explain the high kinetic energies observed for the ejected ions. The ions that are accelerated towards the cathode are thought to play a major role in establishing new arc sites. 


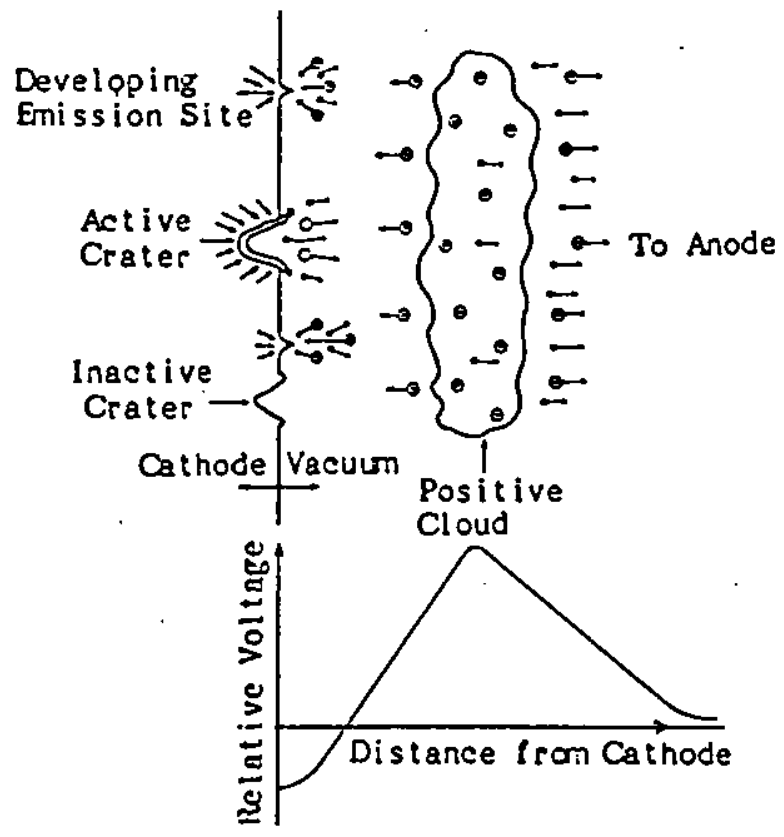

Substrate
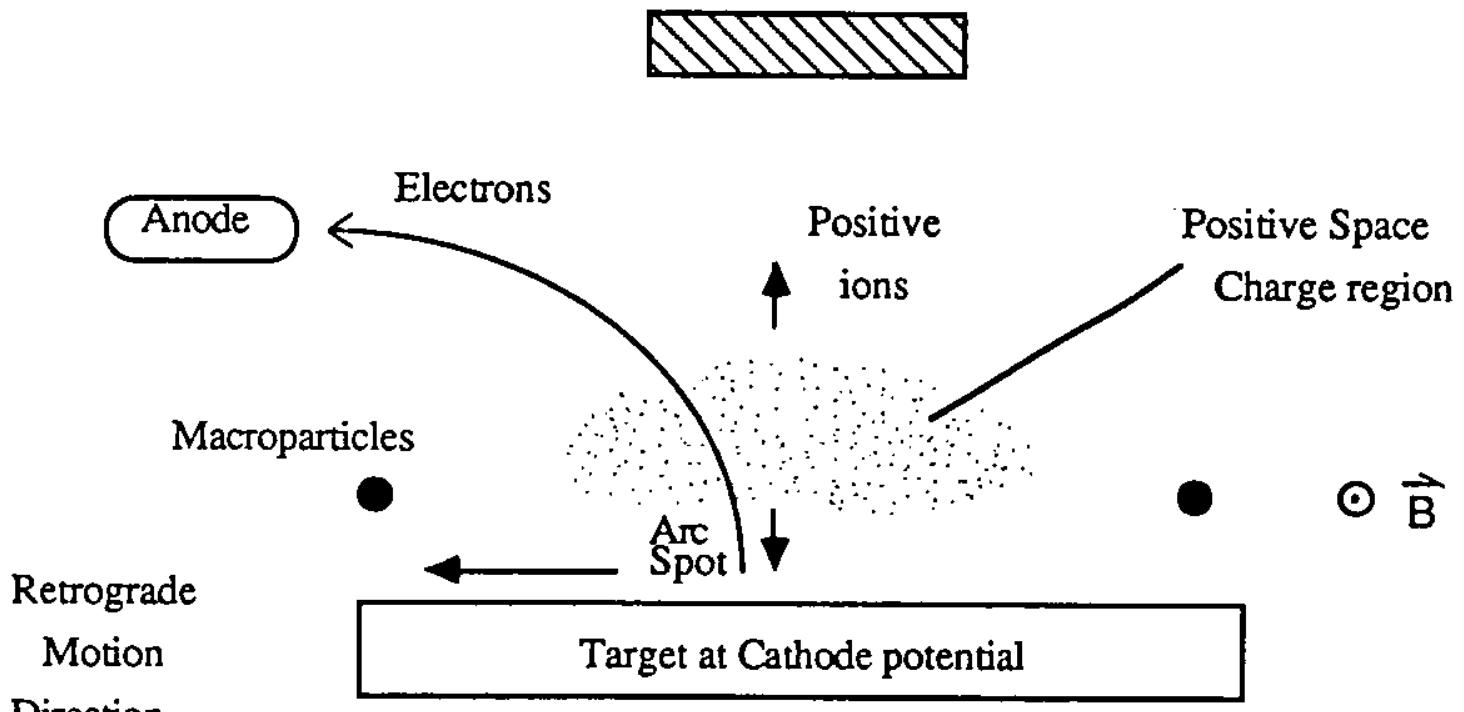

Figure 3.6.a) Schematic shows the structure and dominant processes in a cathodic arc [46]. b) Emission characteristics of a cathodic arc source. Cathode spot of a vacuum arc, which moves across a cathode surface, creates a vapour of electrons, ions, neutral vapour atoms and microdroplets [43]. 


\subsubsection{EMITTED MATERIALS}

As illustrated in fig. 3.6. (b), electrons, ions, macroparticles, and neutral vapour species are emitted from the cathode spot [43].

The high current density carried by an arc spot causes flash evaporation of the source material. The flux emitted from a cathodic arc source consists almost entirely of ions and microdroplets. A major advantage of the CAPD method is the high degree of ionization of the emitted material (10\%-100\%); it is widely acknowledged that neutral metal vapour constitutes only a small fraction $(1-2 \%)$ of the mass transfer. The neutral species are thought to be due to the vaporization of small macroparticles by the interaction with the plasma [90]. The majority of the microdroplets are emitted from the cathode at low angles $\left(0^{\circ}\right.$ to $\left.30^{\circ}\right)$ [46], while the ions are emitted predominantly in a direction perpendicular to the plane of the cathode surface. The electrons are accelerated toward the cloud of positive ions.Figure 3.6 (b) shows emission characteristics from a cathodic arc source [43].

Vacuum arc characteristics are relatively constant for external currents ranging from 10's to 100 's of amps because cathode spots tend to divide and multiply when the average current exceeds a value that depends on physical properties of the cathode material [46 ]. The average current carried per spot depends on the cathode material. According to Kimblin [ 18] the average spot current for Ti is about 70 amps. Metal vapour emission in the form of neutrals and ions is essential for survival of the arc, whereas the droplet phase is not.

Kimblin observed ion emission from cathode spots to be between $8 \%$ and $10 \%$ of the total arc current for a wide variety of cathode materials [91].

For PVD coating purposes, a very important feature of the vacuum arc is that a large fraction of the vapour is ionized and the average ion energy is substantially greater than the arc voltage. In view of the extremely high vapour pressure and high electron density, it should not be surprising that the ionization efficiency of an arc is much greater than that normally observed in glow discharges associated with ion plating and sputtering processes.Table 3. 1. shows ion fraction and ion energy data obtained by Lunev et al. for Ti ions emitted from an arc vapour source operating in vacuum at $100 \mathrm{amps}$ [58]. These results are typical of other data presented by the same authors, as well as by earlier investigators $[14,17]$. Table 3.2 shows the fractional distribution of ion flux from copper [14]. 


\begin{tabular}{|c|l|l|l|}
\hline $\begin{array}{l}\text { charge } \\
\text { state }\end{array}$ & ion fraction & $\begin{array}{l}\text { average } \\
\text { energy per e+ }\end{array}$ & $\begin{array}{l}\text { total } \\
\text { energy }\end{array}$ \\
\hline $1+$ & $27 \%$ & $65 \mathrm{eV}$ & $65 \mathrm{eV}$ \\
\hline $2+$ & $67 \%$ & $39 \mathrm{eV}$ & $78 \mathrm{eV}$ \\
\hline $3+$ & $6 \%$ & $34 \mathrm{eV}$ & $102 \mathrm{eV}$ \\
\hline
\end{tabular}

Table 3. 1. Average charge state and ion energy for a Ti vacuum arc operated in a $5 \times 10^{-6}$ Torr vacuum at 100 amps (Lunev et al. [58]).

\begin{tabular}{|c|c|c|c|c|}
\cline { 2 - 5 } \multicolumn{1}{c|}{} & \multicolumn{3}{|c|}{ Degree of ionization \% } \\
\hline \begin{tabular}{c} 
arc current \\
\multicolumn{1}{c|}{ (A) }
\end{tabular} & Ia & IIb & III & IV \\
\hline 50 & 26 & 55 & 19 & 0.6 \\
\hline 100 & 30 & 54 & 15 & 0.0 \\
\hline 200 & 31 & 55 & 14 & 0.3 \\
\hline
\end{tabular}

$$
\begin{aligned}
& \text { a- it is singly ionized } \\
& \text { b- it is doubly ionized }
\end{aligned}
$$

Table 3. 2. Fractional distribution of ion flux from copper [14] A summary of the cathode spot parameters is shown in Table 3.3. 
A summary of the cathode spot parameters is shown in Table 3.3.

\begin{tabular}{|l|l|c|}
\hline Parameter & Range & Reference \\
\hline current density & $10^{7}-10^{10} \mathrm{~A} \mathrm{~m}^{-2}$ & 35 \\
\hline electron density & $5 \times 10^{20} \mathrm{~m}^{-3}$ (cu) & 92 \\
\hline electron temperature & $\begin{array}{l}3-6 \mathrm{eV}(\mathrm{cu}) \\
6-9 \mathrm{eV}(\mathrm{Al})\end{array}$ & 92 \\
\hline pressure & $0.1-10 \mathrm{Mpa}$ & 92 \\
\hline crater size & $1-20 \mu \mathrm{m}$ & 46 \\
\hline crater formation time & $\sim 10^{-7}(\mathrm{Joule} \mathrm{heating)}$ & 46 \\
& $1.2-4.5 \mathrm{~ns}(\mathrm{Cu})$ & 51 \\
& $1.6-6.2 \mathrm{~ns}(\mathrm{Mo})$ ion impact & 51 \\
\hline ion energy & $25-75 \mathrm{eV}$ & 17 \\
\hline ion fraction & $0.1-1.0$ & 14 \\
\hline
\end{tabular}

Table 3.3 A summary of the cathode spot parameters.

$$
\begin{aligned}
& 1 \text { Pascal }=7.5006 \times 10^{-3} \text { Torr } \\
& 1 \text { bar }=7.5006 \times 10^{2} \text { Tor }
\end{aligned}
$$




\subsubsection{MICRODROPLET EMISSION}

The discharge from a cathodic arc spot includes microdroplets which are hurled off the arc cathodes as molten particles and integrated into the coatings. These microdroplets are sometimes referred to as "macroparticles" because their dimensions are large relative to atomic dimensions [40]. Typical microdroplet sizes range from submicrometer up to 25 $\mu \mathrm{m}$ in diameter $[23,26,94-96]$. The emission of microdroplets is the result of pressure against the local melted zone at the arc spot location on the cathode, and the droplets leave the cathode in a molten state $[19,23,37,53,94,95,97]$. The molten microdroplets are generally spherical in the plasma and upon impact on a substrate the droplets flatten and solidify.

It has been shown by several researchers that most of the droplets produced by a steady vacuum arc leave the cathode at small angles to the cathode plane $[95,98]$ and that the size of the particles depended upon the arc current, choice of cathode material, background gas composition and pressure. Microdroplet emission is higher for lower melting point materials. Elemental cathodes with higher melting temperature materials emit more ions and fewer microdroplets [40]

Higher pressures of active gases in the deposition chamber with a reactive metal will result in reduced microdroplet concentrations [95,99].

The cathode-to-substrate geometry will influence the concentration of microdroplets found in a coating. The largest droplets and their greatest concentration occur at shallow angles relative to the plane of the surface of the cathode $[14,23,40]$. The velocity of the macroparticles is in the range $0.1-800 \mathrm{~m} \mathrm{~s}^{-1}$. The average velocity increases with the melting point of the cathode material, from $140 \mathrm{~m} \mathrm{~s}^{-1}$ for $\mathrm{Cd}$ to $300 \mathrm{~m} \mathrm{~s}^{-1}$ for Mo [76].

\footnotetext{
Aksenov et al [99] reported that higher pressures of noble gases do not have an effect on the droplet formation. However, high pressures of a reactive gas can form a thin layer of a compound on the surface of a cathode. For the combination of titanium and nitrogen it has been suggested that formation of TiN on the surface of the cathode will result in reduced melting [99]. The melting temperature of titanium is $1660^{\circ} \mathrm{C}$ while the melting temperature of $\mathrm{TiN}$ is $2930^{\circ} \mathrm{C}$. The particle size of $\mathrm{Ti}$ is found to decrease with increasing partial pressure of nitrogen as a consequence of the formation of TiN on the cathode surface [96].
} 
Reduction in arc current will reduce the size and perhaps the concentration of microdroplets emitted from a given cathode [35].

External magnetic fields can be used to influence the velocity of the arc spot on a cathode [53]. Higher velocities of the arc spot will result in reduced microdroplet concentrations $[35,53]$. The higher arc spot velocity results in a low mean residence time of the arc spot on a given localized area and thus minimizes localized overheating and thus the size and density of the microdroplets [42].

It is also possible to eliminate microdroplets by combining thermal and arc spot effects [48], which can result in emission free of microdroplets from cathodic arc sources. A modified source with minimized heat conduction from the cathode is normally required to achieve suitably high temperatures.

When the correct temperature of a cathode is reached (within approximately $100^{\circ} \mathrm{C}$ of the melting point of the material), the arc spot will transform into a diffuse discharge covering the entire cathode surface and no microdroplets are emitted $[22,48]$. The transformation into a diffuse discharge also requires that a critical gas pressure be present at the surface of the cathode $[22,48]$, to sustain the emission. This method has a significant technical difficulty in containing the high temperatures required to the cathode alone, except for cathodes of low melting point materials. Because the emission process is altered significantly in this mode of operation it is possible that not all of the features associated with cold cathode emission will be present in the resulting plasma [40].

Measurement of the angular distribution of emitted macroparticles show that the particles ejected at an angle of approximately $30^{\circ}$ to the cathode surface $[95,103,104]$.

Brandolf [105] has proposed the simplest method of reducing the number of macroparticles in the condensing film. This is to take advantage of the spatial distribution characteristics of the macroparticle emission and place the substrate in the deposition chamber in such a location that it is not in direct line-of-sight of the cathode.

Brandolf has used a shield which is interposed between the substrate and arc source; the substrate and shield arc then biased to attract the plasma around the shield and onto the substrate. The macroparticles are then trapped on the front of the shield and do not impinge on the substrate. Figure 3.7 shows macroparticles filtering by shielding [105]. A major limitation of the shielding method is that the deposition rate is reduced although macroparticle-free coatings can be produced [96]. 


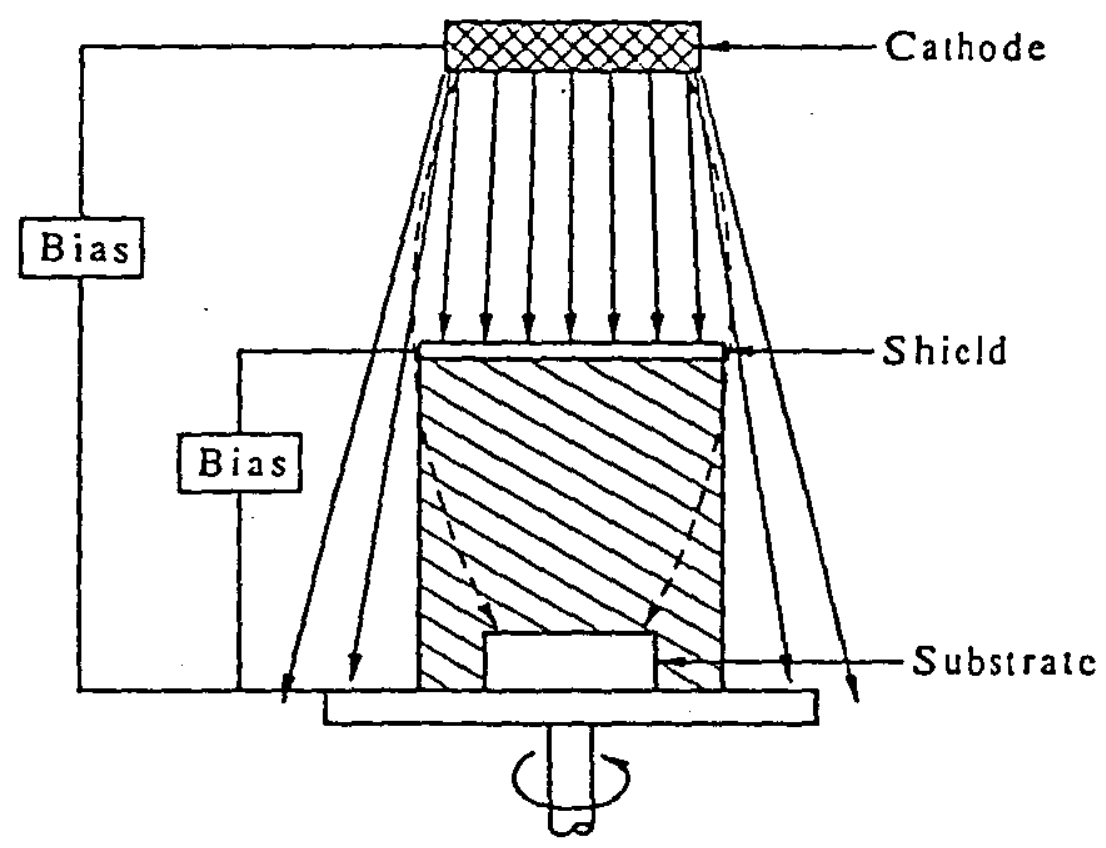

Figure 3.7. Macroparticles filtering by shielding [105]. 
Sources employing ion optics to seperate ions from microdroplets have been reported in the literature [100-103]. This method is discussed in more detail in section 3.4.

Amongst theoretical work about the macroparticle emision, there are at least two theories:

(i) A model based on expulsion of material by action of the plasma pressure [106].

(ii) A second model based upon the concept of explosive emission [76].

McClure [106] has proposed a model based upon plasma expansion in which ions from the ion cloud above the cathode spot are accelerated towards the liquid surface of the active cathode spot.The vapour jet recoil force presses inward on the molten metal, and the escape route for the molten metal is toward the edges of the crater.

Hence, the pressure would be expected to produce an angular distibution of molten droplets that is concentrated near the plane of the cathode [23]. This model predicts that the velocity of the molten metal (copper) is of the order of $20-200 \mathrm{~m} / \mathrm{sec}$.

The second model has been proposed by Boxman et al, based upon the concept of explosive emission [76]. The model assumes that electron emission is concentrated on small surface protrusions on the cathode. The protrusion is rapidly heated by electron emission through it until it eventually explodes at a peak pressure of $2 \times 10^{-10} \mathrm{~Pa}$. The impact from the explosion generates other surface defects and other sites for the process to be repeated.

\subsubsection{REACTIVE DEPOSITION PROCESS}

Reactive deposition involves the deposition of compound coatings from a pure metal or alloy target material in the presence of the appropriate reactive gas.In the case of the filtered arc this can be achieved without causing significant poisoning of the cathode since the source is remote from the region where the gas introduction takes place [96]. Most typical of these processes are the reactive arc deposition of oxides, nitrides, carbides and carbonitrides of the refractory metals as hard coatings suitable for wear-resistant or decorative applications.

It is generally accepted that the major part of the chemical reaction between the metal and the reactive gas happens on the substrate surface. The composition of the coating will then result from the impingment ratio between the gas molecules and the metal atoms [107]. 
Many parameters influence the composition of the deposit, such as the reactive gas partial pressure, the degree of its activation, the evaporation rate of the base metal, the degree of activation of the metallic vapour, the source-to-substrate distance and the substrate temperature. Randhawa et al. [108] claimed that monitoring of the reactive deposition process is possible by simply controlling the total power input, provided the influence of the magnetic field present is also considered, as has been demonstrated by Aksenov et al. [33].

Relatively little work has been reported on the reactive deposition of oxides by the arc method. In contrast to the negative effects that result from the formation of insulating oxides on the surface of sputter targets operating in dc reactive mode, the formation of such oxide films on arc targets can have a very beneficial effect on the quality of the deposited film. The benefit is a very significant reduction in both the number and the size of macroparticles. This reduction is believed to result from the higher arc velocity observed when a metal is eroded in the presence of oxygen. A thin film of oxide forms on the target surface; because of the higher electron emission coefficient of the oxide, the arc spot prefers to reside on an oxide surface. Where the oxide is present only as a thin film, it is rapidly consumed by the arc, which then migrates to an adjacent oxidized site. The location that the arc has just left is at a very high temperature and therefore, is quickly reoxidized by the ambient oxygen. This mechanism produces very rapid arc spot motion, as much as 10 times the spot velocity in the absence of oxygen for the same target metal [43].

Martin et al [67] reported the deposition of titanium oxide films which exhibited very low macroparticle counts, reduced by $95 \%$ compared to pure metal films of titanium.

Aksenov et al. [44] deposited $\mathrm{Al}_{2} \mathrm{O}_{3}$ at pressures of $10^{-3}-1.0 \mathrm{~Pa}$ at rates up to $12 \mu \mathrm{m}$ $\mathrm{h}^{-1}$. The micro-hardness of $\mathrm{Al}_{2} \mathrm{O}_{3}$ produced by the filtered arc has been measured to be $1080-1500 \mathrm{Kg} \mathrm{mm}^{-2}$.

Martin et al [109] have reported the deposition of optical quality $\mathrm{Al}_{2} \mathrm{O}_{3}$ films with a refractive index of 1.67 and extinction coefficient of $6 \times 10^{-4}$ at rates up to 600 $\mathrm{nm} / \mathrm{min}$. They have also deposited $\mathrm{ZrO}_{2}$ with a rate up to $400 \mathrm{~nm} / \mathrm{min}$.Other oxides have been successfully deposited by the filtered arc such as $\mathrm{TiO}_{2}, \mathrm{VO}_{2}, \mathrm{Cr}_{2} \mathrm{O}_{3}, \mathrm{Nb}_{2} \mathrm{O}_{3}$ and $\mathrm{ZrO}_{2}$. Table 3.4 shows the optical properties of oxides deposited by filtered arc evaporation process [110]. 
Table 3.4 . Optical properties of oxides deposited by filtered arc [110].

\begin{tabular}{|c|c|c|}
\hline Film & $n_{633 \mathrm{~nm}}$ & $\mathrm{~K}_{633 \mathrm{~nm}}$ \\
\hline $\mathrm{Al}_{2} \mathrm{O}_{3}$ & $1.670^{\circ}$ & $<0.0005$ \\
\hline $\begin{array}{l}\mathrm{VO}_{2} \\
\text { (ambient) }\end{array}$ & $\begin{array}{l}3.56 \\
2.56^{*}\end{array}$ & $\begin{array}{l}1.16 \\
0.14^{*}\end{array}$ \\
\hline $\operatorname{VO} 2\left(68^{\circ} \mathrm{C}\right)$ & $\begin{array}{l}2.96 \\
1.57^{*}\end{array}$ & $\begin{array}{l}0.41 \\
1.72 *\end{array}$ \\
\hline $\mathrm{ZrO}_{2}$ & 2.190 & $<0.0015$ \\
\hline $\mathrm{Nb}_{2} \mathrm{O}_{3}$ & 2.17 & $<0.0010$ \\
\hline
\end{tabular}

* At $1 \mu \mathrm{m}$

Films of $\mathrm{ZrO}_{2}$ and $\mathrm{TiO}_{2}$ with absorption in visible spectrum of less than $5 \%$ have been reported by Randhawa [42]. The films had excellent adhesion to both glass and plastic substrates.

Randhawa [111] and Schemmel et al [112] have described the deposition and properties of macro-free $\mathrm{Al}_{2} \mathrm{O}_{3}$ films. A quarter torus described with a full diagram in section 3.4 was used to deflect the ion flux from the arc source. The deposited films exhibit correct stoichiometry, good adhesion, high density, and good optical properties and indicate that rates two to three times higher than can be achieved by r.f. sputtering from an $\mathrm{Al}_{2} \mathrm{O}_{3}$ target can be obtained.

Reactive deposition of titanium nitride (TiN) is presently the most common application of cathodic arc deposition technology. Factors which favourably influence the efficiency of reactions in cathodic arc deposition include the high degree of ionization in the plasma, the existence of substantial numbers of ions in multiple charge states, ion and/or molecule collisions, electron and/or molecule collisions and the energy of the ions at the substrate 
$[27,33,44,113,114]$. While TiN has proved highly successful in a variety of wear and decorative situations, the potential of other hard coatings has been increasingly studied during recent years. Other nitride films which have been deposited by the filtered arc include $\mathrm{VN}, \mathrm{ZrN}, \mathrm{NbN}$ and $\mathrm{Fe}_{3} \mathrm{~N}_{4}[96,115]$.

Randhawa and Johnson [115] have reactively deposited TiN and $\mathrm{ZrN}$ and studied the effect of varying nitrogen pressure at a total chamber pressure of $0.26-1.3 \mathrm{pa}$, on the composition of coatings, lattice parameter, micro-hardness and morphology. The temperatures of the substrate during deposition were $300-450^{\circ} \mathrm{C}$.

Performance of the films was evaluated by conventional wear testing methods and the potential for decorative applications by reflectivity measurements. Wear test results indicated that $\mathrm{ZrN}$ is marginally superior to titanium nitride in conventional metal cutting applications, but outperforms TiN by a factor of two when cutting titanium alloy. Reflectance measurements indicated that $\mathrm{ZrN}$-doped films are very similar to gold films. Zirconium nitride films deposited under the same conditions as TiN exhibit a much lower density of much smaller microdroplets ( approximately $0.1-0.2 \mu \mathrm{m}$ ). It is believed that the smaller microdroplets result from higher melting point and low vapour pressure of zirconium coupled with the higher arc spot velocity observed on the zirconium cathode surface. The higher arc spot velocity results in a low mean residence time of the arc spot on a given localized area and thus minimizes localized overheating and therefore the size and density of the droplets [42]. X-ray diffraction of the $\mathrm{ZrN}$ films indicates a cubic $\mathrm{NaCl}$-type lattice with a high degree of preferred orientation along $\{111\}$.

Nitrides of $\mathrm{Ti}$ and Mo have been prepared with micro-hardnesses of 360 and $2400 \mathrm{Kg}$ $\mathrm{m}^{-2}$ respectively [116]. The properties of TiN are strongly dependent upon the deposition conditions, in particular the substrate and bias. An increase in substrate bias (increasing ion energy) is accompanied by a decrease in lattice constant and a reduction in stress [109]. Similar results reported for r.f. sputter deposition of TiN were interpreted in term of ion peening effects resulting in stress relief [117]. Recent theoretical studies suggest that the film stress may be modified to the degree of particle momentum in the depositing atoms [118].

TiN films prepared by the filtered arc exhibit a greatly enhanced corrosion resistance relative to films prepared by unfiltered arcs. 
Veshina et al. [119] found that $2 \mu \mathrm{m}$ thick $\mathrm{Ti}$ and TiN films provided maximum protection to the surface of brass and steel specimens when placed in corrosive media. Films prepared by the unfiltered arc to thicknesses of $0.6-4.5 \mu \mathrm{m}$ did not withstand corrosion testing due to the porosity caused by the presence of macroparticles .

The effect of axial magnetic field focusing and electron magnification on the synthesis of TiN and MoN were studied by Aksenov et al. [33]. Electron magnetization increased the number of gas atom-electron collisions and hence the degree of ionization of nitrogen, yielding an increased reaction coefficient that correlated well with an increase in the concentration of nitrogen in the deposited films. The microhardness of the deposited coatings increased with an increasing magnetic field.

Martin et al. [109] reported the deposition of carbide films by introducing $\mathrm{CH}_{4}$ into the deposition chamber. Randhawa [41] also reported on the deposition and film properties of $\mathrm{TiC}$ and $\mathrm{TiC}_{\mathrm{x}} \mathrm{N}_{1-\mathrm{x}}$.

TiC films have been deposited by a reactive deposition involving titanium and methane gas $\mathrm{CH}_{4}$, whereas titanium cabrbonitride films $\mathrm{TiCN}$ prepared using titanium and a mixture of $\mathrm{N}_{2}$ and $\mathrm{CH}_{4}$ gases. The TiC films deposited at temperatures of $500^{\circ} \mathrm{C}$ and below were found to contain significant amounts of hydrogen whereas films deposited above $600{ }^{\circ} \mathrm{C}$ were virtually free of hydrogen. The properties of carbide films are adversely affected by the incorporation of hydrogen, which gives rise to embrittlement of the film. The wear characteristics were markedly affected by the presence of hydrogen in the films. $\mathrm{TiC}_{\mathrm{x}} \mathrm{N}_{1-\mathrm{x}}$ films with $\mathrm{x}=0.15-0.30$ were found to be superior to TiN films in actual cutting tests. The erosion test on TiC films deposited at temperatures of $600^{\circ} \mathrm{C}$ and above indicates these coatings to be superior to TiN films [41]. Acetylene $\mathrm{C}_{2} \mathrm{H}_{2}$ is generally preferred during the reactive deposition of carbides because the fragmented fractions are simpler and less hydrogen is evolved during the reaction [43]. Generally, high ionization efficiencies are needed for the deposition of carbide films. This makes a cathodic arc source an obvious choice for deposition of these films because of the high degree of ionization in the vapour flux and high ion energies.

Martin et al [109] have used a reactive filtered arc process to deposit macroparticle- free TiC films. TiC films were prepared by reactive evaporation of titanium in a methane gas $\mathrm{CH}_{4}$. The conditions for the deposition of stoichiometric $\mathrm{TiC}$ films were established from $\mathrm{X}$-ray photoelectron spectroscopy measurements of the $\mathrm{Ti}: \mathrm{C}$ ratio.These conditions 
corresponded to a substrate temperature of $350^{\circ} \mathrm{C}, \mathrm{a} \mathrm{CH}_{4}$ partial pressure of $0.5 \mathrm{pa}$, and a deposition rate of $0.5-1.0 \mathrm{~nm} \mathrm{~s}^{-1}$. A comparison has been made between $\mathrm{TiN}$ and $\mathrm{TiC}$ films under the same deposition conditions [109]. The structural properties of both TiN andTiC were found to depend on the degree of negative bias applied to the substrate during deposition. The lattice constant for $\mathrm{TiN}$ was found to decrease with bias, indicating that the stress is reduced whereas the opposite effect was observed in the deposition of TiC. This effect has also been observed in TiC films deposited by reactive r.f. sputtering [117]. It was also reported that bulk lattice constant values were seen at low substrate bias. The effect was believed to be related to the increase in interstitial carbon expanding the lattice with increasing negative substrate bias. The optical properties of the TiC films are shown in figure 3. 8. The refractive index ranges from 2.7 at $400 \mathrm{~nm}$ to a maximum of approximately 3.5 at $700 \mathrm{~nm}$. The extinction coefficient is relatively constant compared with TiN and is approximately $2.4-2.5$ over the measured range. The reflectance of $\mathrm{TiC}$ was found to be around $40 \%$ over the entire range. The micro-hardness of the TiC films was typically $3600 \mathrm{Hv}_{10}$, in close agreement with other data on arc deposited TiC films by Randhawa [41].

Randhawa et al. [108] described the deposition and properties of ternary nitrides such as TiZrN and TiAlN and compared the performance of these films with the performance of TiN and (Ti-6Al-4V)N films prepared under the same deposition process. The greatest hardness was obtained for $\mathrm{Ti}_{25} \mathrm{Zr}_{75} \mathrm{~N}$ films $\left(3.350 \mathrm{Kg} / \mathrm{mm}^{2}\right)$ while the best hardness observed for TiAlN films did not exceed $2.650 \mathrm{Kg} / \mathrm{mm}^{2}$. The performance of TiZrN was very similar to that of TiN in drilling tests. The TiAlN films provided significantly superior performance, however, exceeding the cutting life of TiN by more than two times under the same cutting conditions. Randhawa et al. [42, 108] compared the results of colorimeter tests on a variety of ternary nitrides with those of $10 \mathrm{~K}$ and $24 \mathrm{~K}$ gold. The observations confirm that color comparable to a variety of gold colors may be achieved. The results on $(\mathrm{Ti}, \mathrm{Al})$ nitrides as well $(\mathrm{TiZr}) \mathrm{N}$ show that these films have excellent wear as well as decorative properties.

Freller and Haessler [120] compared TiAlN films deposited by cathodic arc and magnetron sputter ion plating. While the arc-deposited films were somewhat depleted in aluminum, the sputtered films were slightly enriched compared to the target alloy composition. The aluminum depletion in the case of arc-deposited films was strongly. related to the bias applied to the substrate during coating; this phenomenon offers interesting possibilities for changing the composition of coatings during deposition. 
Johansen et al. [120] have studied the morphology, composition, and crystal orientation of arc-deposited TiN, HfN and $\mathrm{ZrN}$ films. HfN proved to be the hardest coating, but also the most sensitive to deposition conditions. Scratch tests indicated that adhesion and film stength varied inversely with hardness. TiN was the least sensitive to parameter variation.

Erturk et al. [78] have prepared $\mathrm{CrN}$ and $(\mathrm{Ti}, \mathrm{Al}) \mathrm{N}$ coatings deposited using the random arc and steered arc techniques. When compared with TiN, CrN coatings are characterized by the fact that they can be deposited as thick, very dense coatings of up to $60 \mu \mathrm{m}$. They exhibit high hardness values of up to $2900 \mathrm{HK}_{0.05}$, very good toughness, relatively smooth coatings and, even in the range of a high coating thickness, lower friction coefficients. At high temperatures they show improved oxidation behaviour in the 400 $750^{\circ} \mathrm{C}$ range, better corrosion resistance in the salt spray test and higher deposition rates.

The (Ti,Al)N coatings have been produced at high deposition rates. A loss of aluminium takes place during a coating phase. Maximum hardness values of up to $3400 \mathrm{HK}_{0.05}$ are attained for coatings with 12 at $\% \mathrm{Al}$. With increasing aluminium content there is an increase in roughness, which is lower on the whole in steered arc coatings.

Boelens and Veltrop [70] have prepared hard coatings of TiN, (TiHf)N and (TiNb)N deposited by random and steered arc evaporation. The conventional arc evaporation process with a random moving cathode spot was modified to minimize the ejection of solid particles from the cathode spot using steered arc evaporation. The potential of steered arc evaporation has been shown under practical machining conditions by depositing TiN and ternary coatings. The TiN coatings $(6-7 \mu \mathrm{m}$ thick) deposited by steered arc evaporation perform better than do TiN coatings (6-7 $\mu \mathrm{m}$ thick) deposited by conventional random arc evaporation, and perform comparably with TiC-TiN coatings (10 $\mu \mathrm{m}$ thick) deposited by chemical vapour deposition (CVD). Inserts coated with ternary coatings of $\mathrm{Ti}_{0.94} \mathrm{Hf}_{0.06} \mathrm{~N}\left(2.5 \mu \mathrm{m}\right.$ thick) and $\mathrm{Ti}_{0.92} \mathrm{Nb}_{0.08} \mathrm{~N}(4.9 \mu \mathrm{m}$ thick) showed lower flank wear than did inserts coated with TiN $(2.5 \mu \mathrm{m}$ thick). 

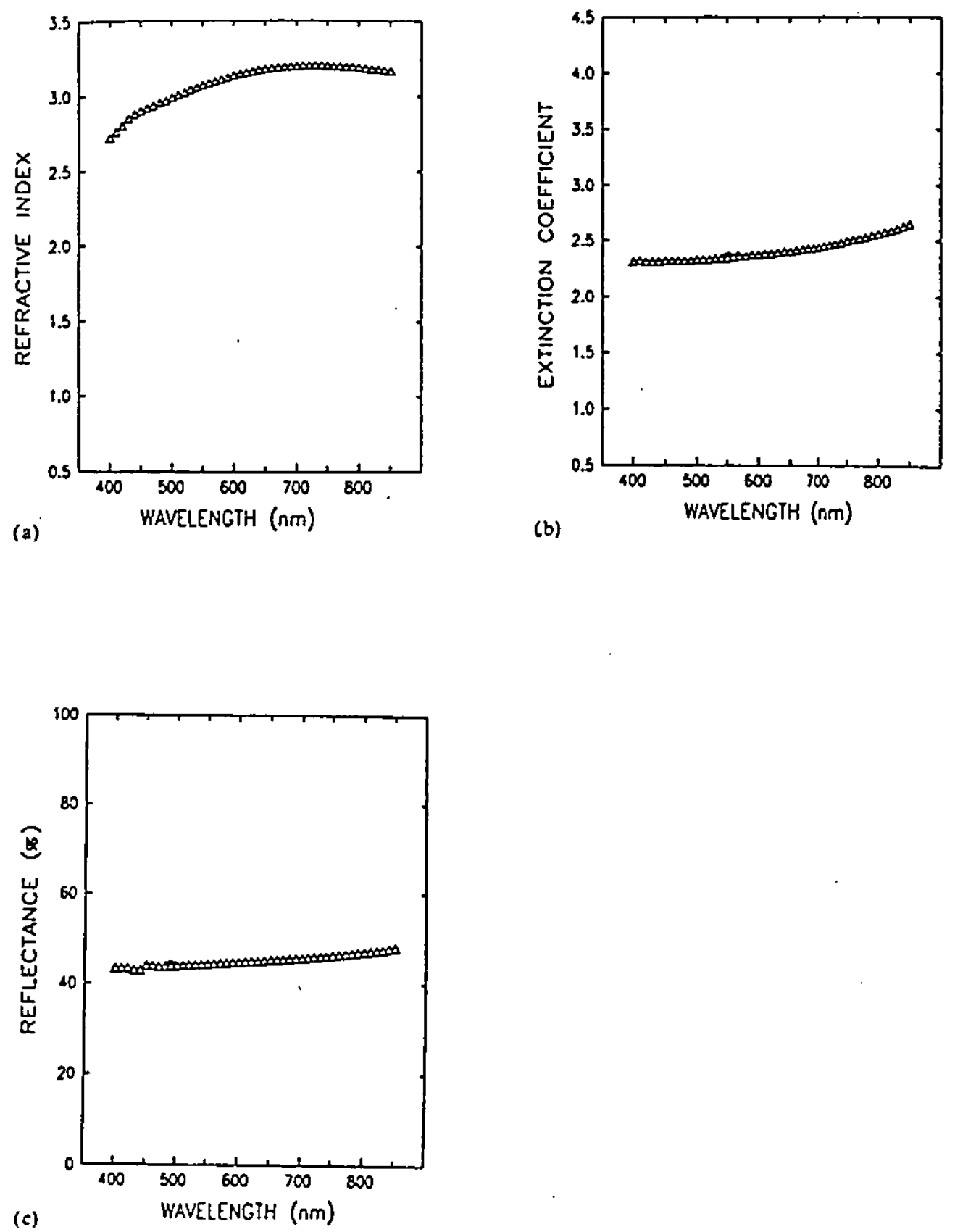

Figure 3.8 The optical properties of the TiC films [109]. (a) Refractive index vs. wavelength, (b) Extinction coefficient vs. wavelength, and (c) Reflectance vs. wavelength. 


\subsection{FILTERED ARC}

\subsubsection{Magnetic filtering}

Several types of magnetic filtering devices have been described in the patent and scientific literature $[104,121,122]$. These devices used magnetic fields of varying complexity to filter the macroparticles normally produced by the cathodic arc source.

Aksenovet al [104] invented an arc plasma generator and a plasma arc apparatus for treating the surfaces of work-pieces, incorporating the same arc plasma generator wherein the electromagnetic system is so constructed that by separating in space the components of the plasma stream in a magnetic field an effective removal of macroparticles from the plasma stream is achieved. Figure 3.9 shows the arc plasma generator used by Aksenov [104].

Sanders and Falabella [121] have developed two macroparticle-filtered cathodic arc sources for use in high-rate coating metals, and reactively produced oxides and nitrides. They found that the flux-tube model of plasma transport to adequately explain the behaviour of these sources and have determined that baffles can be used to protect substrates from macroparticles bouncing off the chamber walls.

The knee source has been shown to operate reliably for many tens of minutes at a time, and can use target materials efficiently, even difficult materials such as graphite. The ion transmission through both filters is improved by adding an anode at the exit of the macroparticle filter, and carrying a portion of the arc through the filter. This current also ionizes any background gas in the chamber, and may improve reactive coatings.Figure 3.10 shows the two arc sources used by Sanders et al [121]. 


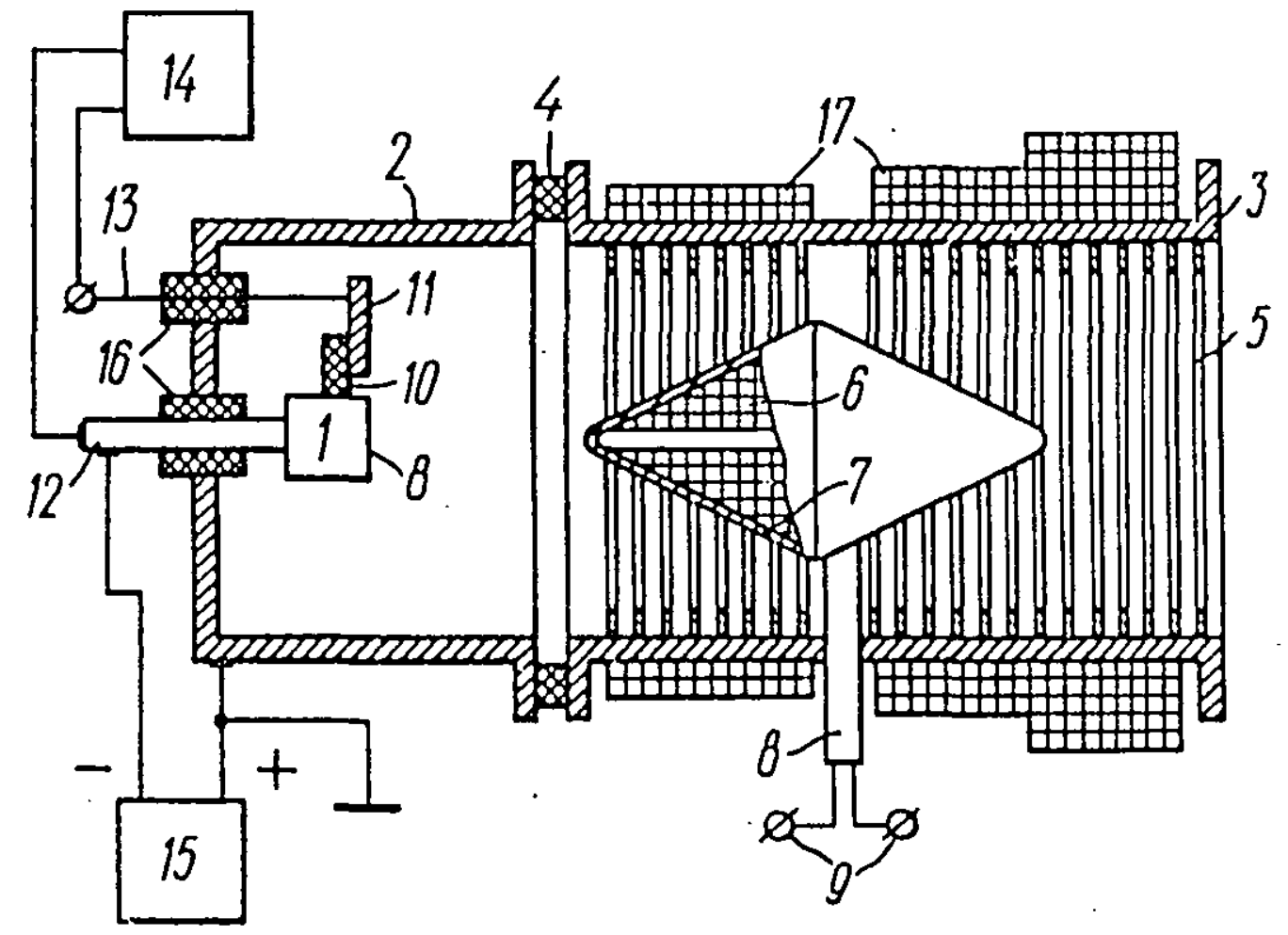

Figure 3.9. Arc plasma generator [104]:

1.A consumable cathode

2. A cylindrical anode

3. A tubular plasma guide

4. Insulator

5. Ribs

6. Electromagnet

7. A nonmagnetic steel housing for electromagnet

8. Hollow prop

9. Leads

10. Ceramic connecting strip

11. Ignition electrode

$12 \& 13$. Designate leads for supplying ignition pulses

14. Ignition pulse generator

15. Arc power supply

16. Dielectric seals

17. Focusing solenoid 


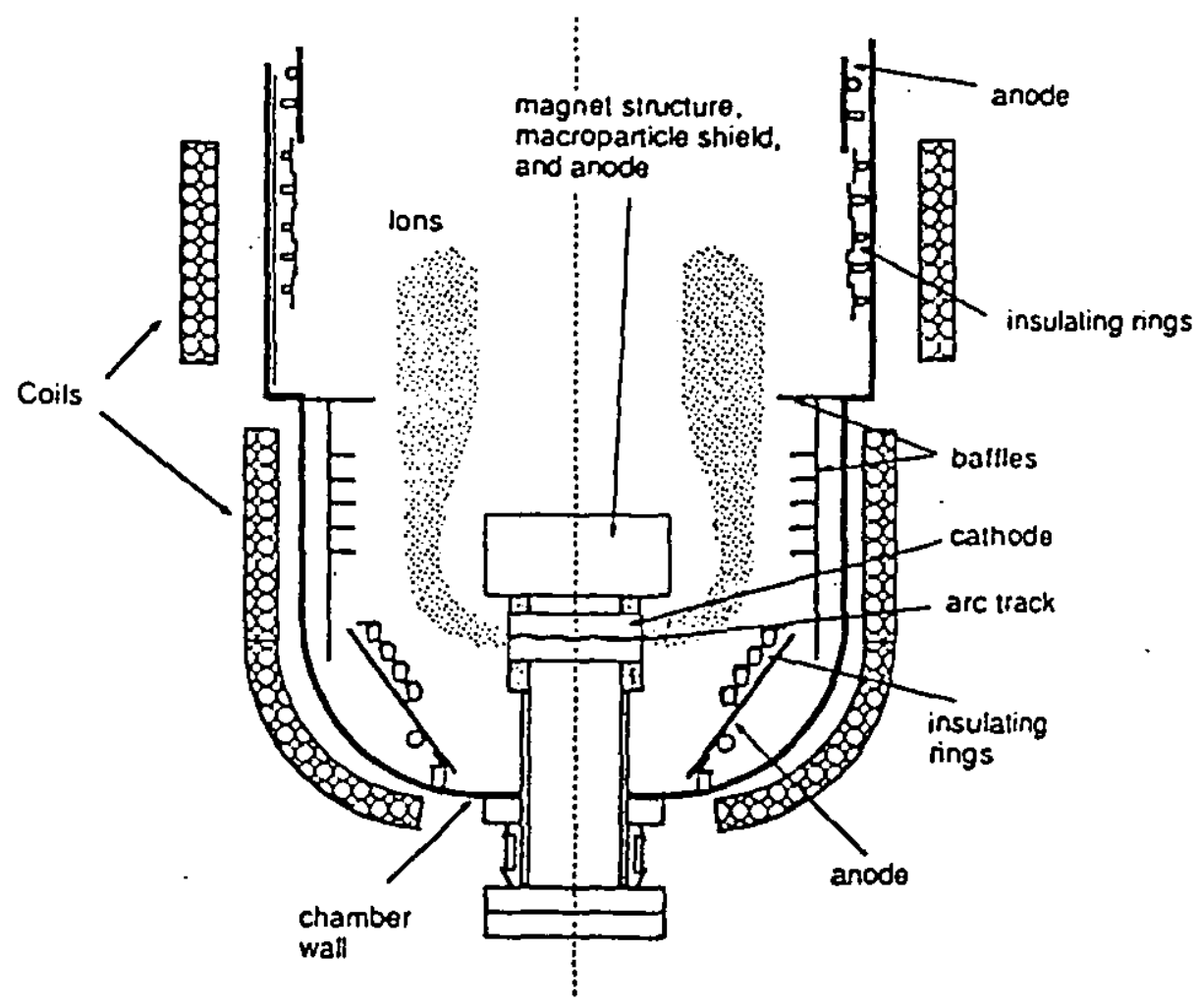

a) 


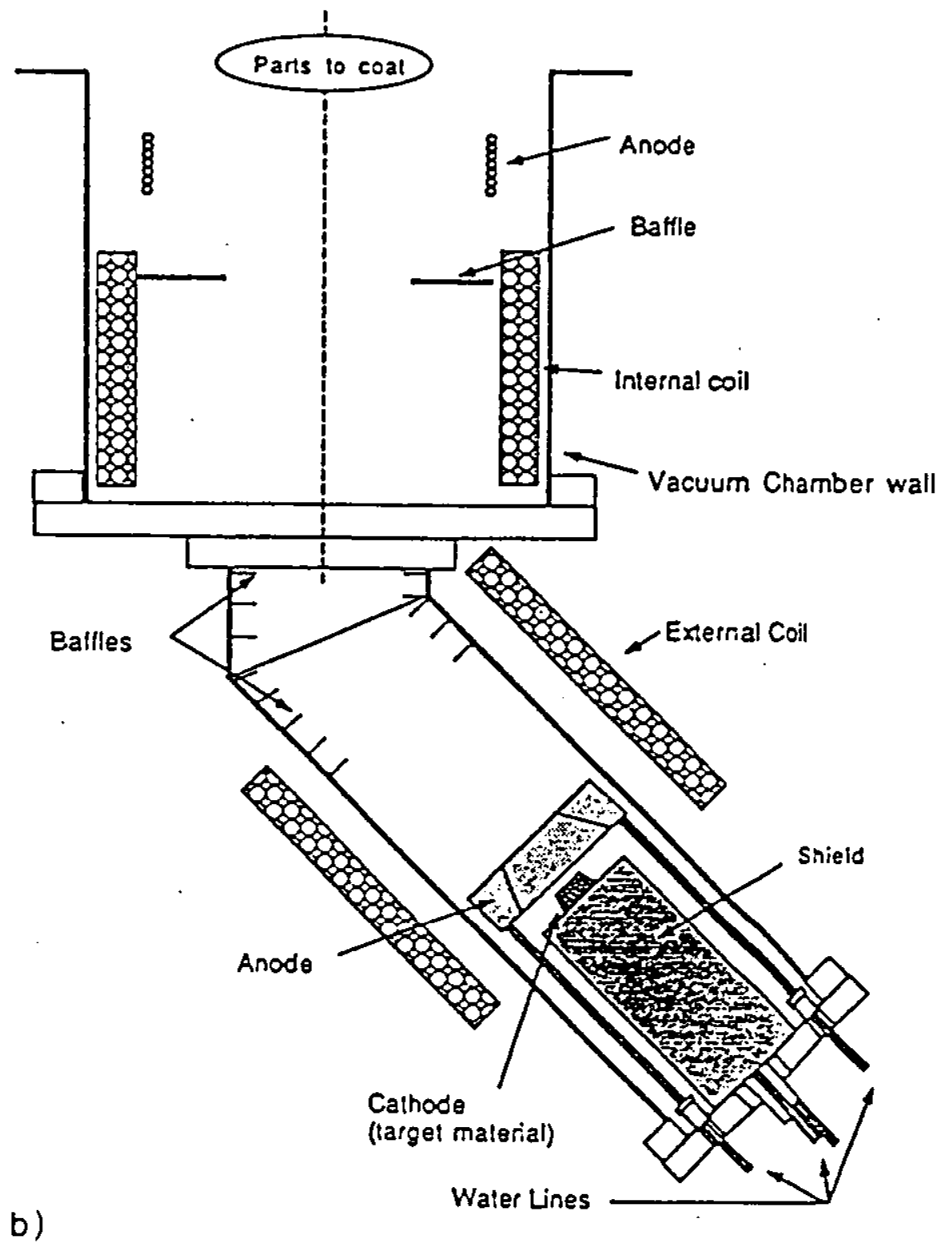

Figure 3.10.(a) schematic diagram of the cathodic-arc Dome source. Ions leave the cathode target radially, and then are turned by the combination of magnetic and electric fields. The baffles prevent macroparticles from bouncing off the walls and reaching the substrates to be coated.

(b) Schematic diagram of the Knee cathodic-arc source. Ions leave the cathode and travel through a $45^{\circ}$ bend to separate macroparticles. Electrons flowing to the ring anode in the chamber produced the electrostatic field that guides the ions [121]. 


\subsubsection{Magnetic plasma duct}

It was first demonstrated by Aksenov and co-workers [101,103,123,124] that a toroidal magnetic field may be used to remove neutrals and macroparticles from an arc source figure 3.11. The technology was developed from the early work on impurity removal from hydrogen plasmas $[125,126]$. The analogous problem of removing neutral and macroparticles has arisen as a result of the development of high-energy plasma technological methods. For example, in the deposition of thin films in vacuum by condensation from a plasma stream produced by a vacuum arc with a cold cathode, it is frequently necessary to remove macrodroplets from the plasma stream. The plasma duct filter is a quarter torus with a magnetic field parallel to the walls of the torus. The condition for transporting a stream a stream of low-density plasma along a toroidal field is given by :

$$
\mathrm{r} / \mathrm{u}>\mathrm{L} / \mathrm{v}_{0} \quad \text { where } \quad \mathrm{u}=\left(\mathrm{M} \mathrm{C} \mathrm{v}_{0}{ }^{2}\right) /(\mathrm{Ze} \mathrm{R} \mathrm{H})
$$

where ;

$\mathrm{u}$
$\mathrm{M}, \mathrm{Z}$ and $\mathrm{v}_{0}$
$\mathrm{R}$
$\mathrm{L}$
$\mathrm{r}$

is the velocity of the centrifugal ion drift in the field, are the mass, charge and longitudinal velocity respectively of the ions, is the radius of curvature of the magnetic lines of force, is the length of the toroidal field and the radius of the plasma duct.

It is not difficult to see that strong magnetic fields are required for the transport of plasma or heavy metals. For example, in a toroidal-field region of length $L=R$ with $r=4 \mathrm{~cm}$ a titanium plasma with an ion energy $E / Z=50 \mathrm{eV}$ ( a typical value for the plasma of a titanium vacuum arc ), then a magnetic field of the order of $2 T$ is necessary [103].

For this reason, the experimental apparatus described cannot provide purely magnetic control of the plasma stream. At the maximum magnetic field, with the plasma duct grounded, so that there is essentially no electric field in the system, the ion current at the exit from the system does not exceed $50 \mathrm{~mA}$. Aksenov and co-workers found that if the duct was biased positively to $15-20 \mathrm{~V}$ then the saturation Ti ion current at the exit of the system increased from $400 \mathrm{~mA}$ to $900 \mathrm{~mA}$ due to plasma-optical focusing effects. 
In the case of crossed electric and magnetic fields the necessary magnetic field value is obtained from the requirement :

$$
\rho_{c<<a} \rho_{i}
$$

where :

$\rho_{\mathrm{e}}, \rho_{\mathrm{i}} \quad$ are the electron and ion Larmor radii respectively and

a the radius of the duct. The magnetic field is reduced to the order of 0.02-0.08T [96].

Figure 3.12 shows the electron and ion Larmor orbits in a magnetic field [127].

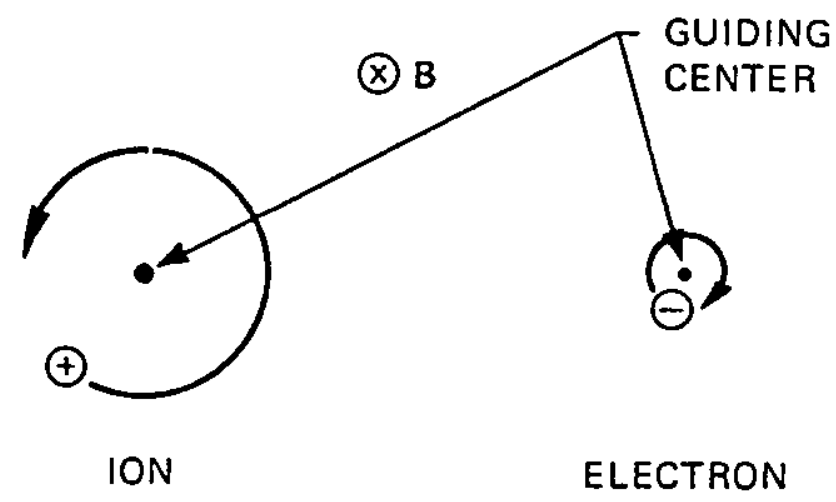

Figure 3.12. The electron and ion Larmor orbits in a magnetic field [127]. 


\subsubsection{MOTION OF PLASMA IN THE PLASMA DUCT}

The motion of charged particles in magnetic and electric fields is defined by Maxwell's equations [83]. Detailed solutions for simple fields are given in texts on plasma physics $[128,129]$.

According to these solutions, electrons are expected to move freely along the magnetic field lines while spiraling around them. The spiraling radius for the heavier positive ions, on the other hand, is substantially larger. For this reason, the ions are relatively unaffected directly by the magnetic fields. There is, however, a strong electrostatic attraction between the positive ions and the negative electrons causing the ions to be pulled along by the electrons. The strategy, then, is to control the ions by controlling the path of the electrons. The solenoid provides a sort of curved pipe which transmits both the ions and the electrons from the source to the substrate.

Storer et al. [130] studied the transport of iron through straight and curved magnetic ducts and found the transmission increased with magnetic strength and saturated at a field at which the ion gyroradius is approximately equal to the radius of the plasma duct. They found that the optimum field strength for coupling the maximum amount of plasma from the metal -ion plasma generator into the duct, was about $0.015 \mathrm{~T}$.

Sanders et al. [9] have modelled the plasma flow in a toroidal plasma guide using the flux-tube model originated by Morozov [131, 132] and used to describe ion motion in macroparticle filter by Aksenov and his co-workers [103, 124,133]. Figure 3.13 shows the projection onto the equatorial plane of the torus of 50 orbits randomly selected from a calculation of the trajectories of $1000 \mathrm{Ti}^{+}$. The ions were all ejected from a point source on the center line of the solenoid.

Their initial speeds were selected from a $23-\mathrm{eV}$ Maxwellian centered about $65 \mathrm{eV}$, and their directions were taken from a $\cos ^{2}$ distribution. The torus had a radius of curvature of $21.8 \mathrm{~cm}$ and the solenoid radius of $3.9 \mathrm{~cm}$, conditions approximating to those of the original Aksenov device. The patterns made by the ions as they enter and leave the toroidal guide section are shown in figure 3.14 (a) and (b) [9]. 


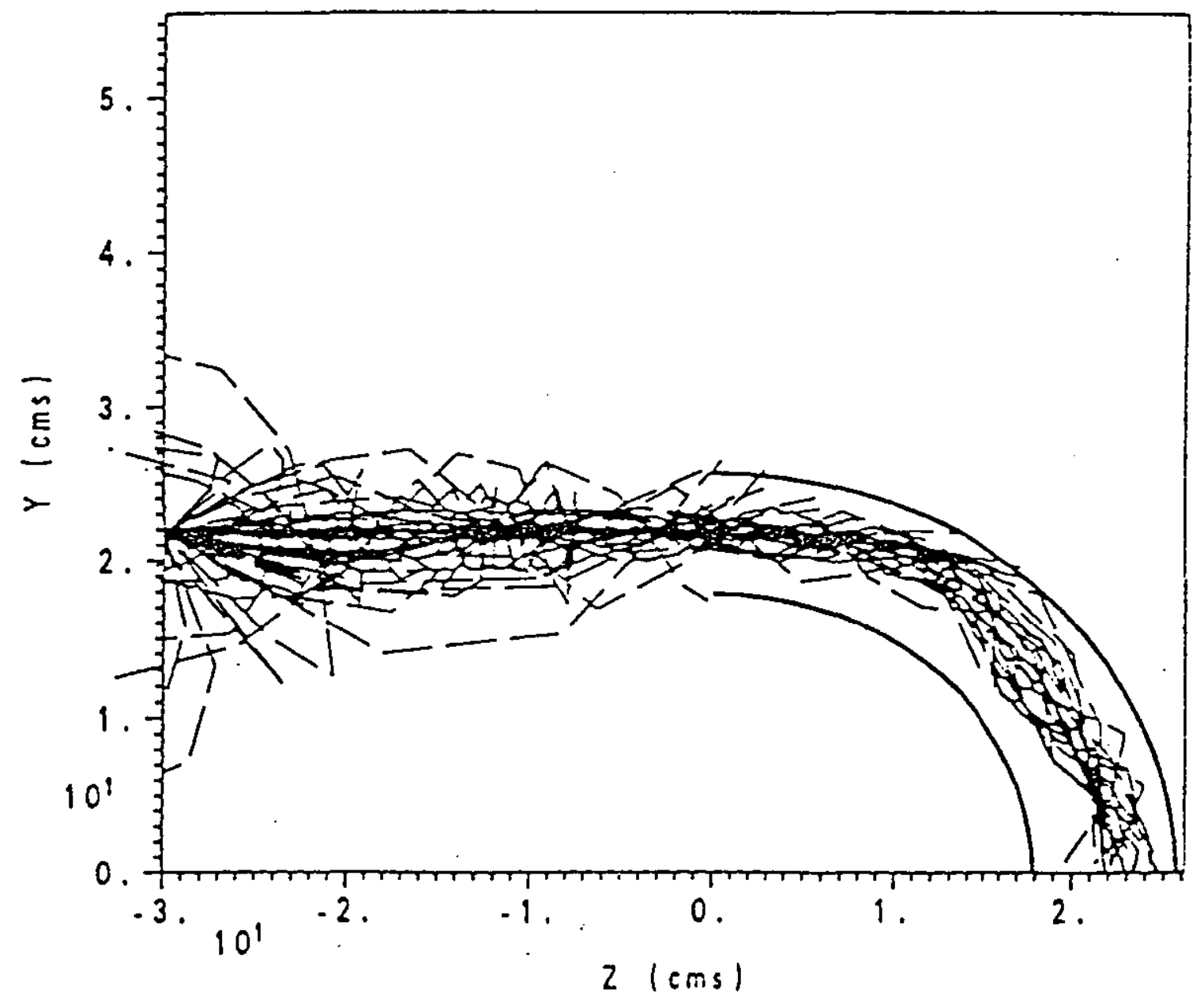

Figure 3.13 Trajectories of $\mathrm{Ti}^{+1}$ through an Aksenov filter. The two dark arcs represent the quarter torus [9]. 


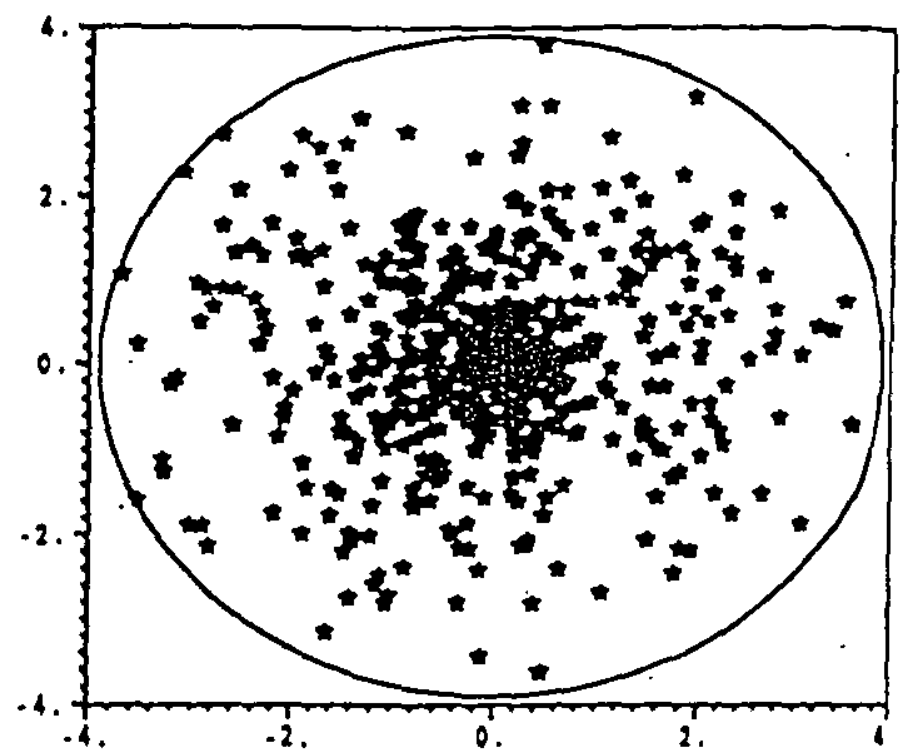

(a)

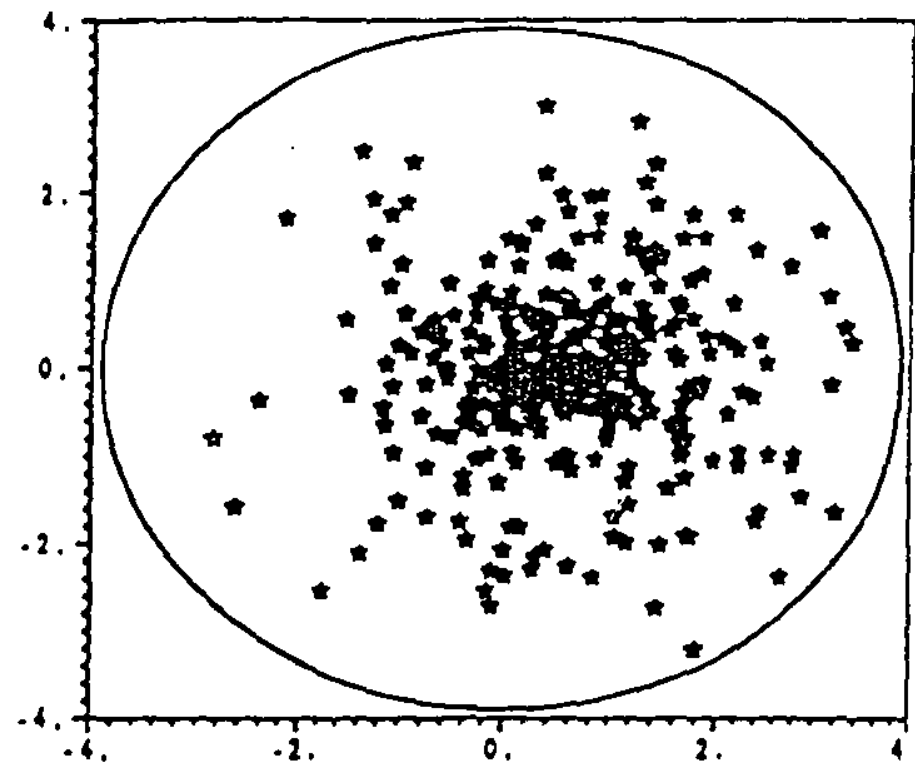

(b)

Figure 3.14. Patterns made by the ions as they (a) enter, and (b) leave the quarter torus [9]. 
The main conclusion reached was that the efficiency of the filter saturated with increasing duct potential and that a maximum total efficiency of $59 \%$ was achieved for a duct potential of $70 \mathrm{~V}$. Several researchers have constructed filtered arc devices based on the magnetic plasma duct with cathode diameters ranging from $15 \mathrm{~mm}$ to $100 \mathrm{~mm}$ $[101,110,112,121]$. The devices have been successfully used in the deposition of metals, alloys, compounds and diamond-like carbon.

Randhawa et al. [112] have described an apparatus to deposit $\mathrm{Al}_{2} \mathrm{O}_{3}$ films from the plasma flux generated from an arc source that is passed through one fourth of an electro-magetic torus. Figure 3.15 shows the cathodic arc filter apparatus used by Randhawa et al. [112]. The axial magnetic field (A) confines electrons in the plasma to helical paths along the axis of the torus. The radial electric field (B) forces the aluminum ions to the central region along the torus.

The neutral particles and macro-particles are not influenced by the electrostatic or magnetic fields, and thus are condensed on the walls of the torus. This gives rise to material flux at the exit port (C) which is very highly ionized [123] and free of macro-particles. 


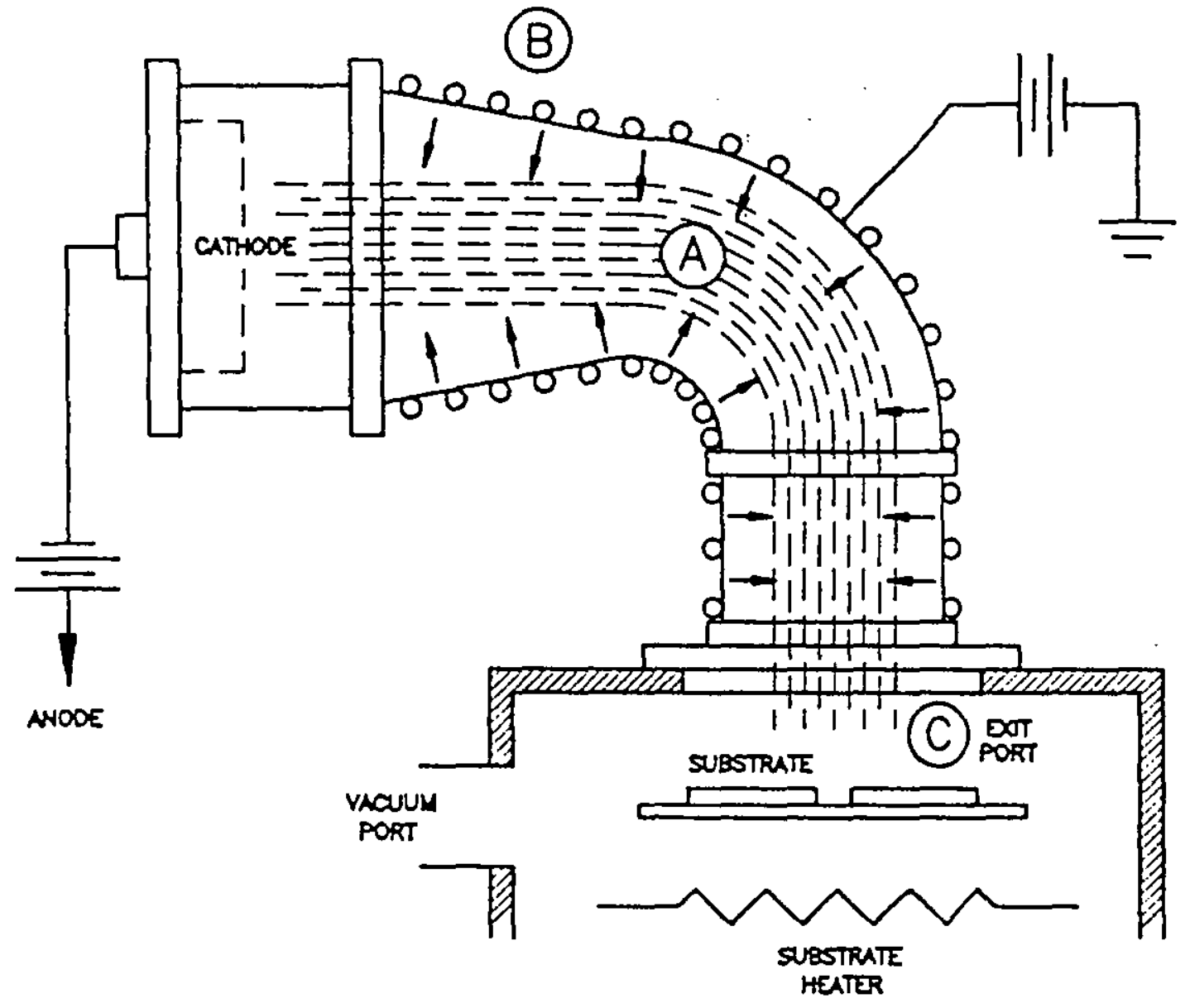

Figure 3.15 The cathodic arc filter apparatus used by Randhawa et al [112]. 


\subsubsection{INDUCED ION BOMBARDMENT}

The properties of thin films deposited by physical vapour deposition techniques, are frequently inferior to those of the bulk material [96]. The films may have a columnar structure and voids with low packing density, reduced refractive index in the case of dielectric optical films, high porosity and low stability, due to the adsorption of water vapour [134].

Conventional thermal evaporation produces atoms of the source material in the vapour state with energies in the range of 0.1 to $0.6 \mathrm{eV}$. Sputtering improves upon these energies, emitting atoms with energies in the range of 4.0 to $10 \mathrm{eV}$. This level of deposition energy, however, still falls short of that needed to produce the levels of adhesion and film properties required [43]. In the case of low-energy deposition such as sputtering and electron beam evaporation, neutral atoms of the coating material arrive at the substrate surface and deposit on top of that surface. Since they have limited energy to contribute to atomic mobility after condensation, particularly during room-temperature deposition, the atoms stick at the point where they arrive. If the substrate surface has adsorbed contamination atoms between the substrate and coating, the resulting coating may have poor adhesion [71]. The result of the lack of atomic mobility is predicted to be a coating of poor density, filled with voids and inpurity atoms as shown in figure 3.16 (a).

The properties and structure of the deposited coating in both the above cases, can be modified by increasing the substrate temperature during deposition, or by applying a bias to the substrate. The nature of the substrate, in many circumstances, limits the temperature that can be used.

The properties of deposited films are greatly improved when the growing film is bombarded with energetic particles, such that an ideal deposition process requires a high flux of film atoms with an energy of approximately $5.50 \mathrm{eV}$ in order to achieve sufficient surface mobility at the substrate to overcome columnar growth and eliminate large volume voids. Ion bombardment during cathodic arc deposition provides sufficient activation energy for control of film morphology. Films deposited by the process exhibit a small-size, equiaxed crystalline structure. The normally less desirable columnar structure is very rarely encountered [43]. 
Adhesion is defined by the work done to separate atoms or molecules of the interface between the film and the substrate [135]. This interface can be identified in terms of mechanical, monolayer-on-monolayer, chemical bonding, diffusion and pseudo-diffusion interface layers. Adhesion of the film to the substrate can be improved remarkably by energetic ion bombardment.

The cathodic arc process produces films having good adhesion resulting from the deposition energies of the ions. High ion energy results in strong atom-to-atom bonding, some degree of surface intermixing at the coating-substrate interface, and elimination of voids at the interface.

The evolution of the microstructure of titanium films deposited by arc evaporation was investigated by Molecular Dynamics ( MD ) simulations [67]. Computational time restricted the film growth to a two-dimensional growth cell where the film extends in the $\mathrm{x}$ direction and grows in the $\mathrm{z}$ direction. The substrate consisted of packed rows of 40 atoms each and of the same species as the film material. Atoms and ions were randomly introduced at successive intervals into the growth cell from the top [67]. The simulation in figure 3.16 (a) shows the microstructure typical for titanium atoms arriving with thermal velocities ( no $\mathrm{Ti}^{+}$bombards the growing film). The energy of the titanium vapour was selected to be $0.1 \mathrm{eV}$. The low incident velocity, and hence small impact mobility of arriving adatoms, promotes microporosity in the growing film. When energetic $\mathrm{Ti}^{+}$ions of $50 \mathrm{eV}$ are introduced into the simulation cell the microstructure that evolves depends on the ion -to- atom arrival rate ratio $\mathrm{j}_{\mathrm{Ti}+}: \mathrm{j} \mathrm{Ti}$.

Figure 3.16 (b) shows the result obtained for $\mathrm{j}_{\mathrm{Ti+}}: \mathrm{j}_{\mathrm{Ti}}=0.16$ where it is seen that the microvoids are greatly reduced [67].

In summary, the benefits of ion bombardment of growing films are well established in the cathodic arc deposition process. They include increased surface mobility of adatoms, formation of dense film structures, good adhesion, desorption of weakly bound species. The energy delivered by ion bombardment allows good films to be grown at low substrate temperatures [93]. 


$$
\mathrm{Ti} \downarrow \text { (no ions) }
$$

(a)
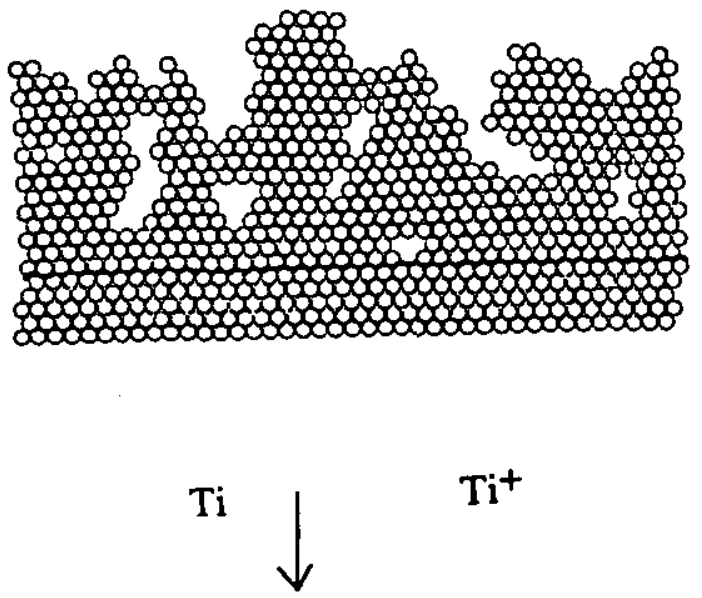

(b)

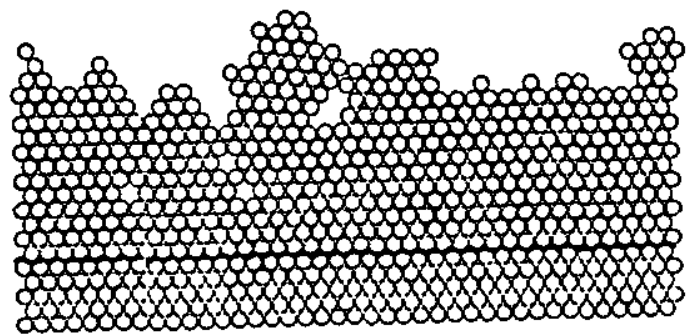

Figure 3.16. Results of a molecular dynamic modeling calculation carried out by Martin et al in Reference [67]. Microstructures obtained for titanium deposition with atom incident energy of $0.1 \mathrm{eV}$ arriving at normal incidence.

(a) No $\mathrm{Ti}^{+}$bombardment, low energy. Sputtering and electron beam evaporation coating atoms are neutral and have limited energy to contribute to atomic mobility after condensation.

(b) $\mathrm{E}_{\mathrm{Ti}^{+}}=50 \mathrm{eV}, \mathrm{j} \mathrm{Ti}^{+}: \mathrm{jTi}=0.16$. High energy. The arc processes produce positive ions which can be accelerated into the part to be coated. Increased atomic mobility can result in improved properties as described in the text. 


\subsubsection{CATHODIC ARC DEPOSITED FILMS}

The filtered arc has been used to deposit a wide range of high quality materials free from macrodroplets. A selection of materials deposited are listed below.

Metals $\quad: \quad \mathrm{Cu}, \mathrm{Al}, \mathrm{Ti}, \mathrm{Cr}, \mathrm{Zr}, \mathrm{Ta}, \mathrm{W}, \mathrm{Mo}, \mathrm{Hf}, \mathrm{Ni}$.

Alloys : SS-304, $\mathrm{Ti}_{6} \mathrm{Al}_{4} \mathrm{~V}$, High Ni alloys, Inconel, MCrAl Y's, Nichrome, Titanium alloys.

Nitrides $\quad: \quad T$ TiN, ZrN, HfN, $\mathrm{Ti}_{6} \mathrm{Al}_{4} \mathrm{VN}, \mathrm{TaN}, \mathrm{CrN},(\mathrm{TiZr}) \mathrm{N},(\mathrm{TiAl}) \mathrm{N}$.

Carbides $\quad$ : TiC, TaC, WC, ZrC, HfC.

Carbonitrides: $\quad \mathrm{TiCN},(\mathrm{Ti}-\mathrm{Zr}$ ) $\mathrm{CN}, \mathrm{ZrCN}, \mathrm{TaCN}$.

Oxides $\quad: \quad \mathrm{CuO}, \mathrm{TiO}_{2}, \mathrm{ZrO}_{2}, \mathrm{Al}_{2} \mathrm{O}_{3}$.

Multi-layer coatings : Infinite combinations.

Diamond-Like Coatings : DLC.

\subsection{SUMMARY}

The fundamentals and features of cathodic arc deposition technology are described.

In terms of thin film deposition, the most interesting properties of the arc process are ;

(i) average charge state per ion,

(ii) ion fraction and (iii) ion energy.

The most effective method of producing macroparticle-free coatings is seen to be the filtered arc evaporation process using a magnetic plasma duct. The other filtering methods have varying degrees of success and may also be incorporated in a magnetic duct system to further improve the arc system. 


\section{REFERENCES}

[1]. H. Randhawa and P. C. Johnson, A review, Surface and Coatings Technology, 31, p.303 (1987).

[2]. H. Randhawa, J. Vac. Sci. Technol. A, 4 (6), p.2755 (1986) .

[3]. R. F. Bunshah, in R. F. Bunshah (ed.), Deposition technologies for thin films and coatings, Noyes, (1982).

[4]. J. L. Vossen and W. Kern (eds). Thin Film Processes, Academic press, New York, (1978).

[5]. J. A. Thornton, in R. F. Bunshah (ed.), Deposition technologies for thin films and coatings, Noyes, (1982).

[6]. W. D. Sproul, Thin Solid Films, 118, p.279 (1984).

[7]. E. Moll, R. Buhl, H. K. Pulker and E. Bergmann. Activated Reactive Ion Plating (ARIP). Surface and Coatings Technology, 39/40, pp.475-486 (1989).

[8]. D. M. Mattox, Electrochem. Technol., 2, p.295 (1964).

[9]. D.M.Sanders, D.B.Boercker, and S. Falabella. Coating technology based on the vacuum arc.A review, IEEE Transactions on Plasma Science, vol. 18, No.6, Dec.(1990).

[10]. J. D. Cobine, "Introduction to vacuum arcs", in Vacuum Arcs: Theory and Application, J. M. Lafferty, (ed.), New York: Wiley, pp1-18 (1980).

[11]. C. W. Kimblin, " A review of arcing phenomena in vacuum and in the transition to atmospheric pressure arcs", IEEE Trans. Plasma Science, vol.PS10, pp.322-330, Aug. (1982).

[12]. J. Vyskocil and J. Musil. Arc evaporation of hard coatings process and film properties. Surf. coat. Technol., 43/44, 299-311(1990).

[13]. P.W. Hatto and D. G. Teer. Ion plating with an arc source. Vacuum/ vol.36, no.1-3, pp. 67-69 (1986).

[14]. A.A.Plyutto, V.N.Ryzhkov and A.T.Kapin, High speed plasma streams in vacuum arcs, Sov. Phys. -JETP, 20, pp. 328-337 (1965).

[15]. J.E. Daalder, Random walk of cathode arc spots in vacuum, J. Phys. D, 16 pp.17-27 (1983) .

[16]. M.S. Agarwal and R. Holmes, Arcing voltage of the metal vapour vacuum arc, J. Phys. D, 17 , pp.757-767 (1984).

[17]. W. D. Davis and H. C. Miller, Analysis of the electrode products emitted by a dc arc in a vacuum ambient, J. Appl. Phys., 40, pp.2212-2222 (1969).

[18]. C.W. Kimblin, Erosion and ionization in the cathode spot regions of vacuum arcs, J. Appl. Phys., 44 , pp.3074-3081 (1973) . 
[19]. T. Utsumi, Measurements of cathode spot temperatures in vacuum arcs, Appl. Phys. Lett., 18, pp. 218-220 (1971).

[20]. E. Hantzsche and B. Juttner, Current density in arc spots, IEEE Trans. Plasma Science, 13, pp. 230-234 (1985).

[21]. D. Y. Fang, Cathode spot velocity of vacuum arcs, J. Phys. D, 15, pp. 833-844 (1982).

[22]. A. M. Dorodnov and B. A. Petrosov, Physical principles and types of technical vacuum plasma devices, Sov. Phys. Tech. Phys., 26, pp. 304-315 (1981).

[23]. J.E. Daalder, Components of cathode erosion in vacuum arcs, J. Phys. D, 9 pp.2379-2395 (1976).

[24]. C.W. Kimblin, Vacuum arc currents and electrode phenomena, Proc. IEEE, pp. 546-555 (April, 1974).

[25]. V. M. Lunev, V.D. Orcharvenko and V.M. Khoroshikh, Plasma properties of a metal vacuum arc I and II, Sov. Phys. Tech. Phys., 22, pp. 855-861 (1978).

[26]. J. T. Tuma, C. L. Chen and D. K. Davies, Erosion products from the cathode spot region of a copper vacuum arc, J. Appl. Phys., 49, pp.3821-3831 (1978).

[27]. A. M. Dorodnov, Technical applications of plasma accelerators, So. Phys. Tech. Phys., 23, pp. 1058-1063 (1978) .

[28]. V. E. Strel'nitskii, V.G.Padalka and S.I. Vakula, Properties of the diamond-like carbon films produced by the condensation of a plasma stream with an r.f. potential, Sov. Phys. Tech. Phys., 23, pp. 222-224 (1978).

[29]. H.C. Miller, "On sputtering in vacuum arcs", J. Phys. D, 12 , pp. 1293-1298 (1979).

[30]. L. P. Harris, chapter (4) in J. M. Lafferty (ed.), Arc cathode phenomena, Wiley-Interscience, New York, pp. 127-128 (1980).

[31]. V.M. Lunev, V.G. Padalka and V. M. Khoroshikh, Use of a monopole massspectrometer for investigating the ion component of a plasma stream generated by a vacuum arc, Instrum. Exp. Tech., 19, pp. 1465-1467 (1976).

[32]. I. I. Aksenov, V.G. Bren', V.G. Padalka and V.M Khoroshikh, Mechanism shaping the ion enrgy distribution in the plasma of a vacuum arc, Sov. Tech. Phys. Lett., 7, pp.497-499 (1982).

[33]. I. I. Aksenov, Yup. Antufev, V.G. Bren', V.G. Padalka, A.I. Popov and V.M Khoroshikh, Effect of electron magnetization in vacuum-arc plasma on the kinetics of the synthesis of nitrogen-containing coatings, Sov. Phys. Tech. Phys., 26, pp. 184-187 (1981). 
[34] I. I. Aksenov, V.G. Bren', V.G. Padalka, and V.M Khoroshikh, Mechanism shaping the ion energy distribution in the plasma of a vacuum arc, Sov. Tech.Phys. Lett., 7, pp. $497-499$ (1981).

[35] J. E. Daalder, Cathode spots and vacuum arcs, Phys. Status Solids C, 104 pp. 91-106 (1981).

[36]. H.C. Miller, Constraints imposed upon theories of the vacuum arc cathode region by specific ion energy measurements, J. Appl. Phys., 52, pp. 4523-4530 (1981).

[37]. A. S. Gilmour and D. L. Lockwood, Pulsed metallic plasma generators, Proc. IEEE., 60, pp.977-991 (1972) .

[38]. D.M. Mattox, Fundamentals of ion platings, J. Vac. Sci. Technol., 10 pp. 47-52 (1973).

[39]. P. A. Lindfors and M. W. Carpenter, Control of coating morphology in cathodic arc deposition technology, Proc. Int. Conf. on Metallurgical Coatings, San Diego, CA, April, (1986).

[40]. P. A. Lindfors, W. M. Mularie and G. K. Whehner, Cathodic arc deposition technology, Surf. Coat. Technol., 29, pp. 275-290 (1986) .

[41]. H. Randhawa,Cathodic arc plasma deposition of $\mathrm{TiC}_{\text {and }} \mathrm{TiC}_{\mathrm{x}} \mathrm{N}_{1-\mathrm{x}}$, Proc. Int. Conf. on Metallurgical Coatings, San Diego, CA, March 1987, in Thin Solid Films, 153, p. 209 (1987) .

[42]. H. Randhawa,Cathodic arc plasma deposition technology, Thin Solid Films, 167 pp. $175-185$ (1988).

[43]. P.C.Johnson, The cathodic arc plasma deposition of thin films, in Thin Film Processes II ( Vossen and Kern eds. ) Academic press, New York, (1991).

[44]. I. I. Aksenov, V. G. Bren', V. G. Padalka and V. M. Khoroshikh, Chemical reaction in the condensation of metal-plasma streams, Sov. Phys. Tech. Phys., 23, pp. $651-653$ ( 1978).

[45]. P. A. Lindfors, M. W. Carpenter and C. F. Artig, Uniformity of coatings on non-line-of sight surfaces using cathode arc deposition, Proc. Int. Conf. on Metallurgical Coatings, San Diego, CA, April, (1986).

[46]. J. E. Daalder, Cathode erosion of metal vapour arcs in vacuum, $\mathrm{PhD}$. Thesis, Eindhoven, The Netherlands, (1978).

[47]. H. Schellekens, IEEE. Trans. on Plasma Science PS 13 (5), 291-295 (1985).

[48]. A. I. Vasin, A. M. Dorodnov and V. A. Petrosov, Vacuum arc with a distributed discharge on an expendable cathode, Sov. Tech. Phys. Lett., 5, pp. 634 - 636 (1979). 
[49]. G. P. Smith, R. R. Dollinger, D.P. Malone and A.A Gilmour, Relative cathode spot and cell areas and currents in a copper cathode vacuum arc, J. Appl. Phys., 51, pp. 3657 - 3662 (1980).

[50]. V. A. Nemchinskii, Gas dynamic acceleration of a cathode jet in a vacuum arc, Sov. Phys. Tech. Phys., 30, pp. 34-37 (1985).

[51]. B. Juttner, Formation time and heating mechanism of arc spot craters in vacuum, J. Phys. D, 14, pp. 1265 -1275 (1981).

[52]. B. Juttner, H. H. Pursh and V. A. Shilov, The influence of surface roughness and surface temperature on arc spot movement in vacuum, J. Phys. D, 17, pp. 131 - 134 (1984)

[53]. J. E. Daalder, Erosion structures on cathode arced in vacuum, J. Phys. D, 12 pp. 1769 - 1779 (1979).

[54]. V. I. Rakhovskii, Experimental study of the dynamics of cathode spots development. IEEE.Trans. on Plasma Science, vol.PS-4, No.2, pp. 81-102 June ( 1976).

[55]. Peter Malkin, The vacuum arc and vacuum interruption. J. Phys. D: Appl. Phys. 22, pp. 1005 - 1019 ( 1989 ).

[56]. V. A. Nemchinskii, Causes of cathode spot motion in a vaccuum arc and an estimate of retrograde velocity in a magnetic field. Sov. Phys. Tech. Phys. 28 (2), pp. $150-155$, February (1983).

[57]. P. J. Martin, Make clean, dense films with a filtered process, R.\& D.Magazine, pp. $108-115$ Oct. (1990).

[58]. V. M. Lunev, V.G. Padalka, and V. M. Khoroshikh, Sov. Phys. Tech. Phys., 22, 858 ( 1977).

[59]. M. G. Drouet, The physics of the retrograde motion of the electric arc, IEEE. Trans. on Plasma Science, vol.PS-13, No.5, pp.235 - 241 Oct. (1985).

[60]. P. D. Swift, D. R. Mckenzie, I. S. Falconer and P. J. Martin, Cathode spot phenomena in titanium vacuum arcs, J. Appl. Phys. 66 (2), 15, pp.505 512, July (1989).

[61]. A. E. Robson and A. Von Engel, Phys. Rev. 93, 1121 (1954).

[62]. L. P. Sablev, Apparatus for vacuum evaporation of metals under the action of an electric arc, U.S. Patent No.3 783231 ( 1 January 1974 ).

[63]. L.P. Sablev, N. P. Atamansky, V. N. Gorbunov, J. I. Dolotov, V.N. Lutseenko, V. M. Lunev, V. V. Usov, US Patent 3,793,179, February (1974).

[64]. A.A.Snaper, Arc Deposition Process and Apparatus, U.S.A. Patent 3625848 (1971). 
[65]. W. M. Mularie, Evaporation Arc Stabilization, U.S. Patent No 4430184 (7 February 1984 ).

[66]. C. F. Morrison, US Patent 4,724, 958, February (1988).

[67]. P.J. Martin, D. R. Mckenzie, R. P. Netterfield, P. Swift, S. W. Filipczuk, K. H. Muller, C. G. Pacey, and B. James. Thin Solid Films, 153, 91-102 (1987).

[68]. H. Randhawa, Hard coatings for decorative applications, Surf. Coat. Technol., 36, 829 - 836 ( 1988 ).

[69]. H. Randhawa, Hard coatings for wear and decorative applications, presented at the 7th Int'l. Conf. on Thin Films, New Delhi, India, Dec. (7 - 11 ) (1987).

[70]. S. Boelens and H. Veltrop. Hard coatings of TiN, ( TiHf )N and ( TiNb)N deposited by random and steered arc evaporation. Surf. Coat. Technol., 33, pp.63-71 (1987).

[71]. David M. Sanders. Review of ion-based coating processes derived from the cathodic arc. J. Vac. Sci. Technol. A 7 (3), p. 2339 May /Jun. (1989).

[72]. R. L. Boxman et al., " Fast deposition of metallurgical coatings and production of surface alloys using a pulsed high current vacuum arc", Thin Solid Films, vol. 139, pp. 41-52, (1986).

[73]. H. Wroe, Stabilization of low presure arc discharges, U.S. Patent No 2972 695 (1 February 1961 ).

[74]. S. Ramalingam, Controlled Vacuum Arc Material Deposition, Method and apparatus, World Patent No 85/03954 ( 12 September 1985).

[75]. E. Erturk, H.-J. Heuvel and H.-G. Dedrichs, Comparison of the steered arc and random arc techniques. Surf. Coat. Technol., 39/40, p.455 ( 1989 ).

[76]. R. L. Boxman and S. Goldsmith, Surface and Coatings Technology, 52, p. 39 (1992) .

[77]. S. Ramalingham et al., US. Patent 4, 673477 ( 1987).

[78]. E. Erturk, H.-J. Heuvel and H.-G. Dedrichs, $\mathrm{CrN}$ and ( $\mathrm{Ti}, \mathrm{Al}$ ) N coatings deposited by the steered arc and random arc techniques. Surf. Coat. Technol., 39/40, pp. 435 - 444 ( 1989 ).

[79]. H.-D. Steffens, M. Mack, K. Mohwald and K. Reichel, Surface and Coatings Technology, 46, p.65 ( 1991 ).

[80]. P. Sathrum and B. F. Coll, Surf. Coat. Technol., 50, p.103 ( 1992 ).

[81]. K. Akari, H. Tamagaki, T. Kumakiri, K. Tsuji, E. S. Koh and C. N. Tai. Reduction in macroparticles during the deposition of TiN films prepared by arc ion plating. Surface and Coatings Technology, 43/44, pp. 312 - 323 (1990). 
[82]. P.J.Martin, R. P. Netterfield, D. R. Mckenzie, I. S. Falconer, C. Pacey, P. Thomas and W. G. Sainty. Characterization of a $\mathrm{Ti}$ vacuum arc and the structure of deposited Ti and TiN films. J. Vac. Sci. Technol., A, 5, p. 22 (1987).

[83]. D. M. Sanders and E. A. Pyle. Magnetic enhancement of cathodic arc deposition, J. Vac. Sci. Technol., A5 (4 ), pp. 2728 - 2731 Jul/Aug. (1987).

[84]. D. M. Sanders, Ion beam - self- sputtering using a cathodic ion source, J. Vac. Sci. Technol., A 6.( 3 ), pp. 1929 - 1933 May / Jun. ( 1988 ).

[85]. I. G. Brown, J. E. Galvin, and R. A. MacGill, Appl. Phys. Lett. 47, 358 (1985).

[86]. I. I. Aksenov and V. Belous, Exitation of a vacuum arc in metallic plasma sources, High Temperatures, 17, 103 (1979).

[87]. I. I. Aksenov and V. Belous, Ignition of a vacuum arc in stationary sources of a metal plasma from an antonomous plasma injector, General Experimental Techniques, 22 (3), 785 - 786 ( 1979). Translated from Pribory i Tekhnika Eksperimenta, No. 3, 160 -162, May - June, (1979).

[88]. S. Mitura and Z. Has' (poland) and V. Gorokhovsky (USSR). The system for depositing hard diamond-like films onto complex- shaped machine elements in an an r.f. arc plasma. Surf. Coat. Technol., 47, pp. 106 - 112 (1991).

[89]. M.I. Ridge. Visibly transparent heat reflecting oxides deposited by reactive magnetron sputtering. $\mathrm{PhD}$. Thesis, Loughborough University of technology, (1984).

[90]. R. L. Boxman and S. Goldsmith, J. Appl. Phys., 52, 252 ( 1981 ).

[91]. C. W. Kimblin, Cathode spot erosion and ionization phenomena in the transition from vacuum to atmospheric arcs, J. Appl. Phys. 45, 5235 ( 1974 ).

[92]. R. L. Boxman and S. Goldsmith, J. Appl. Phys., 51, pp. 3644 ( 1980 ) .

[93]. C. Bergman, Surf. coat, technol., 36, p. 243 ( 1988).

[94]. T. Utsumi and J. H. English, Study of electrode products emitted by vacuum arcs in form of molten metal particles, J. Appl. Phys., 46, pp. 126-131 (1975).

[95]. I.I. Aksenov, I.I. Konovalov, E. E. Kudryavtsev, V. V. Kunchenko, V. G. Padalka and V. M. Khoroshikh, Droplet phase of cathode erosion in a steady state vacuum arc, Sov. Phys. Tech. Phys., 29, pp. 893- 894 (1984).

[96]. P. J. Martin, R. P. Netterfield, A. Bendavid and T. J. Kinder, The deposition of thin films by filtered arc evaporation. Surface and coatings Technology, 54/55, pp. 136 - 142 (1992). 
[97]. B. Ya. Moizles and V. A. Nemchinski, Influence of external gas pressure on cathode spot motion in a magnetic field. Sov. Phys. Tech. Phys., 30, p. 136 (1985) .

[98]. A. W. Baouchi and A. J. Perry, A study of the macroparticle distribution in cathodic-arc-evaporated TiN films. Surface. Coat. Technol., 49, p. 253 (1991).

[99]. I. I. Aksenov, I.I. Konovalov, V. G. Padalka and V. M. Khoroshikh, A study of the effect of volume gas pressure on cathodic process in a steady - state vacuum arc, High Temp., 22, pp. 517 - 521 ( 1984 ).

[100]. V. A. Osipov, V. G. Padalka, L. P. Sablev and R. I. Stupak, Unit for depositing coatings by precipitation of ions extracted from a vacuum arc plasma, Instrum. Exp. Tech., 21, pp. 1650 - 1652 ( 1978 ).

[101]. I. I. Aksenov, V. A. Belous, V. G. Padalka and V. M. Khoroshikh, Apparatus to rid the plasma of a vacuum arc of macroparticles, Instrum. Exp. Tech., 21, pp. $1416-1418(1978)$.

[102]. I. I. Aksenov, S. I. Vakula, V. G. Padalka, V. E. Strel'nitskii and V. M. Khoroshikh, High - efficiency source of pure carbon plasma, Sov. Phys. Tech. Phys., 25, pp. 1164 - 1166 ( 1980 ).

[103]. I. I. Aksenov, V. A. Belous, V. G. Padalka and V. M. Khoroshikh, Transport of plasma streams in a curvilinear plasma optics system, Sov. J. Plasma Phys., 4, pp. 425 - 428. ( 1979 ).

[104]. I. I. Aksenov, V. A. Belous, V. G. Padalka and V. M. Khoroshikh, Arc plasma - generator, US. Patent, 4, 452 686, (1984).

[105]. Brandolf H., US. Patent, 4, 511 593, (1985).

[106]. G. W. McClure, Plasma expansion as a cause of metal displacement in vacuum-arc cathode spots. J. appl. Phys, Vol. 45, No. 5, May (1974), pp. 2078 - 2084, May (1974),

[107]. B. Zega, Hard decorative coatings by reactive physical vapour deposition: 12 years of development. Surf. Coat. Technol., 39 / 40, pp. 507 - 520 (1989).

[108]. H. Randhawa, P. C. Johnson and R. L. Cunningham, Deposition and characterization of ternary nitrides, J. Vac. Sci. Technol., A 6 ( 3) , p.2136 (1988) .

[109]. P. J. Martin, R. P. Netterfield, T. J. Kinder, and L. Descotes, Surf. Coat. Technol., 49, p. 239 ( 1991). 
[110]. P. J. Martin, R. P. Netterfield and T. J. Kinder, Ion-Beam deposited films produced by the filtered arc evaporation, Thin Solid films, 193/194, pp.77 87 ( 1990 ).

[111]. H. Randhawa, High - rate deposition of $\mathrm{Al}_{2} \mathrm{O}_{3}$ using modified cathodic arc plasma deposition processes. J. Vac. Sci. Technol., A 7 ( 3), pp. 2346 - 2349 May / Jun. (1989).

[112]. T. D. Schemnel, R. L. Cunningham, and H. Randhawa, Process for high rate deposition of $\mathrm{Al}_{2} \mathrm{O}_{3}$. Thin Solid Films 181, pp. 597 - 601 ( 1989 ).

[113]. I. I. Demindenko, N. S. Lomino, V. D. Ovcharenko, V. G. Padalka and G. N. Polyakova, Ionization mechanism for nitrogen in a vacuum arc discharge, Sov. Phys. Tech. Phys., 29, pp. 895 - 897 ( 1984 ).

[114]. I. I. Aksenov, V. G. Bren', V. G. Padalka and V. M. Khoroshikh, Special features in synthesis of nitrides on condensation of metal plasma, High Energy Chem. 17 (3), pp. 200 - 202 ( 1983 ).

[115]. P. J. Johnson and H. Randhawa, Zirconium nitride films prepared cathodic arc plasma deposition process, Surf. Coat. Technol., 33, pp. 53 - 62 ( 1987 ).

[116]. I. I. Aksenov,V. A. Belous, V. G. Padalka and V. M. Khoroshikh, Fiz. Khim. Obrab. Mater., 6, p. 89( 1977 ).

[117]. J., -E. Sundgren, B, -O. Johansson, S. E. Karlsson and H. T. G. Henzell, Thin Solid Films, 105, p. 367 ( 1983 ).

[118]. H. Windischmann, J. Vac. Sci. Technol., A, 9, p.2431 ( 1990 ).

[119]. A. K. Vershina, I. A. Bel'chin, A. A. Pitel'ko and S.D. Izotova, Fiz. Khim. Obrab. Mater., 24, p. 93 ( 1990 ).

[120]. H. Freller and H. Haessler, Thin Solid Films, 153, pp. 67 - 74 ( 1987 ).

[121]. S. Falabella and D. M. Sanders, Comparison of tow filtered cathodic arc sources. J. Vac. Sci. Technol., A10 (2), pp. 394 - 397.(1992).

[122]. G. V. Kljuchko, V. G. Padalka, L. P. Sablev and R. I. Stupak, US. Patent 4,492 845, ( 1985 ).

[123]. I. I. Aksenov, V. G. Padalka, N. S. Repalov and V. M. Khoroshikh, Sov. J. Plasma Phys., 6, p. 173 ( 1980 ).

[124]. I. I. Aksenov, A. N. Belokhvotikov, V. G. Padalka, N. S. Repalov and V. M. Khoroshikh," Plasma flux motion in a toroidal plasma guide", Plasma phys. Control fusion, Vol. 28, No. 5, pp. 761-770 ( 1986 ).

[125]. V. S. Voitsenya, A. G. Gorbanyuk, I. N. Onishenko and B. G. Safronov, Sov. Phys. Tech. Phys., 9, p. 221 ( 1964 ). 
[126]. V. S. Voitsenya, A. G. Gorbanyuk, I. N. Onishenko and B. G. Safronov, and V. V. Shkoda. Sov. Phys. Tech. Phys., 12, p. 185 ( 1967 ).

[127]. F. I. Chen, "Introduction to plasma physics"; Plenum press, New York (1977).

[128]. M. A. Uman, "Introduction to plasma physics", McGraw - Hill, chapter 5 (1964).

[129]. T. J. M. Boyd and J. J. Sanderson, Plasma Dynamics ( Barnes and Noble ), New York, (1969).

[130]. J. Storer, J. E. Galvin and I. G. Brown.Transport of vacuum arc plasma through straight and curved magnetic ducts. J. Appl. Phys. 66 ( 11$), 1$ December (1989).

[131]. A. I. Morozov and S. V. Lebedev, "Plasma Optics", in Review of Plasma Physics, Vol. 8, M. A. Leontovich, ed., New York: Consultants Bureau, (1980).

[132]. A. I. Morozov, Focusing of cold quasi-neutral beams in electro-magnetic fields, Sov. Phys.- Dokl., Vol. 10, No. 8, pp. 775 - 777, ( 1966 ).

[133]. I. I. Aksenov, V. G. Padalka, V. T. Tolok, and V. M. Khoroshikh, Motion of plasma streams from a vacuum arc in a long, straight plasma-optics system, Sov. J. Plasma Phys., Vol. 6, p. 504, (1980).

[134]. H.A. Mcleod, J.Vac.Sci. Technol., A4, p.418 (1986).

[135]. H. K. Pulker, Thin Solid Films, 89, p. 191 (1982). 


\section{CHAPTER 4 \\ FILM ANALYSIS TECHNIQUES.}

\subsection{SHEET RESISTANCE MEASURMENT}

The four-point probe technique can be used to evaluate the sheet resistivity of a conducting thin films of known thickness which is assumed to be homogoneous in its electrical properties. The conducting film is usually grown onto an insulating substrate [1]. The geometry of a four point probe is illustrated in figure 4.1.

The film resistivity $p$ can be measured by:

$$
p=d R_{s}
$$

These four probes are connected by a spring which allows them to press against the film. A known current of I (amperes) is passed through the outer probes and a voltage $V$ (volts) is measured using the two inner probes and this allows the calculation of the surface resistance and therefore the film resistivity. When the distances between the probes are equal i.e. $S_{1}=S_{2}=S_{3}=S_{4}$ and $S$ » film thickness $d$, the sheet resistance can be obtained by the equation:

$$
R_{s}=\frac{\pi V}{I \ln 2}
$$

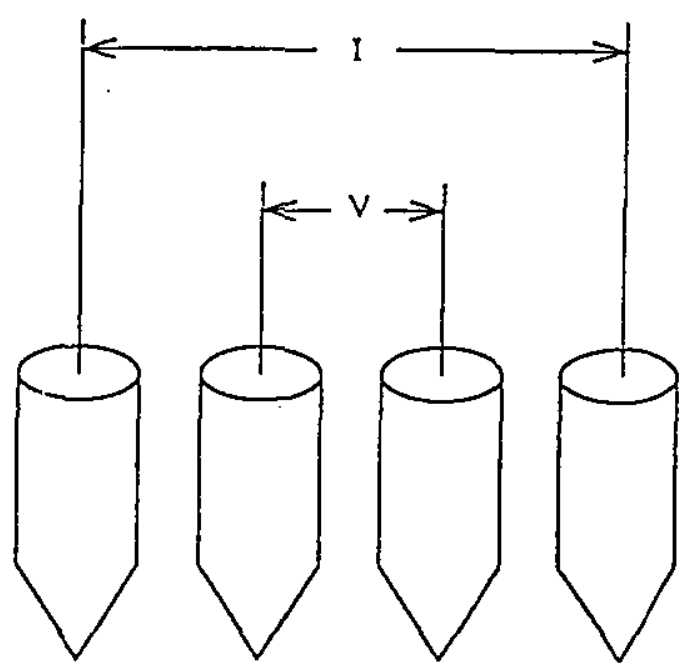

Figure 4.1. The geometry of a four point probe 


\subsection{ELLIPSOMETRY}

Ellipsometry is a convenient and precise technique for measuring the refractive index, the thickness of a thin film and the optical constants of its substrate. The theory ellipsometry for thin films on substrate have been reported by many authors $[3,4]$. The widespread use of ellipsometry was demonstrated by the symposium in 1963 by the National Bureau of Standards [5].

An ellipsometer depends for its action on the fact that if . plane polarized light is incident on a surface it is reflected as elliptically polarized light. The degree of ellipticity in the reflected beam depends on the thickness of the film [6-8]. The apparatus used was a Gaertner L117 ellipsometer. A schematic diagram of this is shown in figure 4.2.

There are many ways to use the ellipsometer to provide the refractive index and the thickness. In our work, we simply determined the polarizer and analyzer angles $\left(P_{1}, A_{1}\right.$ and $P_{2}, A_{2}$ ) which gave minimum detected light levels. There are two minima required, the first is found in the range $0<A_{1}<90^{\circ}$ and $0<P_{1}<135^{\circ}$, and the second is approximately at $A_{2}=180^{\circ}-A_{1}$ and $P_{2}=90^{\circ}+P_{1}$. The second set of values will vary slightly from the calculated $\left(\mathrm{P}_{1}+90^{\circ}\right)$ and $\left(180^{\circ}-\mathrm{A}_{1}\right)$ values but should not differ by more than $4^{\circ}$ for accurate measurements [9-10]. By having the values $\left(p_{1}, A_{1}\right.$ and $\left.P_{2}, A_{2}\right)$, the values $\psi$ and $\Delta$ are calculated. $\psi$ which is the angle between the polarization plane and the plane of incidence [8], and is given by:

$$
\psi=\frac{180-(\mathrm{A} 2-\mathrm{A} 1)}{2}
$$

$\Delta$ is the phase difference : on reflection from the film /surface and is given by:

$$
\Delta=360-\left(P_{1}+P_{2}\right)
$$




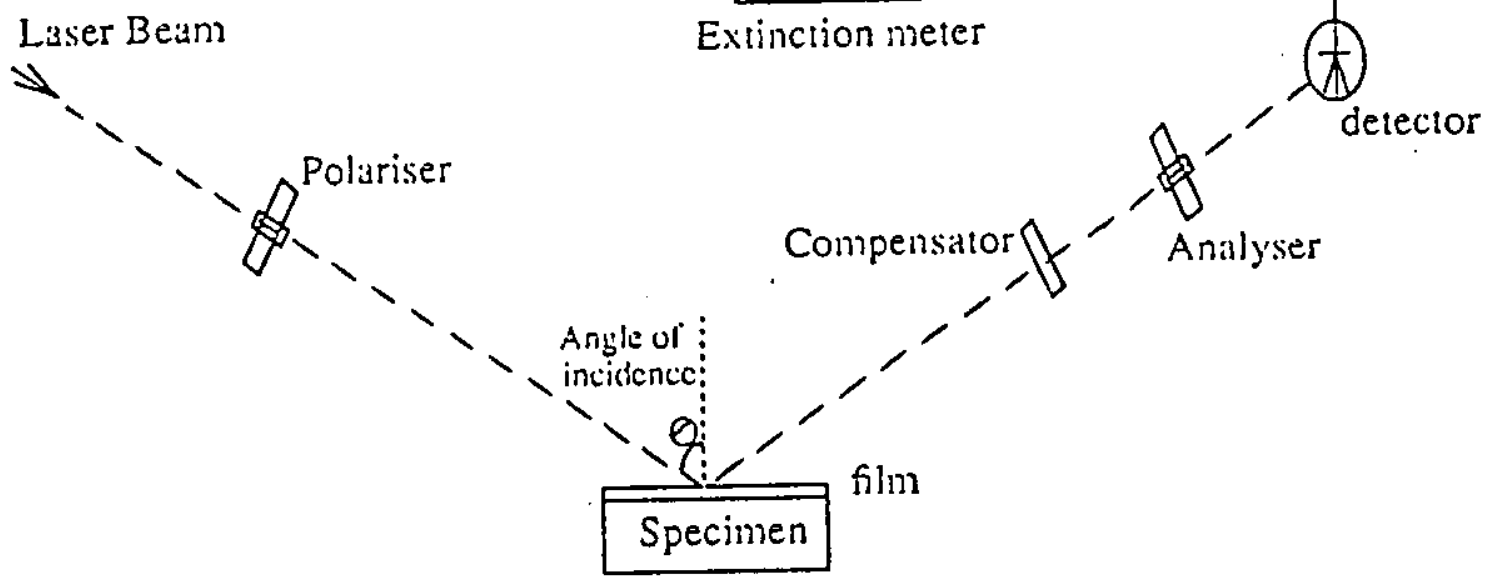

Figure 4.2. A schematic diagram of the ellipsometer 


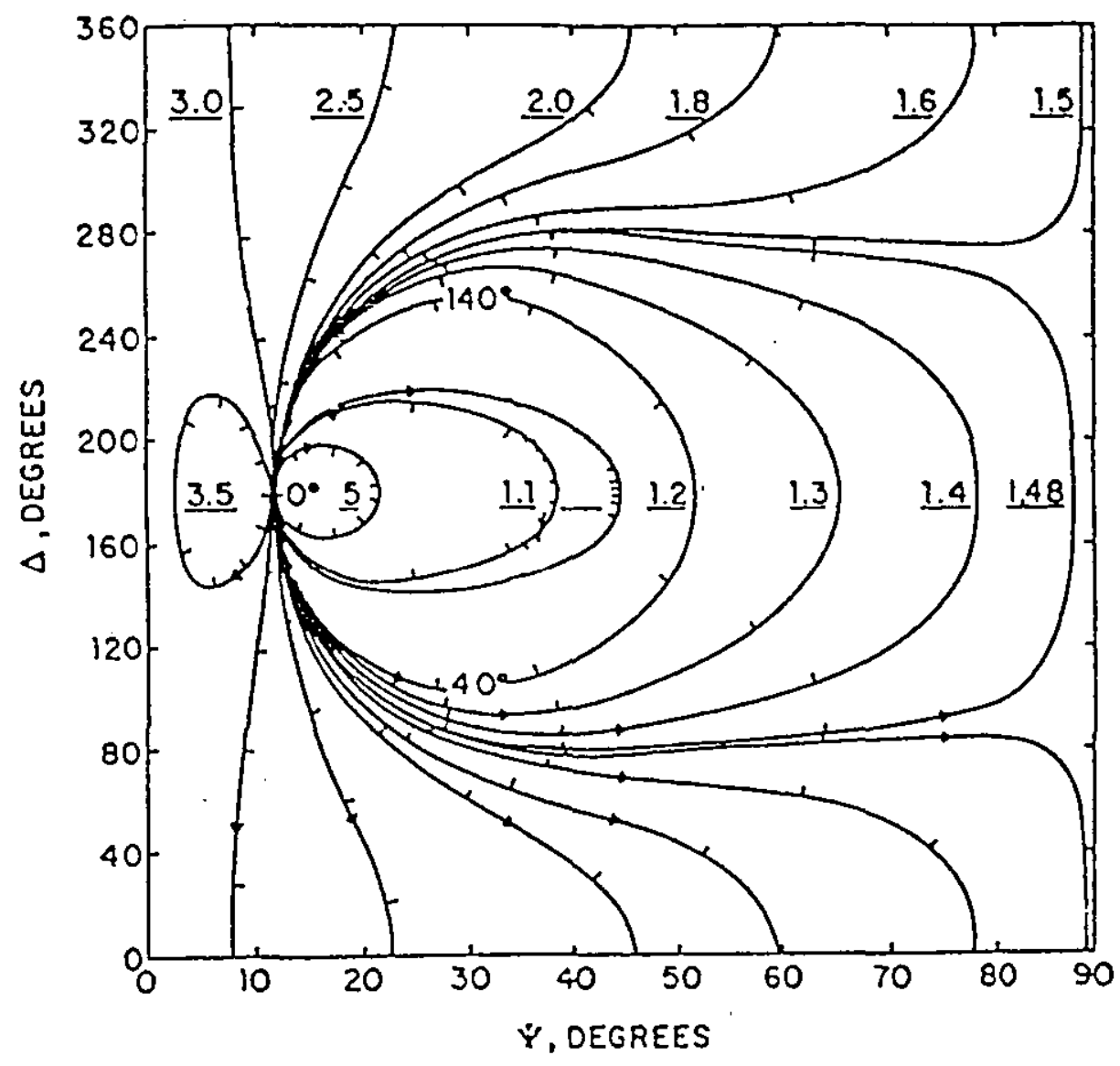

Figure 4.3. shows $\Delta$ and $\psi$ for films of varying refractive index (n) and thickness (d) on silicon [1]. 


\subsection{MEASURING THIN FILM DEPOSITS}

The film thickness measurements were made with Talystep 1, which is the most recent of the talysurf instruments [7]. Talystep measures film thickness by traversing a conical stylus of $12.5 \mu \mathrm{m}$ ( $500 \mu \mathrm{in})$ tip radius either across a test groove formed in the deposit, or over the edge of the deposit. Vertical movement of the stylus is amplified electronically and recorded as graphical presentation of the difference in level between the surfaces of the substrate and the deposit. The instrument will also reveal the surface roughness of a limited range of finely finished surfaces [11]. Assuming all modules thave been correctly adjusted to use the machine, a profile step height will be recorded at the selected vertical magnification $V_{V}$ with an uncertainty of $\pm 1 \%$ of full scale of range used, in addition to $\pm 3 \%$ of step at $V_{v}$ up to $\times 1000000$ [7]. Because of the wide variety of vertical ampification available with this instrument, it is possible to measure film thickness from about $20 \AA$ up to $10 \mu$ with an accuracy of a few percent. Although the talystep is mounted on an anti-vibration platform, the high sensitivity of the instrument demands its use on a rigid table standing on a firm floor.

\subsection{X-RAY DIFFRACTION (XRD)}

$\mathrm{X}$-ray diffraction using $\mathrm{Cu} \mathrm{k}_{\alpha}$ radiation was used to determine the crystal group and crystal size in the coating samples. The (111) $x$-ray line of silicon powder was used as the standard to calibrate the instrument.

If a parallel beam of $\mathrm{x}$-rays, wave length $\lambda$, strikes a set of crystal planes Figure.4.4, it is reflected from the different planes, and the equation giving the angles at which diffraction takes place is the well-known Bragg equation:

$$
n \lambda=2 d \sin \theta
$$

where :

$$
\begin{aligned}
& \mathrm{n}: \text { is an integer, } \\
& \mathrm{d}: \text { is the spacing of the planes, and } \\
& \theta \quad: \quad \text { is the grazing angle of incidence of the rays on the lattice planes, } \\
& \quad \text { (Bragg angle)[15]. }
\end{aligned}
$$




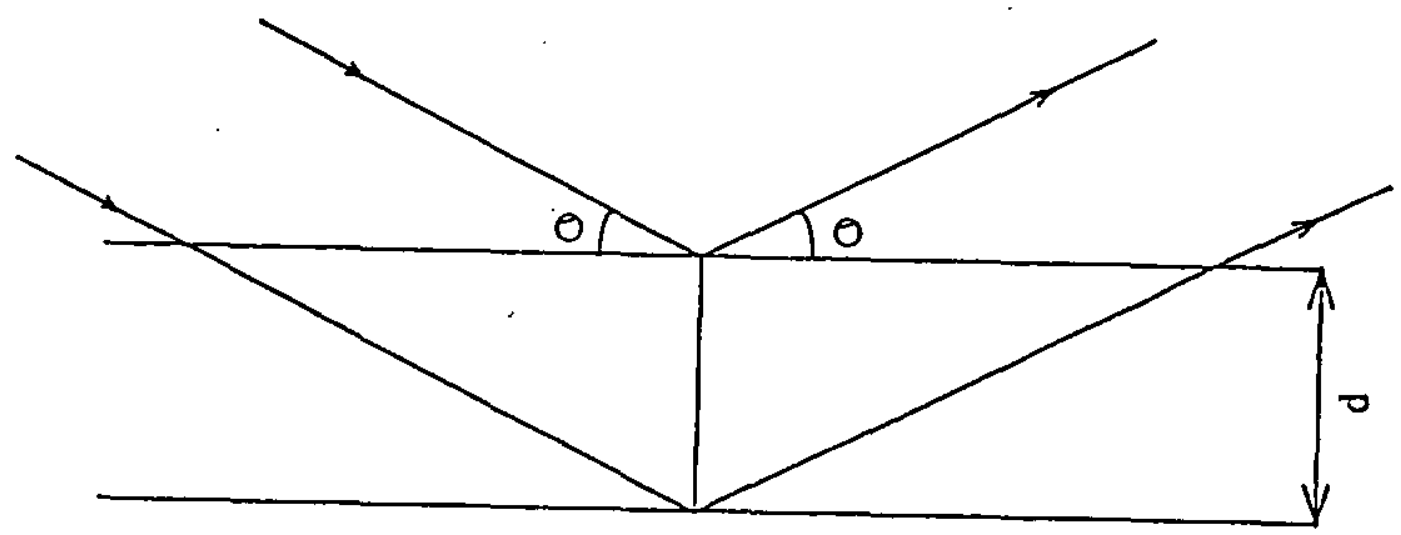

Figure 4.4. Diffraction of X-rays by a crystal.

\subsection{SCANNING ELECTRON MICROSCOPY (SEM).}

The scanning electron microscope (SEM) is an instrument designed primarily for studying the surfaces of solids at high magnification. In this respect, it is closely resembling the optical microscope but using, instead of light, a beam of energetic electrons. Using secondary or back-scattered electrons, leaving the surface on which the incident electron probe impinged [16 -19], the scanning electron microscope posseses much greater resolution and magnification, and produces a seemingly three dimensional image.

With great depth of field, from a sample of any convenient size or thickness, the magnification can vary continuously from 15 diameters to 100000 diameters. The resolution is about $10-20 \mathrm{~nm}$ [17-18].

The machine used to scan the samples was (JEOL - JEM 100CX). This machine is equipped with ${ }^{2}$ scanning unit in order to generate a surface image by secondary electrons. 


\subsection{SPECTROPHOTOMETERY}

The optical layout of the spectrophotometer used for measurement of reflectance, transmittance and absorptance of thin films throughout the visible and near infra-red spectrum with different deposition parameters, is illustrated in fig(4.5).

The instrument is a Perkin-Elmer model 323 UV- VIS- NIR recording spectrophotometer which covers the wavelength range $170-2600$, see Table (4.1)

\begin{tabular}{|l|l|}
\hline Wavelength $(\mathrm{nm})$ & Range \\
\hline $170-220$ & Far ultra-violet \\
\hline $210-360$ & Ultra-violet \\
\hline $340-700$ & Visible \\
\hline $600-2600$ & Near infra-red \\
\hline
\end{tabular}

Table (4.1). shows the wavelength for each range used in the spectrophotometer.

The light source used in the visible and near infra-red $(340-2600 \mathrm{~nm})$ was a tungsten lamp, while the detectors used a photomultiplier tube for the visible range and a lead sulphide $(\mathrm{PbS})$ cell for the near infra-red.

The optical layout shown in figure 4.5 was to examine the transmission property of samples. To examine the films by reflection an attachment shown in figure 4.5 by the dotted lines was fitted; it simply reflects the beam up to a reference mirror and the examined sample and then redirects the beam back to the original optical path.

The reference mirror used was a fresh aluminium front surface mirror deposited by filtered arc evaporation process. 


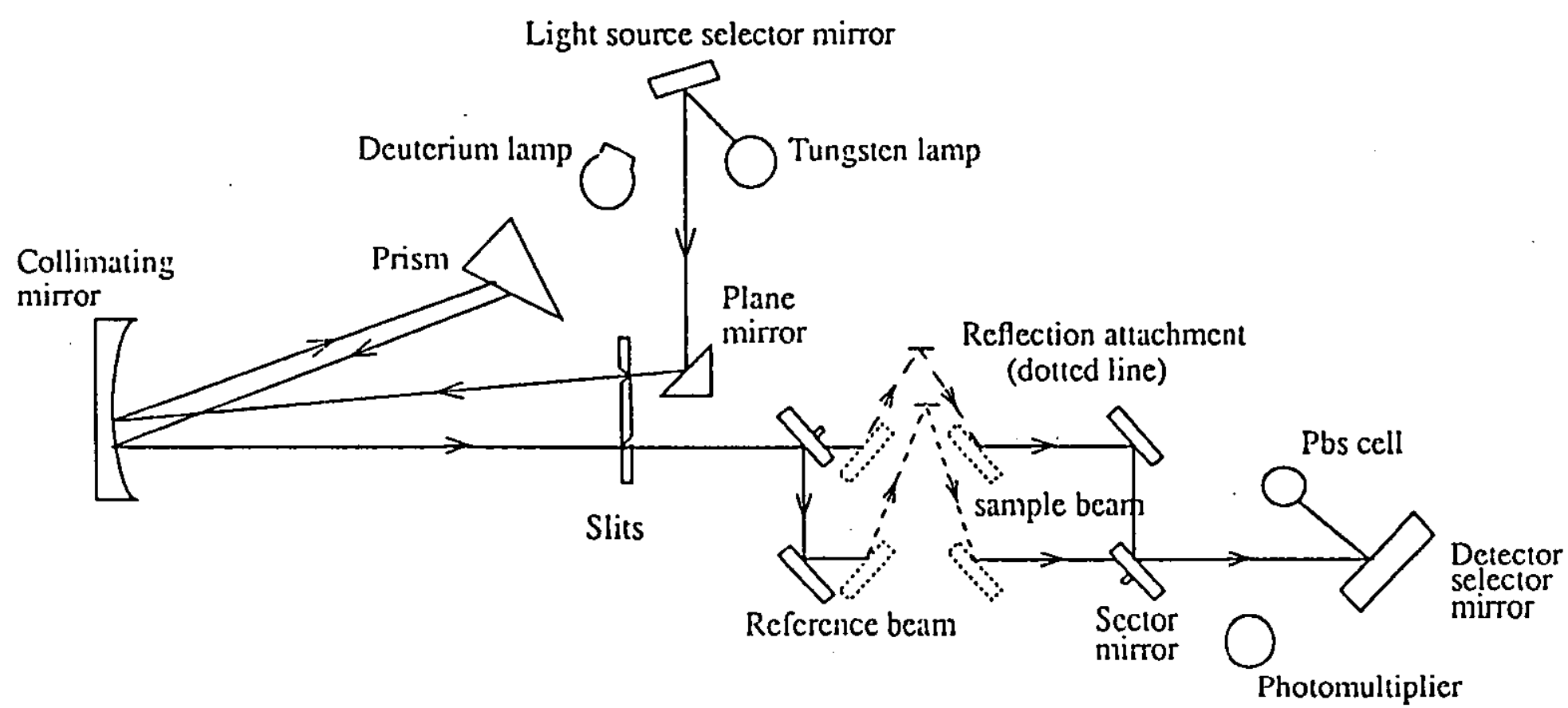

Figure 4.5. Optical layout of the scanning spectrophotometcr 


\section{REFERENCES}

[1]. D.V. Morgan, K. Board.

An introduction to semiconductor microtechnology.

pp 138-139, pubs John wiley \& sons. New York (1990).

[2]. Leon I. Maissel and Reinhard Glang (eds.), Hand book of thin film technology.Chap 13-5.

Electrical properties of metallic thin films. McGraw-Hill book company (1983).

[3]. R. J. Archer, J. Opt. Soc. Am.. 52, 970 (1962).

[4]. M. Umeno, M. Yoshimoto, Hideki Shimizu and Y. Amemiya.

Ellipsometric and infra-red spectroscopic studies of oxide film on GaAs.

Surface science 86 (1979)

[5]. Passaglia E., R.R. Stromberg, and J.Kruger (eds).

Ellipsometry in the measurement of surfaces and thin films,

Nbs Mis. Publ. 256, Government printing office, Washington, D.C, (1964).

[6]. Heavens O.S., Optical properties of thin films. Dover, New york (1965).

[7]. Valeries H. Pitt. (ed.)

The Penguin dictionary of physics. Laurence Urdang Associates Ltd. (1984).

[8]. H.G.Tompkins.

Use of surface and thin film analysis techniques to study metal-organic and metal-polymer interaction. A review. Thin Solid Films 119, pp337-348 (1984).

[9]. Gaertner L117. Ellipsometer manual, (1977).

[10]. A.G. Spencer

High rate reactive magnetron sputtering.

Ph.D. Thesis, LUT, pp. 85-91(1989).

[11]. Handbook of Micro-measurement with talystep.

Manual published by Rank-Taylor-Hobson ( 1987).

[12]. H.P.Klug, L.E.Alexander, "X-ray diffraction procedures for polycrystalline and amorphous materials". John Wiley \& sons. New York (1974).

[13]. A. Guinier, "X-ray diffraction". Freeman (1963).

[14]. B.E. Warren, "X-ray diffraction". Addison-Wesley (1969).

[15]. H. S. Lipson. "Crystals and X-rays". Wykeham (1970).

[16]. D.K.Bowen and C. R. Hall. "Microscopy of materials" .p.117, The Macmillan press Ltd. London (1975).

[17]. D.K.Bowen and C. R. Hall. "Microscopy of materials" .p.13, The Macmillan press Ltd. London (1975). 
[18]. R.E.Smallman, K.H.G. Ashbee. "Modern Metallurgy". Pergammon (1966).

[19]. C.W. Oatley, "The scanning electron microscopy", Cambridge University Press, Cambridge, (1972). 


\section{CHAPTER 5 EXPERIMENTAL}

\subsection{VACUUM SYSTEM}

The filtered arc vacuum system used in film deposition has many similarities to sputtering or ion plating systems. It is one of the high vacuum pumping systems which usually include two pumps in tandem, one mechanical and one diffusion pump. Mechanical vacuum pumps are used to remove about $99.99 \%$ of the air from the system. The remaining air, down to any residual pressure from $10^{-3}$ to $10^{-9}$ Torr, is removed by the diffusion pump discharging into the mechanical pump [1].

The vacuum chamber made of stainless steel, was cylindrical with a height of $600 \mathrm{~mm}$ and a diameter of $500 \mathrm{~mm}$. It was pumped by a $23 \mathrm{~m}^{3} . \mathrm{hr}^{-1}$ mechanical pump and a $25001 . \mathrm{s}^{-1}$ diffusion pump. Before deposition, the chamber was evacuated to a pressure below $10^{-5}$ Torr. The working gas was argon of $99.99 \%$ purity, it was introduced into the chamber via the inert gas inlet valve. Reactive gases used for reactive evaporation, such as nitrogen and oxygen of $99.99 \%$ purity, can be introduced into the chamber via a second gas inlet valve. They are small valves to admit a controlled flow of gas into the vacuum chamber. By pumping to less than $10^{-5}$ Torr before proceeding with deposition a good quality film is achieved, although successful coatings have been deposited after pumping to only $10^{-4}$ Torr.

\subsection{PRESSURE GAUGES}

The partial gas pressure measurement was made by a Pirani gauge. Its applicable range is about $10^{-3}$ to $10^{-1}$ Torr. The total pressure measurement was made by a Penning gauge. It is useful to measure pressure in the range from $10^{-2}$ to $3 \times 10^{-7}$ Torr .

\subsection{FIRST EXPERIMENTAL APPROACH}

Since this work was a preliminary study to investigate the arc process parameters, a number of variations in the basic experimental set-up were explored. First, a circular magnetron shown in figure 5.1 was used to investigate the possibility of arc initiation, with the shield connected to earth. The two power supplies connected in parallel used to create the arc, delivered an open circuit voltage of approximately $19 \mathrm{~V}$, which was not 
enough to create an arc on the magnetron surface. The two supplies were replaced by a welding power supply capable of delivering 85 volts. The arc was created by using a tungsten ignitor but it was difficult to maintain an arc on the magnetron surface, and the arc jumped to the earthed shield. After, a number of variations in the magnetic field behind the magnetron surface and the experimental setup, the magnetron was replaced by a small simple evaporation unit. It consists of a circular cathode of $28 \mathrm{~mm}$ diameter surrounded by an insulator shield. This approach proved the possibility of creating a controlled arc by evaporating the cathode material in an argon atmosphere. An arc source was constructed to investigate the deposition process parameters. A schematic diagram of early arc source design is shown in figure 5.2 .

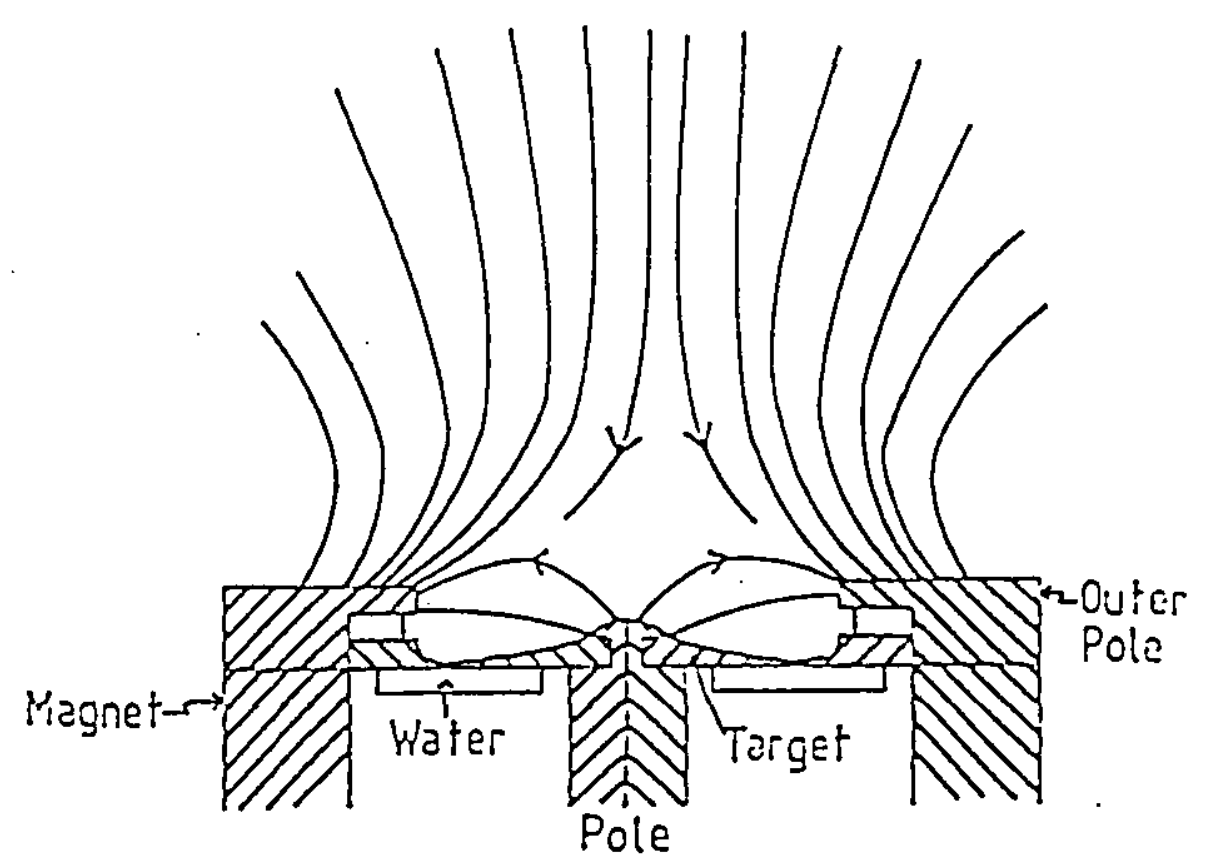

Figure 5.1. A schematic cross-section of the circular magnetron 

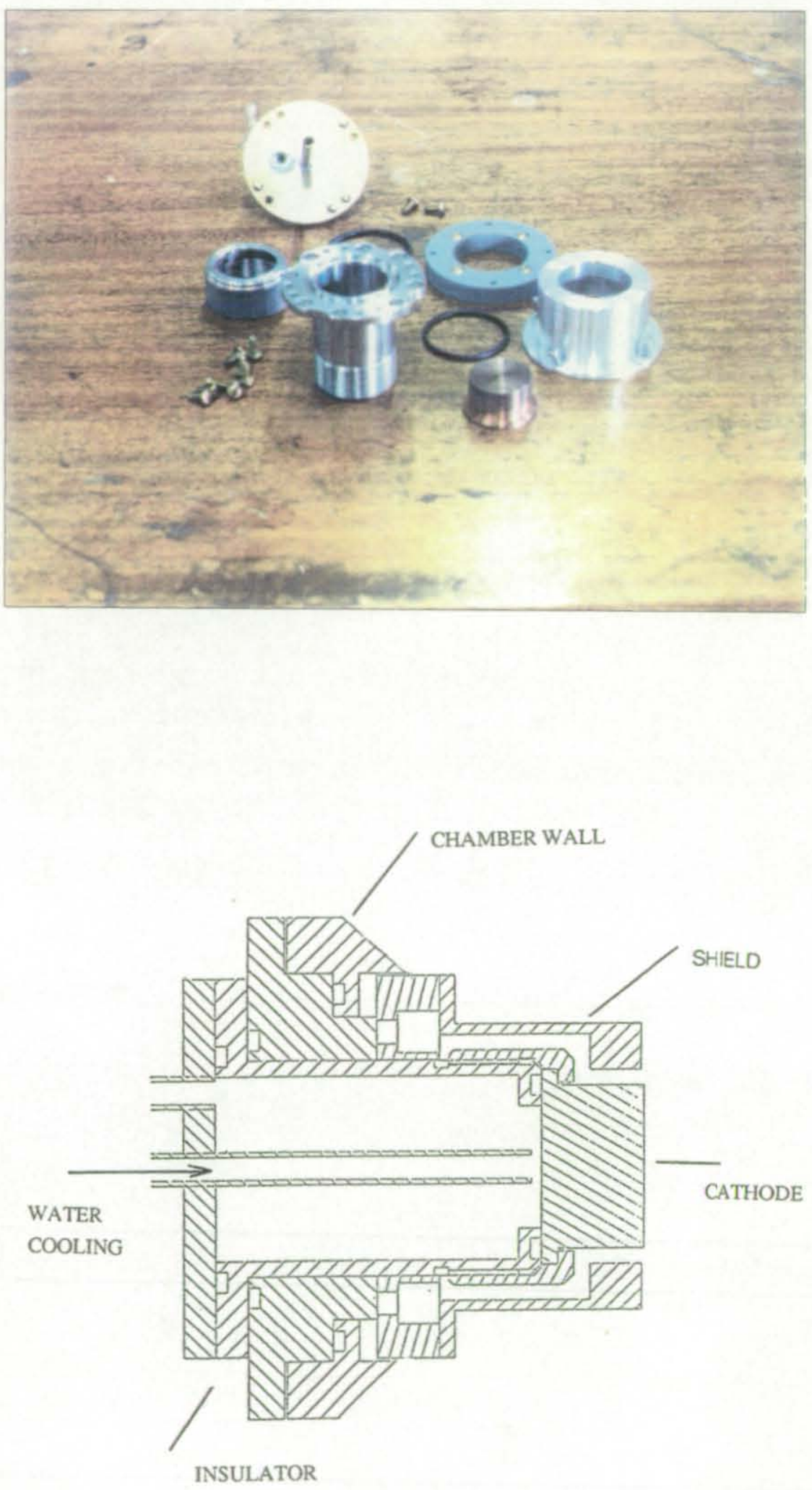

Figure 5.2. An early design of the arc source before the modifications. 
The complete experimental arrangement which was to be tested first is shown in figure 5.3 .

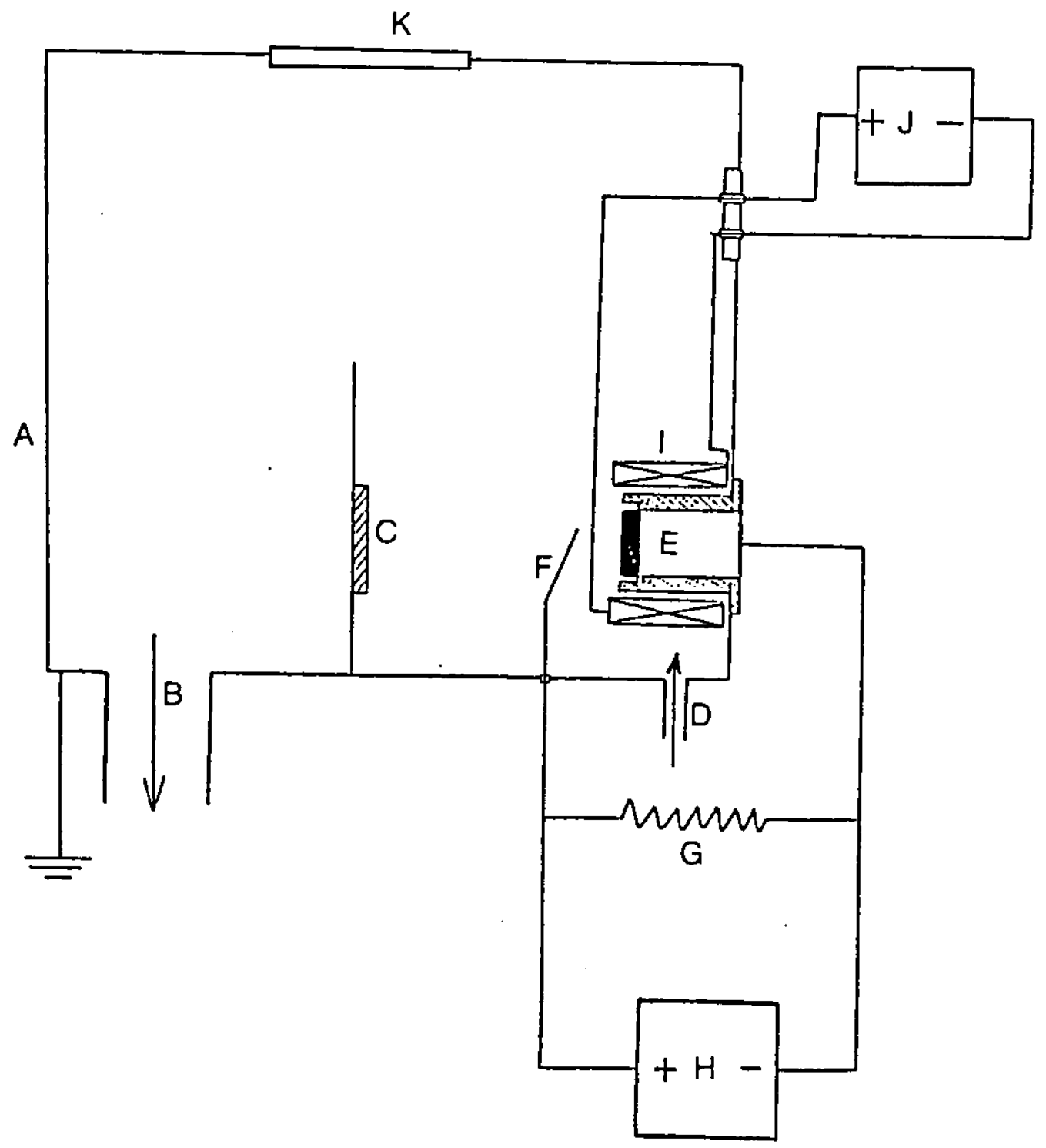

Figure 5.3. The first approach of vacuum arc apparatus used during the experiments. A: Vacuum chamber, B: vacuum pumps,C: substrate platform, D: gas inlet, E: cathode, F: Tungsten-trigger, G: resistors, H: welding-power supply, I: magnetic coil, J: coil power supply, K: window. 
The source target assembly had a removable $32 \mathrm{~mm}$ diameter cathode which was to be evaporated during the arcing process. This cathode is water cooled and connected to the negative pole of the arc welding-power supply, with respect to the chamber ground. A movable tungsten ignitor is located directly above the arcing surface, to strike an electric arc. The ignitor, which is connected to the positive pole of the supply, is supported by an insulator to an armature located outside the vacuum chamber. A floating shield is positioned to capture the plasma originating at the target source. The cathode target is insulated at the back from the shield surrounding the cathode source by means of an insulator, to prevent any contact between the shield and the target. This is very useful, both to control the arc and prevent arcing on the shield itself. Since this was a preliminary investigation, the negative electrode connected to the cathode target inside the vacuum chamber was covered by insulating tapes to avoid arcing except on the target surface, only the material source surface is exposed where arcing is desired.

\subsubsection{Arc Control}

The loss of cathodic arc control can result in rapid destruction of the arc coating equipment. This is what happened when a capacitor in the welding power supply. exploded. The reason of the destruction of that capacitor is the high frequency feedback current produced as noise from the plasma during the arcing process. To overcome this problem, a set of fire elements ( 7 resistors) each of 50 ohms and 1000 watts was connected in series to the cathode of the power supply on one side and to the anode, which is connected to ground in other side, see experimental setup figure (5.3). Total resistance given by these resistors which are connected in parallel, is $7.3 \mathrm{ohms}$. These resistors prevent the feedback current produced from the highly energetic ionised plasma from coming back to the supply. Meanwhile, they cause a drop in the output voltage of the supply from 85 to 75 volts indicated on the power supply meter. At the same time, and before the ignition of the arc, a load of approximately 10 Amperes is recognised on the supply. These resistors were kept in the experimental setup, connected in series between the two poles of the arc power supply.

Electrostatic constraints have been employed up to this point to control the location of the cathodic arc. Electrostatic constraints make use of the concept that a cathodic arc requires an anode to complete the electrical circuit, and vacuum chamber walls may also be considered as anode. The minimum requirement is then a plasma-based current path between the cathodic arc spot and some surface which is electrically positive with 
respect to the cathode. Advantages of electrostatic arc confinement are simplicity and good target utilization. Disadvantages are that the arc sometimes extinguishes without reforming, which requires re-ignition, and undesirable arcing on the cathode surrounding which contaminates the coatings. From early experiments, we concluded the following parameters:

1. Depending on the metal we used (copper, aluminium, and titanium $99.99 \%$ pure), the stability of the arc strongly depends on arc current. To ensure a consistent arc running, a current in the order of $70-100$ Amperes would be necessary.

2. It appears that the deposition rate (film thickness / unit time) is linearly dependent on the current / power applied to the source. Figure 5.4 shows the deposition rate versus source current, argon pressure $=3 \mathrm{mTorr}$, substrate-target distance $=250 \mathrm{~mm}$, coating time $=100$ seconds.

3. Microdroplet emission is high with materials of low melting points.

\begin{tabular}{|c|c|c|}
\hline Current (A) & Thickness $(\mathrm{nm})$ & Deposition rate $(\mathrm{nm} / \mathrm{s})$ \\
\hline 100 & 300 & 3.00 \\
\hline 95 & 320 & 3.20 \\
\hline 90 & 320 & 3.20 \\
\hline 85 & 272 & 2.72 \\
\hline 80 & 250 & 2.50 \\
\hline 75 & 235 & 2.35 \\
\hline 70 & 232 & 2.32 \\
\hline
\end{tabular}

Table 5.1 The deposition rates, and thicknesses for copper taken for various current values. 


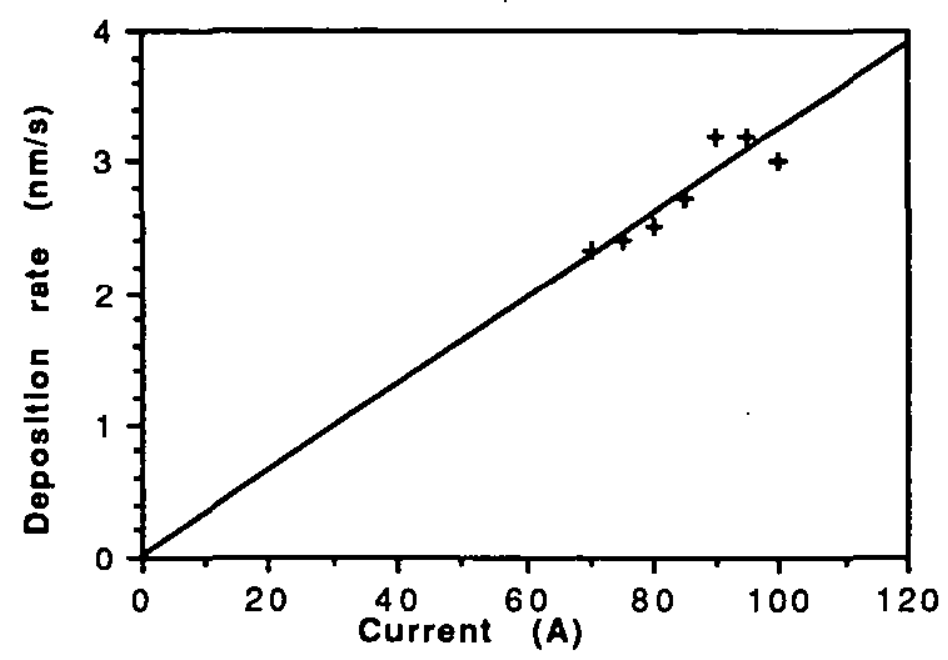

Figure.5.4. The deposition rate versus the arc current for copper. Base pressure $10^{-5}$ Torr , argon pressure $3 \mathrm{mTorr}$, substrate- to - target distance $250 \mathrm{~mm}$.

The water-cooled copper coil shown in figure 5.3 was mounted around the arc source shield to investigate the magnetic field effect on the cathode spot behaviour. It consists of 7 turns with an inner diameter of $35 \mathrm{~mm}$ and a maximum magnetic field of 105 Gauss at a maximum current of $100 \mathrm{~A}$ delivered by the coil power supply. The effect on the cathode spot behaviour of the coil around the target was not very strong. This is because of the source size limitations, and its position in the chamber window, which did not permit necessary turns of the coil. A thinner target with larger erosion surface would allow the use of electromagnets with more turns and adjustable magnetic fields to confine the cathode spot on the surface target.

One property of the coatings produced was observed in this initial study. The roughness of the coatings was measured by a talystep with coating thicknesses. It showed that the coating surface roughness increased with deposition current. This is due to increase of microparticle size and density in the coatings produced, or from delamination due to a combination of compressive coating stress and adhesion failure. 
For the same source to substrate distance ( $160 \mathrm{~mm}$ ), average roughness $R_{a}=235 \mathrm{~nm}$ at current ( $60 \mathrm{~A}$ ), and $\mathrm{R}_{\mathrm{a}}=466 \mathrm{~nm}$ at $(100 \mathrm{~A}$ ). Average roughness ( source to substrate distance $=160 \mathrm{~mm}$ ) was $R_{a}=466 \mathrm{~nm}$ and $R_{a}=433 \mathrm{~nm}$ ( source to substrate distance $=$ $220 \mathrm{~mm}$ ).

\subsection{SECOND EXPERIMENTAL APPROACH}

The modified arc source was mounted in the chamber window, rather than placed inside the chamber, to allow a magnetic coil or any auxiliary equipment to be installed in the system figure 5.5. The resistors were connected in series between the poles of the arc supply as mentioned in the first approach.

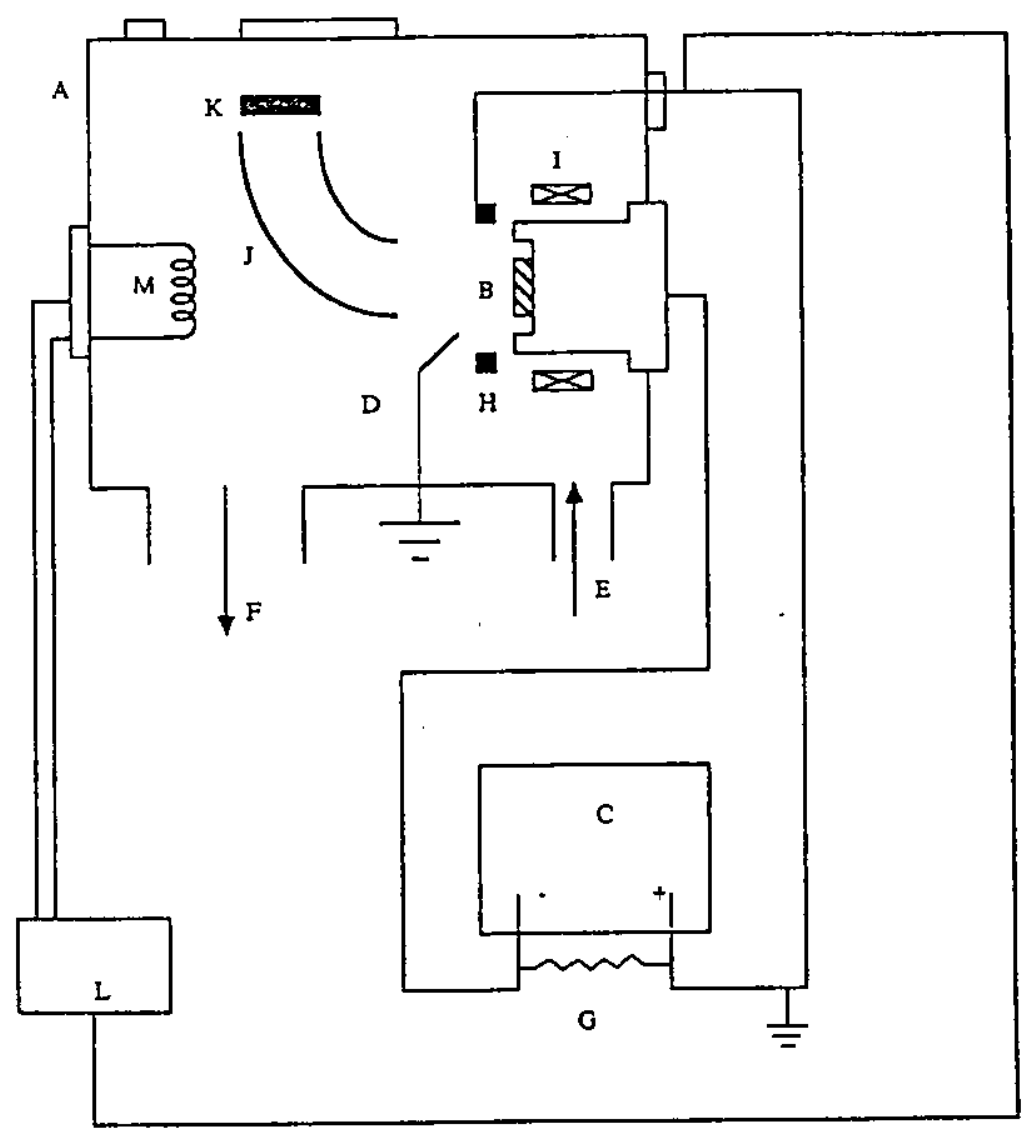

Figure 5.5. Second experimental arrangement: A: Vacuum chamber, B: Cathode, C: Welding power supply, D: ignitor, E: Gas inlets, F: Vacuum pumps, G: Resistors, H: Anode, I: Magnet ring, J : Magnetic coil, K: substrate holder, L: Anode-Filament supply, M: Filament. 


\subsection{THIRD EXPERIMENTAL APPROACH}

The following modifications were introduced to the system :

1. An increase in the arc source length, to prevent overheating of the shield and melting of the insulator chamfer which isolates the arc source from the chamber wall. This was due to the plasma reflecting onto the cathode target.

2. Water cooling of the shield was introduced to prevent the destruction of insulators by overheating from the plasma.

3. A magnetic stabilization for the arc spot was tested by using both permanent and electromagnetic fields

The filtered arc system used in the film deposition is shown in figure 5.6. 


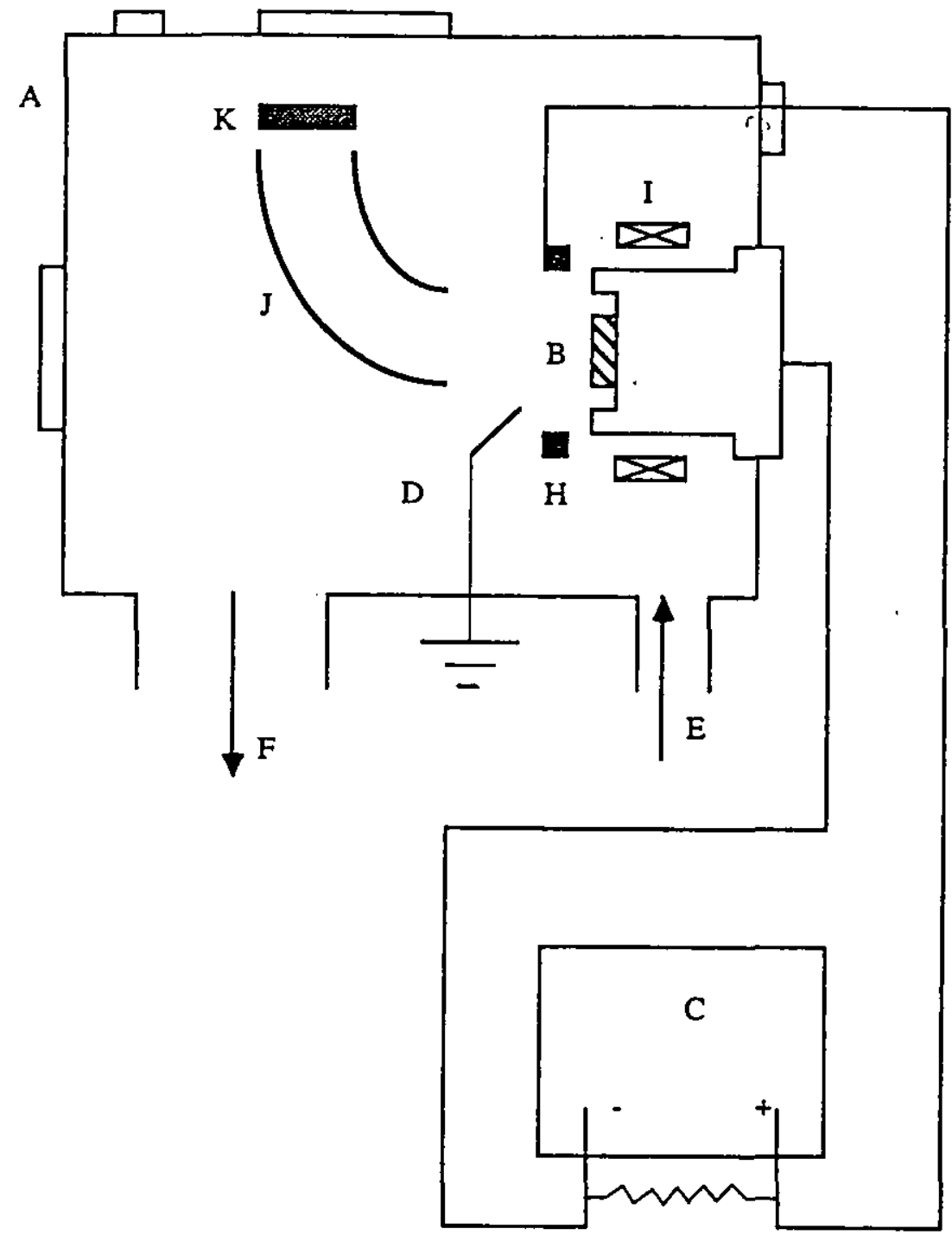

G

Figure 5.6. The filtered arc system. A: Vacuum chamber, B: Cathode, C: Welding power supply, D: ignitor, E : Gas inlets, F: Vacuum pumps, G: Resistors, $\mathrm{H}$ : Anode, I: Magnet ring, J : Magnetic coil, K: substrate holder. 


\subsection{THE CATHODIC ARC SOURCE}

An assembly of the modified arc source is shown in figure 5.7.

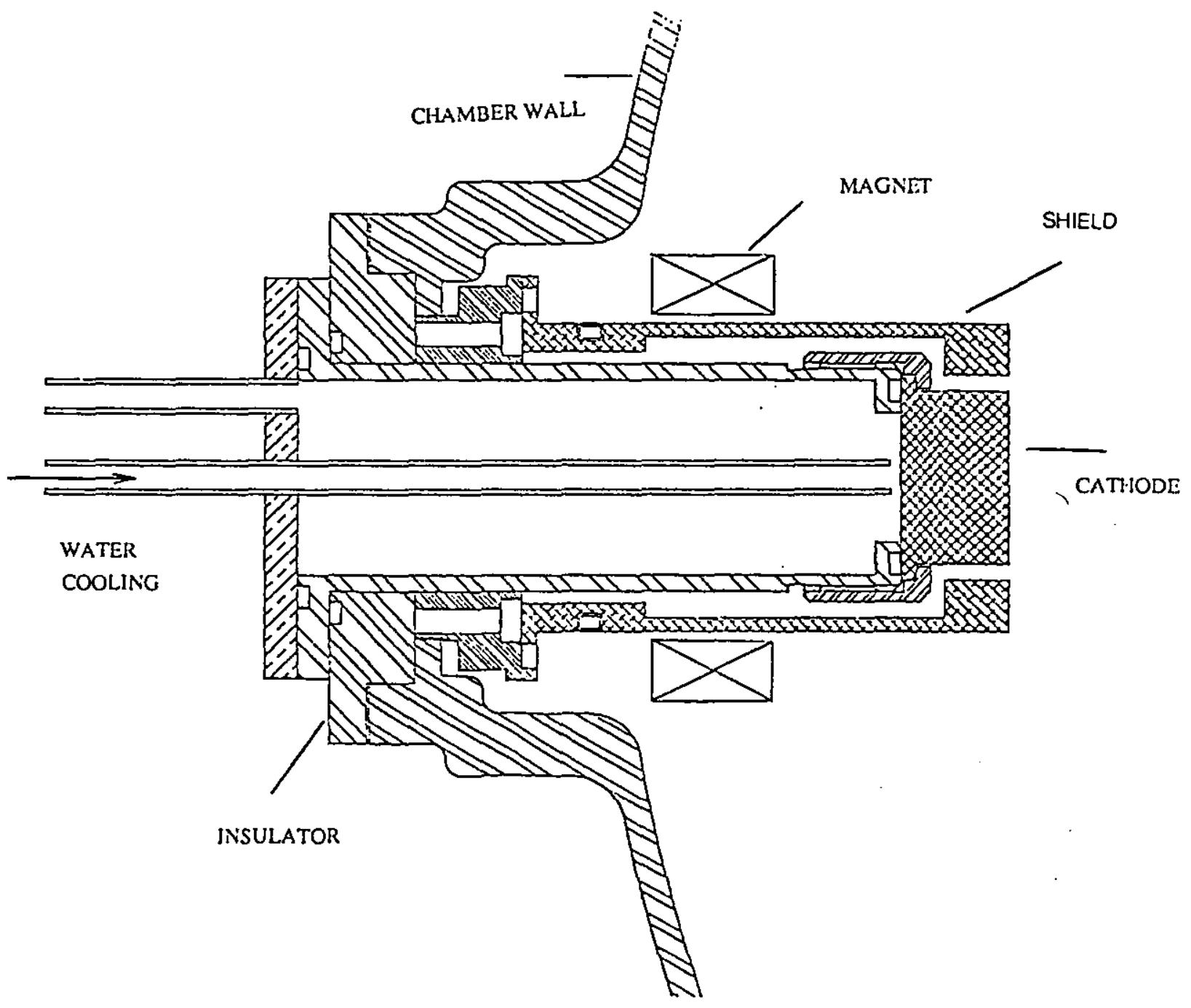

Figure 5.7. A schematic diagram of the modified arc source. 


\subsubsection{The Cathode target:}

For direct current operation, the cathode must be made of conducting material, and most cathodes utilized presently in the film deposition are metals such as aluminum, copper, titanium, stainless steel and carbon. Table 5.2 shows materials used or produced during experiments with their melting points. The cathode of the arc source which is illustrated in figure 5.8 , was $32 \mathrm{~mm}$ in diameter, water-cooled, and connected to the negative side of an arc welding supply.

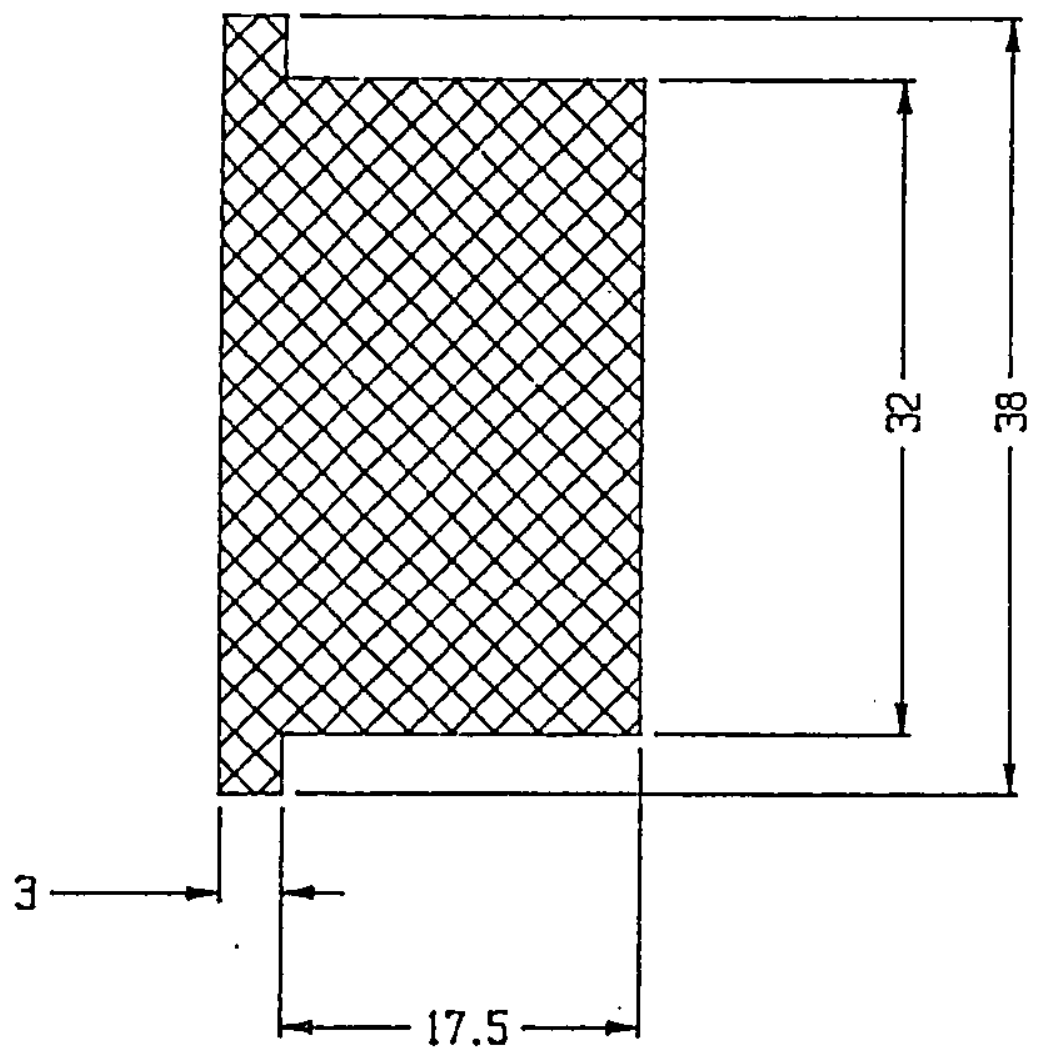

Figure 5.8. It illustrates the cathode arc source target. 


\begin{tabular}{|l|c|}
\hline Materials & Meling Point ${ }^{\circ} \mathrm{C}$ \\
\hline $\mathrm{Al}$ & $659^{\circ} \mathrm{C}$ \\
$\mathrm{C}$ & $-3700^{\circ} \mathrm{C}$ \\
$\mathrm{Cu}$ & $1084^{\circ} \mathrm{C}$ \\
$\mathrm{Ti}$ & $1660^{\circ} \mathrm{C}$ \\
$\mathrm{TiN}^{\circ}$ & $2930^{\circ} \mathrm{C}$ \\
$\mathrm{TiO}_{2}$ & $1825^{\circ} \mathrm{C}$ \\
$\mathrm{Al}_{2} \mathrm{O}_{3}$ & $2047^{\circ} \mathrm{C}$ \\
$\mathrm{AlN}$ & $2250^{\circ} \mathrm{C}$ \\
Tungsten & $-3410^{\circ} \mathrm{C}$ \\
\hline
\end{tabular}

TABLE 5.2 Melting points of materials used/ produced during experiments.

\subsubsection{The anode}

After various considerations, the anode was typically located in front of the cathode, in symmetric position with the magnet ring which provides magnetic stabilization of the arc on the surface of the cathode. The water-cooled anode was made of a copper tubing ring. It was connected to the positive pole of the welding power supply and via a series of resistors to ground. The connection of the anode to ground has proven to be more suitable to stabilise the arc operation on the target surface.

\subsubsection{The Arc source shield}

A floating aluminum shield was mounted around the cathode target. It is illustrated in figure 5.9. It is water-cooled shield of $90.5 \mathrm{~mm}$ length and has an outer diameter of $57 \mathrm{~mm}$. It was used to constrain the arc source plasma of the cathode and prevent any undesirable external influence on the cathode surface. 


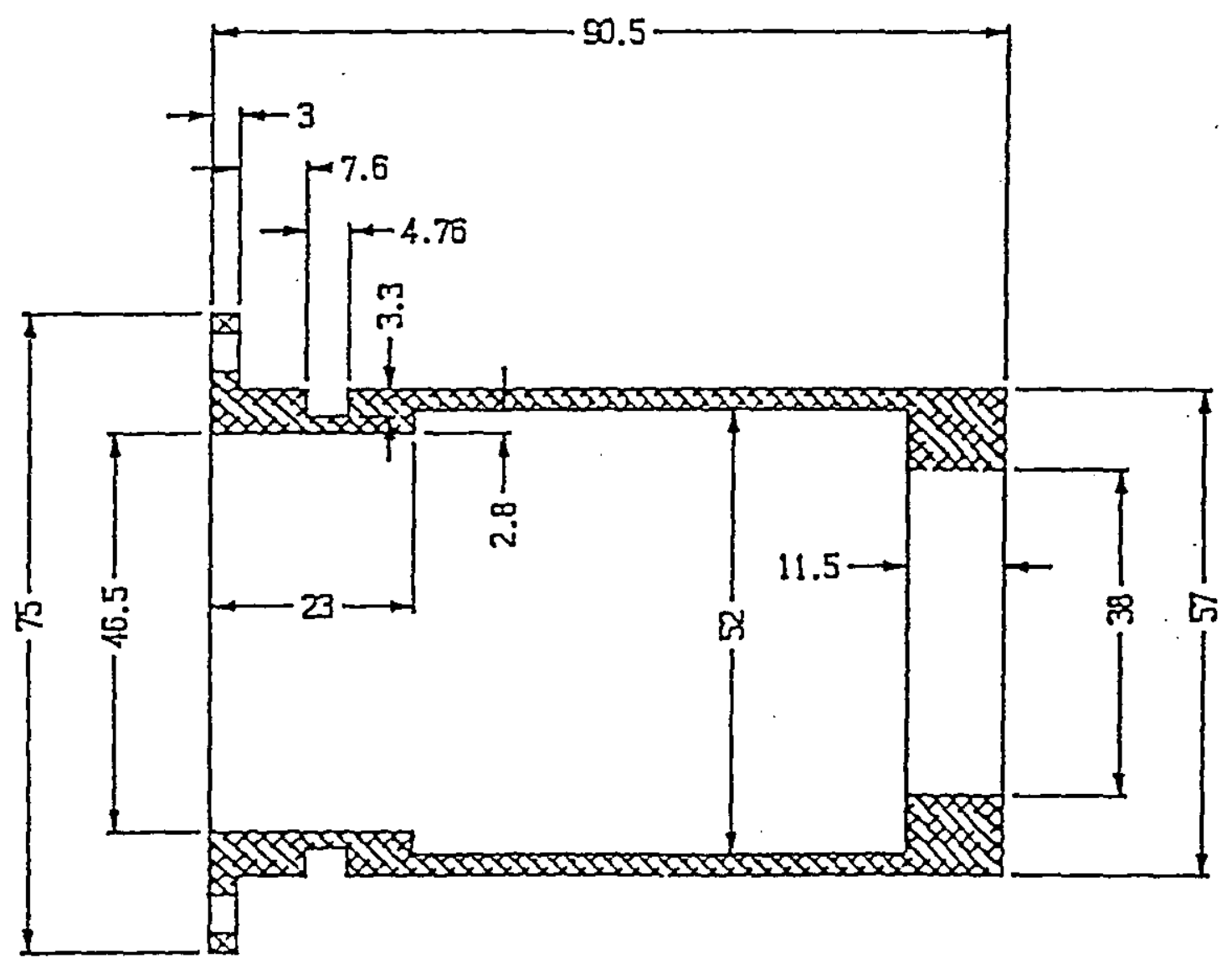

Figure 5.9. It shows the arc -source shield diagram. 


\subsubsection{Arc trigger / ignitor}

The arc may be created or "triggered " in several ways. Common methods are a momentary contact with the cathode by a movable trigger [2], or a high-voltage, low current pulse between the cathode and an adjacent trigger electrode [3].

A movable tungsten trigger connected to ground was used to initiate the arc. It is momentarily touched onto the cathode and then withdrawn from the plasma path to prevent it melting, which would contaminate the coatings during the deposition process. 
chapter five

\subsection{ARC POWER SUPPLY}

The arc was sustained by high-current welding type power supply. It is capable of delivering currents up to 400 Amperes, and a voltage of 85 volts, although the arc was normally operated in the range 75 - 110 Amperes, the lowest range of current at which the arc would run steadily without re-ignition. The arc voltages required were in the range $15-30$ volts, depending on the cathode source material.

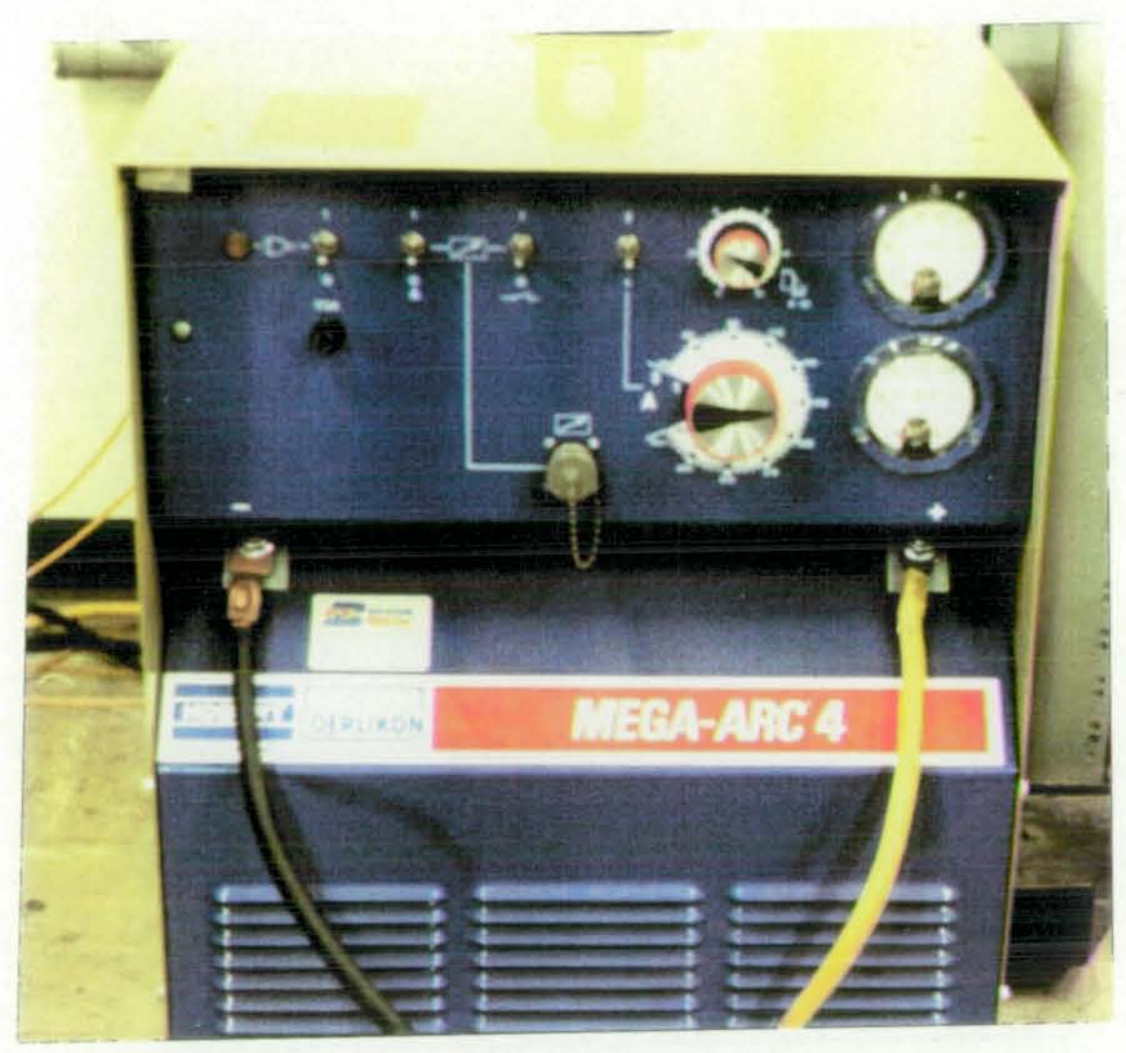

Figure 5.10. A photograph of the arc power supply. 


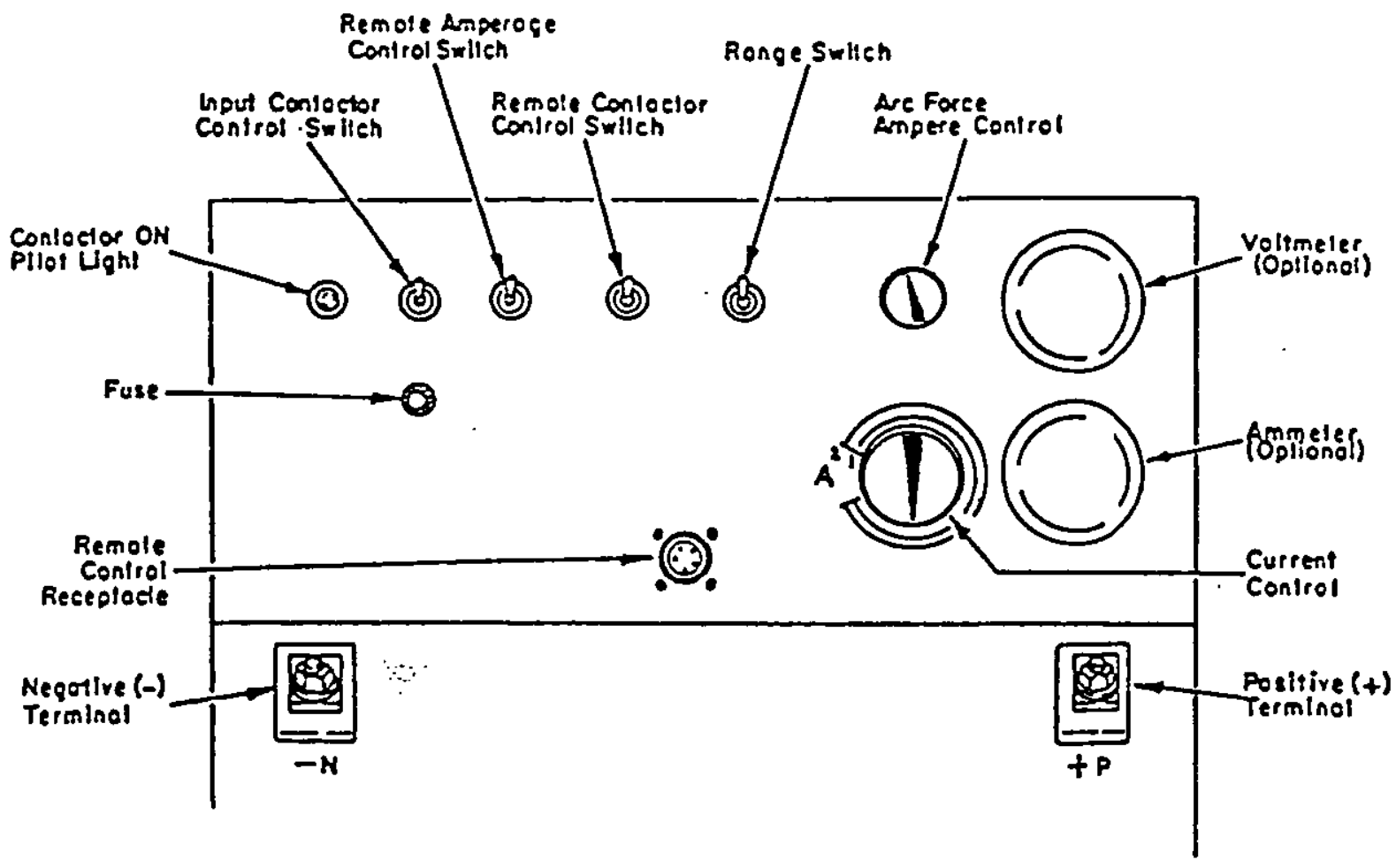

Figure 5.11. A control panel of the arc power supply.

\subsection{BIAS VOLTAGE AND COIL SUPPLIES}

The coil power supply was from a dc supply capable of delivering current up to 70 amperes, and a voltage of 19 volts.

The bias voltage applied to the coil was obtained by a Philips dc power supply, which is capable of delivering currents up to 10 amperes, and a voltage of 150 volts. The bias supply was also used to measure the I-V characteristics and the floating potential from a probe placed in the plasma path towards the substrate.

\subsection{FILAMENT DISCHARGE ENHANCEMENT}

A tungsten filament and anode arrangement was used to create additional plasma around the target surface inside the vacuum chamber. The minimum current required for a discharge was 45 Amperes for the filament, while the minimum current required on the 
anode was 3 Amperes, and the voltage was 35 Volts. It was hoped that such an arrangement would allow simple initiation of the arc and provide stabilisation of its operation, as well as providing plasma for direction to the substrate surface. The filament is illustrated in figure 5.12. It did not provide consistent starting for the arc and a mechanical starter had to be used with a reconsideration of the experimental setup. The only case when the filament discharge allowed the arcing process without a mechanical ignitor was when the target surface was very smooth. This indicated the dependence of the arc creation on the cathode surface microstructure.

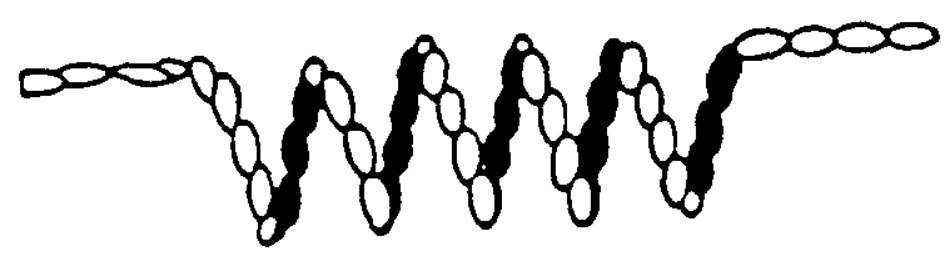

Figure 5.12. Filament used during early experiments.

The admission of oxygen into the system after the plasma generated, required the filament to be tumed off to avoid its oxidation and destruction.

The filament was then removed and the anode connected to ground. This allows a consistent initiation for the arc with a mechanical starter, despite the fact that a re-ignition is common for arc using a mechanical starter because the arc may suddenly switch off. 

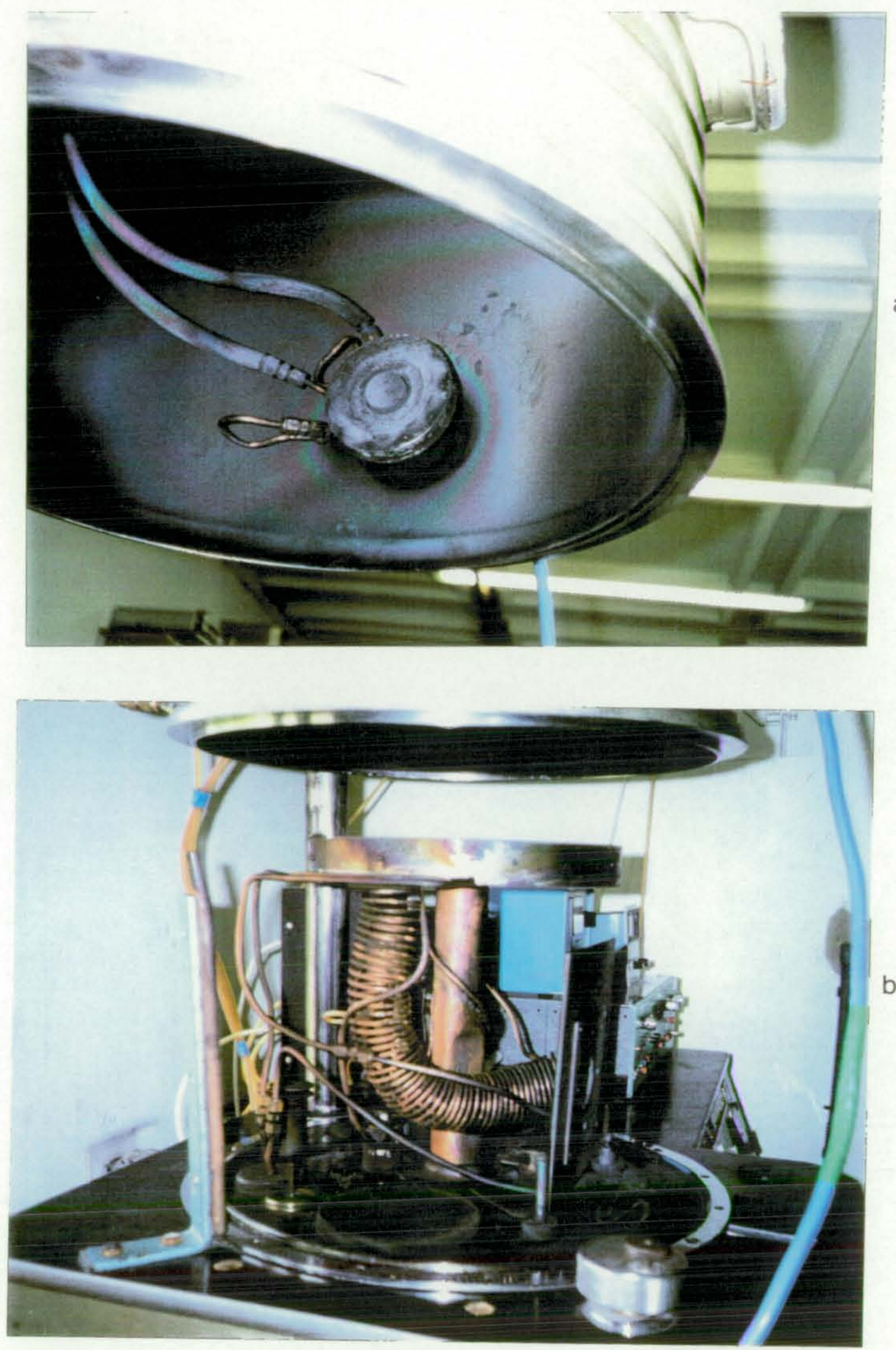

Figure 5.13. A photogragh of the deposition system used during film depositions. (inner view). a) cathodic arc source, b) coil and substrate holder. 


\subsection{MAGNETIC CONFINEMENT}

\subsubsection{Cathode Spot Confinement}

Arc control is necessary to protect the arc coating equipment from destruction and prevent the contamination of coatings from any undesirable material when the arc jumps to the surrounding material or the shield in the absence of a magnetic or electrostatic constraints. Initially, the arc spot moves randomly on the cathode surface. To control the spot motion, a number of approaches were explored to confine the cathode spot on the target surface, but only the main ones are stated here.

\section{A. Coil behind the target}

First, to produce the magnetic field, the copper coil shown in figure 5.14 was mounted behind the target in water, the coil was made of insulated copper wire $2 \mathrm{~mm}$ o.d. with 92 turns. Figure 5.15 shows the coil positioned behind the cathode.

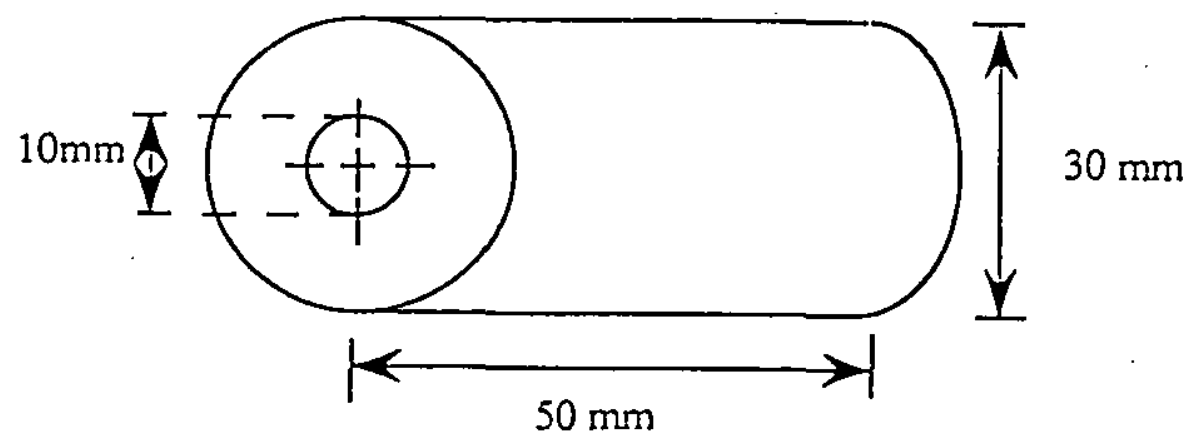

Figure 5.14. A diagram for the coil used behind the target to confine the cathode spot. 


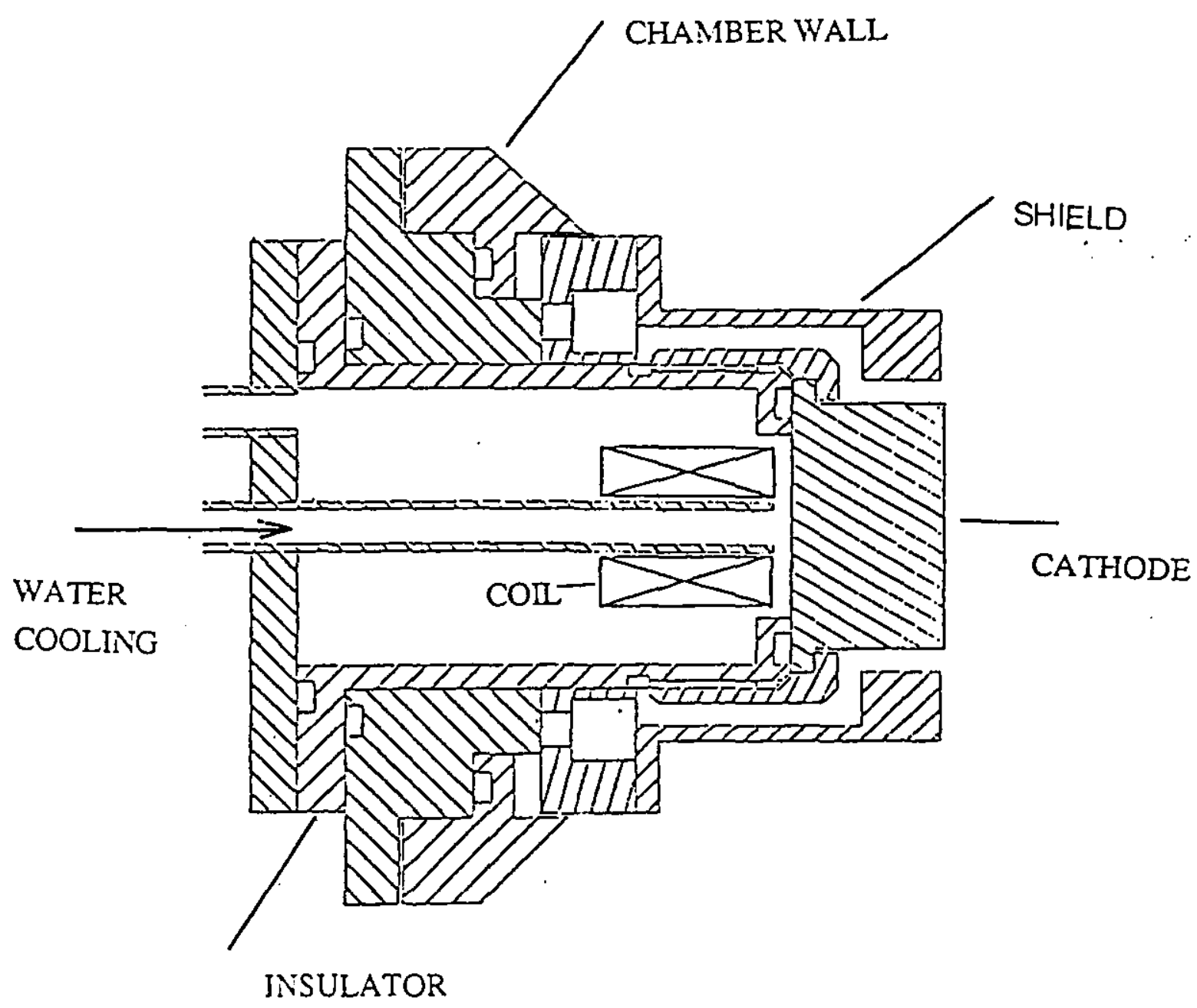

Figure 5.15 shows the coil positioned behind the cathode 
The highest magnetic field produced by the coil with a current of 70 Amperes was only 145 Gauss, which has no effect on the behaviour of the cathodic arc source and was not enough to confine the arc in a circular path. The cause of this aspect was the small surface area of the target and the thickness of the target which limited the effect of the magnetic field on the spot behaviour.

Then, a coil of 220 turns from $1.5 \mathrm{~mm}$ diameter insulated copper wire was wound on a stainless steel tube, the coil was mounted around the arc shield for testing the effect of a uniform magnetic field on the spot motion. The Philips- dc power supply used to feed the coil gives 10 amperes with maximum 40 volts. The test of the coil was limited by overheating if the arc ran for a period of two minutes, and by the lack of cooling used in this test. The magnetic field created was 140 Gauss, and forced the spot of an aluminum target to move in a circular motion on the cathode surface, the arc current was 70 amperes with a $3 \mathrm{~m}$ Torr argon pressure.

\section{B. MAGNET RING}

A magnetic ring was placed around the cathode surface to stabilize the arc and steer the arc spot in a circular motion. The sense of the magnetic field produced by the magnet was reversed by the sense of the solenoid field used to divert and direct the plasma created around the surface of the target, onto the substrate and growing film surface. The ring, made with high-field permanent magnets gives a magnetic field of 345 Gauss around the edges of the ring and nearly negligible field in the centre. This magnetic field defines a well-controlled circular path for the arc to follow. The magnetic fields within and around the magnet ring were measured directly using a gaussmeter. Figure 5.16 shows the cathode spot track caused by the magnet ring around the target. 


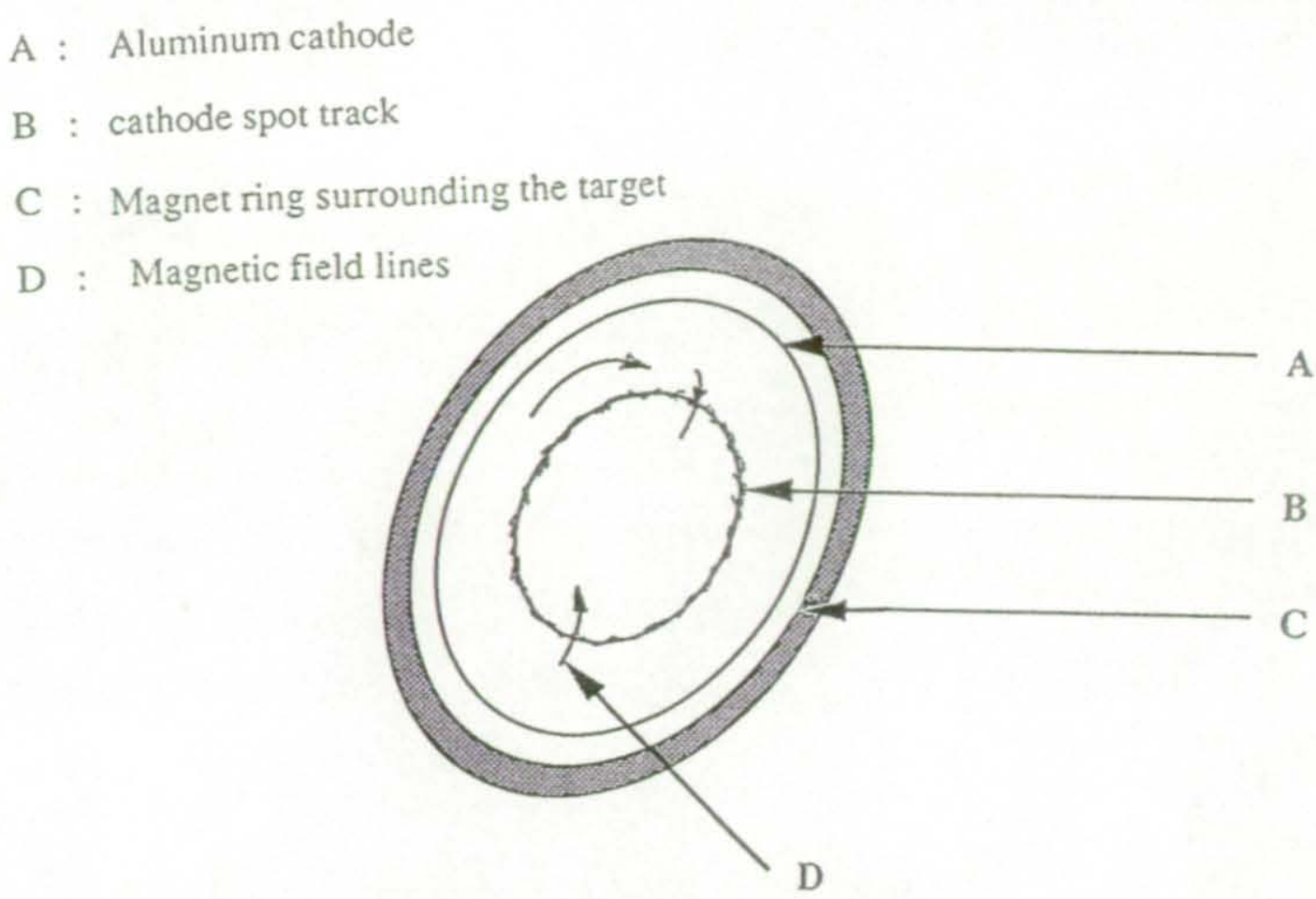

Figure 5.16. A diagram shows the cathode spot track caused by the magnet ring around the target.

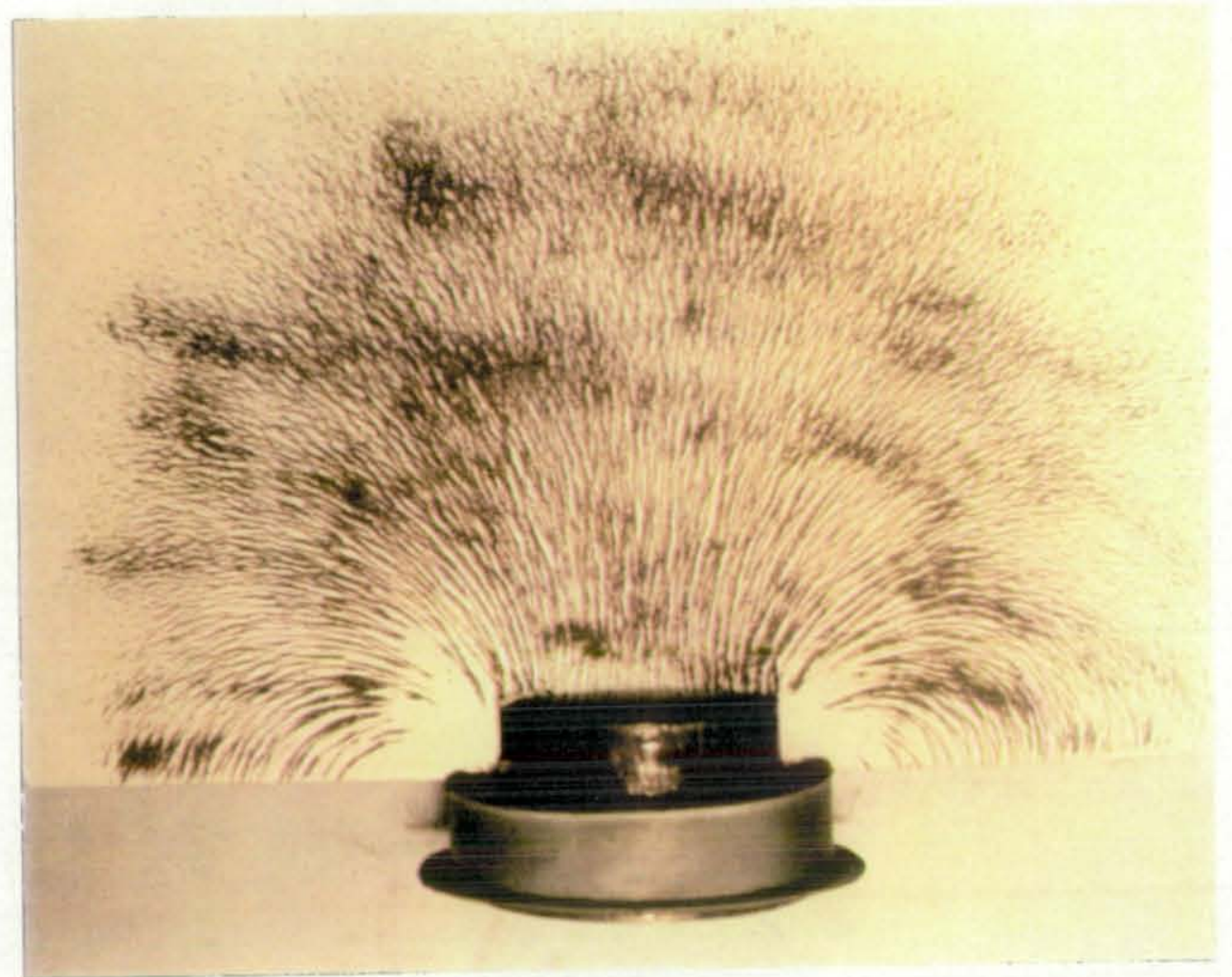

Figure 5.17. A photograph of the iron filing representation of the magnetic field lines used to control the arc spot. 
chapter five

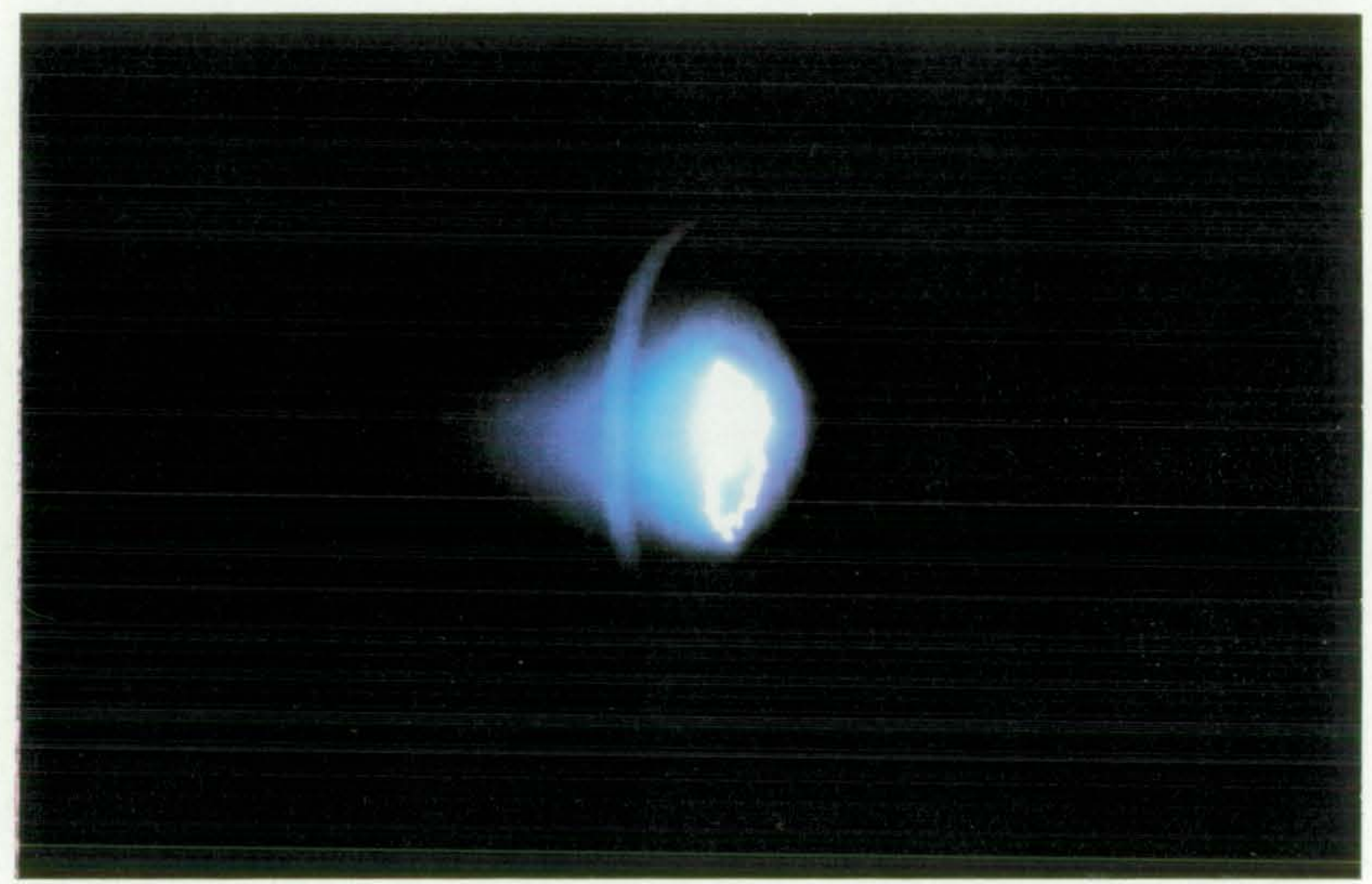

Figure 5.18. A photograph of the cathode spot trajectory caused by the magnet ring. 


\subsubsection{Plasma binding by a permanent magnet}

One simple configuration is a circular magnet with a core inside, used to bind the plasma and to provide a no-line-of-sight path for the plasma towards the substrate. The substrate was fixed on a platform behind a shield which precludes line-of-sight microparticles from passing to it, while allowing a relatively high transmission of plasma steered by the magnetic field produced by the permanent magnet behind the substrate figure 5.19 .

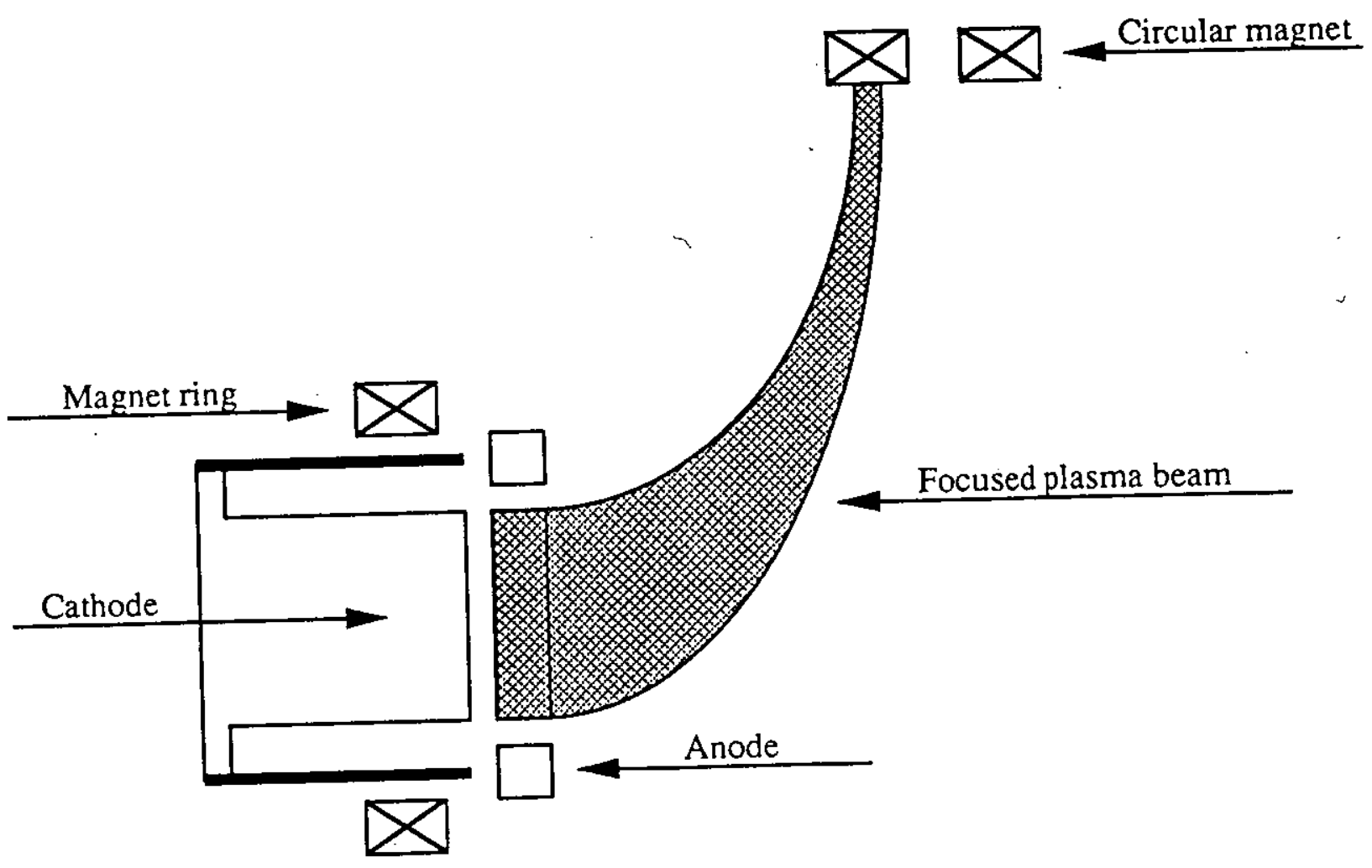

Figure 5.19. A diagram shows the focusing of the beam on the edge of the permanent magnet: 


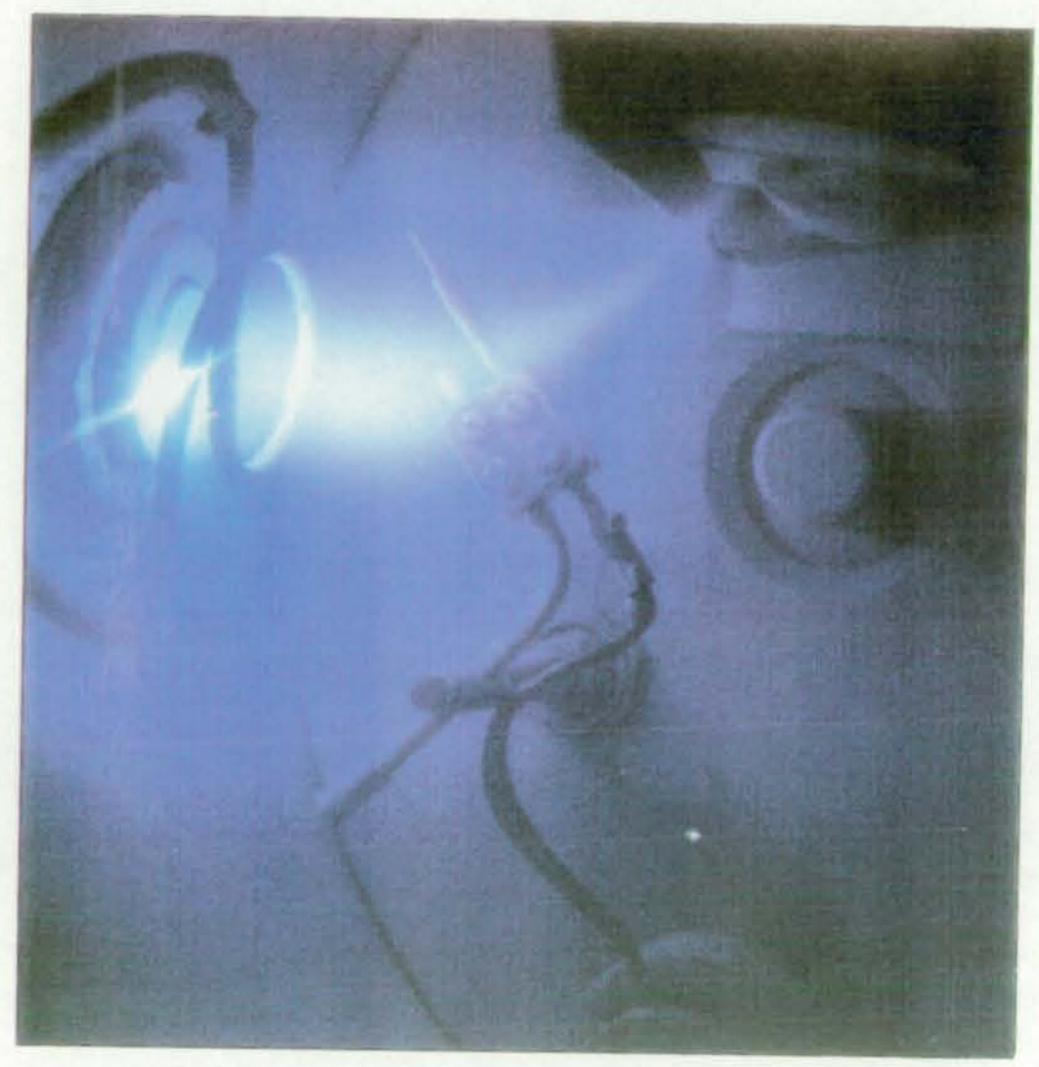

Figure 5.20. A photograph of the beam steered by the permanent magnet

The substrate was also slightly separated from the area where the beam is focused. When the apparatus is in operation, the microparticles and the neutral particles move in straight lines, generally at low angles from the surface of the cathode [7]. The charged ions and electrons were moving along the plasma path defined by the magnetic field, and reach the substrate during deposition.

The plasma stream that condenses on the substrates contains no microparticles. A photograph of the beam steered by the permanent magnet shown in figure 5.20. 


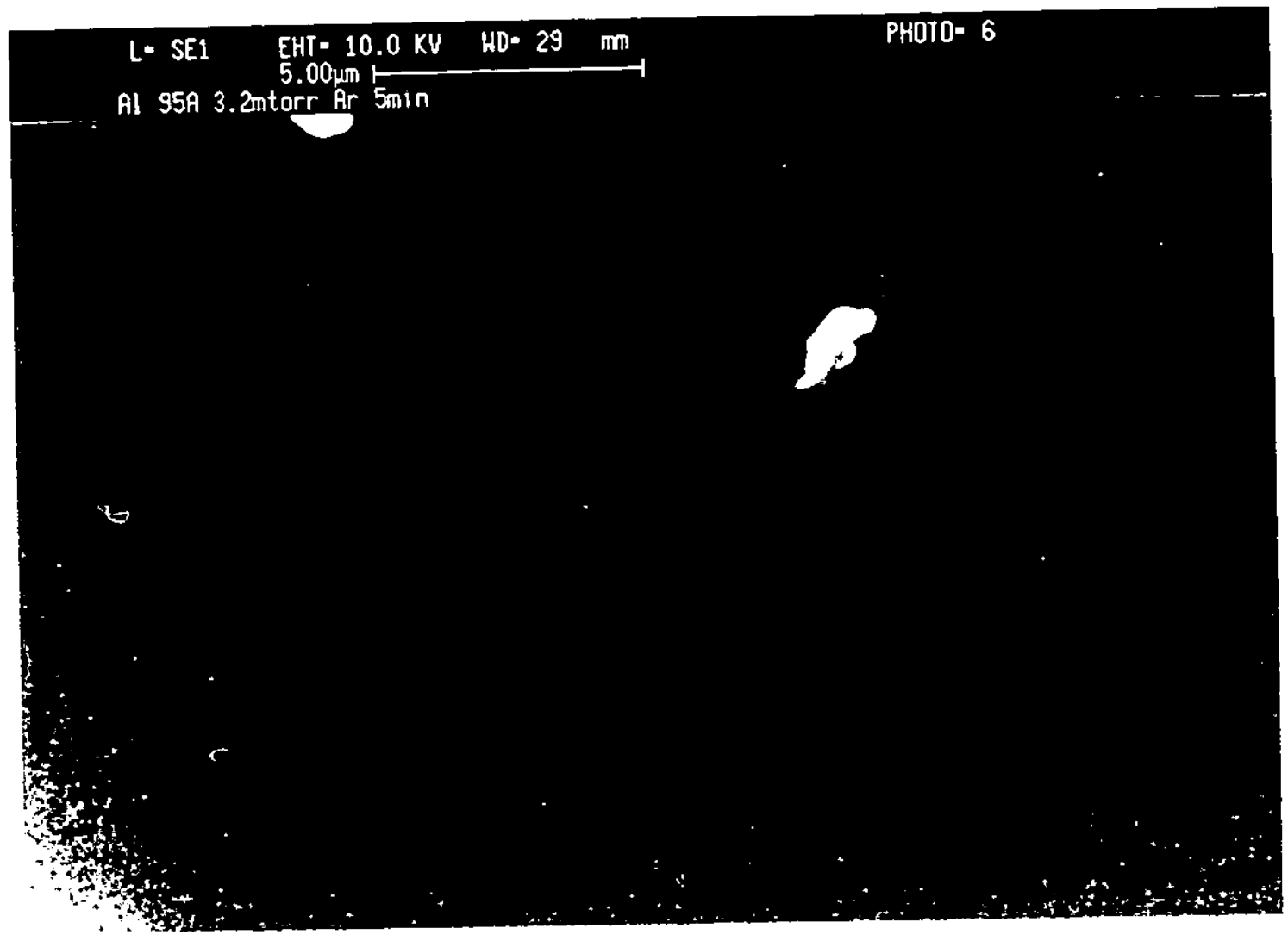

Figure 5.21. SEM microgragh of Aluminum film deposited by arc evaporation, microparticles free, by binding the plasma with a permanent magnet. 
One disadvantage of this approach, is that the plasma beam bent . towards the edge of the permanent magnet, and was focused rather than broadened at the contact with the substrate surface, which caused the overheating seen on the films deposited onto glass.

To avoid this defect on the film and permit: plasma transmission with good efficiency, another approach was explored, it was a curved solenoid to allow a relatively high transmission of plasma by virtue of an axial magnetic field and precludes line-of-sight microparticles from passing through it towards the substrate.

\subsubsection{Plasma duct}

The plasma duct was a solenoid wound from copper tubing through which water passes for cooling. The solenoid consists of 56 turns of $4 \mathrm{~mm}$ o.d. tubing wound with an average turn-to-turn spacing of $1.5 \mathrm{~mm}$. The inner diameter of the solenoid is 52 $\mathrm{mm}$ and its length is $350 \mathrm{~mm}$. The maximum magnetic field obtained was 250 Gauss with a dc current of 70 Amperes.

To understand the operation of the solenoid, we must consider the motion of electrons and ions in electric and magnetic fields. Electromagnetic forces dominate the motion of charged particles at the atomic level. If an electric field $\mathrm{E}$ and a magnetic field $\mathrm{B}$ exist in a region, then the combined force $F$ on a particle with charge $q$ and velocity $v$ is given by:

$$
F=q E+q v \times B
$$

This force is often called the Lorentz force.

We first consider the motion of a charged particle in a uniform magnetic field with no electric field present. Suppose that the magnitude of the field is B and that the direction is out of the plane of the page, as shown in figure 5. 22 . If the velocity is perpendicular to a uniform magnetic field and no other forces are acting, then the charged particles moves in a circular path. The speed of a particle of mass $m$ and the radius of its circular path are connected by :

$$
\mathrm{r}=\mathrm{m} v / \mathrm{qB}
$$


Equation 5.2 shows that, in a uniform magnetic field, the angular speed or the angular frequency, of the circular motion depends only on the field $B$ and on the charge-to-mass ratio $\mathrm{g} / \mathrm{m}$ for that type of particle. The angular frequency is often called the cyclotron frequency

$$
\mathrm{w}_{\mathrm{c}}=\mathrm{v} / \mathrm{r}=\mathrm{qB} / \mathrm{m}
$$

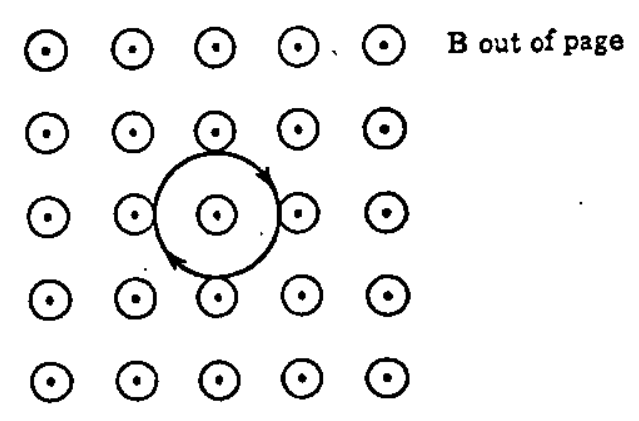

Figure 5.22. A positively charged particle moves in a circular path perpendicular to a uniform magnetic field [9].

We now consider a configuration of crossed electric and magnetic fields which act as a velocity selector for charged particles entering the region with velocity perpendicular to the crossed fields. Only those with velocity $v=E / B$, pass through the selector undeviated. A velocity selector is used in devices such as the mass spectrometer [ 8] 

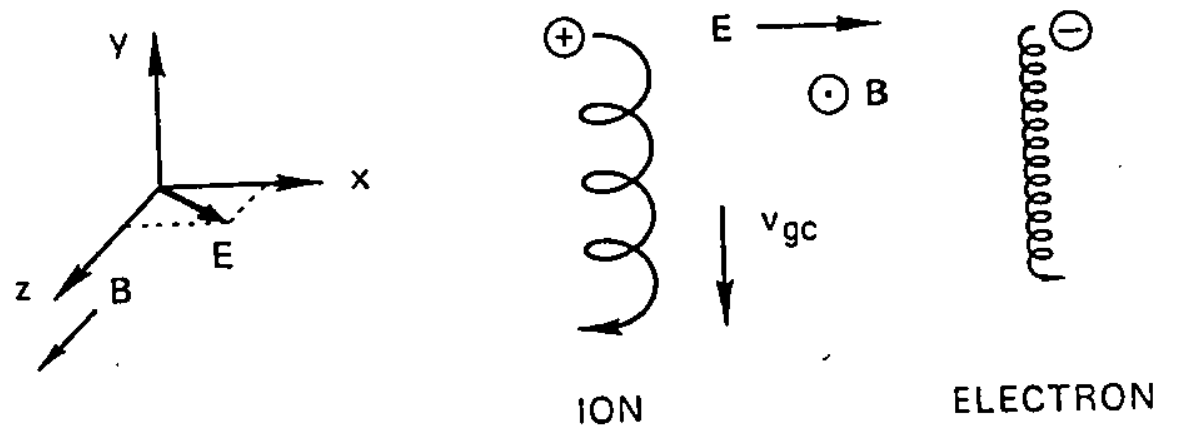

Figure 5.23 . A positively charged particle / electron move in crossed electric and magnetic fields [10].

When the plasma duct is in operation, the microparticles and the neutral particles move in straight lines generally at low angles from the surface of the cathode and settle on the inner surface of the plasma duct entrance. Then, the neutral particles and microdroplets are not influenced by the electrostatic or magnetic fields. 
At the maximum magnetic field, with the plasma duct grounded, so that there is essentially no electric field in the system, it is the low-energy ions which are transported through the system [4].

When the plasma duct is "detached" from ground i.e. floating and crossed electric and magnetic fields exist, the axial magnetic field confines electrons in the plasma to helical paths along the axis of the duct. The radial electric field forces the ions to the central region along the duct, which acquires a positive potential of between 12 and 18 volts even without being connected to a special supply source. The positive floating potential is evidently due to the ionised species bombarding the duct walls [7].
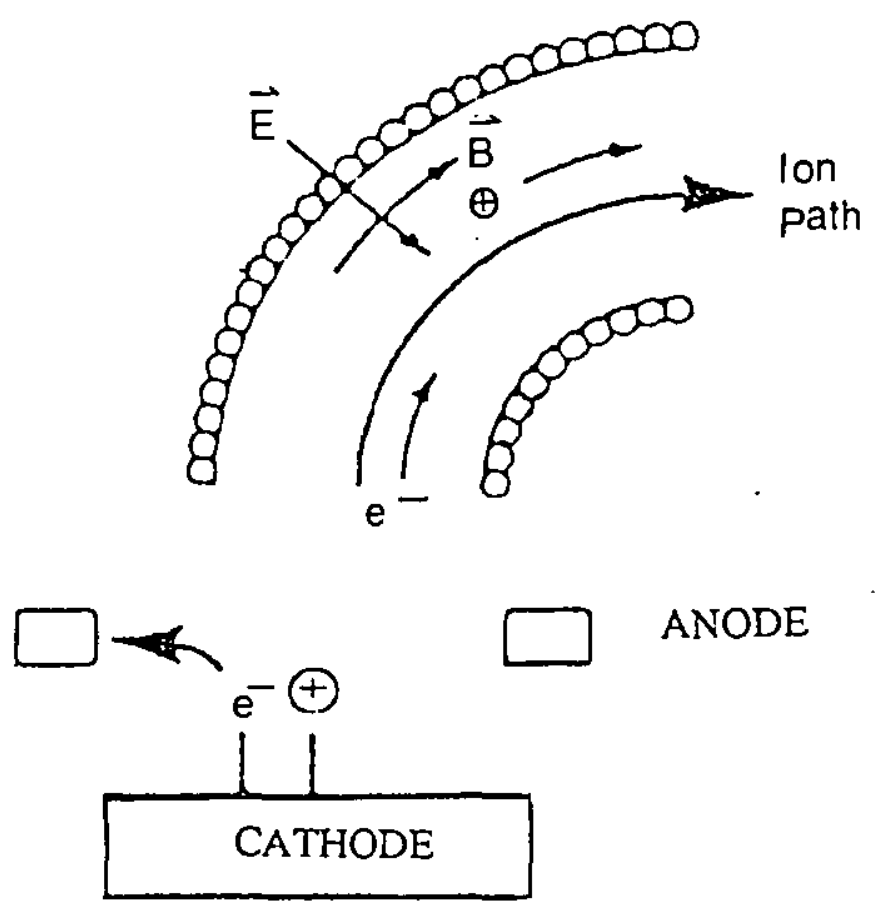

Figure 5.24. A diagram of the plasma duct with the crossed electric and magnetic fields. 


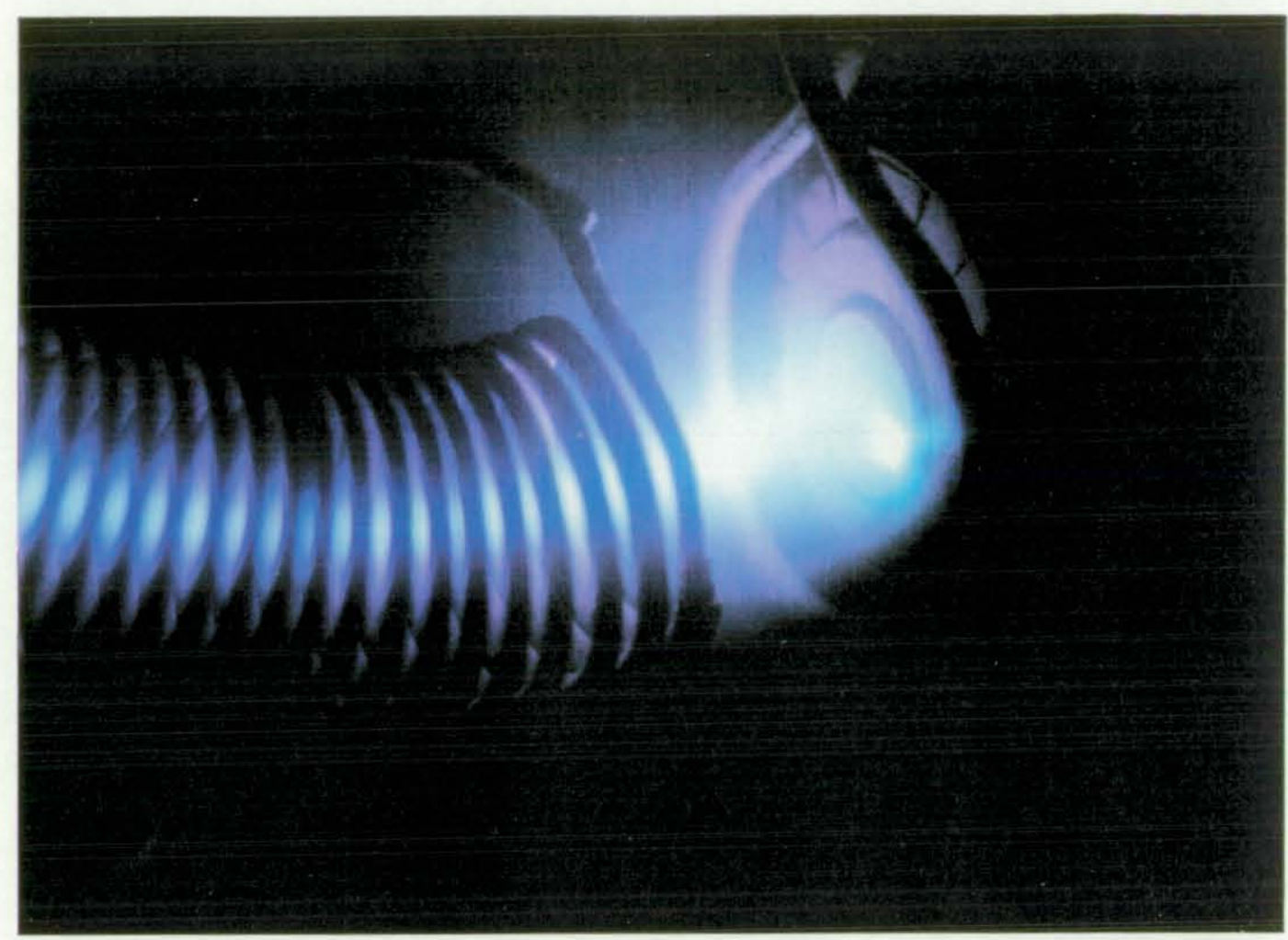

Figure 5.25. A photogragh of the steered plasma through the coil when the coil is floating (entrance).

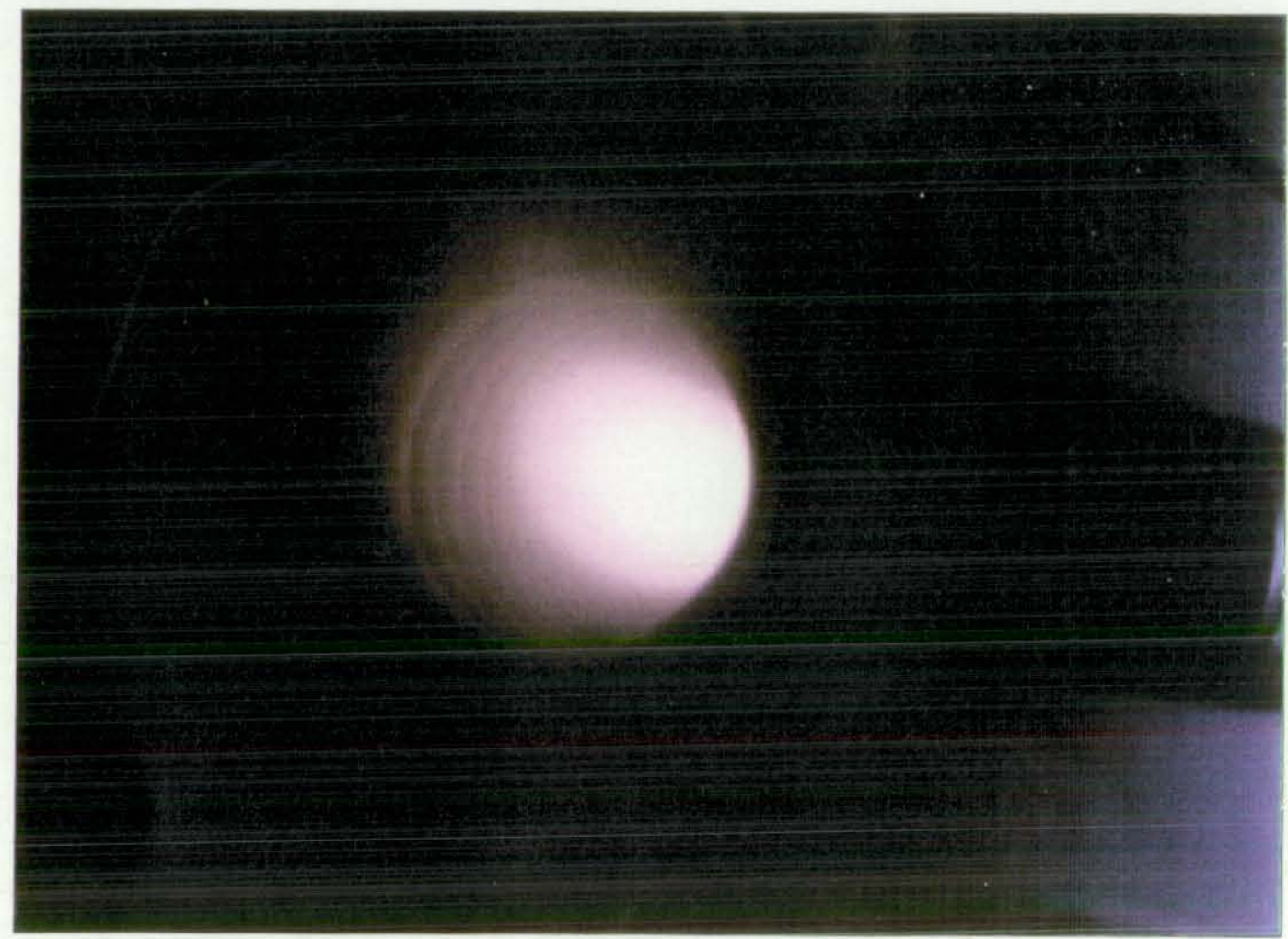

Figure 5.26. A photogragh of the plasma at the coil exit, when the coil is floating. 


\subsection{PROBE CONFIGURATION}

The probe used to give I-V characteristics and hence to give values of the ion-currents flowing to the growing film surface and floating potential of the substrate was a one centimetre square surface made of stainless steel, mounted on the centre axis of the solenoid and in the substrate position, $200 \mathrm{~mm}$ from the arc source.

A pyrex tube was used to cover the probe body except the surface which will be exposed to the plasma stream, this tube serves as an electrical and thermal insulator between the probe and the holder. A copper lead was used to connect the probe to a bias power supply. The power supply used capable of delivering a voltage of 150 Volts and a current of 10 Amps. The probe was biased at various voltages and the currents were measured.

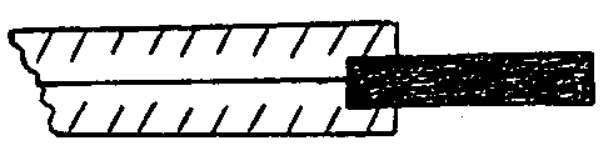

Figure 5.27. illustrates a configuration of the probe used. 


\subsection{SUBSTRATE HOLDER}

The substrate holder design is primarily dictated by the coating uniformity requirement, and the shape and geometry of the substrate or parts to be coated. Since the substrates used were microscope slides of size $12 \times 76 \mathrm{~mm}$, thickness $1 / 1.2 \mathrm{~mm}$, a multi-substrate holder ( 6 substrates) was made with water cooling connection and rotated by an external motor drive. The speed of scanning the substrate was adjusted to achieve uniformity and higher deposition rate. The substrate holder is shown in figure 5.29. 


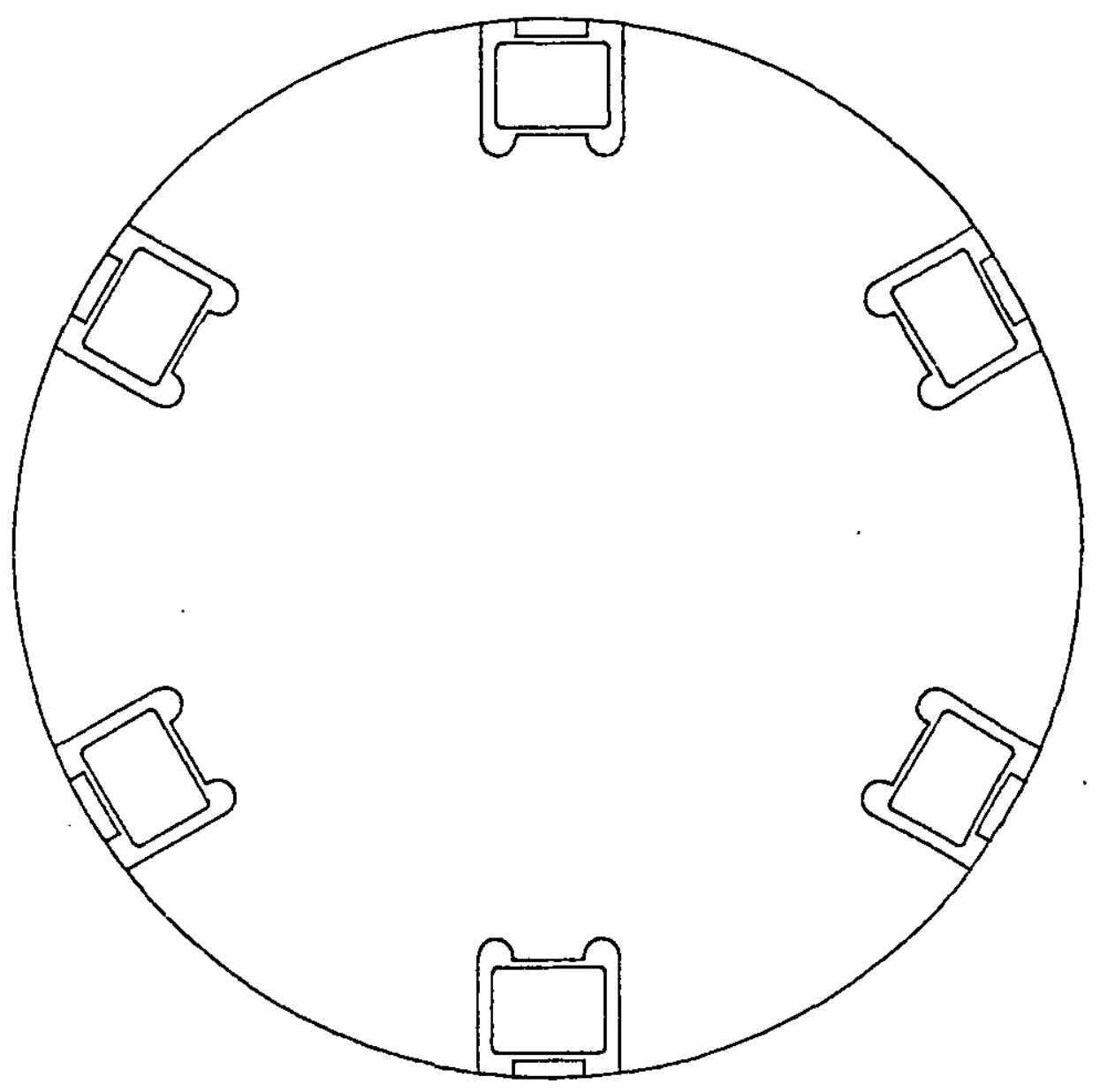

Figure 5.29. shows the substrate holder. 


\subsection{SUMMARY}

- During the plasma transfer through the solenoid, when the plasma duct is floating, i.e. detached from ground, a positive potential arises at the duct walls from the positive ions striking the walls. This assures a more efficient transport of the plasma than when the plasma duct was connected to ground.

- The arc creation process on the cathode depends on the cathode surface micro-structure.

- Depending on the metals we used (copper , titanium and aluminium $99.99 \%$ pure ), the stability of the arc strongly depends on the arc current.

- The open circuit voltage of the arc power supply must exceed approximately $30 \mathrm{~V}$ for reliable arc ignition. 


\section{REFERENCES}

[1]. Saul Dushman. "ScientificFoundation of Vacuum Technique ". John Wiley \& Sons Inc., New york (1962).

[2]. A.A. Snaper, US Patent, No.3, 625, 848 (1971).

[3]. I.G. Brown, J.E. Galvin, and R.A. Macgill, Appl. Phys. Lett.47,358, (1985).

[4]. I.I. Aksenov, I.I. Konovalov, E.E. Kudryavtseva, V.V. Kunchenko, V.E. Padalka, and V.M. Khoroshikh, Sov. Phys. Tech. Phys. 29, (8), 893 (1984).

[5]. R.L. Boxman and S. Goldsmith, J. Appl. Phys. 52, 252 (1981)

[6]. H.Randhawa, Thin Solid Films 167, (1988)

[7]. H.Randhawa. High rate deposition of $\mathrm{Al}_{2} \mathrm{O}_{3}$ films using modified cathodic arc plasma deposition processes. J. Vac. Sci. Technol. A7 (3), May/Jun (1989). 2346

[8] T. J. M. Boyd and J. J. Sanderson, "Plasma Dynamics".Barnes and Noble, New York, (1969).

[9]. M. A. Uman," Introduction to plasma physics" (McGraw-Hill), chapter 5 (1964).

[10]. F. F. Chen, "Introduction to plasma physics". Plenum Press. New York (1977). 


\section{CHAPTER 6 \\ COMPARISON OF REACTIVE MAGNETRON \\ SPUTTERING AND REACTIVE FILTERED \\ ARC EVAPORATION}

\subsection{INTRODUCTION}

In recent times, techniques of providing relatively low voltage ion-bombardment of a growing film have appeared which resulted in improved properties of the films that are made. They involve placing the insulating or isolated substrate in a dense $\mathrm{DC}$ plasma, where the self-bias that appears on the surface due to the need for electron and ion current to equalize causes the ions to be accelerated through voltages of up to 100 volts [1]. This bombardment is of particular consequence in reactive processing and has been used with plasmas produced by low voltage electron beam guns in evaporation systems [2], the highly ionised product of arc evaporation [3] and by redirecting the plasma created in a planar magnetron onto the substrate by unbalancing the magnetic field which confine it [4].

We have considered the performance of an unbalanced magnetron to identify the ion bombardment that can be created on an insulating substrate surface $[1,5]$. They can produce a bias of over 100 volts with a current density of $100 \mathrm{mAmp}$ per square centimetre. The surface bombardment is dependent on process parameters such as magnetron power and gas pressure, and a general diminution of the bombardment occurs as the pressure is increased.

The success of arc evaporation methods has been attributed to the considerable proportion of the evaporated material which is ionised, the reason for this being the low voltages present in an arc, for which there is a considerably greater cross section for ionization of atoms by electrons than at higher voltages encountered in electron beam and magnetron systems [3]. The technique has demonstrated considerable success in producing highly adherent thick films of titanium nitride onto biased metal substrates to provide wear resistant surfaces [3]. The coatings have been found to contain considerable amounts of droplets ejected from the target by the arc, which can be removed by separating ionized atoms from larger particles in a mass spectrometer type 
selector [6]. We have found that the plasma beam created in an unbalanced magnetron can be manipulated easily in a low value magnetic field intended to direct the electrons in the plasma, the ions are moved by the electrostatic attraction of them to the electrons. Very similar systems can then be envisaged for creating films under ion bombardment, between the output from an unbalanced magnetron and that of a selective arc evaporation. It was this comparison that forms the object of this investigation.

A comparison has been made between TiN films obtained from the optimised filtered arc process as described in chapter seven, and TiN films produced by the unbalanced magnetron.!

1

\subsection{THE SYSTEMS}

The unbalanced magnetron that was used is shown in figure 6.1 [5].

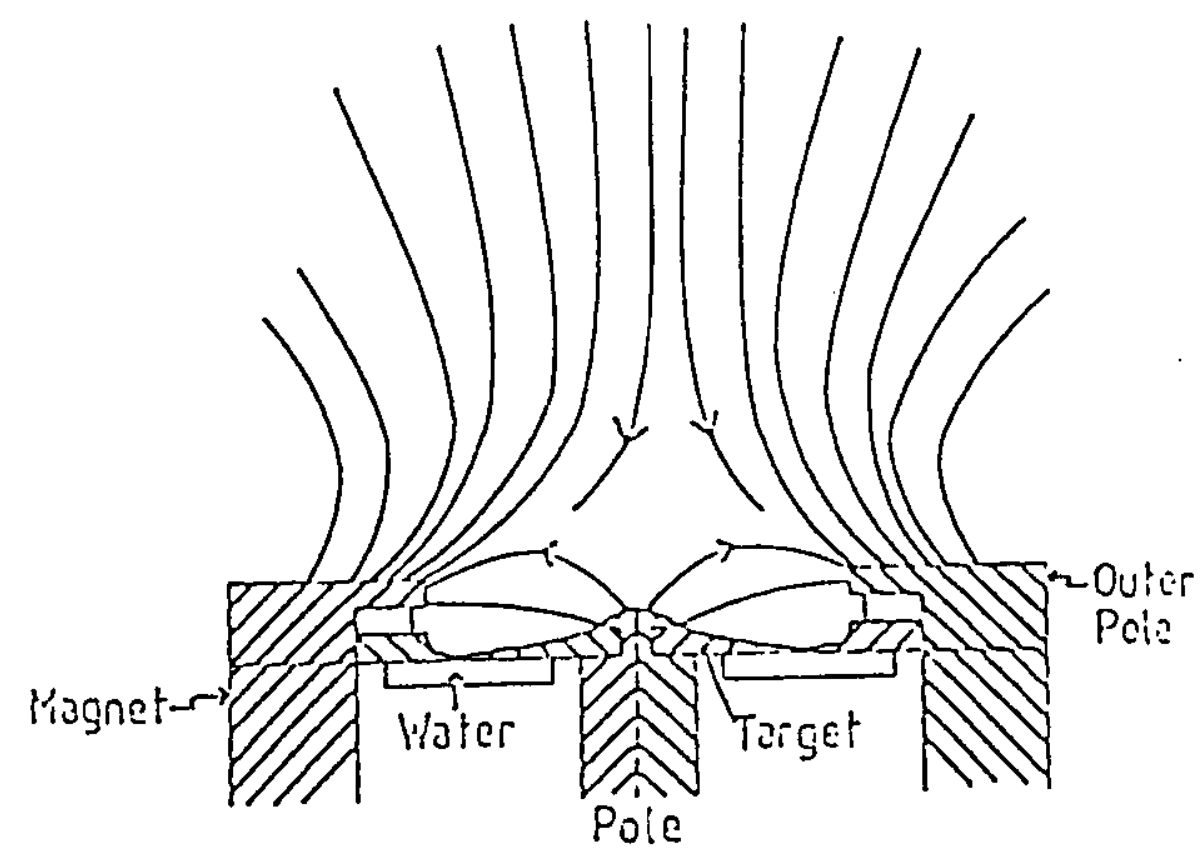

Fig.6.1 shows the unbalanced magnetron used with the magnetic field line configurations. 
The unbalanced magnetron has a magnetic circuit construction which gives a field across the cathode having a concentration of flux at one pole, so that some field lines do not join these pole pieces, but are diverted around the system creating a field further away from the surface and directed away from the cathode. Electrons trapped in the planar magnetron field, which is parallel to the surface, can be scattered into this unbalanced field and be directed towards the substrate. They will take ions with them by electro-static forces to give a plasma beam directed onto the substrate surface. If the substrate is insulating or isolated, its surface will acquire a charge when immersed in this dense plasma, so as to equalize the electron and ion currents that flow to it. The electrons are more mobile and have a longer mean free path, so that the surface acquires a negative charge and potential. This accelerates the ions which constitute the equalizing, positive-charge current to give a bombardment of the substrate. This bombardment can be assessed using a biased probe to give the acceleration potential and the ion current density [1]. A circular planar magnetron, with concentric poles is a natural system to be unbalanced, either with magnetic material at each pole or with magnetic material concentrated at the periphery, with the magnetic return circuit being made with high permeability material. This is because of the ease in providing magnetic material volume at the extreme edge of the circle [7].

Manipulation of the plasma beam emitted from the centre of the circular magnetron, was employed using a low current solenoid to impinge it onto a substrate placed so as not to have direct line of sight to the target. Very little material was deposited, demonstrating that the plasma in the beam contained principally ions of the sputtering gas argon and not those of the sputtering material. An unbalanced magnetron can than be thought of as a source of high energy sputtering material which deposits in the presence of bombardment of low energy ions of the sputtering gas which are directed to impinge on the growing film; an ion assisted process.

The arc source, which had magnetic stabilization of the arc on the surface of the electrode and a solenoid to divert and direct the plasma created around the surface of the target onto the substrate and growing film surface, was described in chapter (5). The plasma beam that was directed along the axis of the solenoid when the arc was operated at 95 Amps, resulted in the deposition of a thin film of the target material even though there was no direct line of sight, indicating a high proportion of ionized species in the evaporating material. Figure 6.2 shows the filter arc evaporator. 


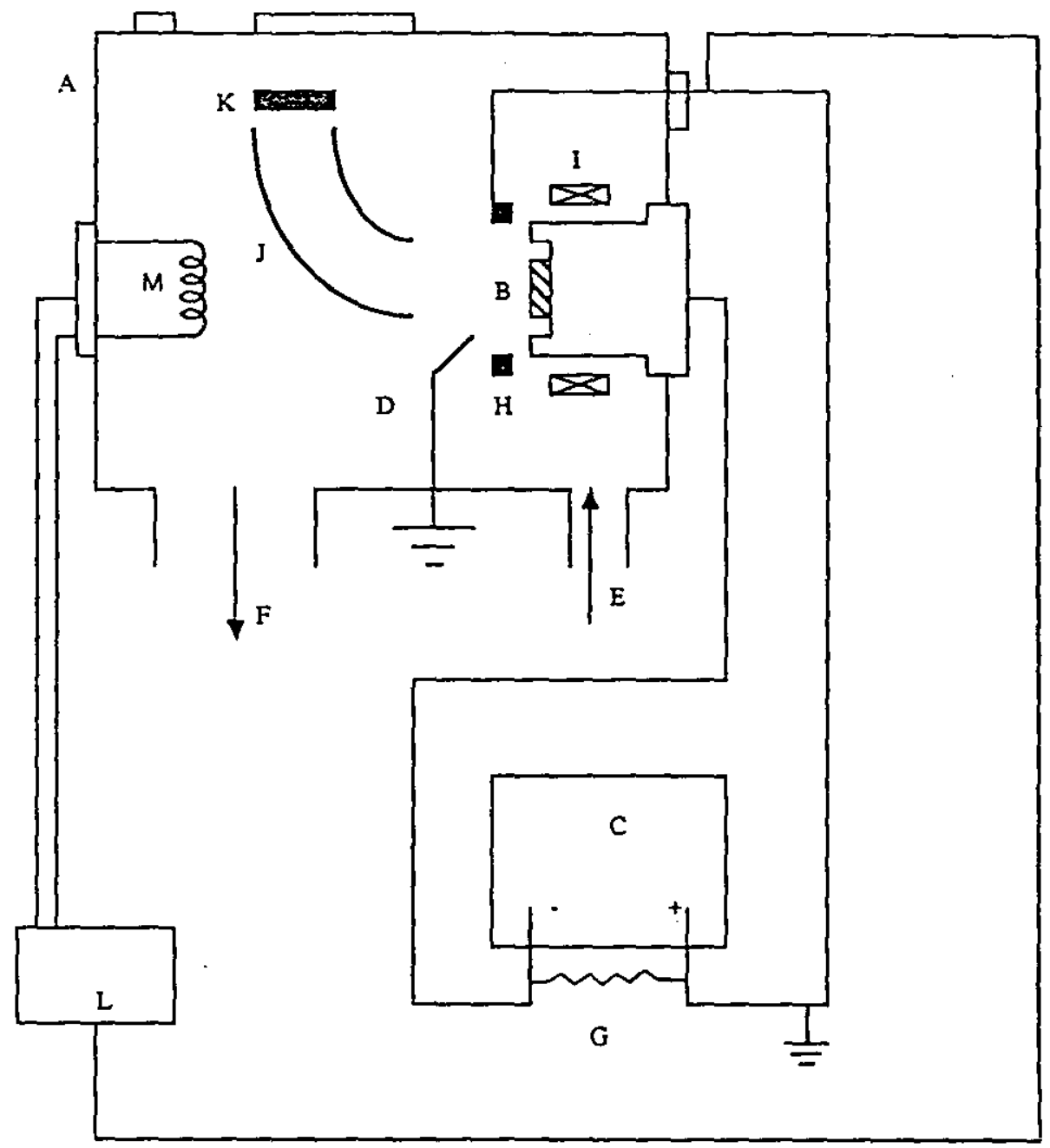
A : Vacuum chamber
B : Cathode
C : Power supply
D : Ignitor
E : Gas inlets
$F$ : Vacuum pumps
G : Resistors

$\mathrm{H}$ : Anode

I: Magnet ring

$\mathrm{J}$ : Magnetic coil

$\mathrm{K}$ : substrate

L : Anode-filament supply

M: Filament

Figure 6. 2. The arc evaporation apparatus. 
Probes placed in the substrate position were used to ascertain I-V characteristics and hence to estimate values of the floating potential and saturated ion currents flowing to the growing film surface. Figures 6.3 and 6.4 give characteristics obtained with an unbalanced magnetron and with an arc respectively. With additional magnetic confinement the unbalanced magnetron could give up to 100 volts self bias with ion currents of up to $100 \mathrm{mAmps}$. This would be due to argon ions, which will activate the depositing material, expected to be principally neutral material. The arc system gave a bias voltage value of 10 to 20 volts with ion currents of around $100 \mathrm{mAmperes}$. This might be expected to consist almost entirely of ions of the evaporating material.

The arc evaporation process was not affected by the admission of a reactive gas and reactive processes could be undertaten with few additional problems.

Commonly the admission of the reactive gas in a reactive sputtering process is done through control of the flow with a simple mechanical valve or an electronic feedback device which can indicate the magnitude of that flow. In high rate reactive sputtering with a planar magnetron conditions are often created where the process is unstable, switching between "metallic" and "oxide" sputtering modes without allowing access to the intermediate point, which is the one generally required. Control of the partial pressure of the reactive gas with rapid feedback can prevent this instability. We have found that this can be best done by observation of the spectral line emission of the gas or the sputtering material [8]. It remains however important to observe the magnitude of the flow even though the partial pressure is being controlled. The object of the process is to create films of closely controlled stoichiometry and structure. The rate of incidence of the sputtering metal and the reactive gas, from the residual atmosphere, together with the reaction kinetics of the surface reaction will obviously be important in this. We have seen that a measurement of the flow of the gas into the film-making process can allow prediction of film properties and provide an indication of the efficiency of the reaction kinetics. The flow measurement can be obtained by using a closed system or by substracting the amount that flows to the pumps from the total flow figure. 


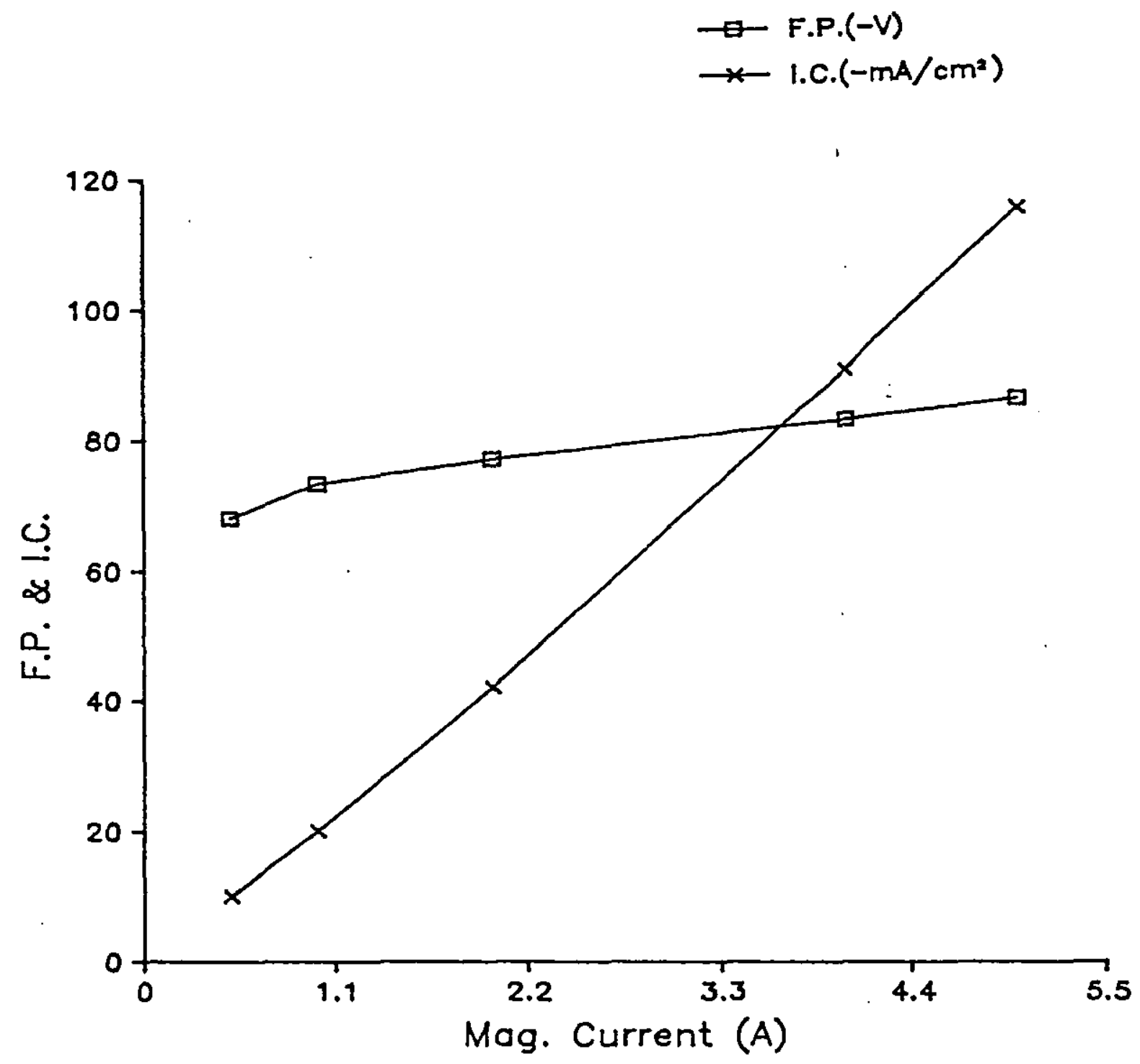

Figure 6.3. The I-V characteristics of a probe placed in the "leaked " plasma from an unbalanced magnetron. FP is the floating potential and IC the ion current. 


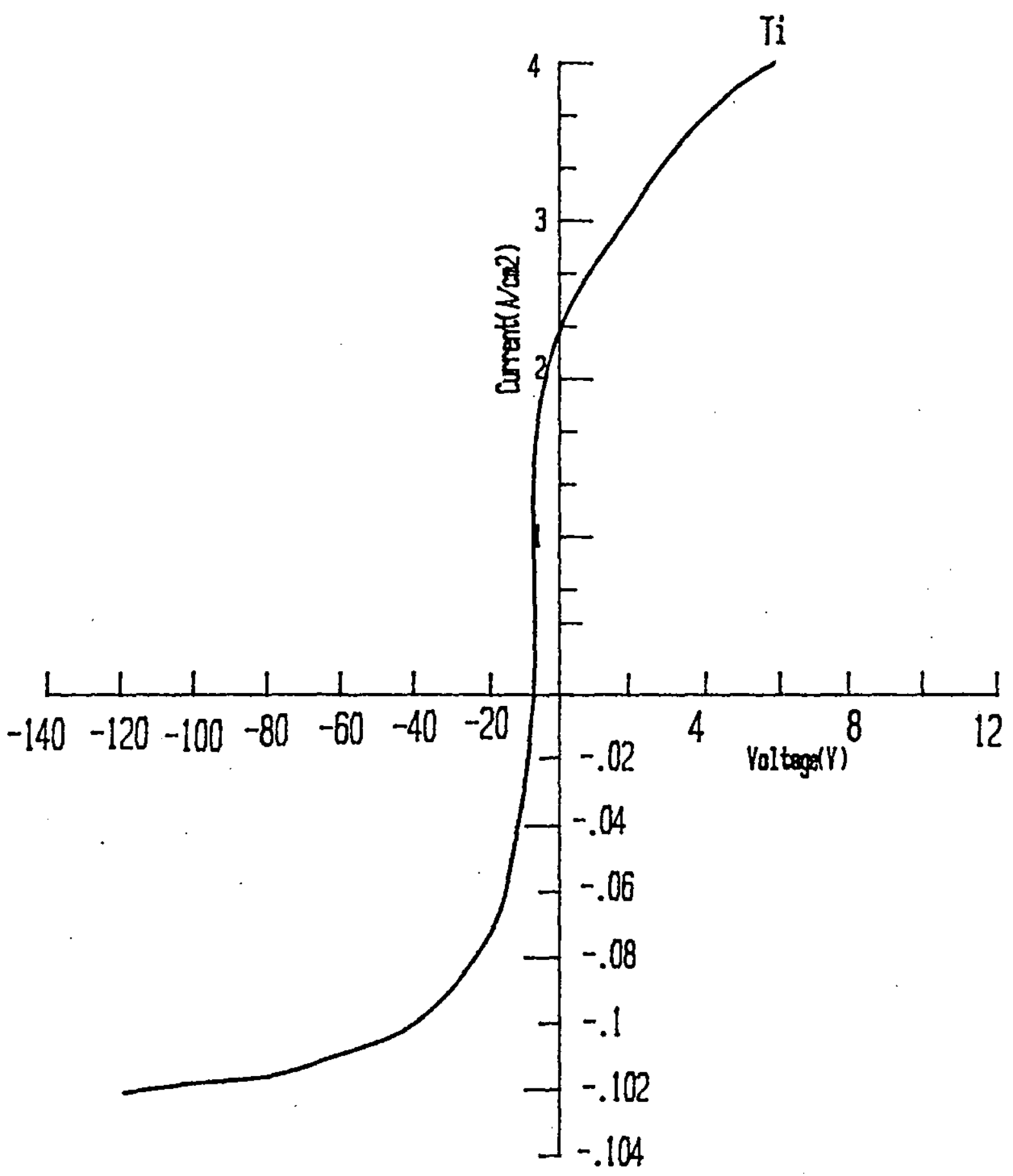

Figure 6.4. The I-V characteristics for a probe placed in the directed plasma from the arc source 


\subsection{METAL MATERIALS}

Aluminium, titanium and copper films have been prepared by both techniques. High quality, highly reflecting films of aluminium could be prepared by both techniques. They had good adhesion and showed no signs of droplet contamination figure 6.5 . Titanium was similar but arc evaporated copper was rough and discontinuous.

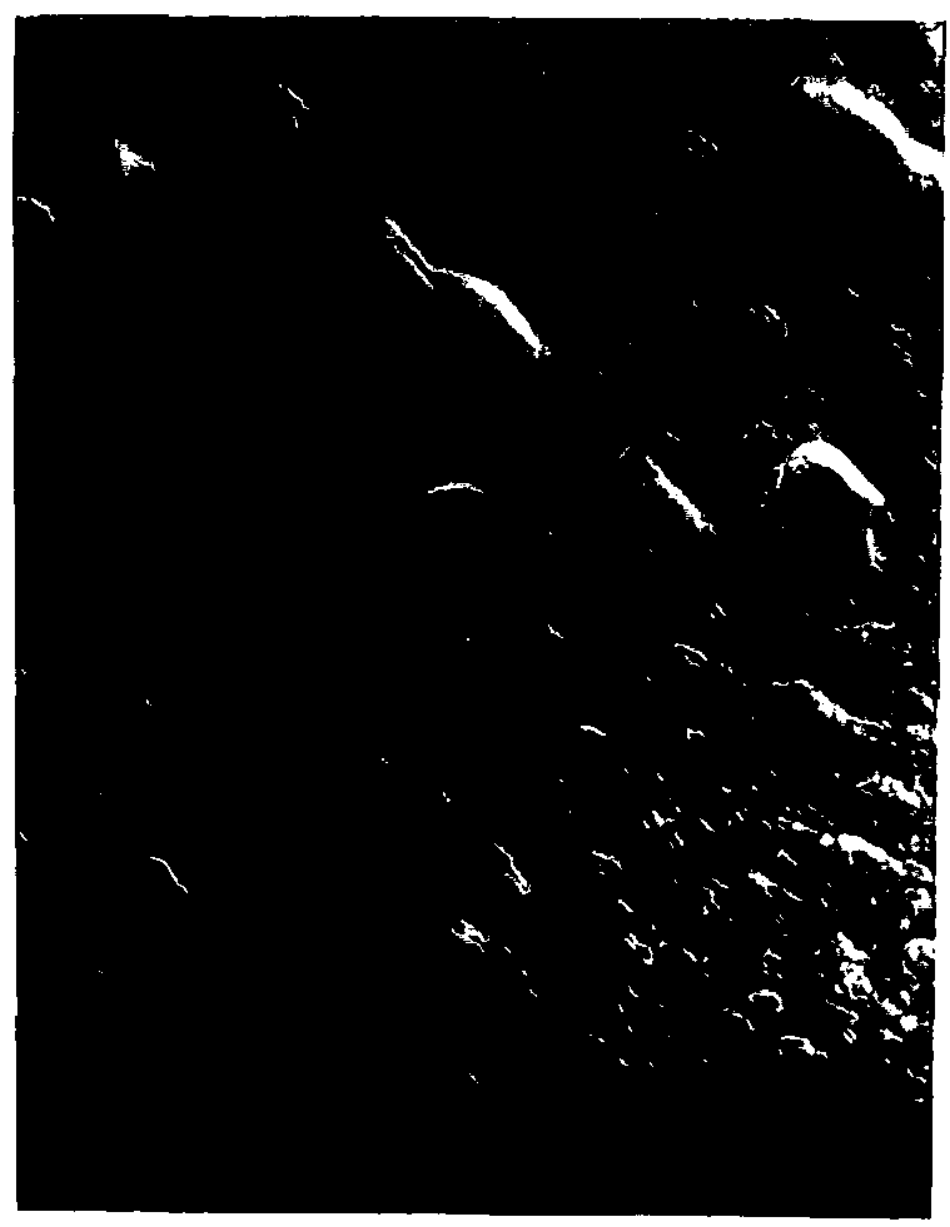

The magnification of the SEM was such that $1 \mathrm{~mm}$ represents $10 \mathrm{~nm}$. The same magnification is used in all subsequent micrographs unless otherwise stated.

Figure 6.5 SEM micrograph. front surface of aluminium films obtained by filtered arc evaporation. 
chapter six

\subsection{REACTIVE PROCESSES}

The preparation of titanium nitride by sputtering requires great care [9] and evidently is much easier by arc evaporation [10]. The reflectance characteristics of films deposited on glass by both techniques is shown in figure 6.6. The sputtered film was the best, prepared by a getter sputter technique using careful partial pressure control of the nitrogen added for the reaction [9] and that made from the arc used an atmosphere of. 1.5 millitorr of nitrogen and 3.5 millitorr of argon. The sputtered film had a sheet resistance of $10 \mathrm{ohm}$ per square while that of the filter selected evaporated one was 4 ohm per square. A lower resistance and better spectral selectivity is a measurement of the quality and potential use of titanium nitride for optical applications. 


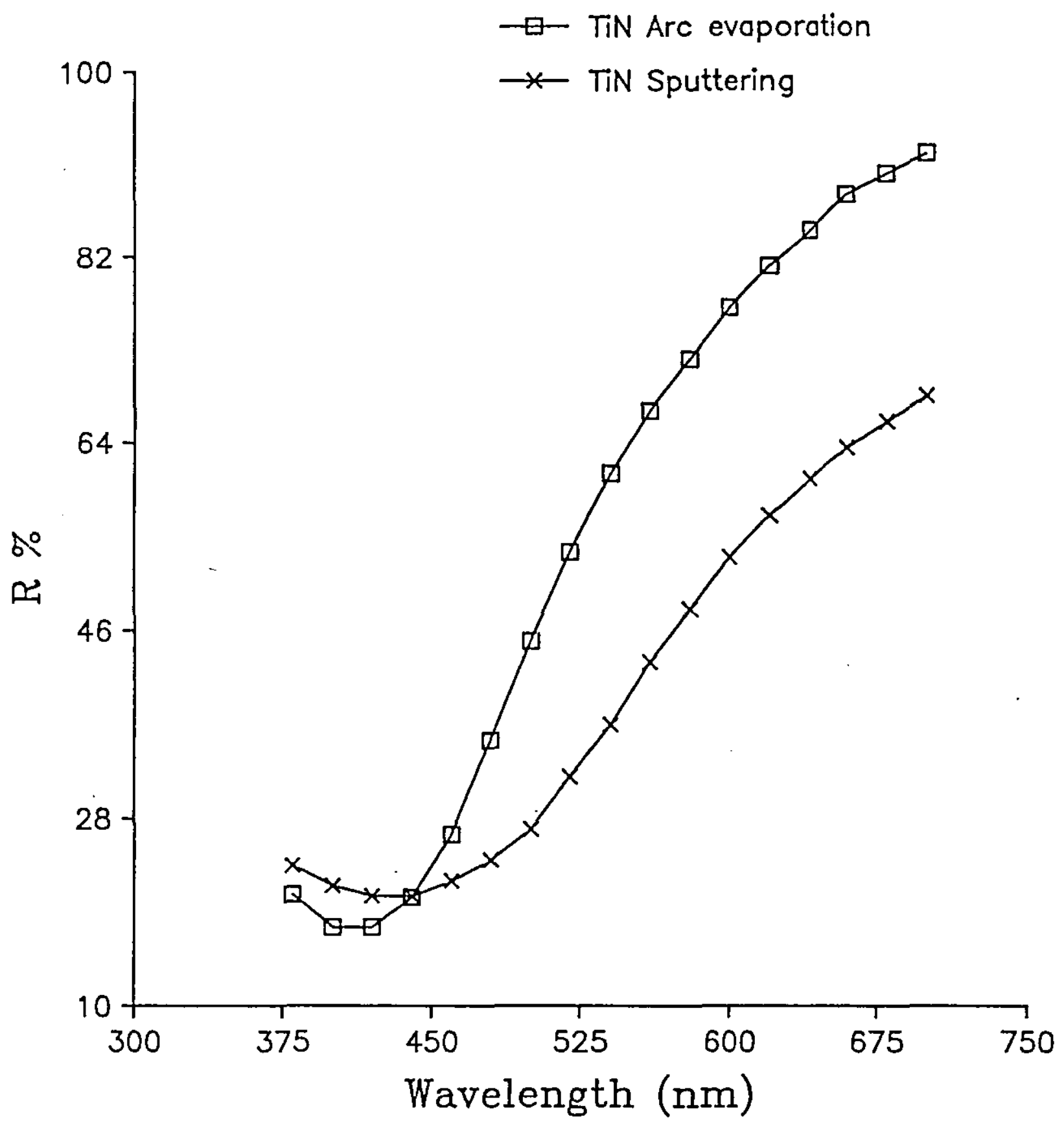

Figure 6.6. The reflectance in the visible region of an arc evaporated film compared to that of one reactively sputtered. 
In contrast to the negative effects that result from the formation of insulating oxides on the surface of sputter targets operating in dc reactive mode, the formation of such oxide films on arc targets can have a very beneficial effect on the quality of the deposited film. The benefit is a very significant reduction in both the number and the size of microdroplets. This reduction is believed to result from the higher arc velocity observed when a metal is eroded in the presence of oxygen. A thin film of oxide forms on the target surface; because of the higher electron emission coefficient of the oxide, the arc spot prefers to reside on an oxide surface. Where the oxide is present only as a thin film, it is rapidly consumed by the arc, which then migrates to an adjacent oxidized site. The location that the arc has just left is at a very high temperature and, therefore, is quickly reoxidized by the ambient oxygen. This mechanism produces very rapid arc spot motion, as much as 10 times the spot velocity in the absence of oxygen for the same target metal.

Aluminium oxide was evaporated by arc evaporating aluminium in a mixture of argon and oxygen. By using 3.5 millitorr of argon and 1.5 millitorr of oxygen, a clear film of refractive index 1.66 was obtained. These films are notoriously difficult to sputter because of arcing on the cathode surface.

\subsection{SEM}

TiN films examined by scanning electron microscopy, showed a columnar structure of the sputtered films with grain size of $50 \mathrm{~nm}$ while of those of the arc evaporated had a less columnar structure with small grain size of $20-30 \mathrm{~nm}$. This is one advantage of the filtered arc deposits bombarded with energetic ions at the substrate to overcome columnar growth. 
chapter six
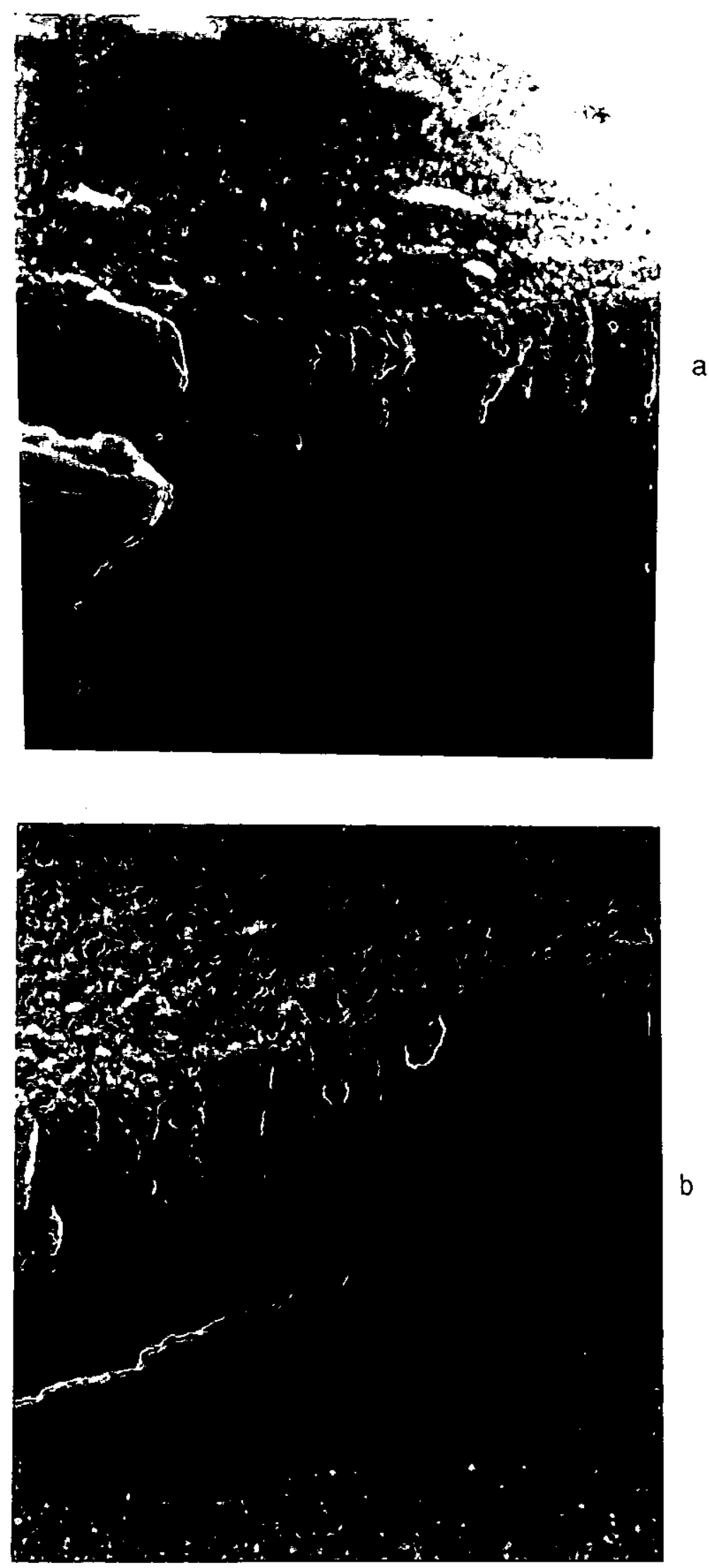

b

Figure 6.7. SEM cross section micrographs of TiN films.a) by filtered arc and b) by magnetron sputtering. 


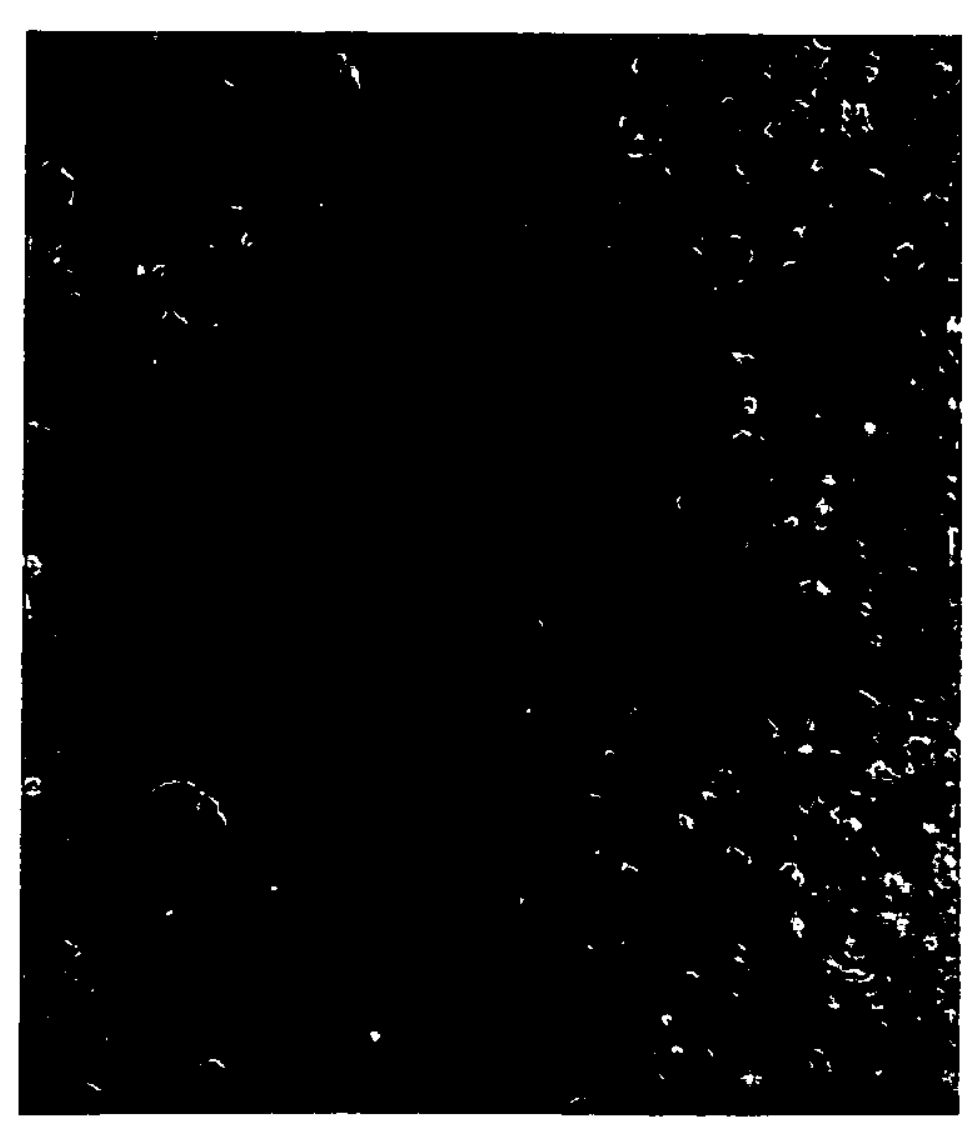

chapter six

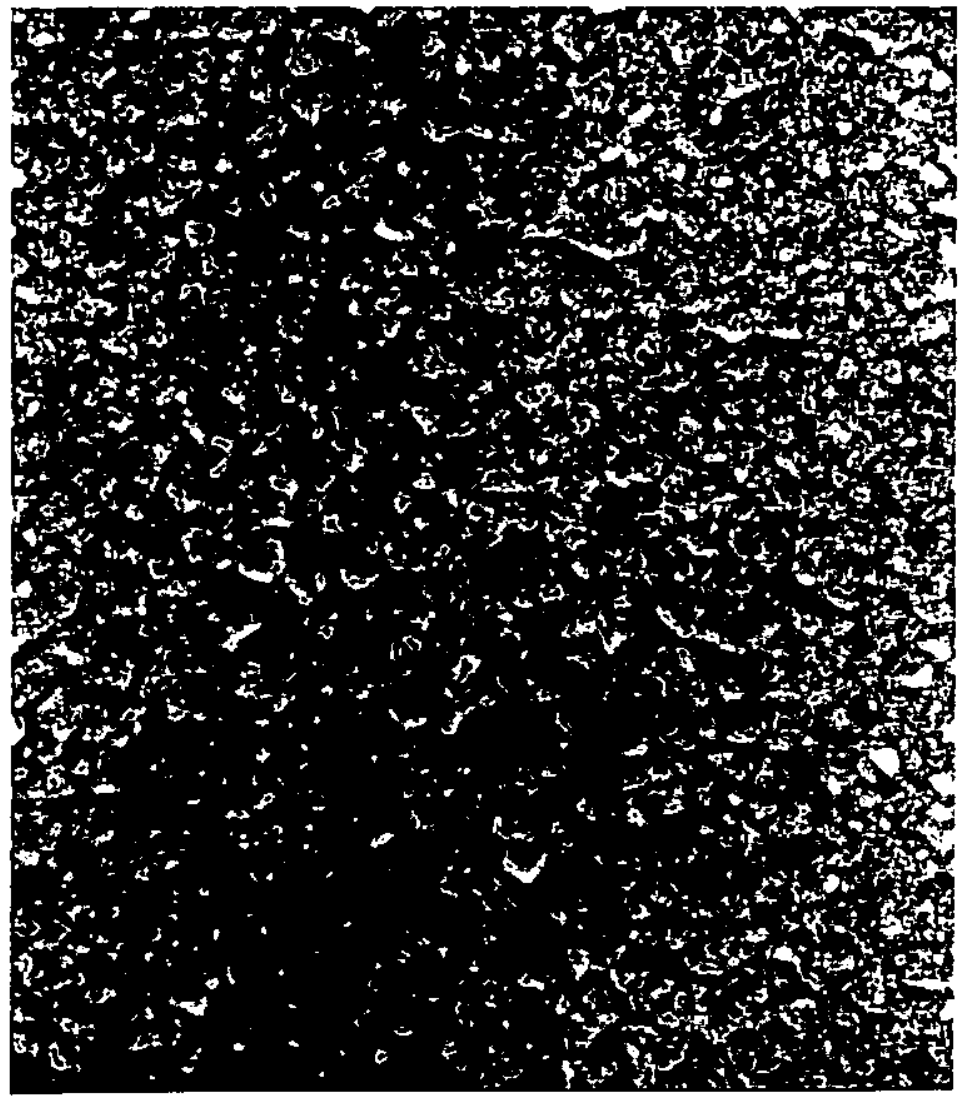

Figure 6.8. SEM Surface view micrographs of TiN films. a) by filtered arc and b) by magnetron sputtering. 


\subsection{CONCLUDING REMARKS}

Despite similar pressures of operation and methods of the manipulation of the plasmas that are produced, there are very real differences between magnetron sputtering and arc evaporation of thin films onto insulating substrates. The magnetron process is one of ion assisted growth of a thin film with the depositing species arriving at the substrate with considerable energy, acquired as a result of the sputtering process, but in a neutral form, the growing film is bombarded by low voltage ions of the sputtering gas and may include a component of reactive gas. With arc evaporation it is the evaporating material which is charged and will be accelerated onto the growing film surface by the bias voltage which appears as a result of the substrate being immersed in the dense plasma from the process.

TiN films examined by scanning electron microscopy, showed a columnar structure of the sputtered films while those of the arc evaporated had a less columnar structure with small grain size. This is one advantage of filtered arc deposits, bombarded with energetic ions at the substrate to overcome columnar growth.

The manipulation of the product of arc evaporation has been shown to be possible with a simple low field solenoid following the principles seen with an unbalanced magnetron. Direction of the product to a substrate out of direct line of sight of the source results in films free from droplet contamination.

In reactive processing the ionised metal constituent provided by arc evaporation does appear to make the kinetics of the substrate reaction process much more simple than the careful balance required with argon-ion-assisted sputter processes. And, on the evidence of titanium nitride deposited onto room temperature substrates, gives better quality films. A clear aluminium oxide film of refractive index 1.66 was obtained by arc evaporating aluminium in a mixture of argon and oxygen. 


\section{REFERENCES}

[1]. R.P. Howson, H.A. Ja'fer and A.G. Spencer.

"Substrate effects from an unbalanced magnetron". Thin Solid Films, 193/194, pp.127-137 (1990)

[2]. J. Ebert. "Ion assisted reactive deposition processes for optical coatings". Surface and Coatings Technology, 43/44, pp. 950-962,(1990)

[3]. J. Vyskocil and J. Musil. "Arc evaporation of hard coatings:process and film properties". Surface and Coatings Technology, 43/44, pp.299-311, (1990).

[4]. B. Window and N. Savvides. "Unbalanced magnetrons as sources of high ion fluxes". J. Vac. Sci. Technol. A4(3), pp. 453-456, (1990)

[5]. H. A. Ja'fer, R. P. Howson, M.E. Stenlake and A.G. Spencer.

"Design, contruction and performance of an unbalanced magnetron for use with insulating substrates". IPAT (1991)

[6]. P.J. Martin, R.P. Nettlefield and T.J. Kinder.

"Ion -beam-deposited films produced by filtered arc evaporation"

Thin Solid Films, 193/194, pp. 77-83 (1990).

[7]. R.P.Howson, H.A. Ja'fer, G. W. Hall, M. Stenlake, R. A. Swady, A. G.Spencer, H. Biederman, S. Kadleck and H. Barankova. Reactive sputtering with an unbalanced magnetron. Proc. 1st Int'l Symp. on ISSP 91 Tokyo (1991), 43-52

[8]. R.P. Howson, A.G. Spencer, K. Oka and R.W. Lewin.

"The formation and control of direct current magnetron discharges for the high-rate reactive processing of thin films".

J. Vac. Sci. Technol. A7, 1230, (1989)

[9]. R.A. Swady and R.P. Howson.

"The reactive sputtering of thin films of TiN onto glass".IPAT,May Belgium, (1991).

[10]. R.P. Howson, N. Mustapha, H.A. Ja'fer and M.E. Stenlake.

A comparison between the performance of an arc evaporation source with ion selection and an unbalanced magnetron sputtering source. IPAT, Belgium, May (1991). 


\section{CHAPTER 7}

\section{RESULTS}

\subsection{TiN FILMS}

\subsubsection{INTRODUCTION}

Arc deposited TiN coatings are proving very successful in improving the life and performance of a wide variety of industrial tools, in addition to uses in other industrial applications and decorative coatings [1]. The cathodic arc evaporation method has been highly successful for TiN coating, owing both to the high degree of ionization and the energy of the evaporated species. The principal disadvantage of the method is the presence of microdroplets of cathode material in the vapour stream [2]. Recently, there has been increasing interest in the use of this coating for micro-electronics, aerospace and nuclear energy applications [3]. Now, in Europe, the production of TiN coatings for surgical implants, biomedical applications and various surgical tools is being investigated, to prevent corrosive attack as well as to maintain the cutting performance of these surgical tools [4].

\subsubsection{EXPERIMENTAL PROCEDURE}

TiN coatings were prepared with an arc current of 90 Amps. Before deposition, the vacuum chamber was evacuated to a typical base pressure of $10^{-5}$ Torr. The process gas pressures were adjusted in the range 2-6 mTorr with a combination of argon and nitrogen both typically $99.99 \%$ pure. The gas ratio was varied to obtain the best rate whilst maintaining film quality. The titanium target used had a purity of $99.99 \%$ positioned at the entrance of a plasma duct described earlier. The substrate was situated at the exit port of the duct. Both glass and silicon coated glass were used in the process, and substrates were cleaned prior to deposition using Acetone, and a D.I. water rinse. Deposition temperature was kept at ambient during all depositions. A spectrophotometer was used to obtain optical reflectance curves in the visible region for thin films $(100-200 \mathrm{~nm})$ on glass substrates. The film thickness was measured using the talystep instrument. SEM / was used to compare the surface topography and film microstructure of reactive arc evaporation, and reactively sputtered TiN films. 
used to determine the crystallographic orientation and phases in the TiN coating. The (111) X-ray line of silicon powder was used as the standard to calibrate the instrument. To facilitate the X-ray diffraction processes, films of 150-200 nm thickness were used during analysis.

\subsubsection{RESULTS AND DISCUSSION}

\subsubsection{Process rate}

The film characteristics were not influenced by the location of the nitrogen gas inlet, and good quality TiN films over varying $\mathrm{N}_{2}$ pressure were obtained with substrate temperature maintained at ambient. In addition, microdroplet free clear films with a reflectance of $82.5 \%$ at $633 \mathrm{~nm}$ were also obtained at a nitrogen pressure of $1.5 \mathrm{mT}$ Trr and argon of $3.5 \mathrm{mTorr}$. The optimized TiN film has shown a low sheet resistance of 4 ohmsper square.' The optimization procedures are given in reference [7].

High pressures of reactive gases reduce the number of microdroplets in reactive deposition processes because, it is believed, the reaction on the target surface forms a compound surface film. The presence of such a film, TiN for example, on the surface of the target leads to reduced melting, because Ti melts at $1660^{\circ} \mathrm{C}$, while TiN melts at $2030^{\circ} \mathrm{C}$.

By increasing the nitrogen gas pressure above 1.5 millitorr, a cathode poisoning phenomenon, i.e. nitriding by the $\mathrm{N}_{2}$ gas, similar to that obtained with reactive sputter deposition processes was also observed with arc sources. This is recognised during deposition by a sudden increase in pressure, when the cathode surface cleaning by the arc can no longer keep up with surface poisoning by the nitrogen gas. The surface is converted to a nitride, having a higher melting point than titanium, resulting in reduction of evaporation rate and reduction in the microdroplet emission. Depositions made without intentional heating of the substrate required $25 \%$ nitrogen to maintain clear films at deposition rate of $30 \mathrm{~nm}$ per minute. The deposition rate was found to vary with nitrogen partial pressure, although it is a relatively constant $25 \mathrm{~nm}$ per minute over the $\mathrm{N}_{2}$ pressure range 1.2 - 2 mtorr. This is due to surplus $\mathrm{N}_{2}$ present throughout the deposition chamber . 
Process optimization for the deposited TiN films yielded the following parameters:

(1) The bias potential on the walls of the plasma duct was $12-18$ volts which appears as the dense plasma from the process is charged and accelerated throughout the duct onto the growing film surface.

(2) The estimated transfer efficiency for the entire duct is of the order of $40 \%-45 \%$ depending on the proximity of the coil to the cathode, and other process deposition parameters.

(3) The reason that TiN films have been successfully deposited over a varying range of $\mathrm{N}_{2}$ pressure is thought to be the high fraction of material ions arriving at the substrate, coupled with a low activation of $\mathrm{N}_{2}$ molecules.

(5) The substrate temperature can be maintained at ambient for TiN.

\subsubsection{Optical properties}

The reflectance spectrum of the TiN films in the visible region is shown in figure 7.1.1. These films had a reflectance of $82.5 \%$ at $633 \mathrm{~nm}$. The optical properties of the TiN films as reported by Martin et al. [2] are shown in figure 7.1.2. The refractive index and extinction coefficient are similar to that reported by Karlsson and Ribbing [5] for TiN films prepared by CVD. These films had a maximum reflectance of $80 \%$ at $850 \mathrm{~nm}$. The maximum reflectance reported for TiN films produced by unfiltered arc sources is approximately $65 \%$ at a wavelength of $550 \mathrm{~nm}$, which is in gond agreement with the data represented by Martin et al. for TiN deposited films by the filtered arc evaporation process. 


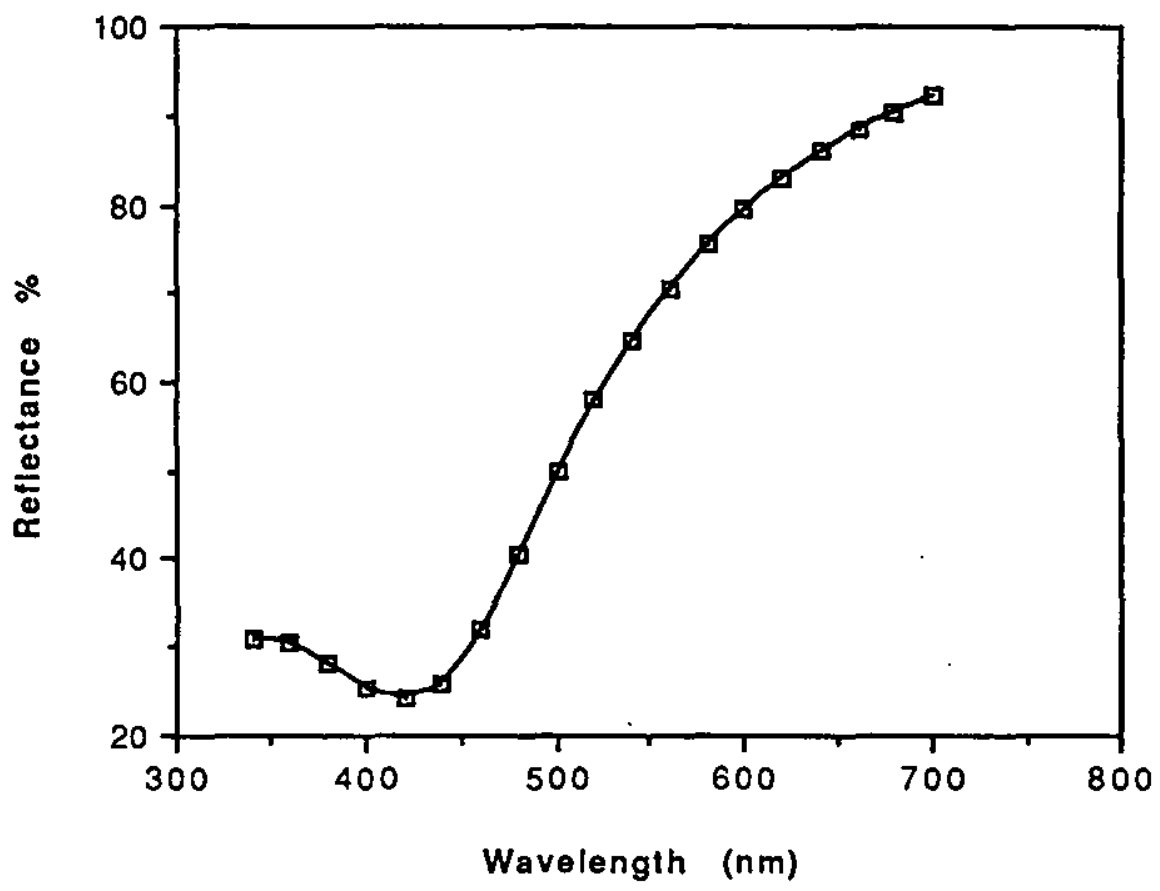

Figure 7.1.1. The reflectance spectrum of a TiN film (thickness $=200 \mathrm{~nm}$ ). 

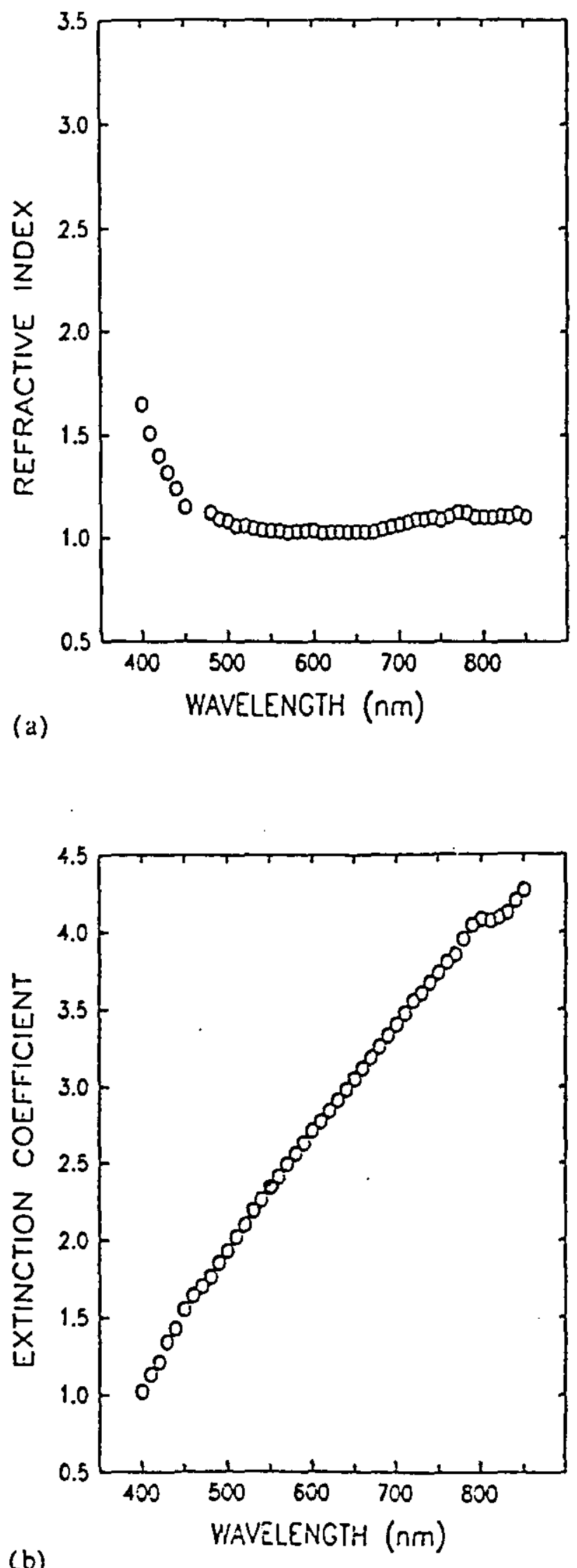
chapter seven

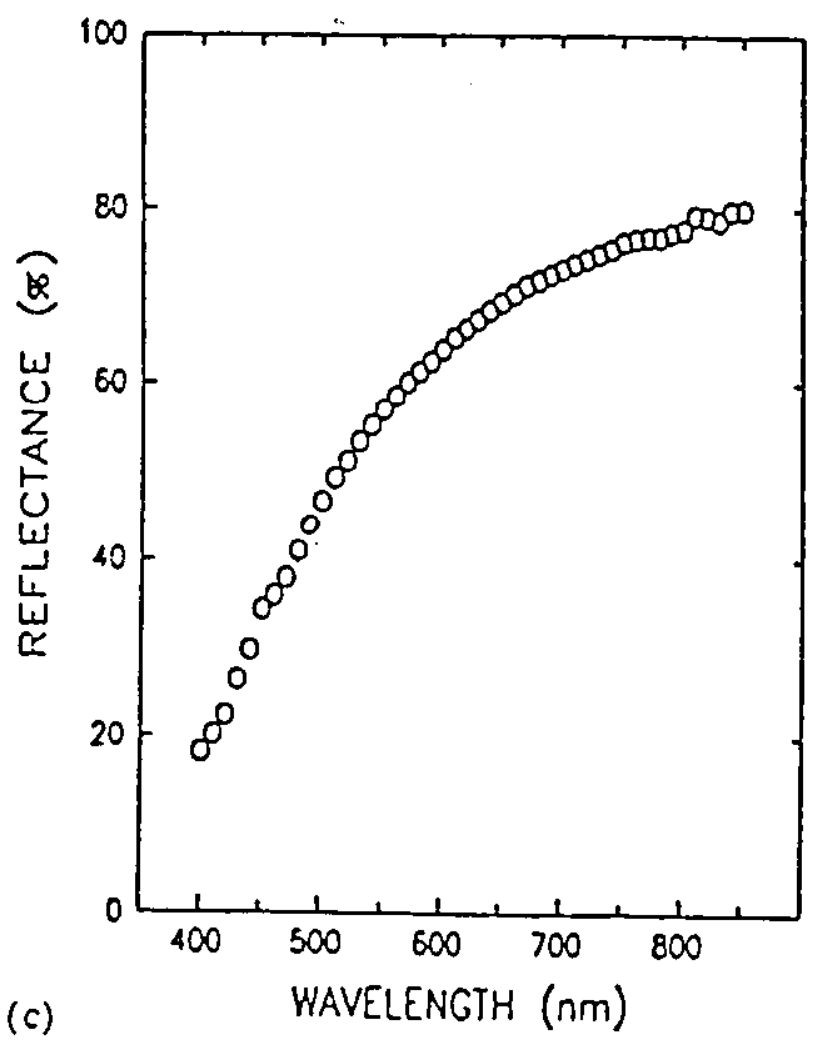

Figure 7.1.2 . (a) Refractive index vs. wavelength, (b) extinction coefficient vs. wavelength, and (c) reflectance vs. wavelength for TiN films [2]. 
Since the data presented by Martin et al. [2] were measured in air after removal from the vacuum system, it is possible that surface oxidation may affect the optical reflectance as observed previously on TiN films prepared by activated reactive evaporation [6].

\subsubsection{X-ray diffraction (XRD)}

The TiN films were examined by $X$-ray diffraction and the results are shown in figure 7.1.3. It can be seen that the films exhibit a strong $\{111\}$ preferential texture in all coatings with no significant change over the reactive gas pressure range and deposition parameters. Films deposited also exhibit a $\{200\},\{311\}$ and $\{222\}$ peaks.

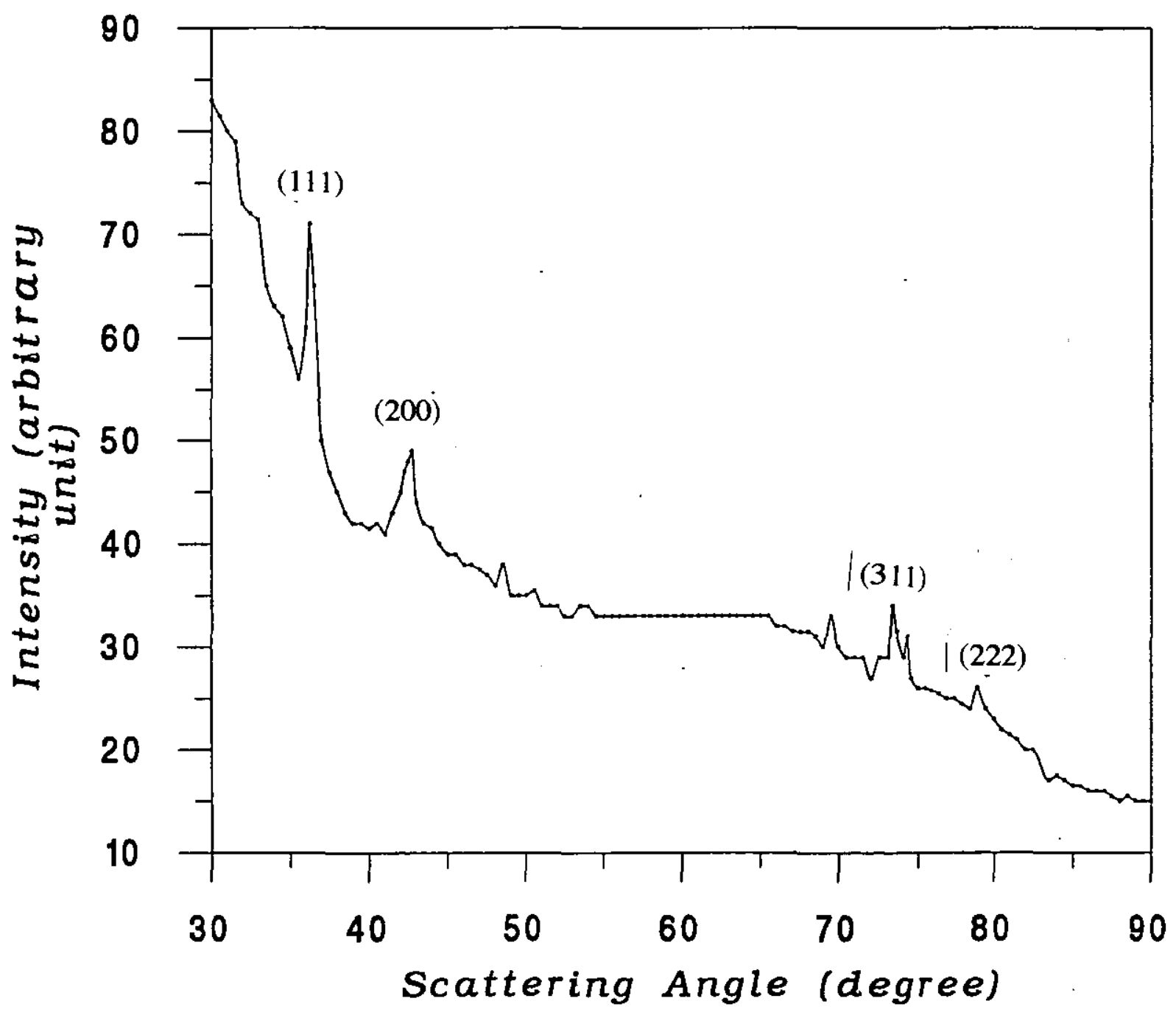

Figure 7.1.3 X-ray diffraction pattern for the TiN thin films. 


\subsubsection{Scanning Electron Microscopy ( SEM)}

TiN films examined by scanning electron microscopy, showed a fine structure of the films with a small grain size of $20-30 \mathrm{~nm}$. This illustrates one advantage of the filtered arc; the bombardment with energetic ions at the substrate to overcome columnar growth.

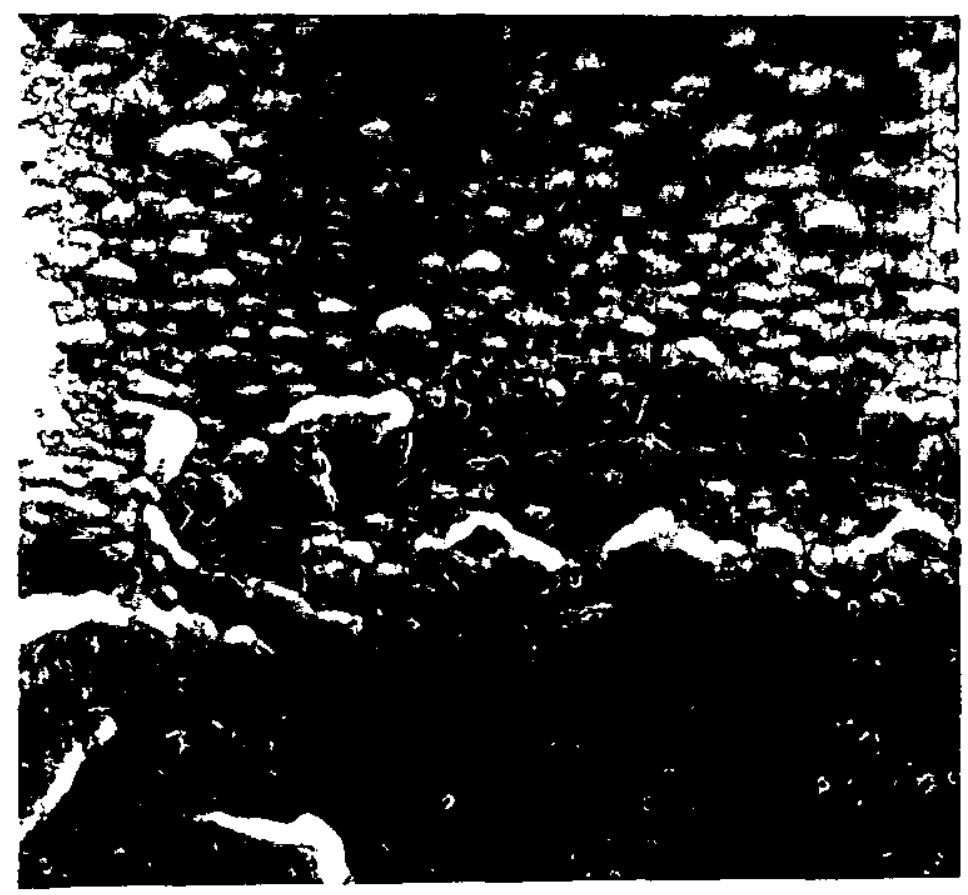

The magnification of the SEM was such that $1 \mathrm{~mm}$ represents $10 \mathrm{~nm}$. The same magnification is used in all subsequent micrographs unless otherwise stated. 


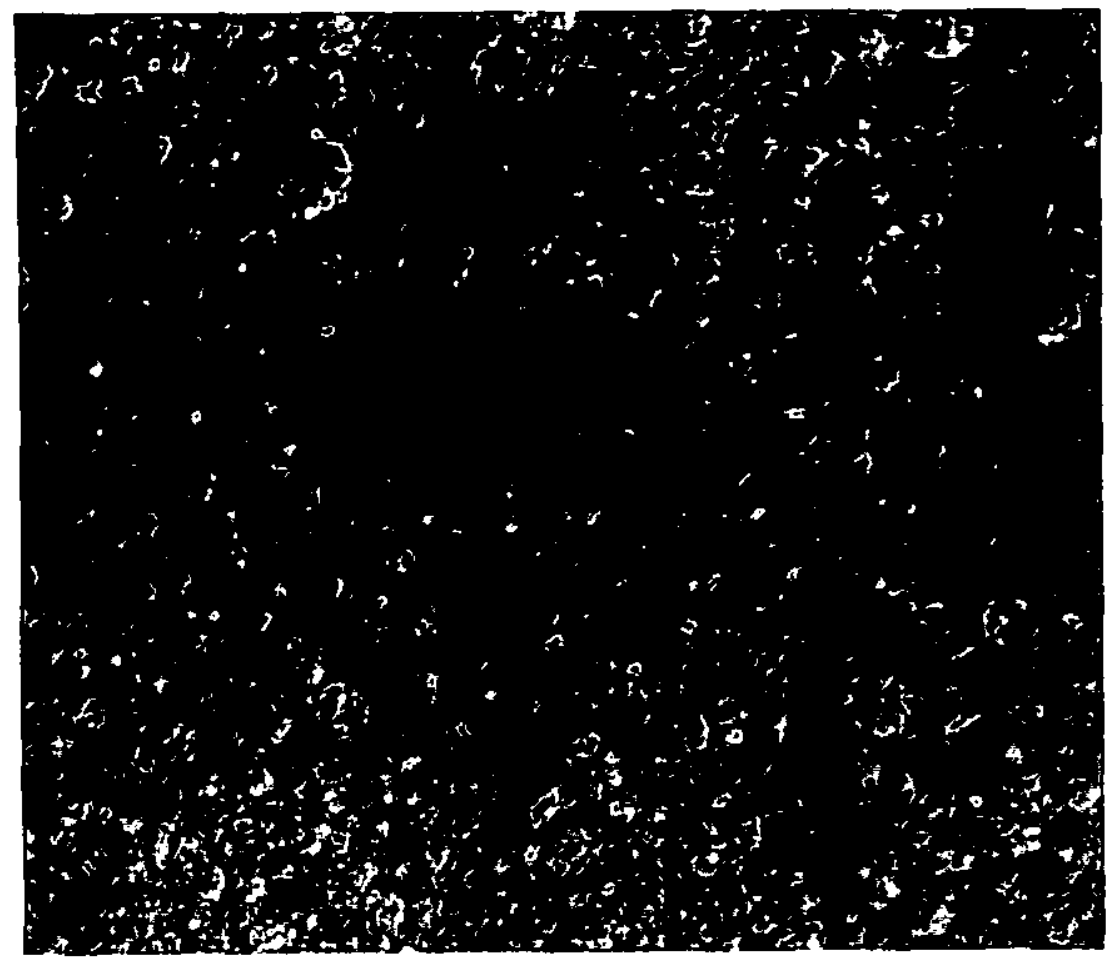

b

Figure 7.1.4. SEM micrographs of TiN film. a) cross-section and b) front surface.

\subsubsection{SHEET RESISTANCE}

The TiN films showed low sheet resistance in the range 3-4.5 ohm per square. Lower resistance and high reflectance are a measurement of the quality and potential use of titanium nitride for optical applications.

\subsubsection{CONCLUDING REMARKS}

The preparation of titanium nitride by filtered arc evaporation onto room temperature substrates gives a high quality films. The evaporated film had a sheet resistance of 4 ohm per square. The reflectance characteristics of films deposited on glass show a typical spectral selectivity of the filter arc films. A lower resistance and better spectra selectivity is a measurement of the quality and potential use of titanium nitride for optical applications. The Golden-yellow colour of the titanium nitride highlights the importance of its use for decorative applications. It is clear from the TiN films obtained that the film composition can be suitably adjusted to match the actual gold color required fo decorative applications.

The TiN coatings deposited onto glass substrates by the filtered arc showed a fine crystalline stucture, with the grain size in the range $20-30 \mathrm{~nm}$ at ambient temperature and for all deposition conditions. Finally, TiN coatings show great promise for further improvement. 


\section{REFERENCES}

[1]. P.J.Martin, R.P. Netterfield and T. J. Kinder. Ion-Beam-Deposited films produced by filtered arc evaporation. Thin Solid Films, 193/194, pp.77-83 (1990).

[2]. P.J.Martin, R.P. Netterfield, T. J. Kinder and L. Descotes. Deposition of TiN, $\mathrm{TiC}$ and $\mathrm{TiO}_{2}$ films by filtered arc evaporation. Surface and Coatings

Technology, 49, pp.239 - 243 (1991).

[3]. J.A. Sue and H. H. Troue.

Effect of crystallographic orientation on erosion characteristics of arc evaporation titanium nitride coating.Surface and Coatings Technology, 33, pp.169-181 (1987).

[4]. Bernard F. Coll and Patrick Jacquot. Surface modification of medical implants and surgical devices using TiN layers. Surface and Coatings Technology, 36, pp. $867-878$ ( 1988 ).

[5]. B. Karlsson and C. G. Ribbing, Proc. Soc. Photo. Opt. Instrum. Eng., 324 p. 52 (1982).

[6]. P.J.Martin, R.P. Netterfield and W. G. Sainty, Vacuum, 32, p. 359 (1982).

[7]. The arc current was kept at $90 \mathrm{~A}$ for all the depositions to maintain arc stability with deposition rates of $30 \mathrm{~nm} / \mathrm{min}$. By adjusting the argon pressure at $3.5 \mathrm{mtorr}$, process optimization for the TiN films required a step wise change in the nitrogen pressure.

The nitrogen pressure was increased gradually from 0.5-3.5 mtorr (step size: 0.25 mtorr), then the deposited films were taken for examination by spectrophotometer and ellipsometer for optical properties and by a talystep for the film thickness. The sheet , resistance was also measured for the deposited films. This was done subsequently for all deposited films. The thickness of the films was increased consequently from 100-200 $\mathrm{nm}$ to examine any change in film properties.

A stabilization process is necessary to investigate the process parameters, and the film properties. It was found that for the case of TiN, a current of $90 \mathrm{~A}$ is necessary for a j stable arc process. The argon pressure was 3.5 mtorr to avoid a repeated ignition, while the nitrogen pressure must exceed 0.75 mtorr to obtain TiN films. A film of high optical reflectance and low sheet resistance required $30-50 \%$ of nitrogen. 


\section{2. $\mathrm{Al}_{2} \mathrm{O}_{3}$ FILMS}

\subsubsection{INTRODUCTION}

Aluminum oxide is an almost ideal material for corrosion and wear resistance applications and its excellent diffusion and thermal barrier properties can also be very useful. $\mathrm{Al}_{2} \mathrm{O}_{3}$ films are widely used for a variety of applications, including barrier layers in semiconductors, optics, and microelectronics [1]. However, little progress has been made in commercially depositing $\mathrm{Al}_{2} \mathrm{O}_{3}$ by PVD [2]. Currently Aluminum oxide films are being produced by i.f. sputtering, reactive d.c. sputtering $[3,4]$, or reactive evaporation.

Bunshah and Schramm reported that the transformation to a more stable, hard alumina occurs in the range $750-1200^{\circ} \mathrm{C}[5]$, while this temperature range is very high for most substrate materials used in all deposition processes. Randhawa et al reported an optimized process using a modified cathodic arc apparatus to deposit $\mathrm{Al}_{2} \mathrm{O}_{3}$ [1].

Gorachev et al [6] reported that the transition from amorphous to polycrystalline structures is determined by the substrate temperature, but no influence on the deposition rate or the structure of the films was observed in the range $15-25 \mathrm{~nm} / \mathrm{min}$.

The objective of this investigation was to determine the experimental parameters necessary for the deposition of Aluminum oxide films by the reactive filtered arc evaporation process, and their influence on the structure and morphology of the deposits, comparing the results with other deposition processes results.

\subsubsection{EXPERIMENTAL DETAILS}

The $\mathrm{Al}_{2} \mathrm{O}_{3}$ films were deposited in the vacuum system described earlier. The system had a typical base pressure of $10^{-5}$ Torr. Process gas pressures were adjusted in the range $2-7 \mathrm{~m}$ Torr with a combination of argon and oxygen, both typically $99.99 \%$ pure. The gas ratio was varied to obtain the best rate while maintaining film quality. The aluminum target used had a purity of $99.99 \%$, positioned at the entrance of the plasma duct, while the cleaned microscope slide substrate was mounted on the grounded substrate holder at the exit port of the duct. Both glass and silicon coated glass were used in the process. Deposition temperature was kept at ambient during all depositions. 
A spectrophotometer was used to obtain optical transmittance and reflectance curves in the visible region for thin films $(100 \mathrm{~nm})$ on glass substrates and the absorptance was calculated as

$$
A=100 \cdot(\mathrm{R}+\mathrm{T})
$$

Refractive index was measured with an ellipsometer for films deposited onto both glass and silicon coated glass.

The film thickness was measured using a talystep and by ellipsometry. SEM of $\mathrm{Al}_{2} \mathrm{O}_{3}$ films was used to study surface topography and film microstructure by reactive arc evaporation and the results were compared with those obtained by reactive sputtering. The film crystal structure was studied using X-ray diffraction.

\subsubsection{RESULTS}

\subsubsection{Process rate}

The arc current was kept at 95 Amps for all the depositions. By introducing the oxygen at the exit of the plasma duct near the substrate surface, and the argon near the cathode target, high optical quality films were obtained. This indicates that film characteristics were influenced by the location of the oxygen gas inlet. This also results in stabilization of the arc discharge by reducing oxidation at the target surface.

Aluminum oxide was evaporated by arc evaporating aluminum in a $3.5 \mathrm{mT}$ Torr argon, 1.5 mTorr oxygen mixture. A clear film of refractive index 1.66 was obtained. These films are notoriously difficult to sputter because of arcing on the cathode surface [7]. Depositions made without intentional heating ( substrate temperature maintained at ambient ) required $30 \%$ oxygen to maintain clear films at a deposition rate of 25 $\mathrm{nm} / \mathrm{min}$. The deposition rate was found to vary with oxygen partial pressure.

The arc evaporation process was not affected by the admission of oxygen gas and reactive processing could be undertaken with few additional problems. In the case of reactive d.c. sputtering, however, it is quite difficult to make stoichiometric aluminum oxide stable with a high deposition rate without any gas controller system [8]. 
In contrast to negative effects that result from the formation of insulating oxides on the surface of the sputtering target operating in dc reactive mode, the formation of such oxide films on an arc target can have a very beneficial effect on the quality of the deposited film. This benefit provides a very significant reduction in both the number and size of microdroplets. This reduction is believed to result from the higher arc velocity observed when a metal is eroded in the presence of oxygen.

A thin film of oxide forms on the target surface, and because of the higher electron emission coefficient of the oxide, the arc spot prefers to reside on an oxide surface where the oxide is present only as a thin film, it is rapidly consumed by the arc, which then migrates to an adjacent oxidized site. The location that the arc has just left is at very high temperature and, is therefore quickly re-oxidized by the ambient oxygen. This mechanism produces very rapid arc spot motion, as much as 10 times the spot velocity in the absence of oxygen for the aluminum target.

Process optimization for the deposited films yielded the following parameters:

(1) The longitudinal magnetic field inside the duct was 220 Gauss maximum at the bend, with the average field strength in the vicinity of the cathode and at the exit of the duct 85 Gauss.

(2) The bias voltage on the walls of the plasma duct was $12-20 \mathrm{~V}$.

(3) Film thickness uniformity can be achieved by rotating the substrate at the plasma exit.

(4) The estimated transfer efficiency for the entire duct is of the order of $30-50 \%$ depending on the proximity of the coil to the cathode for the same deposition parameters. 


\subsubsection{OPTICAL PROPERTIES}

Refractive index values were obtained using an ellipsometer and were in the range 1.64-1.67. However, the $\mathrm{Al}_{2} \mathrm{O}_{3}$ films prepared with both d.c. and r.f. magnetron sputtering with the highest transmittances had refractive index in the region of 1.61-1.62, which is that shown by films evaporated using electron beam heating [3]. The ellipsometer also gave the film thickness, so that the deposition rate could be calculated. A set of films deposited on glass substrates was examined for optical transmission in the wave length range $340-700 \mathrm{~nm}$ using a spectrophotometer figure 7.2.1. All deposited films showed low absorption less than $4 \%$ at $632.8 \mathrm{~nm}$.

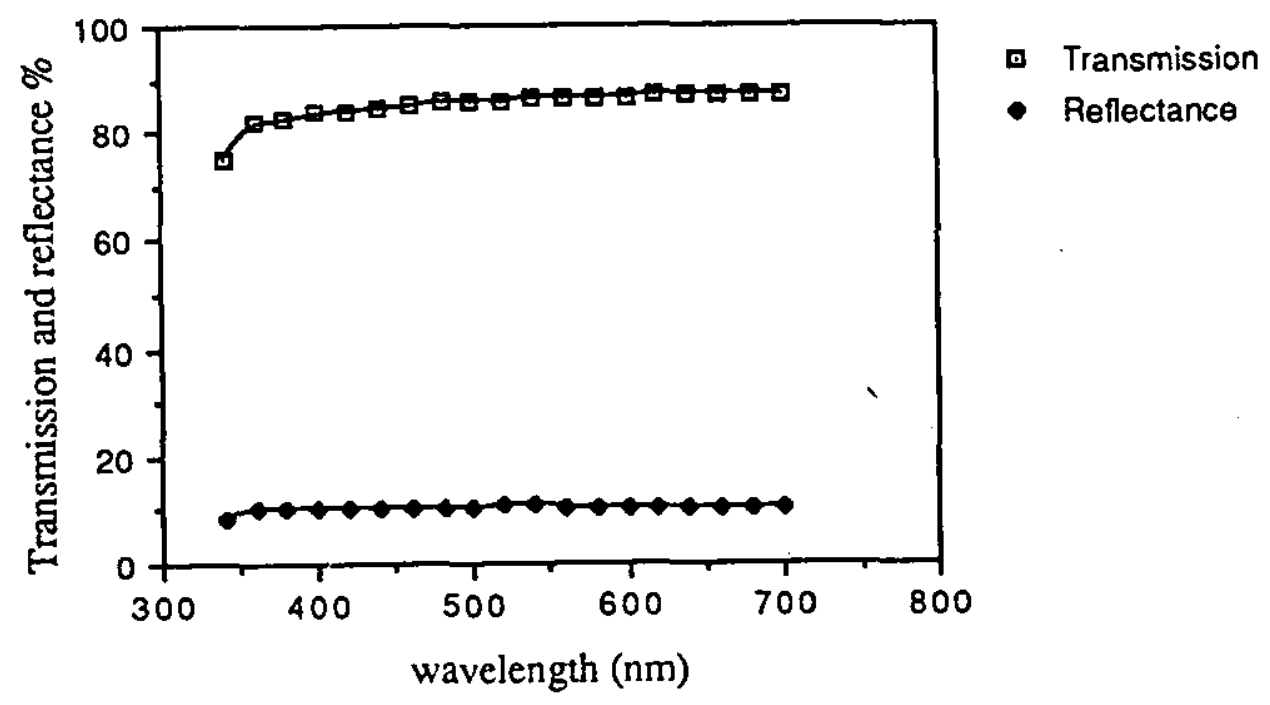

Figure 7.2.1. The optical spectra of aluminum oxide film. 


\subsubsection{X-ray diffraction}

The $\mathrm{x}$-ray diffaction results show no diffraction peaks, indicating that the films deposited at ambient temperature were amorphous, as reported previously by Randhawa [9] for arc deposition onto ambient temperature. Randhawa et al [1] reported that films deposited at temperatures $\geq 300^{\circ} \mathrm{C}$ had a polycrystalline hexagonal phase.

\subsubsection{SEM}

Aluminum oxide films examined by scanning electron microscopy, were dense and showed no sign of microdroplet contaminations, figure 7.2.2.

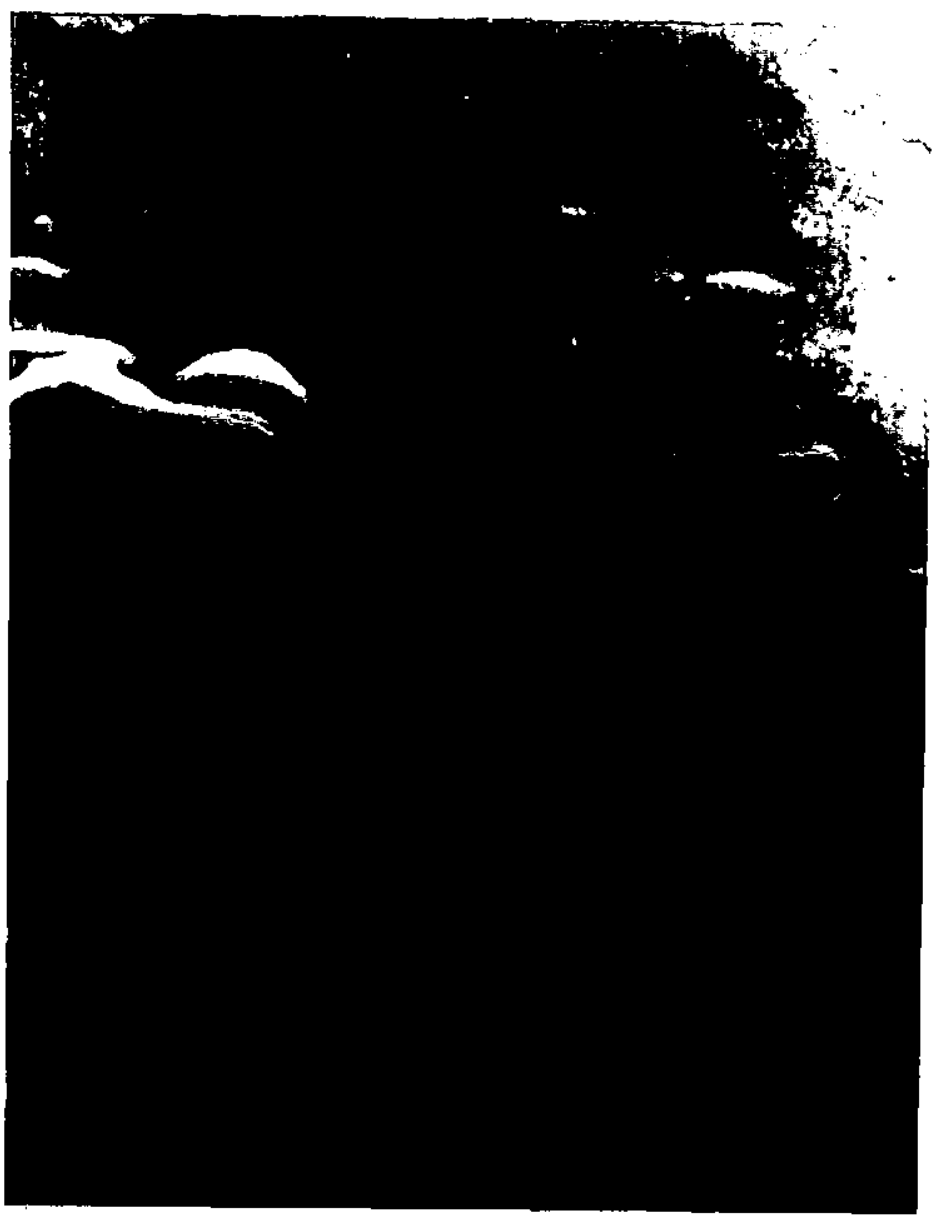




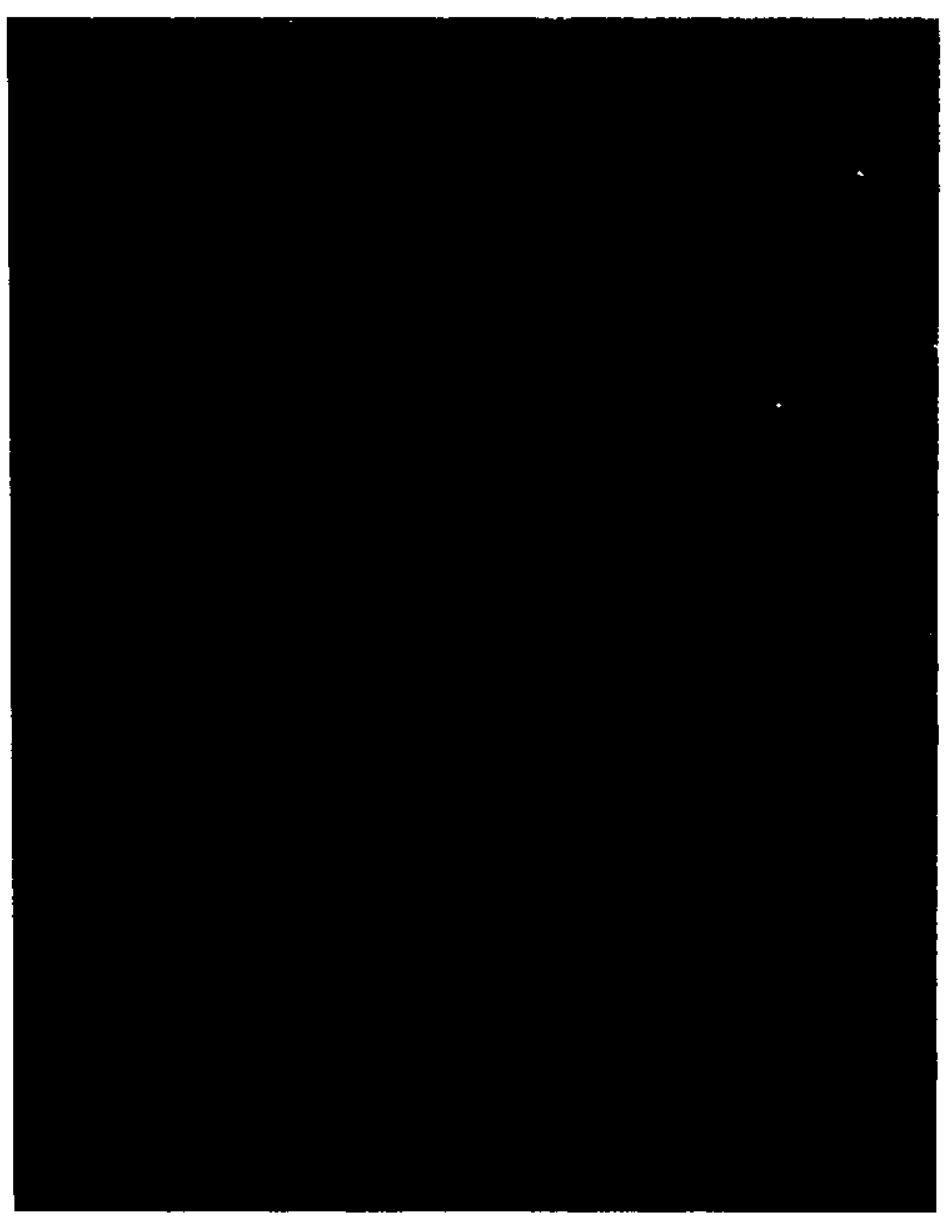

Figure 7.2.6. SEM micrographs of aluminium oxide films deposited by the filtered arc. a) cross-section; and b) front surface. 


\subsubsection{CONCLUDING REMARKS}

- Aluminum oxide films produced by filtered arc evaporation were found to be of high optical quality.

- A rapid increase in the cathode spot velocity when oxygen is introduced into the deposition chamber.

- The cathode spot velocity depends on the transverse magnetic field, arc current and the target material.

- No influence of the deposition rate on the structure of the films was observed in the range $15-25 \mathrm{~nm} / \mathrm{min}$.

- Dense films deposited at ambient temperature and examined by X-ray diffraction show no diffraction peaks which indicated that their structure is amorphous.

- The filtered arc evaporation process is a promising technique for oxide film deposition and may prove to be a viable alternative to the conventional ion-assisted techniques. 


\section{REFERENCES}

[1] T.D. Schemmel, R.L. Cunningham and H. Randhawa, Process for high rate deposition of $\mathrm{Al}_{2} \mathrm{O}_{3}$. Thin Solid Films, 181, pp. 597-601, (1989).

[2] H. Randhawa and P.C. Johnson, Cathodic arc deposition advances coating technology. Vacuum Technology. (1987).

[3] C. Deshpandey, L: Holland, Preparation and properties of $\mathrm{Al}_{2} \mathrm{O}_{3}$ films by d.c. and r.f. magnetron sputtering.Thin Solid Films, 96, pp. 265- 270 (1982).

[4] M. Scherer, R. Latz, and U. Patz, A novel solution for the fast deposition of $\mathrm{Al}_{2} \mathrm{O}_{3}$ by d.c.reactive magnetron sputtering. IPAT (1989).

[5] R.F.Bunshah and R.J. Schramm, Alumina deposition by activated reactive evaporation. Thin Solid Films, 40, pp.211-216 (1977).

[6] B. Granchev and V. Orlinov, Bulgaria F. Przyborrowski and CHR. Weieemantel. G.D.R.

Stucture of aluminum oxide films deposited by $d$. c. reactive sputtering. Thin Solid Films, 70, pp.111-116 (1980) .

[7] R.P. Howson, N. Mustapha, H.A. Ja'fer and E.M. Stenlake. A comparison between the performance of an arc evaporation source with ion selection and an unbalanced magnetron. IPAT (May)1991. Belgium

[8] Oka K., Plasma activated growth of a reactively sputtered optical thin films. Ph.D. Thesis LUT (1988).

[9] H. Randhawa,

High-rate deposition of $\mathrm{Al}_{2} \mathrm{O}_{3}$ films using modified cathodic arc plasma deposition processes. J.Vac.Sci.Technol. A7(3), May/Jun (1989). 


\subsection{AIN FILMS}

\subsubsection{INTRODUCTION}

AlN films are of interest both for their piezoelectric properties [1] and as a III-V compound with a thermal expansion coefficient similar to that of GaAs [2]. Recently the synthesis and properties of aluminum nitride have been the subject of intense study due to the wide applicability of AlN for microelectronics devices. The high resistivity, chemical and thermal stability of AIN films makes them suitable as insulating and passivating layers in semiconductor devices [3 - 6].

AlN has high thermal conductivity, high hardness, good corrosion resistance, high transparency [7, 8], and has been used as substrates in integrated circuits [9] for its high thermal conductivity.

Thin films of AIN have been prepared by several techniques, including chemical vapour deposition $[10,11]$, reactive sputtering and evaporation [12- 16] and ion-beam nitridation $[3,17-20]$.

The objective was to investigate the experimental parameters for the deposition of aluminum nitride films AlN by the reactive filtered arc evaporation process onto insulating substrates and silicon coated glass, and to examine the influence of the deposition conditions on the structure and morphology of the deposits, in order to compare the results with those of other deposition processes.

\subsubsection{EXPERIMENTAL DETAILS}

Aluminum nitride films AlN were deposited with a typical base pressure of $10^{-5}$ torr.The process gas pressure was adjusted in the range 2 - 7 mtorr with a combination of argon and nitrogen, both $99.99 \%$ pure. The gas ratio was varied to obtain the best rate while maintaining film quality. The aluminum target used had a purity of $99.99 \%$, positioned at the entrance of a plasma filter described earlier, whilst the substrate was at the exit port of the filter. Both glass and silicon coated glass were used in the deposition process. Substrates were cleaned prior to deposition using a chemical solvent a D. I. water rinse and were then dried. 
Optical transmittance and reflectance curves in the visible region fo thin films 50 - 150 $\mathrm{nm}$ on glass substrates were obtained using a spectrophotometer.Refractive index was measured by an ellipsometer for films deposited onto both glass and silicon coated glass. The film thickness was measured using talystep. Scanning Electron Microscopy SEM was used to study AIN films surface topography, film crystal structure using $\mathrm{X}$-ray diffraction. The results obtained by reactive filtered arc evaporation were compared with those obtained by reactive sputtering.

\subsubsection{RESULTS}

\subsubsection{Process rate}

The arc current was maintained at 90 Amps for all depositions.

Preliminary results indicated that the film characteristics were not influenced by the location of the nitrogen gas inlet, and that AIN films could be obtained over a varying $\mathrm{N}_{2}$ pressure. A clear film, free of microdroplets with refractive index 2.092 was obtained at nitrogen and argon pressures of 1.9 mtorr and 2.4 mtorr respectively. Aluminum nitride films deposited onto unheated substrates were absorbing for all deposition rates and nitrogen pressures tested. The films were found to be transparent for deposition rates up to $0.56 \mathrm{~nm} / \mathrm{s}$ and nitrogen partial pressure of $60 \%$.

Process optimization for the deposited films yielded the following parameters:

(1) The bias voltage on the walls of the plasma duct was $12-16 \mathrm{~V}$.

(2) The uniformity of the films can be obtained by rotating the substrate at the exit of the plasma duct.

(3). The longitudinal magnetic field inside the duct was 220 Gauss maximum at the bend. The average field strength in the vicinity of the cathode and the exit of the duct was 85 Gauss.

(4) The estimated transfer efficiency for the entire duct is of the order of 30 $50 \%$, depending on the proximity of the coil from the cathode and deposition parameters.

(5) Heating of the substrates is thought to be necessary to obtain high optical properties with very low absorption.

(6) The films were found to be transparent for a nitrogen partial pressure range of $0.75-5$ mtorr. 
chapter seven

\subsubsection{Optical properties}

Refractive index values were obtained using an ellipsometer and were in the range 1.91 -2.09 ( $120 \mathrm{~nm}$ thick), where the thickness of the films deposited onto glass substrates were given by the ellipsometer.

A set of films deposited on glass substrates was examined for optical transmission and reflectance in the visible region. 
chapter seven

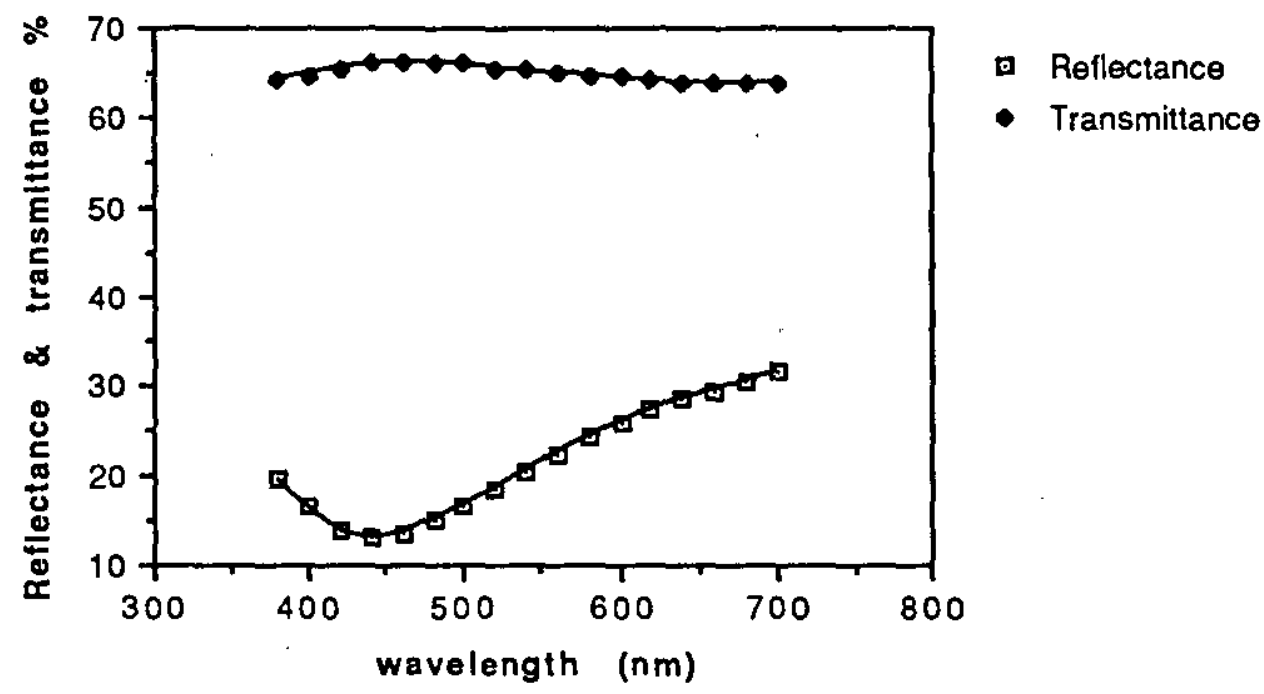

Figure 7.3.1. shows the transmittance and reflectance of AlN film. 


\subsubsection{SEM}

SEM micrographs of aluminium nitride films showed that all films were microdroplet-free.

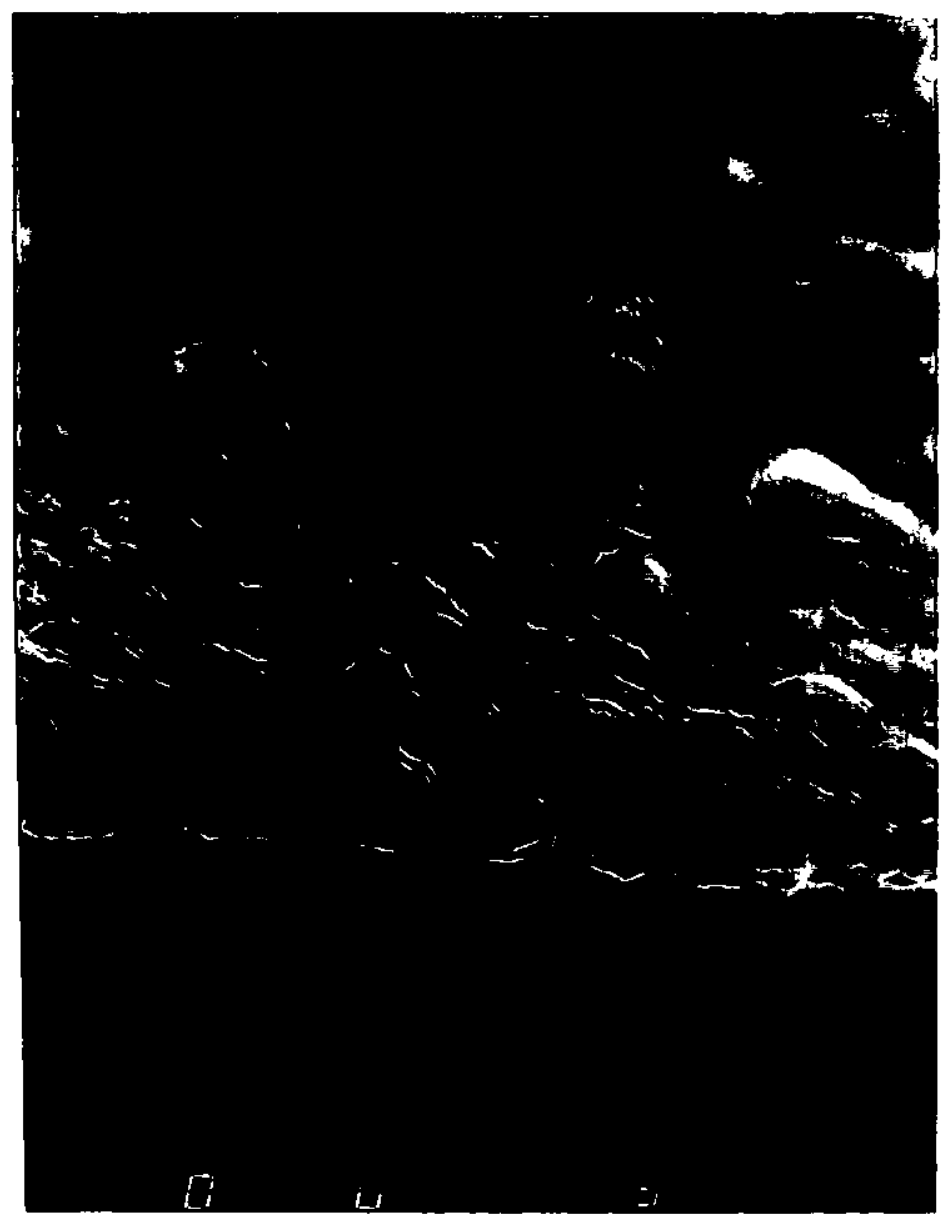

Figure 7.3.2 SEM micrograph of aluminium nitride film. 


\subsubsection{X-ray diffraction}

The X-ray diffractuion results indicated that the AlN films deposited at ambient temperature were amorphous.

\subsubsection{CONCLUDING REMARKS}

All AlN films deposited onto unheated substrates were absorbing and substrates had to be heated to improve film quality. 


\section{REFERENCES:}

[1]. S.V. Krishnaswamy, W. A. Hester, J. R. Szedon, M. H. Francombe, and M. M. Driscoll, Thin Solid Films, 125 , p. 291 (1985).

[2]. R. O. Pashley and B.M. Welch, Solid State Electron.18, 977 (1975).

[3]. H. Birey, S.J. Pack, J. R. Silcs, and J. F. Wager, J. Vac. Sci. Technol. 16, 2086 (1979).

[4]. A. Fathimulla and A. A. Lakhani, J. Appl. Phys. 54, 4586 (1983).

[5]. G. Este, R. Surridge, and W. D. Westwood, J. Vac. Sci. Technol.A4, p.989 (1986).

[6]. R. Bensalem, A. Abid, and B.J. Sealy, Thin Solid Films, 143, p.141 (1986).

[7]. N. Kuramoto and H. Tanigushi, J. Mater. Sci. Lett. 2, p.471 (1984).

[8]. N. Kuramoto, H. Taniguchi, and I. Aso, IEEE Trans. Components, Hybrids Manuf. Technol. CHMT - 9, p.386 (1986).

[9]. Functional crystalline materials and artificial minerals, edited by Engineering Society of Artificial Minerals, Kodansho, Tokyo, 105 ( 1991 ).

[10]. J. K. Lin, K.M. Lakin, and K. L. Wang, J. Appl. Phys. 46, 3703 (1975).

[11]. G. A. Slack and T. f. Mcnelly, J. Cryst. Growth 34, 263 (1976).

[12]. P.N. Favennec, L. Henry, T. Janicki, and M. Salvi, Thin Solid Films, 47, p.327 (1977).

[13]. L. Xinjiao, X. Zechuan, H. Ziyou, C. Huazhe, S. Wuda, C. Zhongcai, Z. Feng, and W. Enguang, Thin Solid Films 139, p.261 (1986).

[14]. L. Xinjiao, X. Zechuan, H. Ziyou, C. Huazhe, S. Wuda, C. Zhongcai, Z. Feng, and W. Enguang, Thin Solid Films 139, p.261(1986).

[15]. H. Yamashita, K. Fukar, S. Misawa, and S. Yashida, J. Appl. Phys. 53, 896 (1979).

[16]. P. J. Martin, R. P. Netterfield and T. J. Kinder, Ion - Beam - deposited films produced by filtered arc evaporation. Thin Solid Films, 193 / 194, pp.77 83 (1990).

[17]. A. Singh, R. A. Lessard, and E. J. Knystautas, Thin Solid Films, 138, p.79 (1986) .

[18]. J. A. Taylor and J. W. Rabalais, J. Chem. Phys. 75, 1735 ( 1981 ).

[19]. I. M. Belyi, F. F. Komarov, E. G. openchuk, and S. Yu. shiryaev, Sov. Phys. Crystall. 24, 233 (1979).

[20]. J. M. E. Harper, J. J. Cuomo, and H. T. G. Hentzell, Appl. Phys. Lett. 43, 547 (1983). 


\subsection{TiO2 FILMS}

\subsubsection{INTRODUCTION}

Titanium dioxide has many unusual properties which make it suitable for a variety of applications. Its excellent optical transmittance, high refractive index, and durability are attractive features for optical applications. Extensive studies have been made relating the optical properties of $\mathrm{TiO}_{2}$ films with structure and preparation conditions [1-5].

\subsubsection{EXPERIMENTAL PROCEDURE}

The filtered arc system used in the film deposition has been described earlier. The substrate holder was connected to earth. The deposited film thickness was $50-150 \mathrm{~nm}$. Thin films of $\mathrm{TiO}_{2}$ were deposited onto glass microslides arranged such that optical transmission and reflectance measurements could be made using spectrophotometer. The structure of the deposited films were examined by $\mathrm{X}$-ray diffraction and the refractive index was measured using ellipsometry at $632.8 \mathrm{~nm}$. The thickness of the films was measured with a talystep instrument.

\subsubsection{RESULTS AND DISCUSSIONS}

Titanium oxide films deposited onto unheated glass microslides were absorbing for all deposition rates (16 $-20 \mathrm{~nm} / \mathrm{s}$ ) and oxygen pressures ( $0.5-2$ mtorr).

Martin et al [1] reported that the optical properties were improved significantly, when the substrate was heated to approximately $350^{\circ} \mathrm{C}$. A typical value for the extinction coefficient $k$ was 0.07 and the refractive index $n_{633}$ was 2.735 . The structure was identified from X-ray diffraction as the rutile phase of $\mathrm{TiO}_{2}$. These agreed with previous studies on the structure of $\mathrm{TiO}_{2}$ films prepared by reactive evaporation of titanium onto substrates heated to $350^{\circ} \mathrm{C}[6]$.

Randhawa [7] has reported the deposition of $\mathrm{TiO}_{2}$ by reactive arc evaporation using an oxygen-argon mixture. $\mathrm{TiO}_{2}$ films with very low absorption (less than $5 \%$ ) in the visible region and excellent adhesion to plastics and glass substrates have been deposited. In fact $\mathrm{TiO}_{2}$ films with a sharp cut-off at approximately $400 \mathrm{~nm}$ were found to be very suitable for UV filters. 
We found the refractive index for the films deposited in this work is in the range 2.41- 2.51. The transmittance and reflectance properties spectra are shown in figure 7.4.1.for films of $120 \mathrm{~nm}$ thick. Figure 7.4.2 is an SEM micrograph of the titanium oxide films. The films were dense with no sign of microdroplet contamination. X-ray diffraction shows no diffraction peaks, suggesting all films deposited onto unheated substrates were amorphous.

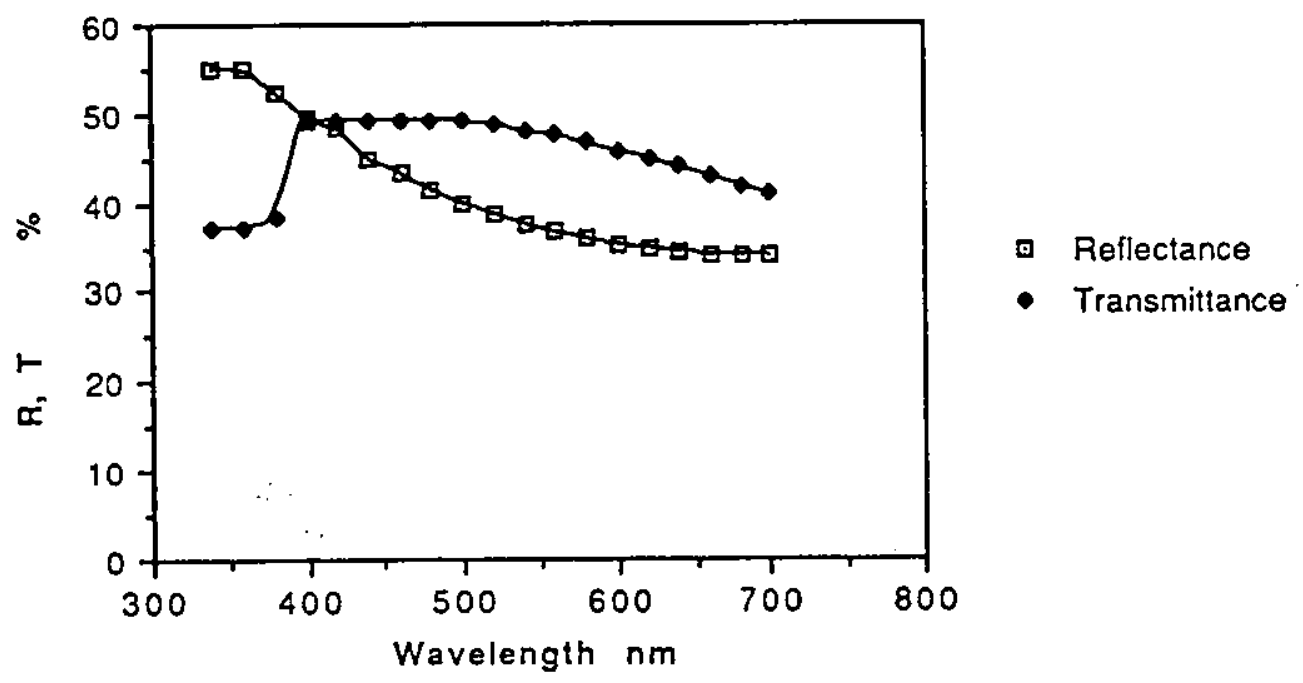

Figure 7.4.1 The reflectance and transmittance of $\mathrm{TiO}_{2}$ film deposited onto unheated glass. 
chapter seven

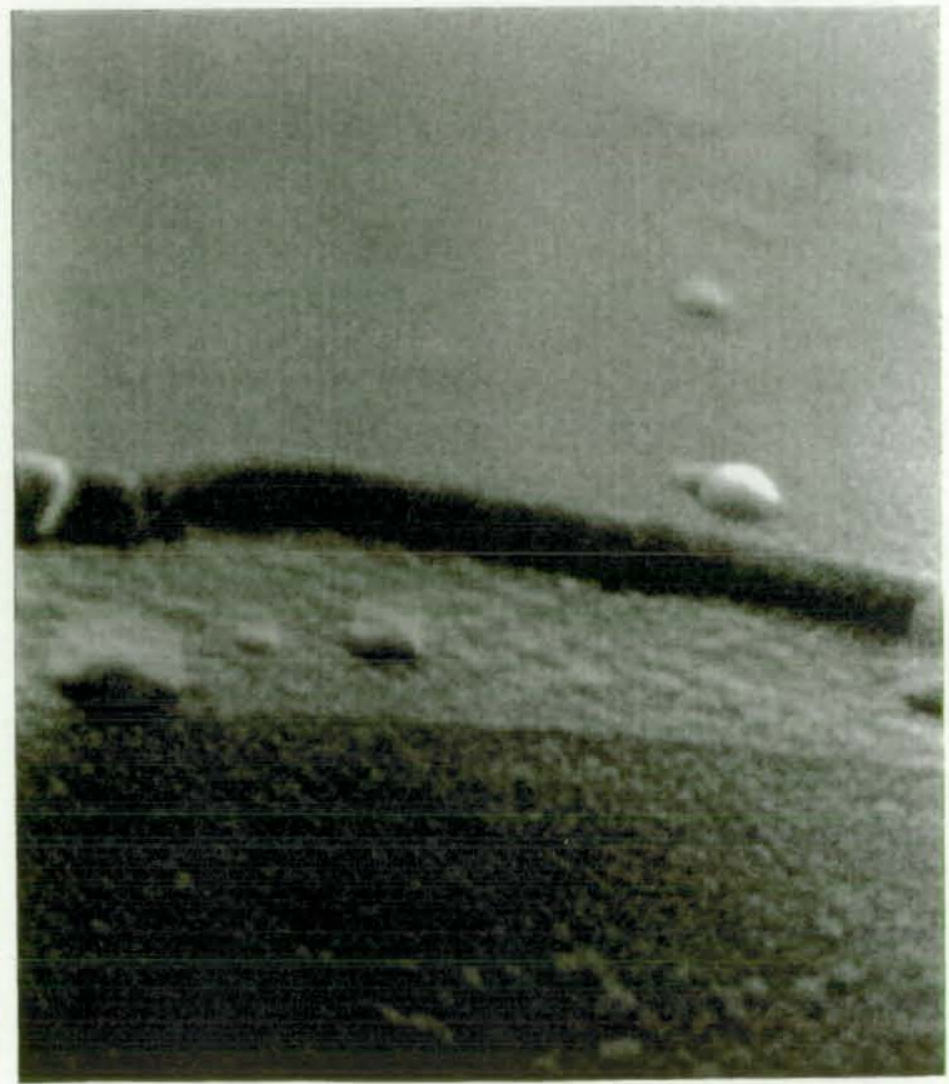

Figure 7.4.2. SEM micrograph of titanium oxide film. 


\section{REFERENCES}

[1]. P. J. Martin, R. P. Netterfield, T. J. Kinder, and L. Descotes. Deposition of TiN, TiC and $\mathrm{TiO}_{2}$ by filtered arc evaporation. Surf. Coat. Technol., 49, pp. 239-243 (1991).

[2]. . R.P.Howson, K. Suzuki, C.A. Bishop, and M.I. Ridge, Vacuum 34, p.291 (1984).

[3]. E. Ritter, J. Vac. Sci. Technol., 3, 225 (1966).

[4]. H. Kuster and J. Ebert, Thin Solid Films, 7043 (1980).

[5]. P.J. Martin, H.A. Macleod, R.P. Netterfield, C. G. Pacey, and W. G. Sainty, Appl. Opt. 22, 178 (1983).

[6]. H. K. Pulker, G. Paesold and E. Ritter, Appl. Opt., 15, p.2986 (1976).

[7]. H. Randhawa, Cathodic arc plasma deposition technology, Thin Solid Films, 167, pp. 175-185 (1988). 


\subsection{CARBON FILMS}

\subsubsection{INTRODUCTION}

In recent years, diamond-like carbon film ( DLC film ) has become a very attractive material because of its outstanding properties of high hardness, high electrical resistance, high thermal conductivity and high optical transmittance, especially in the infrared region.

Hard diamond-like carbon (DLC) was recently produced using three variations of the vacuum arc technique. The first technique uses a curved magnetic field to filter macroscopic particles from the arc plasma stream $[1,4]$, the second uses a pulsed arc [5-6], while the third uses a r.f. biasing of the substrate $[7,8]$. Aksenov et al have demonstrated the use of the plasma-optical separator to produce high quality diamond-like coatings, with density was $3.4 \mathrm{~g} \mathrm{~cm}^{-3}$ and electrical resistivity of $10^{8} \mathrm{ohm} . \mathrm{m}$. The properties and structure of the coatings can be varied over a wide range, from diamond to graphite as a function of deposition conditions [1]. Diamond-like coatings ( DLC's ) produced by the deposition of fast atoms or carbon ion fluxes on to cooled substrates possess mechanical properties resembling those of diamond and can evidently be used as a wear-resistant material to strengthen different sliding units and machine parts [2]. The pulsed arc-discharge method can be used to produce DLC films with excellent tribological properties, comparable to those of films deposited using mass-separated ions, with a coefficient of friction about the same as that of natural diamond. The curved solenoid reduces the number of particles hitting the deposited sample. By using an appropriate vacuum system it should be possible to reduce the hydrogen impurities $[5,6]$. As a result of using the three mentioned vacuum arc techniques for deposition of carbon films, hard, thick and highly adhesive coatings are obtained on to a variety of substrates at room temperatures [1-12].

\subsubsection{EXPERIMENTAL DETAILS}

Carbon films were deposited onto glass and silicon coated glass. In general the carbon deposits were stressed and exhibited minimal adhesion to the substrate after prolonged exposure to air. Fig 7.5.1 shows a SEM micrograph of a fresh carbon film deposited on glass. 
The carbon films were partially transparent with a refractive index in the range $1.91 \div 2.3$ at $632.8 \mathrm{~nm}$ for an average thickness of between 35 and $50 \mathrm{~nm}$. The optimum deposition rate achieved was $40 \mathrm{~nm} \mathrm{~min}^{-1}$ at a current of $75 \mathrm{~A}$ and argon pressure of 2.5 mtorr.

We know that the filtered arc system gives a very high value of ion current in the centre of the solenoid $>150 \mathrm{~mA} / \mathrm{cm}^{2}$. This may cause resputtering of the growing film and hence result in low deposition rate. Without optimization, the energetic beam leaving the solenoid damaged the glass substrates. By adjusting the beam profile i.e. setting an optimum ion current value to the growing film, better adhesion of the film to the substrate and a higher deposition rate may be achieved. Films deposited on silicon coated glass show better adhesion to the substrates. This shows that both mechanical and chemical properties of the substrate surface and the microstructure of the substrate material have a decisive influence on film growth conditions [11].

Other important factors are the positioning and movement of the substrate in relation to the cathode, which determine thermal loading of the substrate surface.

The chamber atmosphere also affects the running behaviour of the arc on the target surface. It appears that high inert gas e.g. argon, have a stabilizing effect on the arc process. 


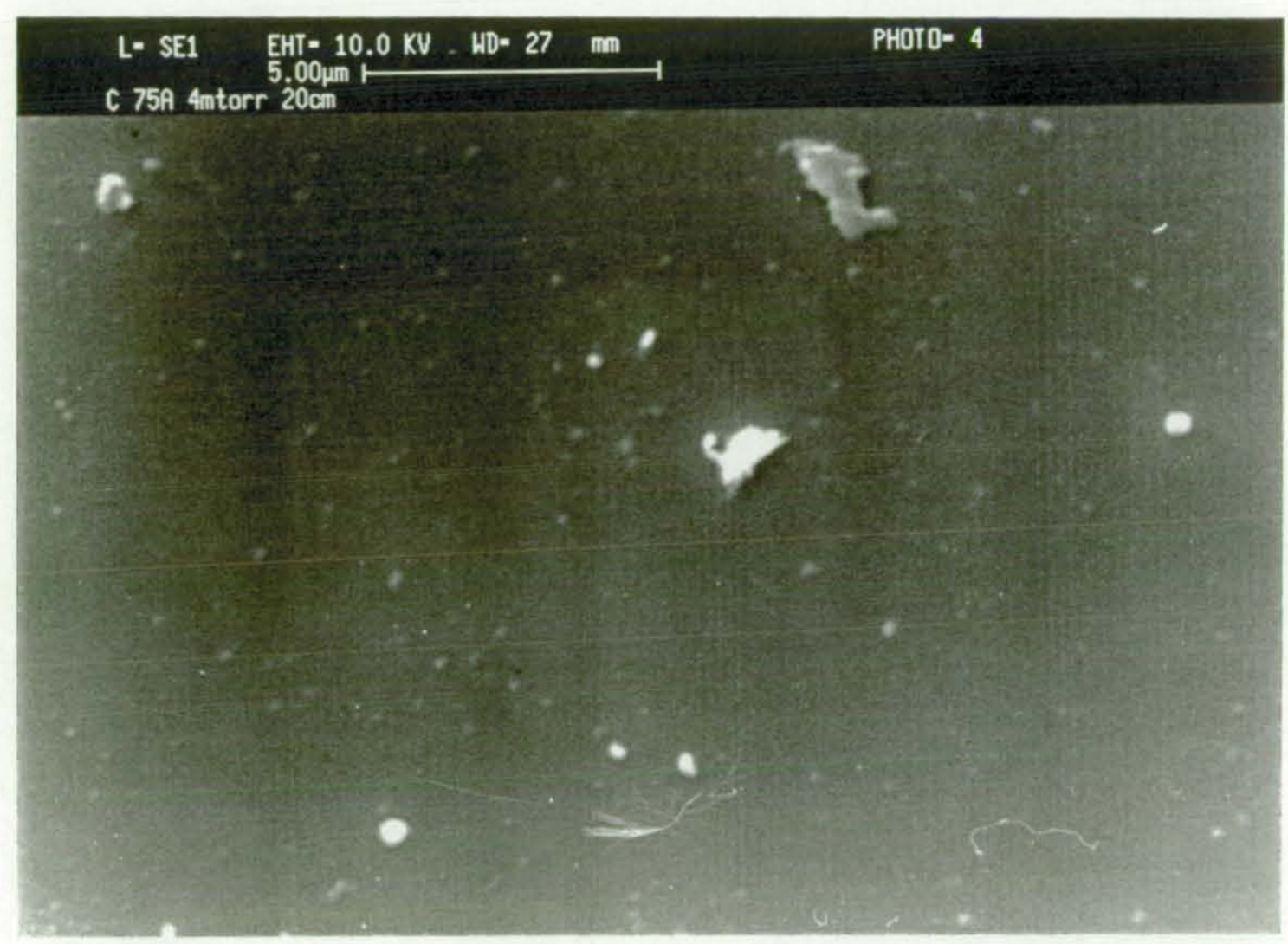

Figure 7.5.1. SEM micrograph of a fresh carbon film. 


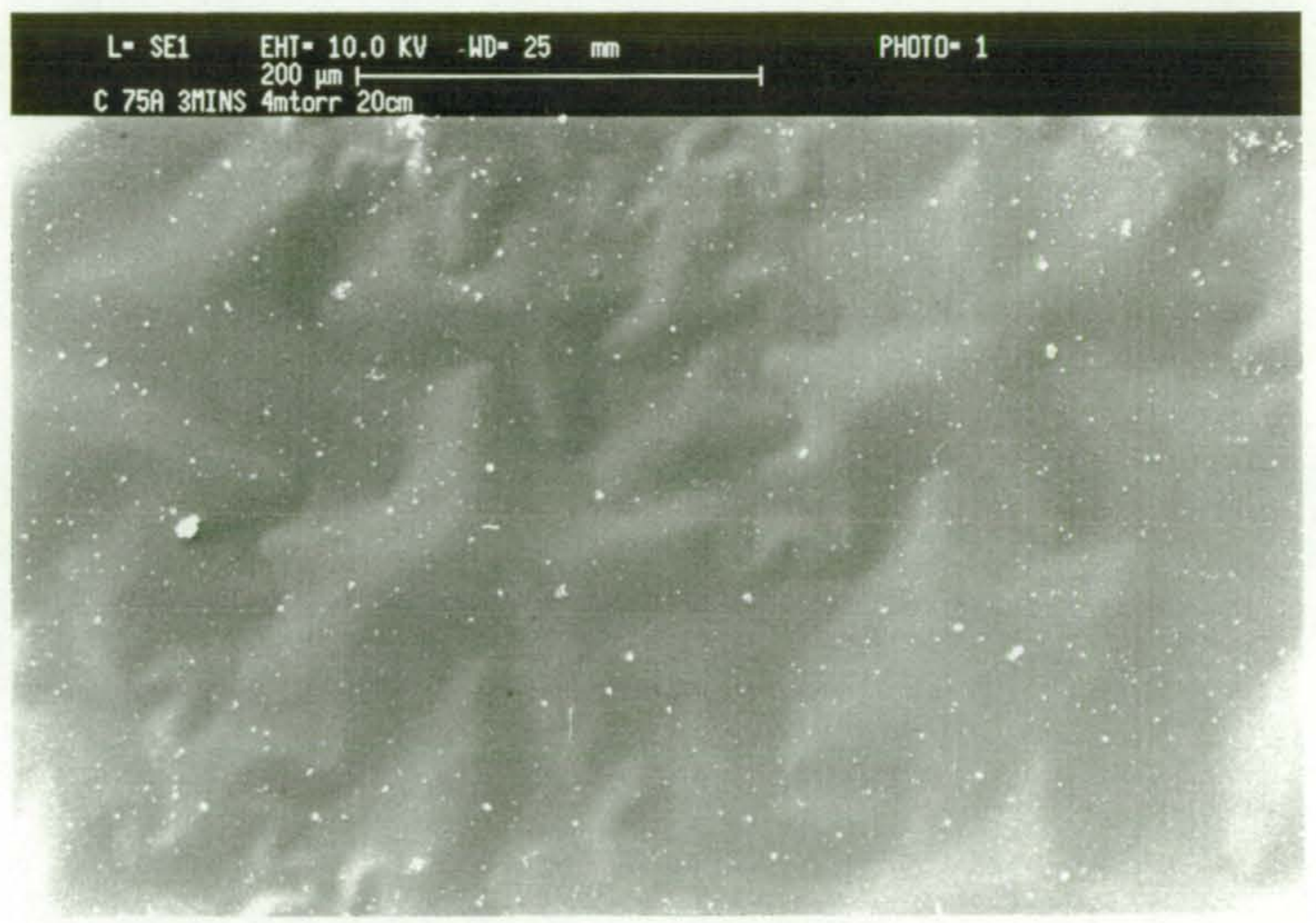

Figure 7.5.2 SEM shows compressive stress on a carbon film after exposure to air. 


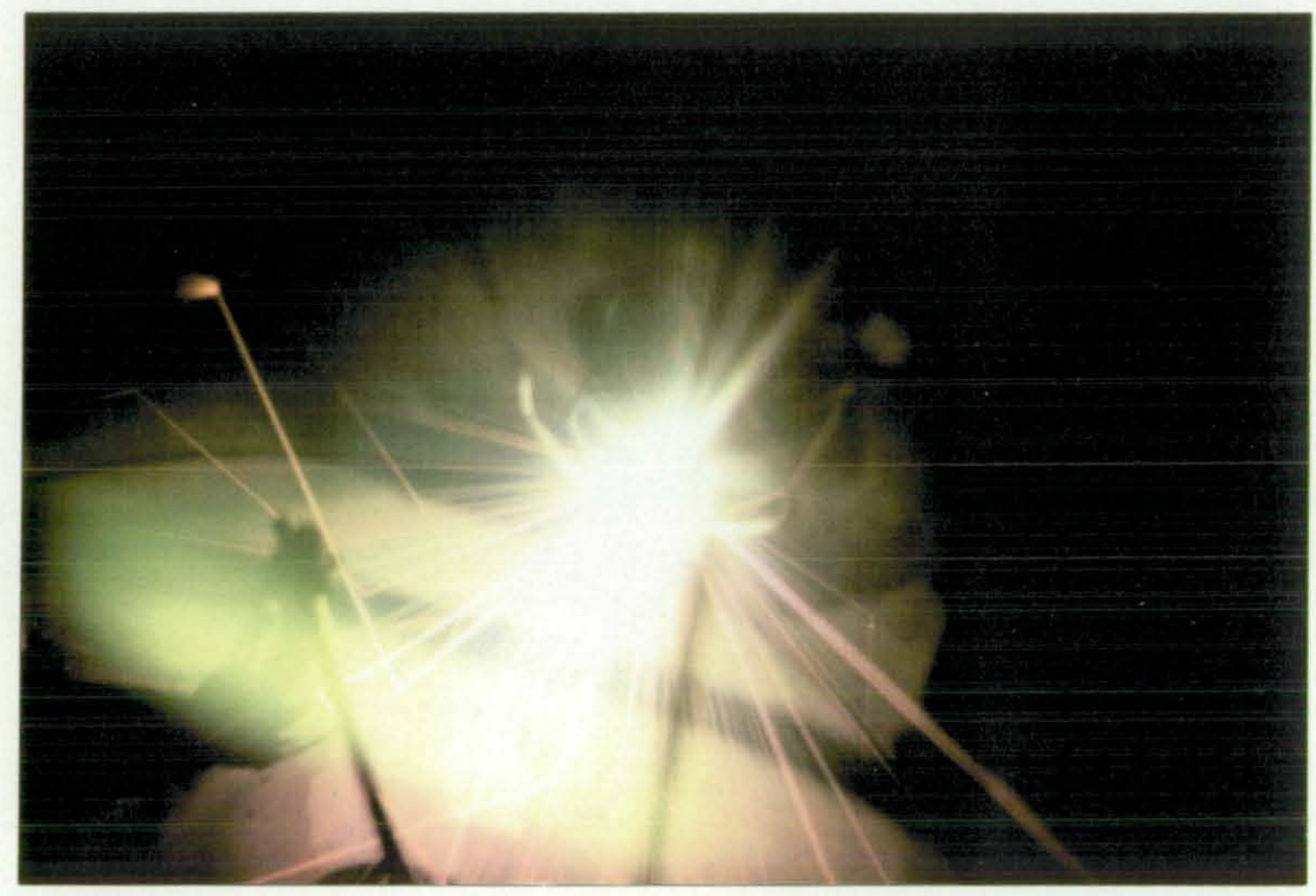

Figure 7.5.3 A photograph of droplet flux emitted from the carbon cathode. 


\subsubsection{X-RAY DIFFRACTION}

A fresh sample examined by $\mathrm{X}$-ray diffraction showed that the deposited film is amorphous.

\subsubsection{CONCLUSION AND DISCUSSIONS}

1. The technique of filtered arc evaporation promises to be a relatively low-cost method of depositing hard carbon films onto a variety of substrates at room temperature.

2. Transmission of carbon plasma through a curvilinear plasma-optical filter system is more effective than transmission of plasma formed of heavy elements such as copper or titanium.

3. Cathodic arc evaporation can produce amorphous films of carbon with the structural characteristics of diamond.

4. By using beams of completely ionized carbon plasma from a filtered arc, diamond-like carbon coatings can be produced, the quality of which ( purity, hardness ) is significantly greater than that of coatings produced by condensation of the unpurified plasma from a vacuum arc. Guiding of the product to a substrate out of direct line of sight of the source results in films free from droplet contamination.

5. The effective removal of carbon macroparticles from intense carbon ion beams by transmission through a curvilinear plasma optical system has been shown possible with a simple low field solenoid.

6. Filtering of the vacuum arc evaporation source with a magnetic plasma duct is seen to be the most effective method of producing macroparticle-free coatings. Other filtering methods have varying degrees of success and many of these modifications may also be incorporated in a magnetic duct device to further improve the performance [12]. 
7. The similar system requirements of cathodic arc and magnetron sputtering permit these techniques to be combined in a single coating system. Such a configuration lends itself to multilayer coatings in which the greatest advantage may be derived from the best qualities of each. In the case of diamond - like carbon films, the magnetron sputtering permits a thin sputtered layer of material such as silicon, germanium and molybdenum to be deposited over the substrate prior to carbon deposition. This provides highly adherent, dense carbon coatings deposited by the filtered arc [12].

From these results we can conclude that the energetic nature of arc technology can produce coating structures having highly unusual bonding. Once again, in spite of the exstensive activity which has been carried out with diamond coatings in general, there is rather inadequate understanding of the exact nature of the processes which occur during the production of the coatings. Improved understanding would increase the chance of obtaining large single crystal coatings that might find extensive application in microelectronics.

Martin et al [10] reported that for a carbon cathode, the emitted material is primarily $\mathrm{C}^{+}$ ions with kinetic energies broadly peaked at around $22 \mathrm{eV}$. In addition to carbon ions, the cathode spot also emits a significant flux of microdroplets figure 7.5.3. These can be removed using a plasma-optical filter.

Optimum procedures remain to be determined to provide a sputtered pre-coat followed by a film of Diamond-Like Coatings (DLC), and the assessment of the deposited film properties is yet to be completed. However, preliminary results indicated that carbon films deposited on silicon coated glass were more adhesive to the substrate. Both carbon and silicon are group IV elements and in terms of electronic properties they are nearly analogous. This might enhance the interaction between the $C$ ions and the silicon atoms at the substrate-surface interface.

Experience has shown that bombarding the growing film with predominantly the same species of atoms as the film has many advantages over bombardment with inert gas species. Therefore the combination of filtered arc evaporation with magnetron sputtering would result in improved film properties. 


\section{REFERENCES}

[1]. R. L. Boxman et al., " Fast deposition of metallurgical coatings and production of surface alloys using a pulsed high current vacuum arc", Thin Solid Films, vol. 139, pp. 41-52, (1986).

[2]. L. P. Sablev, Apparatus for vacuum evaporation of metals under the action of an electric arc, U.S. Patent No.3 783231 ( 1 January 1974 ).

[3]. W. M. Mularie, Evaporation Arc Stabilization, U.S. Patent No 4430184 (7 February 1984 ).

[4]. H. Wroe, Stabilization of low presure arc discharges, U.S. Patent No 2972 695 (1 February 1961).

[5]. S. Ramalingam, Controlled Vacuum Arc Material Deposition, Method and apparatus, World Patent No 85/03954 ( 12 September 1985).

[6]. I.I Aksenov, S.I. Vakula, V. G. Padalka, V. E. Strel'nitskii, and V. M. Khoroshikh. High-effeciency source of pure carbon plasma. Sov. Phys. Tech. Phys. 25(9), (September 1980).

[7]. V. E. Strel'nitskii, I.I Aksenov, S.I. Vakula, V. G. Padalka, and V.A. Belous. Properties of diamond-like carbon coating produced by plasma condensation. Sov. Tech. Phys. Lett. 4(11), (November 1978).

[8]. V. E. Strel'nitskii, V. G. Padalka,and S.I. Vakula. Properties of the diamond-like carbon film produced by the condensation of a plasma stream with an rf. potential. Sov. Phys. Tech. Phys. 23(2), (February 1978).

[9]. P. J. Martin and D. R. Mckenzie. Make clean, dense films with a filtered process.Research \& Development Magazine, (Oct. 1990).

[10]. P. J. Martin, S. W. Filipczuk, R. P. Netterfield, J. S. Field, D. F. Whitnall and D. R. Mckenzie, , J. Mater. Sci. Lett. 7, p.410 (1988).

[11]. J. C. Angus, P. K. Koidl and S. Domitz, in J. Mort and F. Jansen (eds.), Plasma Deposited Thin Films, CRC Press, Boca Raton, FL, p.89 (1986).

[12]. N. Mustapha. Preparation of carbon films by filtered arc evaporation. Internal review report, Physics dept., LUT (1993). 


\subsection{THE PLASMA EFFECTS ON THE SUBSTRATE.}

The currents were measured under a bias of from 0 to 150 volts at 3 mtorr of argon. The currents in the plasma were related to the arc cathode current and rose to around $100 \mathrm{mAmperes}$ his was not constant during arcing which is one characteristics of the arc plasma instability. The ion current did not change when the filament generated plasma was switched off and might be expected to consist almost entirely of ions of the evaporating material.

In this case, the current collected by the probe is due entirely to either positive ions or electrons. The probe placed in a plasma is bombarded by a flux of electrons and ions and reaches a floating potential $V_{f}$, which is the point of intersection with the current curve on the applied bias voltage axis. It was negative in this case. The floating potential became saturated at about 20 Volts with a maximum magnetic field through the solenoid (245 Gauss).

We have measured the ion current for the plasmas from a titanium and aluminium arcs under the same deposition parameters ( $90 \mathrm{~A}$ arc current and $3 \mathrm{mtorr}$ argon). Figure 7.6.1. shows the current-voltage characteristics of the probe for these two methods.

The plasma obtained from a titanium cathode shows a higher ion current than the plasma obtained from aluminium one. Since the I-V characteristics measurements were carried out under the same deposition conditions, titanium has a higher ionization level (roughly $80 \%$ ) than aluminium (roughly $50 \%$ ). This indicated that more titanium ions condensed on the substrate. This eased the reactive process during TiN deposition and resulted in titanium nitride films of high quality.

The melting point of the cathode material possibly plays an important role in the ionization process. The higher the melting point, the higher is the ionization level.

The addmission of reactive gas (0.75-2 mtorr) during TiN film deposition has no significant effect on the ion current.

\subsubsection{CONCLUDING REMARKS}

Titanium has a higher ionization level (roughly $80 \%$ ) than aluminium (roughly $50 \%$ ), more titanium ions condense on the substrate. This provides adherent, dense coatings deposited by the filtered arc. 


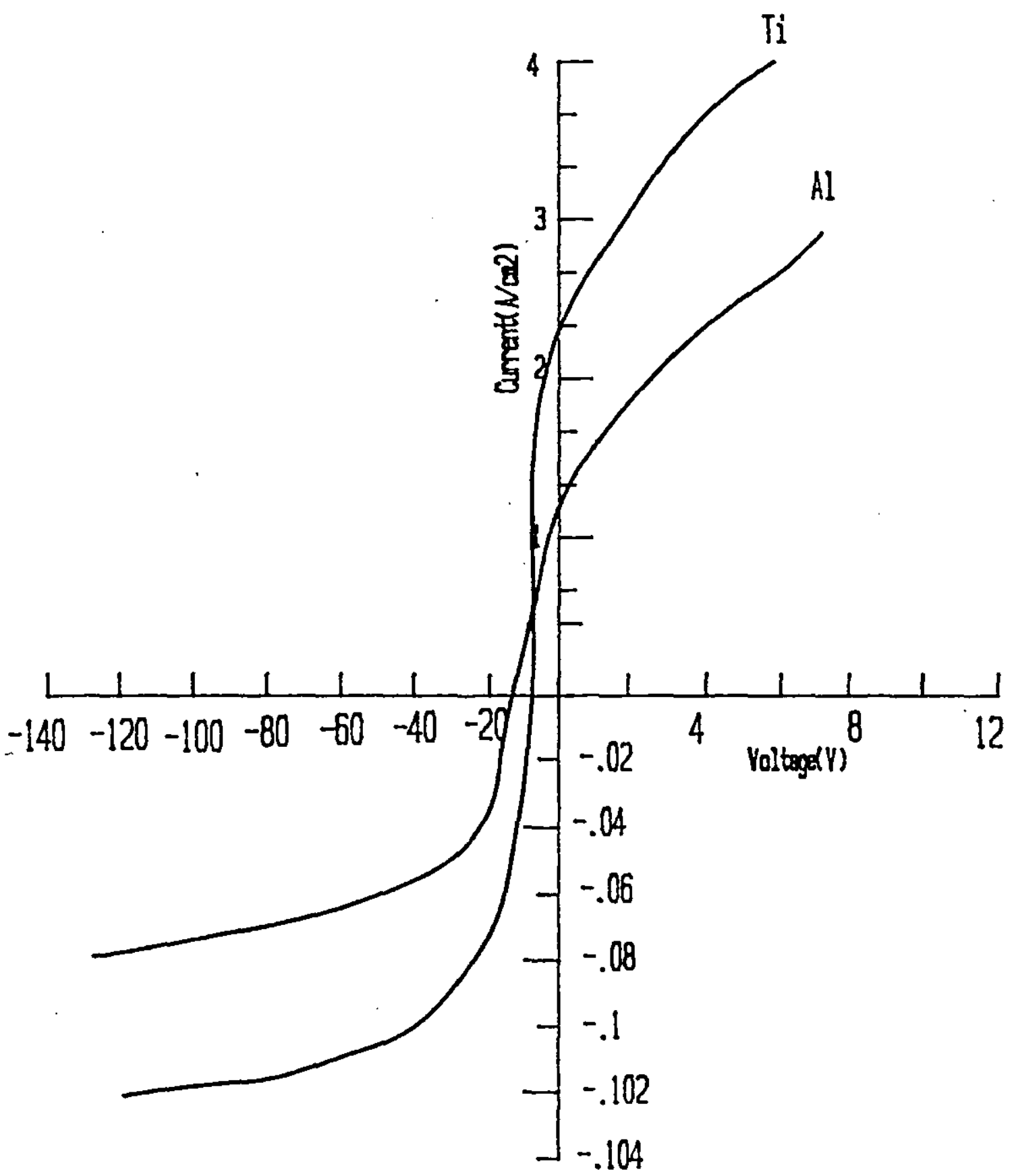

Figure 7.6.1. The current-voltage characteristics of the probe. 


\subsection{ELEMENTAL MATERIALS}

Microdroplet emission results from the extreme conditions that occur in craters on the source surface. Figure 7.7.1 shows emission craters on various metal sources. In an uncontrolled situation very high microdroplet densities may be produced and deposited onto the substrates. Figure 7.7.2 shows microdroplet emission from various metals having different melting points.

Aluminium, titanium and copper films have been prepared by the filtered arc technique. High quality, highly reflecting films of aluminium could be prepared. They had good adhesion to the glass substrates and showed no signs of droplet contamination. Figure 7.7.3 shows a micrograph for aluminium and titanium films from the filtered arc. Titanium was similar but arc evaporated copper was rough and discontinuous. A possible reason of this is the heavier atomic mass of copper and it appears that only low energy copper atoms were transported through the plasma duct, which resulted in poor quality copper films. Deposition rates were in the range $30-45 \mathrm{~nm} \mathrm{~min}-1$.

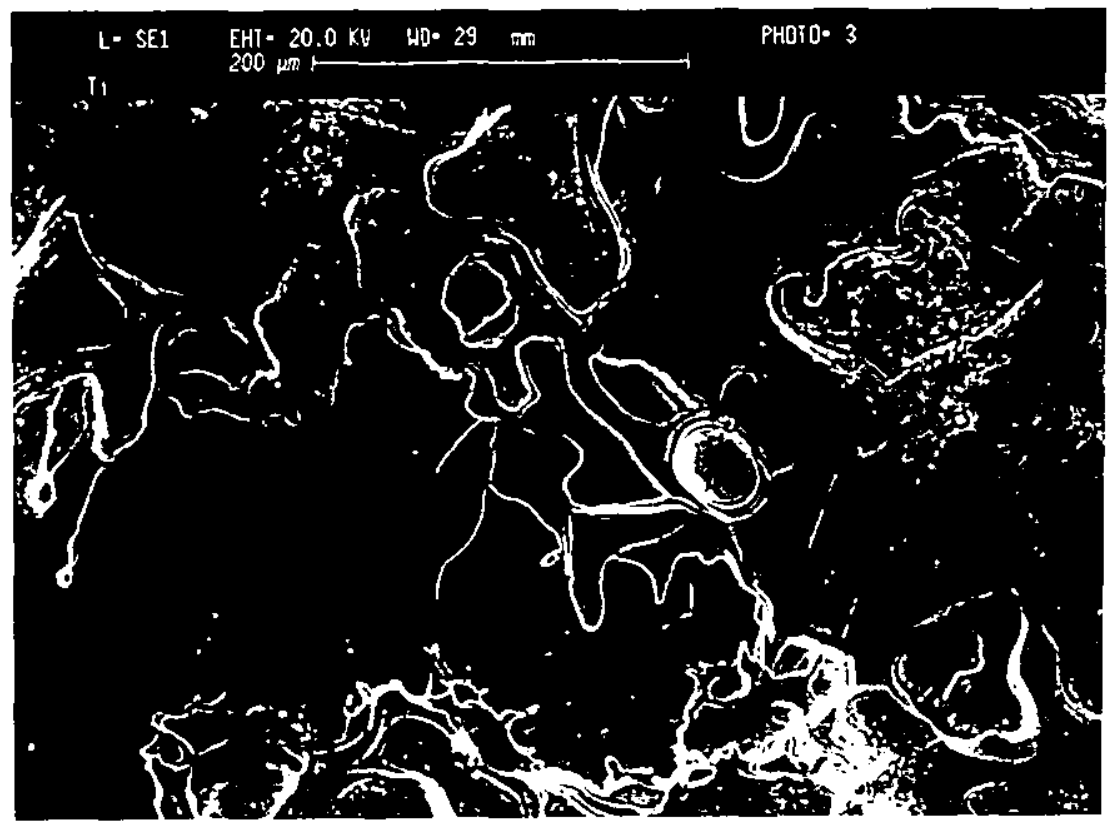




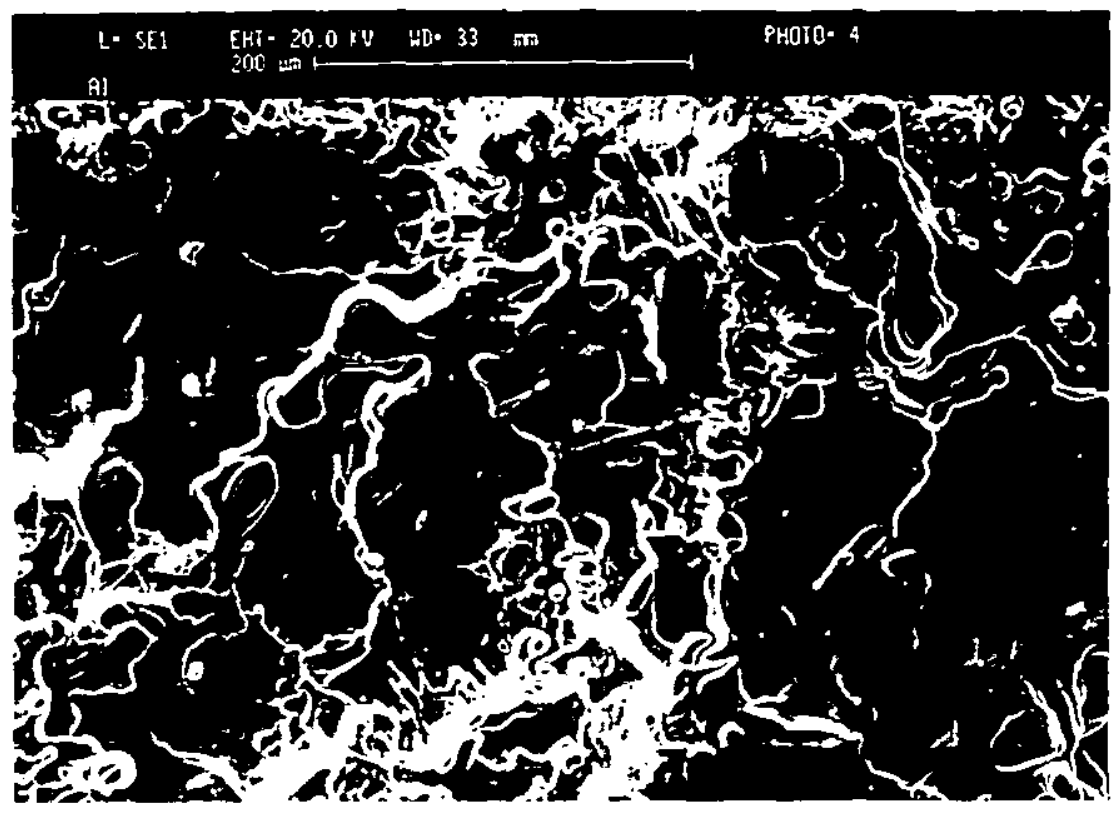

b

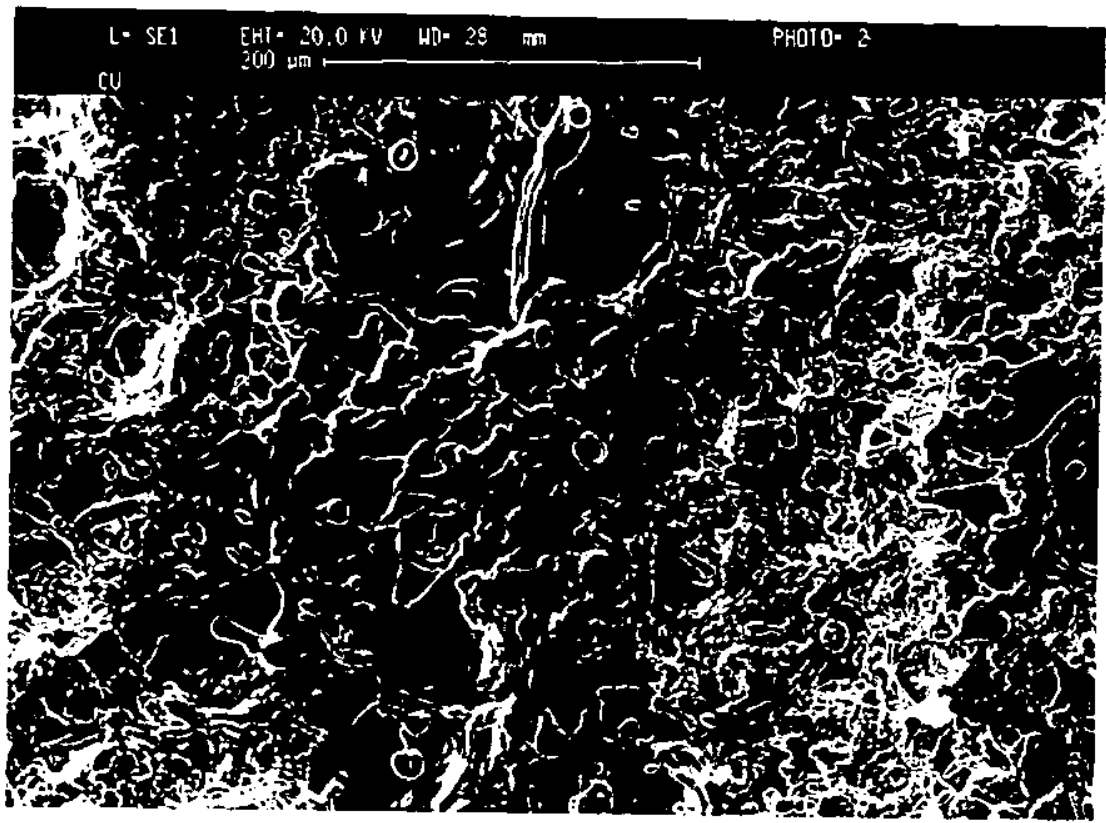

C

Figure 7.7.1 SEM micrographs of the cathode surface for (a) titanium; (b) aluminium; (c) copper 

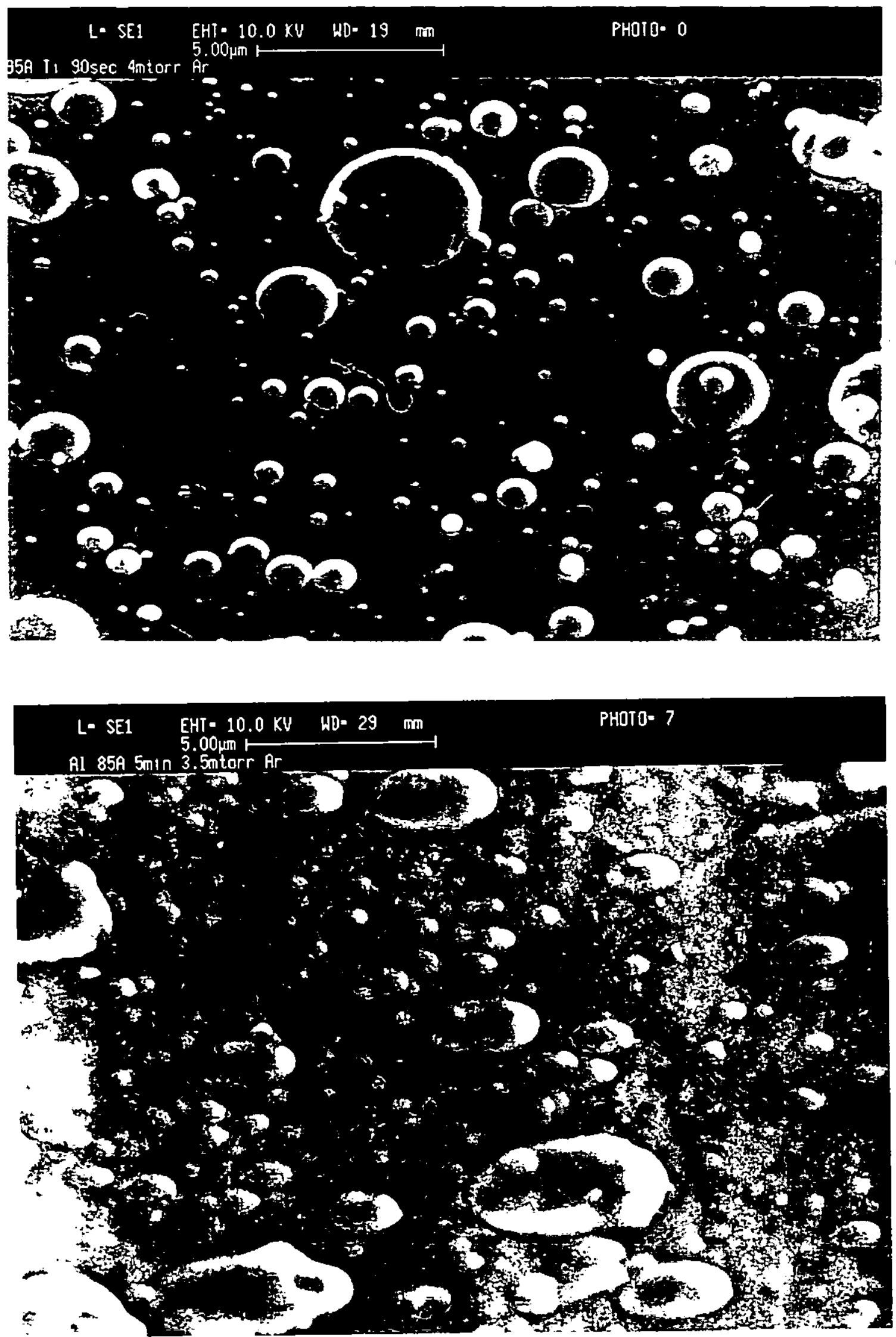
chapter seven

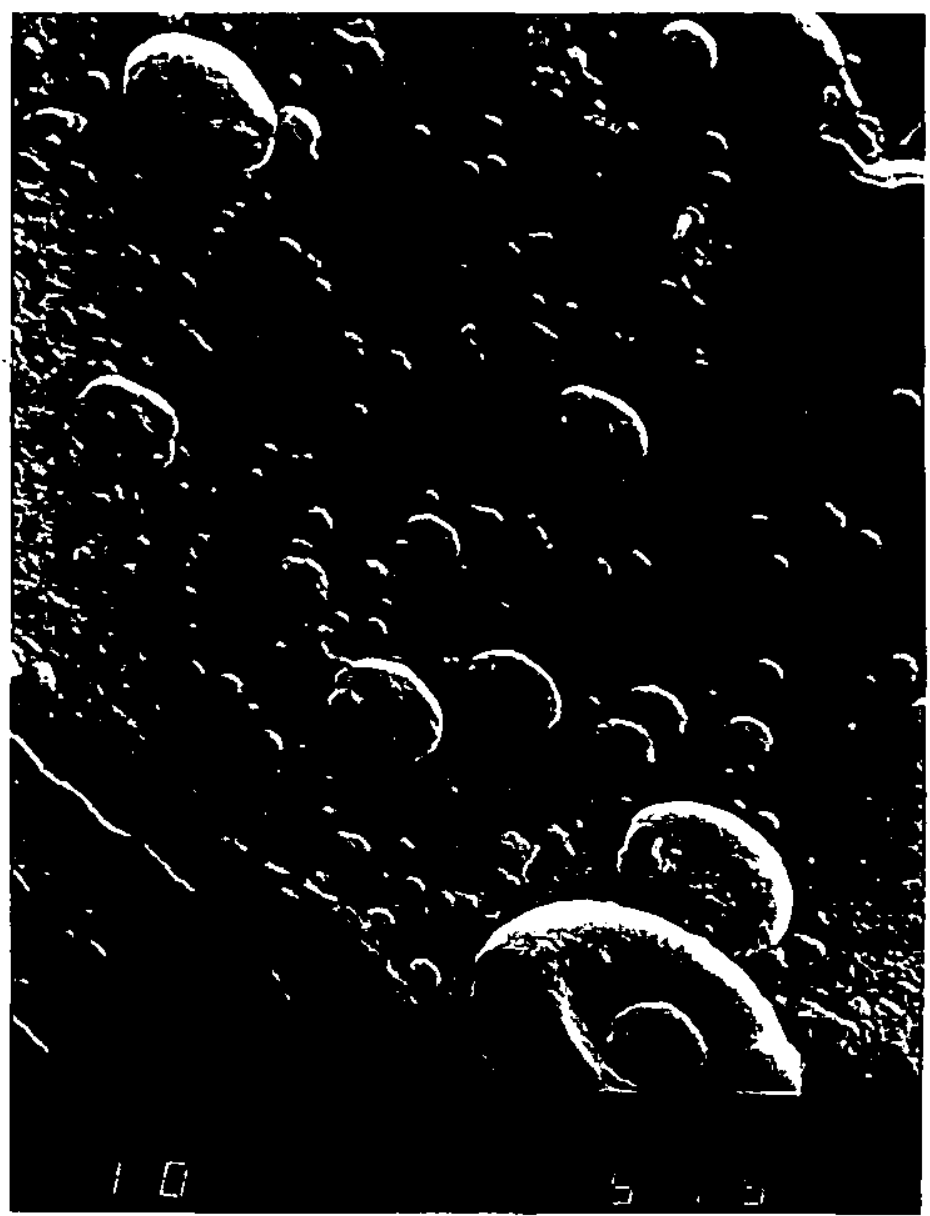

C

Figure 7.7.2. SEM micrographs for various metals with microdroplets ( no plasma filter). (a) titanium; (b) aluminium; (c) copper. 


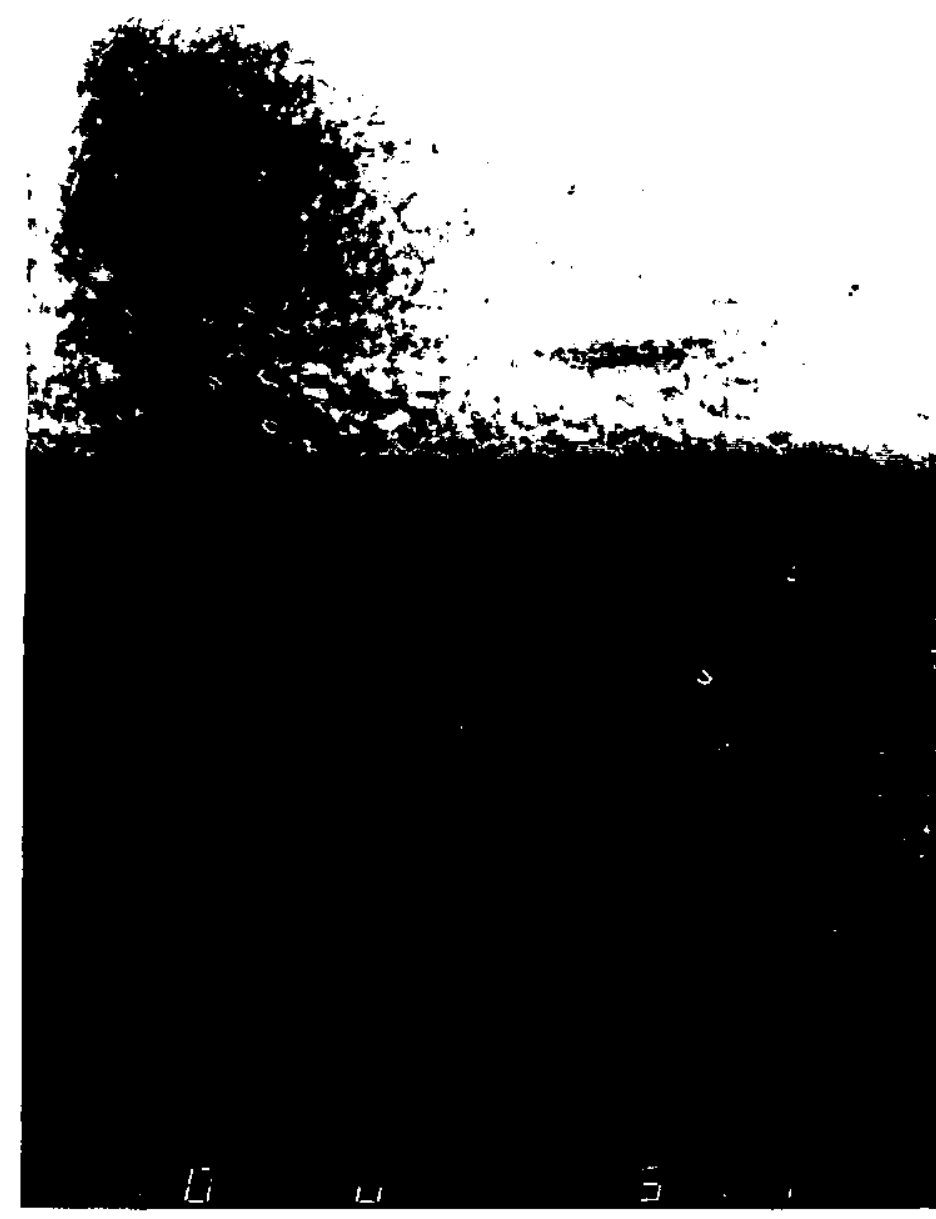


chapter seven

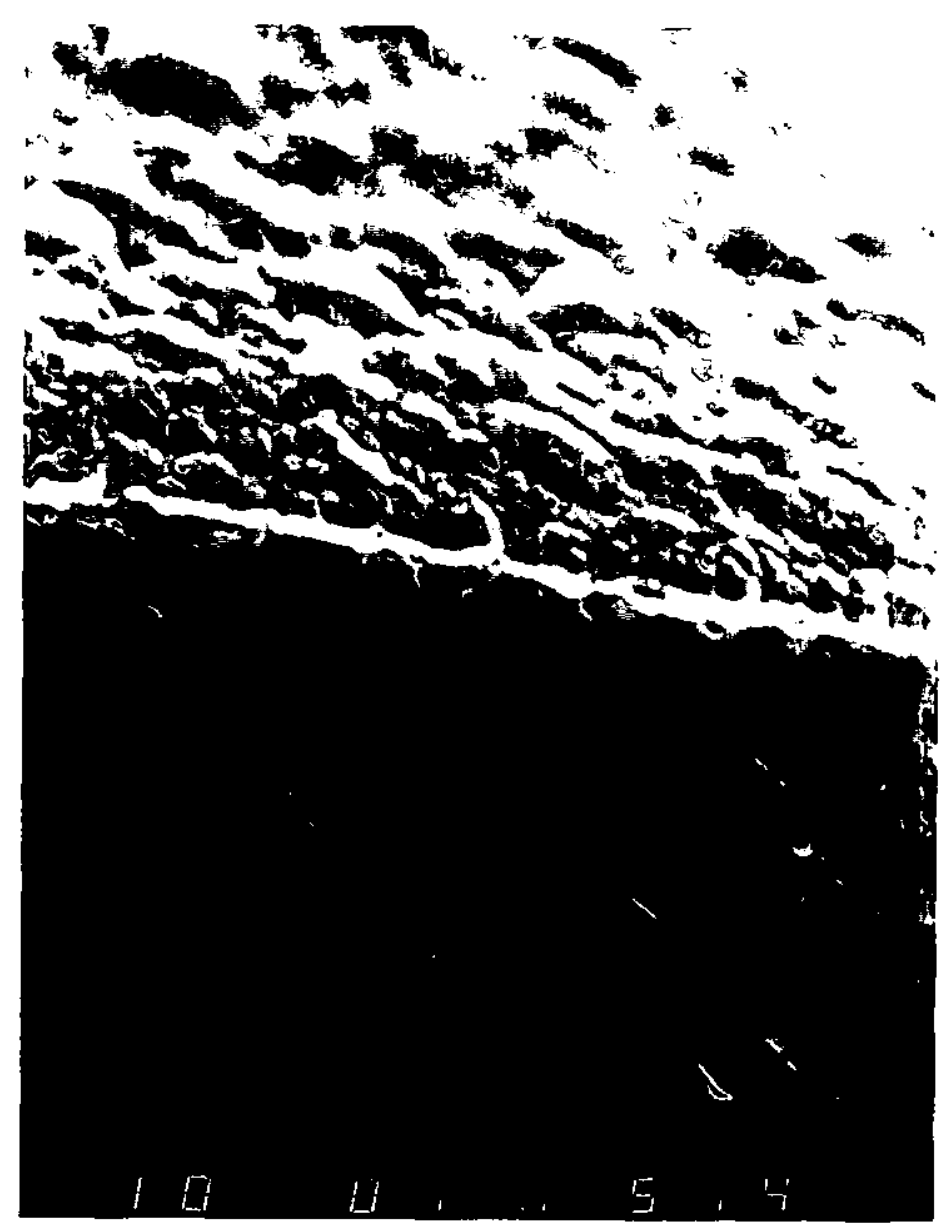

b

Figure 7.7.3. SEM micrographs of various metal films using filtered arc process.

(a) titanium; (b) aluminium. 
chapter seven

\subsubsection{CONCLUDING REMARKS}

The filtered arc produced high quality, high reflecting films of aluminium and titanium. 


\section{CHAPTER 8 \\ CONCLUSIONS AND SUGGESTIONS FOR FUTURE WORK}

\subsection{CONCLUSIONS}

The main conclusions of this research can be summerised as follows :

1. Vacuum arc deposition is an attractive technique from many standpoints; it is very promising for decorative applications, particularly because of the easy control of parameters. The evidence has shown golden-yellow TiN coatings deposited by filtered arc evaporation have great potential for further improvement.

2. Despite similar operating pressures and methods used for plasma manipulation, there are very real differences between magnetron sputtering and arc evaporation of thin films onto insulating substrates.

The magnetron sputtering process is one of ion-assisted growth of a thin film with the depositing species arriving at the substrate with considerable energy, but in a neutral form. The growing film is simultaneously bombarded by low voltage ions of the sputtering gas and may include a component of reactive gas.

With arc evaporation, it is the evaporating material which is charged and will be accelerated towards the growing film surface by the bias potential, which appears as a result of the substrate being immersed in the dense plasma from the process.

3. Manipulation of the deposition products of arc evaporation has been shown to be possible with a simple low magnetic field solenoid following the principles seen with an unbalanced magnetron. Direction of the product to a substrate out of direct line of sight of the source results in films free from droplet contamination.

4. In reactive processing the ionised metal constituent created by arc evaporation does appear to simplify the kinetics of the substrate reaction process to a greater degree than the careful balance required by argon-ion-assisted sputter processes. In addition, the evidence is that Titanium nitride deposited onto room temperature 
substrates gives films with better properties.

5. Stoichiometric TiN films with superior adhesion and higher densities can be obtained with widely varying $\mathrm{N}_{2}$ pressure and Ti evaporation rates. The arc evaporation process was not affected by the admission of reactive gas and reactive processes could be undertaken with few additional problems.

6. The substrate temprature can be maintained at ambient for $\mathrm{Al}_{2} \mathrm{O}_{3}$ and $\mathrm{TiN}$ while heating of the substrate is required for $\mathrm{AlN}$ and $\mathrm{TiO}_{2}$ deposition.

7. The technique of a filtered d.c. vacuum arc with a magnetic plasma duct has been demonstrated to be an effective means of depositing smooth, high quality metals, nitrides and oxides.

8. Sputtered TiN films examined by Scanning Electron Microscopy showed a columnar structure, while those which were arc evaporated had a less columnar structure with smaller grain size. This feature is one advantage of the filtered arc deposits bombarded with energetic ions at the substrate to overcome columnar growth.

9. Transmission of a carbon plasma through a curvilinear plasma-optical filter system is more effective than that of a plasma comprising heavier elements.

10. The technique of filtered arc evaporation promises to be a relatively low-cost method of depositing hard carbon films onto a variety of substrates at room temperature.

11. Whilst ion plating processes require substrate bias to avoid the deposition of films having columnar structure, it has been shown that in the case of cathodic arc deposition, dense amorphous coatings could be deposited with no substrate bias.

12. The filtered arc deposition process yields films having outstanding adhesion to the substrates, resulting from the high deposition energies involved. High energy results in strong atom - to - atom bonding, some degree of surface intermixing at the coating- substrate interface, and elimination of voids at the interface. 
13. The similar system requirements of cathodic arc and magnetron sputtering permit these techniques to be combined in a single coating system. Such a configuration lends itself to multilayer coatings, where the greatest benefit may be derived from the best qualities of each. In the case of diamond - like carbon films, magnetron sputtering permits a thin sputtered layer of material such as silicon, germanium and molybdenum to be deposited over the substrate prior to carbon deposition. This provides highly adherent, dense carbon coatings deposited by the filtered arc. 


\subsection{SUGGESTIONS FOR FUTURE WORK}

Experience in the manipulation of the magnetic field associated with the unbalanced magnetron has demonstrated that ionised material can easily be controlled by small magnetic fields which influence the electrons in the plasma, which are subsequently followed by the ions.

This experience led to the construction of a magnetic filter selector for the arc evaporator, which showed that better films of titanium nitride can be made than when this is produced by magnetron sputtering. This was attributed to the fact that completely ionized metal species were used for the deposition process. The equipment used to achieve this was built by modifying an existing evaporation unit and has inherent disadvantages.

Arcs jumping to the shield and to the cooling fittings of the arc source, would contaminate the coatings. A larger shield around the cathode target would have been useful to protect the evaporation unit from undesirable arcing, except that required on the target surface. Because of the high vapour density of the arc and associated mean free path in the region of the cathode spot, however, magnetic confinement is necessary, since it is important to prevent the arc tracking between the cathode and the shield chamfer. This suggests the use of large target surface, allowing a well controlled trajectory for the cathode spot by using an electromagnet behind the target surface. Rather than instead of present permanent magnets, larger semi - circular solenoids are recommended to manipulate the evaporated ionised species. This would result in continuous confinement of the cathode spot and improve target utilization.

A somewhat simpler method is to employ several magnetic coils behind the target and to switch the power frequently between the coils. The arc is alternately captured by the different magnetic fields and hence kept in motion on the target surface.

We know that the solenoid filter concentrates the beam along the axis so that, in order to obtain practical areas of uniformly deposited film, substrate movement is required. It is also necessary to raise the controlled temperature of the depositing film to affect the film structure favourably. The addition of substrate heating is thus necessary. A quartz / $250 \mathrm{~W}$ tungsten halogen lamp can be mounted directly behind the substrate to provide substrate heating to $300-450{ }^{\circ} \mathrm{C}$ independent of the arc source. The temperature can be monitored with a thermocouple. 
The anode can be used to increase the effective deposition rate, to improve target utilization, and also to modify the deposition uniformity at the substrate. It achieves this by acting as a collector of material that would otherwise be deposited on the walls of the chamber, reducing both the accumulation of deposits on the walls and the need for frequent maintenance. An anode connected at the exit of the arc filter was found to improve the deposition rate slightly.

The minimum current and discharge voltages required for stable arc source operation are strongly dependent on the anode configuration. As area of the anode exposed to the arc source is increased, the lower the discharge voltage becomes. 


\section{APPENDIX}

1. R.P.Howson, N. Mustapha, H.A. Ja'fer and M.E. Stenlake.

A comparison between the performance of an arc evaporation source with ion selection and an unbalanced magnetron sputtering source. IPAT, May (1991) Belgium. 
